\title{
Assessment of instrumentation
} needs for advanced coal power plant applications: Final report

Nelson, E.T.; Fischer, W.H.; Lipka, J.V.; Rutkowski, M.D.; Zaharchuk, R.

Oct 1987

Gilbert/Commonwealth Associates, Reading, PA (USA)

Reproduced and Distributed by:

U.S. DEPARTMENT OF ENERGY

Office of Scientific and Technical Information P.O. Box 62

Oak Ridge, TN 37831 


\section{DISCLAIMER}

This report was prepared as an account of work sponsored by an agency of the United States Government. Neither the United States Government nor any agency Thereof, nor any of their employees, makes any warranty, express or implied, or assumes any legal liability or responsibility for the accuracy, completeness, or usefulness of any information, apparatus, product, or process disclosed, or represents that its use would not infringe privately owned rights. Reference herein to any specific commercial product, process, or service by trade name, trademark, manufacturer, or otherwise does not necessarily constitute or imply its endorsement, recommendation, or favoring by the United States Government or any agency thereof. The views and opinions of authors expressed herein do not necessarily state or reflect those of the United States Government or any agency thereof. 


\section{DISCLAIMER}

Portions of this document may be illegible in electronic image products. Images are produced from the best available original document. 


\section{DISCLAIMER}

This report was prepared as an account of work sponsored by an agency of the United States Government. Neither the United States Government nor any agency thereof, nor any of their employees, makes any warranty, express or implied, or assumes any legal liability or responsibility for the accuracy, completeness, or usefulness of any information, apparatus, product, or process disclosed, or represents that its use would not infringe privately owned rights. Reference herein to any specific commercial product, process, or service by trade name, trademark, manufacturer, or otherwise does not necessarily constitute or imply its endorsement, recommendatinn, or favoring by the United States Government or any agency thereof. The views and opinions of authors expressed herein do not necessarily state un reflect those of the United States Government or any agency thereof.

This report has been reproduced directly from the best available copy.

Available from the National Technical Information Service, U. S. Department of Commerce, Springfield, Virginia 22161.

Price: Printed Copy A09

Microfiche A01

Codes are used for pricing all publications. The code is determined by the number of pages in the publication. Information pertaining to the pricing codes can be found in the current issues of the following publications, which are generally available in most libraries: Energy Research Abstracts (ERA): Government Reports Announcements and Index (GRA and 1); Scientific and Technical Abstract Reports (STAR): and publication NTIS-PR-360 available from NTIS at the above address. 


\title{
Assessment of Instrumentation Needs for Advanced Coal Power Plant Applications
}

\author{
Final Report
}

\author{
E.T. Nelson \\ W.H. Fischer \\ J.V. Lipka \\ M.D. Rutkowski \\ R. Zaharchuk
}

Work Performed Under Contract No.: DE-AC21-86MC23088

\author{
For \\ U.S. Department of Energy \\ Office of Fossil Energy \\ Morgantown Energy Technology Center. \\ P.O. Box 880 \\ Morgantown, West Virginia 26507-0880
}

By

Gilbert/Commonwealth

P.O. Box 1498

Reading, PA 19603 
The purpose of this study was to identify contaminants, identify instrumentation needs, assess available instrumentation and identify instruments that should be developed for controlling and monitoring gas streams encountered in the following power plants: Integrated Gasification Combined Cycle (ICCC), Pressurized Fluidized Bed Combustion (PFBC), and Gasification Molten Carbonate Fuel Cell (MCFC).

Emphasis was placed on hot gas cleanup system gas stream analysis, and included process control, research and environmental monitoring needs. Commercial process analyzers, typical of those currently used for process control purposes, were reviewed for the purpose of indicating commercial status. No instrument selection guidelines were found which were capable of replacing user interaction with the process analyzer vendors.

This study leads to the following conclusions:

- Available process analyzers for coal-derived gas cleanup applications satisfy current power system process control and regulatory requirements, but they are troublesome to maintain.

- Commercial gas conditioning systems and in situ analyzers continue to be unavailable for hot gas cleanup applications.

- Many research-oriented gas stream characterization and toxicity assessment needs can not be met by commercially available process analyzers.

- Greater emphasis should be placed on instrumentation and control system planning for future power plant applications.

Analyzers for specific compounds are not recomnended other than those needed for current process control purposes. Instead, some generally useful on-1ine laser-based and inductively coupled plasma methods are recommended for further development because of their potential for use in present hot gas cleanup research and future optimization, component protection and regulation compliance activities. 


\section{ACKNOWLEDGEMENTS}

In addition to the principal contributors listed on the title page, Vijay Kothari, the METC Project Officer, Bob Bedick, Tom Grindley, Mike McMillian and Jan Wachter, also of METC, and Vinod Jalan of ElectroChem, Inc., have provided valuable guidance and assistance. 
1.0 INTRODUCTION _.

1.1 Background 1

1.2 Approach 2

2.0 TASK 1 - CONTAMINANT IDENTIFICATION

2.1 Contaminant Release 2

2.2 IGCC Power System 10

2.2.1 Power System Description $\quad \ldots \quad 10$

2.2.2 Contaminants Detrimental to Components , 12

2.3 PFBC Power System $\quad 17$

2.3.1 Power System Description 17

2.3.2 Contaminants Detrimental to Components '21

2.4 MCFC Power System 21

2.4.1 Power System Description 21

2.4.2 Contaminants Detrimental to Components 22

3.0 TASK 2 - INSTRUMENTATION REQUIREMENTS 26

3.1 Classification of Power Plant Instrumentation Needs 26

3.1.1 Introduction 26

3.1.2 Operational Needs 26

3.1.3 Research Needs 27

3.1.4 Environmental Needs based on Existing
And Possible Future Regulations

3.2 Methodology for Comparing Instrumentation Requirements
with Instruments Available 
3.3 Cleanup System Process Descriptions 36

3.3.1 IGCC Power Systems 36

3.3.2 PFBC Power Systems 4?

3.3.3 MCFC Power Systems 48

3.4 Cleanup System Process Control 51

3.4.1 System Dynamic and Load Following Considerations 51

3.4.2 IGCC Power Systems 53

3.4.3 PFBC Power Systems 57

3.4.4 MCFC Power Systems 58

3.5. Preliminary Instrumentation Requirements $\quad 60$

3.6 Gas Sampli: Bonditioning Systems $\quad 86$

3.7 Contaminant Curtrol and Monitoring Strategies 89

3.8 Plant Laboratory Instrumentation 91

14.0 TASK 3 - INSTRUMENTATION AVAILABILITIES 96

4.1 Characterization of Instrumentation Availabilities 96

4.2 Sampling System Availabilities $9 \overline{8}$

4.3 Identification of Available Process Analyzers 98

4.4 Identification of Available Laboratory Analyzers 102

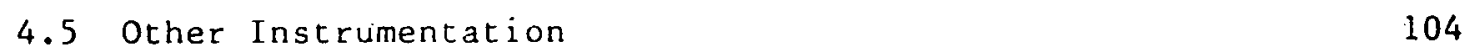

5.0 TASK 4 - COMPARISON OF REQUIREMENTS WITH AVAILABILITIES 107

5.1 Comparison of Gas Cleanup System Requirements with
Avalabilities

5.2 Comparison of Process Analyzer Requirements with
Avallabilities 
5.3 Research and Development Needs

5.3.1 Process Analyzers $\quad \therefore, \cdots, \cdots$

5.3 .2 Research Instrumentation 112

5.3.3 Laboratory Analyzers

116

5.3.4 Zinc Ferrite Process/IGCC Dynamic Study

116

$\quad 5.3 .5$ Analyzer Information Management .
$\therefore 5.4$ Current or Recent Research and Development Projects NOMENCLATURE

\section{REFERENCES}

APPENDICES
A. IGCC Power System Description.
B. PFBC Power System Description
C. . MCFC Power System Description 
2-1 IGCC System with Cold Gas Cleanup 10

2-2 IGCC System based on the METC Zinc Ferrite Process 11

2-3 IGCC System based on the Battelle Solid Supported Molten Salt Process

2-4 IGCC System based on the IGT Mixed Metal Oxide Process

The MCFC Reference Power System

3-1 Simplified İGCC Cold Gas Cleanup Sysţem . 39

3-2 METC Zinc Ferrite Process $\quad 40$

3-3 Battelle Solid Supported Molten Salt Process 43

3-4 IGT Mixed Metal Oxide Process , 45

3-5 Simplified MCFC Cold Gas Cleanup System $\quad 49$

3-6 Typical Absorber Instrumentation $\quad \cdot \quad \cdot 52$

3-7 Some Typical Sampling System Components $\quad 87$

4-1 Instrumentation Selection Procedure $\quad 99$

A-1 IGCC Reference System Process Flow Diagram A-11

A-2 IGCC Reference System Gas Cleanup Process Flow Diagram 'A-11

B-1 PFBC Reference System Process Flow Diagram B-8

B-2 General Electric PFB Combustor B-8

C-1 MCFC Reference Power System C-13

C-2 MCFC Reference System Gas Cleanup Process Flow Diagram C-13 
2-1 Ranges of Analyses of Illinois No. 6 Coal 4

2-2 Ranges of Gas Compositions from Illinois No. 6 Coal $\quad 8$

2-3 Conventional Gas Turbine Fuel Specifications ... 15

2-4 Current Research Turbine Tolerance Limits for Particulate Material

2-5 Summary of the Effect of Impurities' and 'Tolerance'Limits'. 25

3-1 Environmental Concerns Addressed by Various Technologies · 30

3-2, Emission Rates from Coal Convertors 31

$3-3:: \quad$ Resource Commitments and Waste Products for Various
Technologies

3-4 IGCC Cold Gas Cleanup System Stream Conditions . 39

3-5 METC Process Gas Streams 42

3-6 Battelle Process Gas Streams $\quad 44$

3-7 IGT Process Gas Streams $\quad \ldots 6$

$3-8 \cdot$ MCFC Cold Gas Cleanup system Stream Conditions 49

3-9 Summary of Gas Cleanup Instrumentation Needs $\cdots \quad \cdots \quad \cdots \quad 61$

3-10 Other Instrumentation Needs $\quad, \cdots, \cdots, \cdots, \quad, \cdots$,

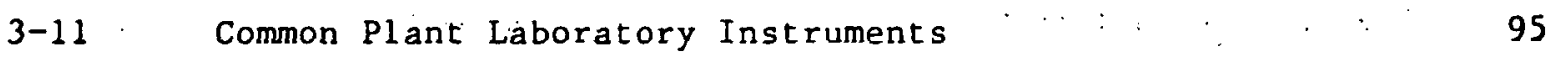

3-12 Primary Process Streams Monitored $\quad \ldots \quad \cdots \quad \cdots \quad \ldots \quad: \quad 95$

$1=1$
$:-1$ Summary of Process Analyzer Availabilities $\quad \therefore \quad 100$

5-1: . Current or Recent R\&D Projects $\quad \because \quad \because \quad 118$

A-1 IGCC Power System Performance Summary $\quad \cdots: A-3$

A-2 IGCC Power System Process Flow Diagram Stream Conditions A-5

B-1 Principle Thermodynamic Cycle Parameters $\quad \therefore \quad \cdots, B-3$

B-2 PFBC System Performance Summary : $:$ B-7

B-3 PFBC Power System Process Flow Diagram Stream Conditions: B-8

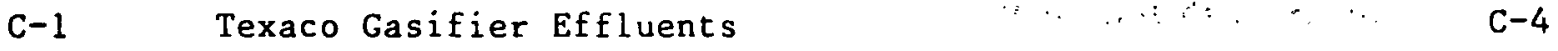

C-2 MCFC Power System Stream Conditions C-13 


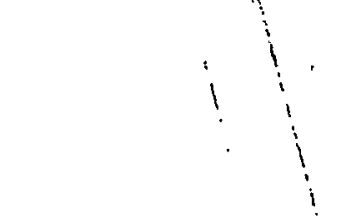

\section{EXECUTIVE SUMMARY}

The purpose of the study was to provide an assessment of instrumentation needs for advanced coal conversion process applications. The work was divided into four tasks:

1. Identification of the contaminants and their control levels for gas streams encountered in the three power plants listed below.

2. Identification of the instruments available for controlling and monitoring these contaminants.

3. Identification of the instrumentation required to implement the necessary control strategies.

4. Identification of the instrumentation technology that should be developed for controlling and monitoring gas stream contaminants.

The following power plant systems were considered:

- Integrated Casification Combined Cycle (IGCC)

- Pressurized Fluidized Bèd Combustion (PFBC)

- Gasification/Molten Carbonate Fuel Cell (MCFC)

Three base case power system designs were selected on the basis of the amount and quality of the published information available for defining instrumentation needs. Three additional IGCC power system configurations were selected which used the following hot gas cleanup processes:

- The METC Zinc Ferrite Process

- The Battelle Solid-Supported Molten Salt Process

- The IGT Mixed Metal Oxide Process

Throughout the instrument requirements phase of the study, an emphasis was placed on hot gas cleanup system gas stream analyses for process control purposes. This requirement was classified as an operational need. Kesearch and environmental needs were also considered. The term "research" was used to refer primarily to pilot and demonstration plant measurement requirements.

Analytical techniques for environmental control applications were also included. The laboratory techniques selected were considered to be typical of those encountered in a power system plant laboratory. The following frequently encountered applications were addressed:

- Standard coal analyses

- Standard ash analyses 
- Polynuclear áromatic hydrocarbon-analyses

- off-line gas analyses

- Particulate analyses

- Trace metal analyses

- Water analyses

Contaminants detrimental to the environment and the more critical power system components (the gas turbine and molten carbonate-fuel cell) were 1 isted. Instrument requirements were then listed based on a set of system requirements and constraints (process conditions, range, accuracy and response time), and a set of user requirements and constraints (type of need, cost, reliability and maintainability).

Representative analyzers, commercially available or almost available, were reviewed and categorized. The approach used to carry out the instrumentation availability study was as follows. First, the requirements listed during the Task 2 effort were divided into two groups - system requirements and user requirements: The system requirements were primary component, range, accuracy and response time. The user requirements were operational needs, research needs and two levels of environmental needs. Next, some system constraints and user constraints were added: The system constraints considered were temperature, pressure, other components to be measured, and any interfering components. The user constraints considered were cost, reliability; maintainability and communications compatibility. The available instruments were characterized as follows:

- In situ systems

- Extractive systems

- Single parameter syśtems

- Multiparameter systems

- General purpose systems

Finally, appropriate analyzers were identified using an iterative approach which required an evaluation of the identified system requirements and constraints, the instrument types available, and the identified user requirements and constraints. The purpose of this identification work was to indicate current commercial status and provide a basis for identifying research and development needs.

In most cases an optical or probe type instrument was selected as a first choice in order to minimize capital cost, maintenance and response time. For many of the hot gas cleanup applications, $\mathrm{H}_{2} \mathrm{~S}$ was selected as the primary component. That measurement was used to implement the sulfur absorption control strategies described in the Task 2 portion of the study: 
Today's analyzers have evolved due to improvements in their components such as their radiation sources, optical filters and detectors. Deficiencies exist largely in the sense that evolutionary improvements are always needed. An analyzer system usually consists of an analyzer plus a sampling system. Sampling systems continue to perform poorly. It follows that analyzer system deficiencies will exist as long as sampling systems are necessary and deficient. Some problems were identified which are related to current instrumentation systems design deficiencies rather than to deficiencies in specific analyzer methods. The more important trends and deficiencies are summarized below.

Today's optical (infrared and ultraviolet) analyzers have benefited significantly from recent improvements in radiation source assemblies, optical filters and solid state photodetectors. Split architecture designs permit the sample cell to be located so that the uptics and electronics can be protected from harsh environments. However, such systems are not available which can operate at hor gas cleanup temperatures without sampling systems.

Recently, the instrument manufacturers have become interested in providing integraced analyzer systems which include sampling systems. Because of limited near term demand, this trend may not lead to the early availability of analyzer systems specifically designed for hot gas cleanup applications. Therefore, hot gas cleanup deficiencies will continue to exist in the sampling system area. Guidelines for designing less troublesome sampling systems should be developed. At the same time instrument development studies should continue with the objective of developing improved in situ systems which do not require sampling systems.

A systems analysis deficiency exists in the sense that a greater emphasis should be placed on top-down planning for gas cleanup system instrumentation needs. The primary options are for instrumentation needs to be control oriented, emissions oriented or research oriented. Each option generates different measurement requirements and therefore different instrument design specifications. A plan based on a preferred option or mix of options is required as a starting point for specifying future instrumentation needs, Also, an interactive instrument availability data base would be helpful having some built-in expert system capability to assist the user in selecting an instrument for a given application.

For the purpose of this study, a plan was selected which places initial emphasis on the development of new instruments for research applications in the gas stream characterization and toxicity assessment areas. The plan emphasizes the use of in situ laser-based techniques and responsive extractive techniques based on inductively coupled plasma specteroscopy. Using these techniques, the problems associated with sampling systems can be avoided, and the reponse times of the instruments will enable them to support chemical kinetic and reactor engineering studies. At the end of these research activities, hardened versions of the instruments should be packaged and commercialized based on the process control and component protection needs outlined in this study and the regulatory needs which will be evident at that time. 
A power system dynamic study should be performed to establish a control strategy for one or more IGCC power system configurations which use the zinc ferrite process. The objective should be to establish preferred dynamic response requirements for the zinc ferrite process based upon typical electric utility load-following needs.

Some development work should be carried out on an integrated analyzer information management system. Such development work would be valuable because it would complement the currently active ISA (Instrument Society of America) project to develop standards for communications between field instruments (such as process analyzers) and the control room systems which will be needed to implement the higher level hot gas cleanup process control strategies. The same study, or a separate study, should cover the possibility of transmitting atomic or molecular excitation energy to various process streams (using fiber optics), and returning each response to a centrally located analyzer. This approach would be useful. for research and contaminant monitoring purposes. 
1.0 INTRODUCTION

1.1 BACKGROUND

In 1982, a study was completed by TRW, Energy Engineering Division, entitled "Monitoring Contaminants in Coal-Derived Gas for Molten Carbonate Fuel Cells." The study had the principal objective of assessing available instrumentation for monitoring and.controlling cleanup of coal gasifier product gas for use in molten carbonate fuel cell power plants. This included contaminant identification, instrument design requirements, identification of available instruments, comparison of instruments, and identification of development needs. Since this study was made, gas cleanup and molten carbonate fuel cell technologies have advanced, as have gas cleanup technologies for use with other coal conversion processes. In addition, instrumentation availabilities have changed..

The purpose of this study is to provide an integrated assessment of the instrumentation needs for advanced coal conversion process applications by (1) identifying contaminants and their control levels in the gas stream for use in the three power plants 1 isted below, (2) assessing available instrumentation for measuring and monitoring these contaminants, including in situ and/or on-line techniques which can be operated at high temperatures and pressures, (3) identifying deficiencies in the available instruments, and (4) identifying the instrumentation that must be developed for monitoring gas streams for electric power generation. The power plant systems considered are:

- Integrated Gasification Combined Cycle (IGCC).

- Pressurized Fluidized-Bed Combustion (PFBC)/Turbine.

- Gasification/Molten Carbonate Fuel Cell (MCFC).

Much instrument availability information can be obtained from the in'strument vendors, but many of the commercially available instruments operate under ambient or near-ambient conditions. For high temperature and pressure applications involving dusty gas streams, it is usually necessary to use sampling systems which are troublesome to maintain, and which frequently introduce undesirable delays in obtaining composition measurements. In situ measurements would be preferred if cost competitive instruments existed or could be developed. A large amount of information exists in the form of reports on various instrument development studies, and the more recent developments in the area of gas cleanup processing are also described in numerous reports on research and development studies. There exists a need to evaluate all of this available information, and to document the results so that the newer instrumentation and gas cleanup process technologies will be given careful consideration by the electric utility and other industries as they search for more efficient and economical means of using coal. 
A major portion of the coal used in the United States is burned in utility boilers to produce steam that is converted to electrical energy. As a result, significant research and development investments have been made to determine more efficient and economical means of using coal for this purpose. To a large extent, the anticipated efficiency and plant size improvements depend upon operating at high temperatures and pressures. The results of past investigations have also shown that electricity can be produced efficiently using IGCC, PFBC and MCFC systems.

To realize the full potential of these emerging energy technologies, improved methods must be developed to control the contaminants that are generated during the energy conversion process. As a result of government, industrial and academic investigations, many improved methods have been developed recently or are in the process of being developed. However, as indicated in the previous section, this information from recent $R \& D$ investments needs to be assessed and documented in such a manner that the new technologies are seriously considered for early commercialization.

Due to information availability problems and in the interest of keeping the study oriented to commercial practice, it was decided to discuss three base case commercially viable power generation configurations, and to introduce various advanced alternative configurations as probable deviations from each base case. It was not possible to start with the more advanced gas clean-up systems, integrate them into optimized power generation configurations, and develop the cost/performance trade-off and load-following information which was considered to be necessary for carrying out an exhaustive instrumentation assessment study.

2.0 TASK 1 - CONTAMINANT IDENTIFICATION

\subsection{CONTAMINANT RELEASE}

When using coal as an energy source, one would like to have clean product gases, such as only hydrogen and carbon monoxide from a coal gasifier or only water and carbon dioxide from a coal or gas combustor. Unfortunately, coal contains many components in addition to hydrogen and carbon. An often studied coal is Illinois 非, for which a "typical" analysis is usually given. Such a

"typical" coal does not exist as shown by the range of constituents

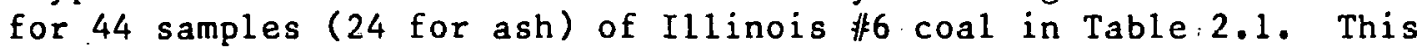
table was developed from information contained in references 2,5 , $14,18,19$, and 20 . As the concentration of the various constituents decreases, the variability increases, from less than a factor of two for major elements to over two orders of magnitude for trace elements. Although only $65 \%$ of the naturally occurring elements are included in the table, the remainder probably also occur in coal but are not reported. 
In IGCC and MCFC systems, contaminants are principally introduced by the coal and are modified by the gasifier type, but may also come from the gas cleanup system. Those contaminants not removed by the gas cleanup systems may be troublesome in the power train. In PFBC systems the concentrations of contaminating elements in the sorbent and the ratio of sorbent to coal used are such that the coal is the principal source of contaminants.

Contaminants are often considered in the following groupings:

Sulfur Compounds: $\mathrm{H}_{2} \mathrm{~S}, \mathrm{COS}, \mathrm{CS}_{2}, \mathrm{RSH}$, Thiophene, $\mathrm{SO}_{2}, \mathrm{SO}_{3}$

Nitrogen Compounds: $\mathrm{NH}_{3}, \mathrm{HCN}, \mathrm{HCNS}, \mathrm{NO}_{\mathbf{x}}$

Halogen Compounds: $\mathrm{Cl}_{2}$, HCl, HF, alkali halides

Trace Elements: As, $\mathrm{Cd}$, Ge, $\mathrm{Hg}, \mathrm{Pb}, \mathrm{Se}, \mathrm{Sn}, \mathrm{Te}, \mathrm{V}, \mathrm{Zn}$

Hydrocarbons: $\mathrm{CH}_{4}, \mathrm{C}_{2} \mathrm{H}_{6}$, benzene, toluene, phenols, oils, tars

Particulates: ash, char, solid compounds of volatile metals and halides

Oils and tars are condensed mixtures of aromatics; polycyclic aromatics, phenols and organic sulfur and nitrogen heterocyclics which also carry sulfur, nitrogen and trace metal compounds. 
TABLE 2.1

RANGES OF ANALYSES OF ILLINOIS NO. 6 COAL 16

(Dry Whole Coal Basis)

Proximate Analysis (wt. $\%$ )

\begin{tabular}{|c|c|}
\hline $\begin{array}{l}\text { Volatile Matter } \\
\text { Fixed Carbon } \\
\text { Ash } \\
\text { (Moisture. }\end{array}$ & $\begin{array}{r}39.40 \\
\because 43.40 \\
7.40 \\
2.80\end{array}$ \\
\hline
\end{tabular}

HHV (Btu/Ib as received).

$11,714-: 13,480$

U1timate Analysis (wt.\%) (Major Elements)

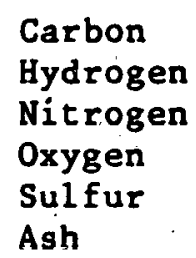

Sulfur Forms (wt. $\%$ )

$$
\begin{array}{r}
62.49-75.13 \\
4.19-5.98 \\
0.93-1.75 \\
5.75-14.36 \\
0.85-6.52 \\
7.34-16.46
\end{array}
$$

$\begin{array}{ll}\text { Pyritic } & 0.29-4.56 \\ \text { Organic } & 0.53-5.36 \\ \text { Sulfate } & 0.01-0.67\end{array}$

Ash Analyses (wt. $Z$ of dry ash) 17

$\mathrm{SiO}_{2}$
$\mathrm{Al}_{2} \mathrm{O}_{3}$
$\mathrm{Fe}_{2} \mathrm{O}_{3}$
$\mathrm{CaO}$
$\mathrm{MgO}$
$\mathrm{Na}_{2} \mathrm{O}$
$\mathrm{K}_{2} \mathrm{O}$
$\mathrm{TiO}_{2}$
$\mathrm{P}_{2} \mathrm{O}_{5}$
$\mathrm{SO}_{3}$

Elemental Content

$\begin{array}{ll}\text { Minor (wt.\%) } & \\ \mathrm{Al} & 1.00-3.04 \\ \mathrm{Ca} & 0.21-1.91 \\ \mathrm{Fe} & 0.45-3.50 \\ \mathrm{~K} & 0.07-0.24 \\ \mathrm{Mg} & 0.02-0.11 \\ \mathrm{Na} & 0.015-0.145 \\ \mathrm{Si} & 1.89-4.63\end{array}$




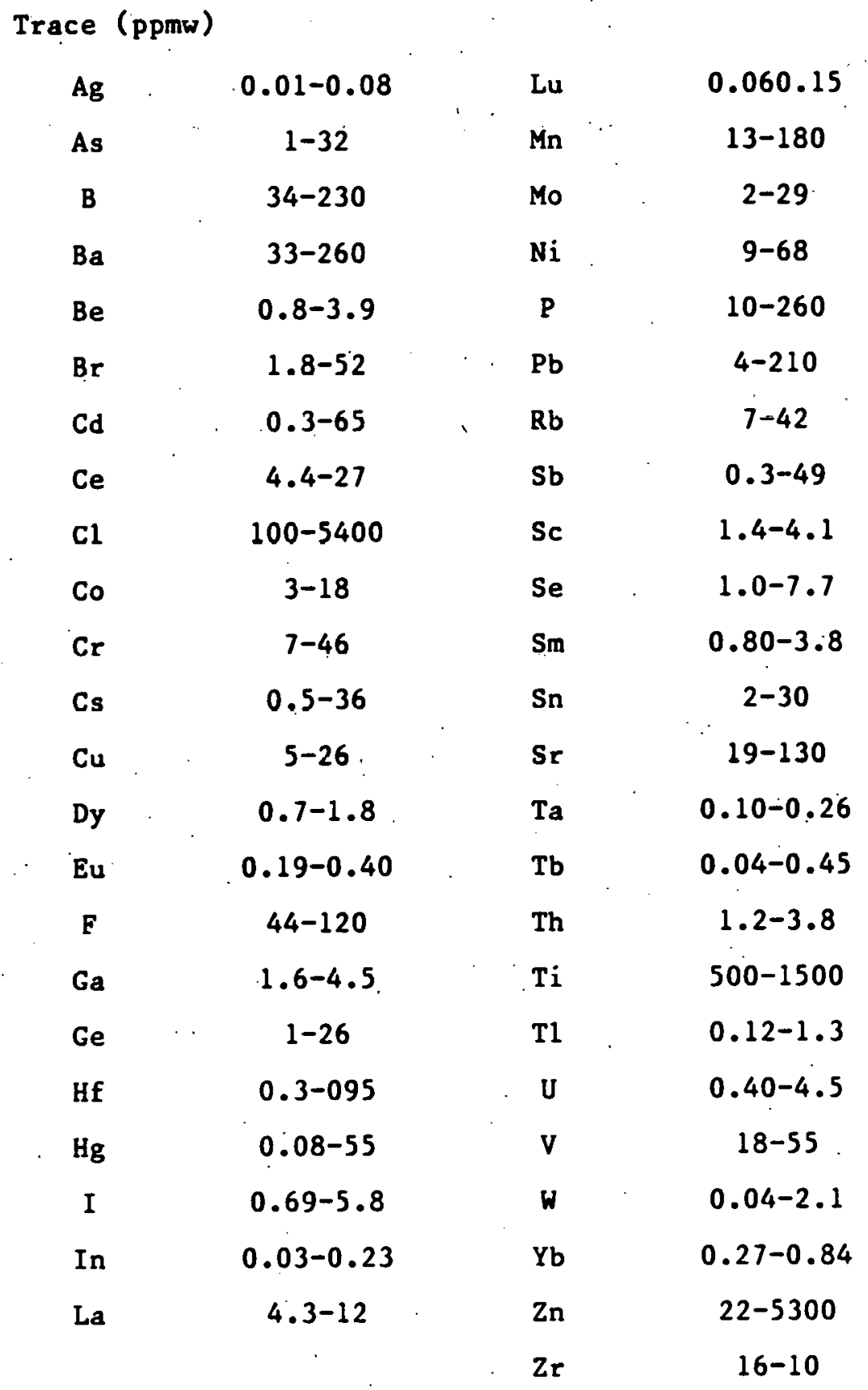


Particulates from gasifiers contain, in addition to ash. constituents, significant amounts of unreacted carbon, soot and unburned hydrocarbons. Dust from PFBC is primarily ash with a low carbon content in the smaller size range, with sorbent making up the larger size range. Sizes in all cases may range up to a few hundred micrometers.

Trace element emissions from gasifiers and PFBCs are less than those from pulverized coal burners.

The raw gas composition from gasifiers is influenced by coal type, gasifier type and operating conditions. Fixed bed gasifiers that do not subject the distilled products (i.e., volatile matters), to a temperatures above approximately $1600^{\circ} \mathrm{F}$ contain significant amounts of oils, tars and organic sulfur and nitrogen compounds in the raw gas.

Fluidized and entrained bed gasifiers that operate at higher temperatures produce little or none of these materials. Increasing operating temperature also favors the formation of hydrogen and carbon monoxide as compared to water, carbon dioxide and methane.

Gasifier pressure and the overall H/O atomic feed ratio also influence the raw gas composition. High pressure operation suppresses the formation of hydrogen and carbon monoxide in favor of water, carbon dioxide and methane. High H/O atomic ratios favor formation of hydrogen and methane in comparison with carbon monoxide and carbon dioxide.

Table 2.2 indicates the ranges of contaminant concentrations to be expected from gasifiers and PFBC's. These concentrations may have to be reduced before the gas or its combustion products are admitted to the various power trains. The reduction required will depend on the power train being considered. In any system, the stack emissions must comply with environmental regulations but these may be less stringent than the power train requirements. The scope of this study was limited to gas stream contaminants. Approximately $90 \%$ of the primary contaminants (from the sulfur in the coal) are initially discharged in the gas phase as $\mathrm{H}_{2} \mathrm{~S}, \mathrm{COS}$, $\mathrm{CS}_{2}$, thiophenes, mercaptans and tar and oil. In the case of the hot gas cleanup option, the remainder appear as sulfides and sulfates in the ash and fines. If the cold gas cleanup option is used, they appear mainly in the wastewater. Instruments available for monitoring such materials will be reviewed where instrumentation needs are indicated in Sections 3.5 and 3.8 . 
The environmental regulations 24 for new or modified electric utility steam generators over $250 \mathrm{milli}$ on $\mathrm{Btu} / \mathrm{hr}$ heat input, in $1 \mathrm{~b} / \mathrm{million}$ Btu are:

Particulate

$\mathrm{SO}_{2}$

$\mathrm{NO}_{\mathbf{x}}$
0.03

1.2 from anthracite

1.2 from other coals and coal-derived fuels. In addition, the percentage reduction must be at least $90 \%$ until emissions do not exceed $0.6 \mathrm{lb} /$ million Btu; and the percentage reduction must be at least $70 \%$ for emissions below $0.6 \mathrm{lb} / \mathrm{mill}$ ion Btu.

0.5 from sub-bituminous coal and all coal-derived fuels of any form

0.6 from anthracite, bituminous and 1 ignite, except

0.5 from lignite mined in North Dakota, South Dakota or Montana and burned in a slag tap furnace 
TABLE 2.2

RANGES OF GAS COMPOSITIONS FROM ILLINOIS NO. 6 COAL

(volume percent)

OXYGEN-BLOWN GASIFIERS

SPECIES

FIXED

BED

20-30

7-60

3-15

02 .

$\mathrm{H}_{2} \mathrm{O}$

$\mathrm{CH}_{4}$

$\mathrm{C}_{2} \mathrm{H}_{6}$

$\mathrm{H}_{2} \mathrm{~S}$

$\cos$

$\mathrm{CS}_{2}$

$\mathrm{SO}_{2}$

$\mathrm{SO}_{3}$

$\mathbf{N}_{2}$

Ar

$\mathrm{NO}_{\mathbf{x}}(\mathrm{ppm})$

$\mathrm{NH}_{3}$ (ppm)

$\mathrm{HCN}$ (ppb)

HCl (ppm)

HF (ppm)

$\mathrm{NaCl}$

$\mathrm{KCl}$

$\mathrm{Pb}$ (ppm)

As (ppm)

Tar \& oil (ppm)

* N2 plus Ar

$0.6-1.5$

$0.2-3 \div$

$\sim 700$

$300-7000$

$\begin{array}{cc}\text { FLUIDIZED } & \text { ENTRAINED } \\ \text { BED } & \text { BED }\end{array}$

COMBUSTOR

PFB

$16-40$ 30-38

37-54

39-64

1-22

20-130 ppm

10-15

3-12

5-15

0.1-6

4-10

1.5-25

$<0.5 \mathrm{ppm}$

-1 ppm

$0.7-1.4$

$0.4-1.2$

$0.06-0.3$

$<0.1 \mathrm{PPM}$

$\sim 0.003$

$$
\text { 10-1000 ppm }
$$

2-300 ppm

$0.5-1.5 \%$

$0.3-1.0$

$0.1-0.2$

50-80

0.9

80-350

4000-9000

$300-400$

200-1100

$\sim 20$

$200-700$

$\sim 400$

30-60 ppm gas

0.1 ppm dust

$$
\text { 1.5-25 }
$$

28-35 ppb

0.8-23 ppm

8-46 ppm

$0.1-40 \mathrm{ppm}$ gas

$2 \mathrm{ppm}$ dust

13-16 ppb

2-12 ppm

4-1000 ppm

$0.06-15.5$ ppm gas

7. $2 \mathrm{ppm}$ dust $\sim 2$

$\sim 2$

$\sim 9$

$\sim 2$

$\sim 5$ 
TABLE 2.2 (cont'd)

RANGES OF GAS COMPOSITIONS FROM ILLINOIS NO. 6 COAL

(volume percent)

\section{OXYGEN-BLOW'N GASIFIERS}

$\begin{array}{lcccc}\text { SPECIES } & \begin{array}{c}\text { FIXED } \\ \text { BED }\end{array} & \begin{array}{c}\text { FLUIDIZED } \\ \text { BED }\end{array} & \begin{array}{c}\text { ENTRAINED } \\ \text { BED }\end{array} & \begin{array}{c}\text { COMBUSTOR } \\ \text { PFB }\end{array} \\ \begin{array}{c}\text { Particulate } \\ \text { (gr/scf) }\end{array} & 1.5-5 & 3.5-7 & 10-50 & 4-14 \\ \begin{array}{c}\text { Pressure } \\ \text { (psia) }\end{array} & 15-400 & 15-250 & 15-1000 & 90-300 \\ \begin{array}{c}\text { Temperature } \\ \left({ }^{\circ} \text { F) }\right.\end{array} & \sim 1000 & \sim 1700 & \sim 2400 & \sim 1650 \\ & & & & \\ \text { References } & 1,2,3,4,5,6 & 3,4,5,6,7 & 1,2,3,4,5, & 12,13,14,15\end{array}$




\subsubsection{Power System Description}

Coal gasification is continuing to evolve. There are many coal gasification processes that are either commercially available or under development. Most have their peculiar technical and economic advantages and disadvantages. Many may be either oxygen or air-blown. Any of the three generic types ( $f$ ixed bed, fluidized bed or entrained flow gasifiers) can be used in an integrated coal gasification combined cycle power plant if a suitable cold or hot gas cleanup system is employed downstream of the coal gasifier.

The gasifier, and to some extent the gas cleanup systems, impact steam turbine and gas turbine integration. Also, the gasifier and cleanup systems must have good load-following capabilities plus an ability to deal with upsets and turndown situations. Air-blown systems tend to have lower overall costs and higher thermal efficiencies, but nther considerations, such as combustor availability, gas. turbine availability and cleanup system efficiency may favor oxygen-blown gasifiers. The technical and economic factors involved are complex, consequently it is difficult to specify a preferred configuration without performing a coal and site specific study.

When oil prices stabilized in the early 1980's, only a few process developers were able to proceed with demonstration programs. Examples of these programs were Texaco's Cool Water project $(1,000$ TPD) in Southern Cal ifornia, Allis-Chalmers' RILnGas demonstration plant (600 TPD) in Illinois, and the Britioh Cac Corp./Lurgi's Slagging gasifier (600 TPD) demonstration program in Scotland, U.K. The Shell, Dow and KRW (formerly Westinghouse) coal gasification processes should be considered as contenders on the basis of their past developmental history, even though they are without large-scale demonstration plants at the present time.

Most of these gasifiers are aimed at utility power plant applications, but little information has been published on their integration into power systems which must follow typical utility loads. The BGC/Lurgi gasifier was selected as the base case system because of information availability related to power system integration and power plant control philosophy. In addition, it was considered that the Lurgi gasifier and cold gas cleanup options would inject a broad range of instrumentation needs into the study.

In describing this plant which is shown diagrammatically in Figure 2-1, emphasis was placed on descriptive material needed to discuss gas clean-up instrumentation requirements. The bulk of this material is included as Appendix $A$ which contains two process flow diagrams. One shows the power system as a whole, the other shows a more detailed process flow diagram of the gas cleanup system. Both of these drawings have been provided with stream 


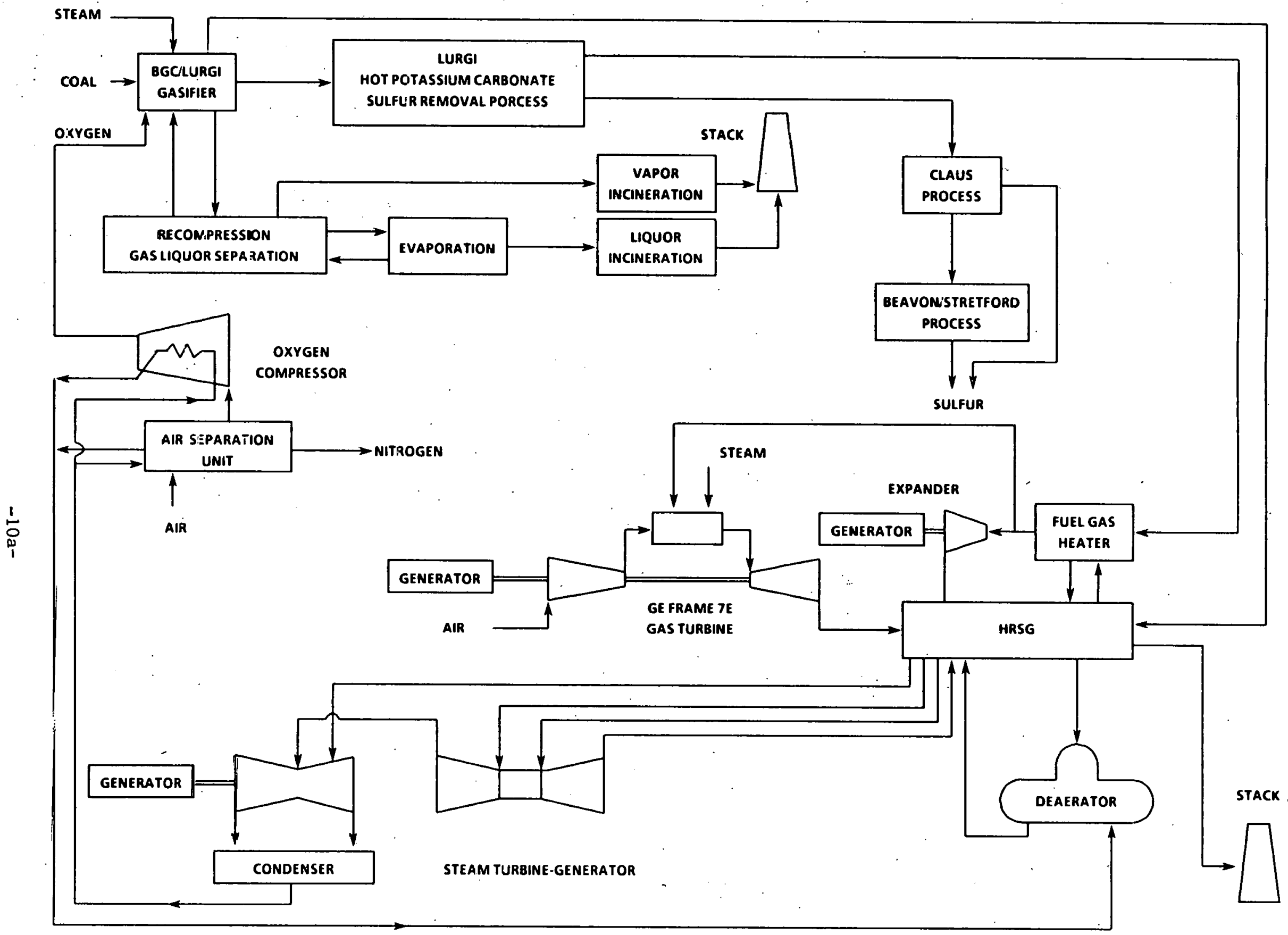

Figure 2.1 - IGCC SYSTEM WITH COLD GAS CLEANUP 
numbers which are used to reference stream conditions. The selected BGC/Lurgi system uses a cold gas clean-up system.

There are no hot gas cleanup processes commercially available. A few are in the early stages of development and require additional laboratory, pilot and demonstration work before their technical and economic feasibility can be assured. Most of the requirements for new or improved gas cleanup instrumentation will occur in this area.

Three of the more developed hot gas cleanup systems are shown in Figures 2-2 through 2-4. Recently, these and other configurations were used by Gilbert/Commonwealth to develop a variety of power system cost comparisons 26 . For information availability reasons a slagging BGC/Lurgi gasifier has been assumed but this is not necessarily the best gasifier for use in conjunction with hot gas cleanup. Instrumentation needs for other gasifiers will be developed by referencing Figure 2.2 through 2.4 in the instrumentation needs discussion, and by noting configuration changes that may be necessary as a result of using a different gasifier.

The essential purpose of the DOE/METC hot gas cleanup program is to eliminate the need for heat recovery and gas-liquor/tar/dust separation systems, and to avoid the efficiency losses associated with these systems.

It is recognized that all cleanup systems (whether hot or cold) should be properly matched and integrated with a selected gasifier and a selected power generation subsystem. Some possible configurations are shown in Figures 2-2 through 2-4. However, due to scope limitations, it was impossible to cover all possibilities. Therefore, for the purpose of this study, hot gas cleanup technology was treated somewhat as a "unit operation"; that is, an operation which can be separately studied and investigated.

Brief descriptions of each of the three selected cleanup processes follow, and more detailed descriptions have been included in Section 3.3.

The METC Zinc Ferrite Process is based upon the use of zinc ferrite, $\mathrm{ZnFe}_{2} \mathrm{O}_{4}$, which tends to combine the high sulfur affinity of zinc oxide with the good regenerability of iron oxide. Both iron oxide and $z$ inc oxide are effective in removing sulfur compounds at high temperatures, and both can be regenerated by roasting with air or oxygen.

The Battelle Solid-Supported Molten Salt Process is based on the reversible reaction of $\mathrm{H}_{2} \mathrm{~S}$ with molten 1 ithium, sodium, potassium or calcium carbonates. The solid-supported approach was developed as a practical means for handling these corrosive molten compounds. Regeneration with a carbon dioxide and steam-rich stream releases $\mathrm{H}_{2} \mathrm{~S}$ at a high concentration which is converted to elemental sulfur. 


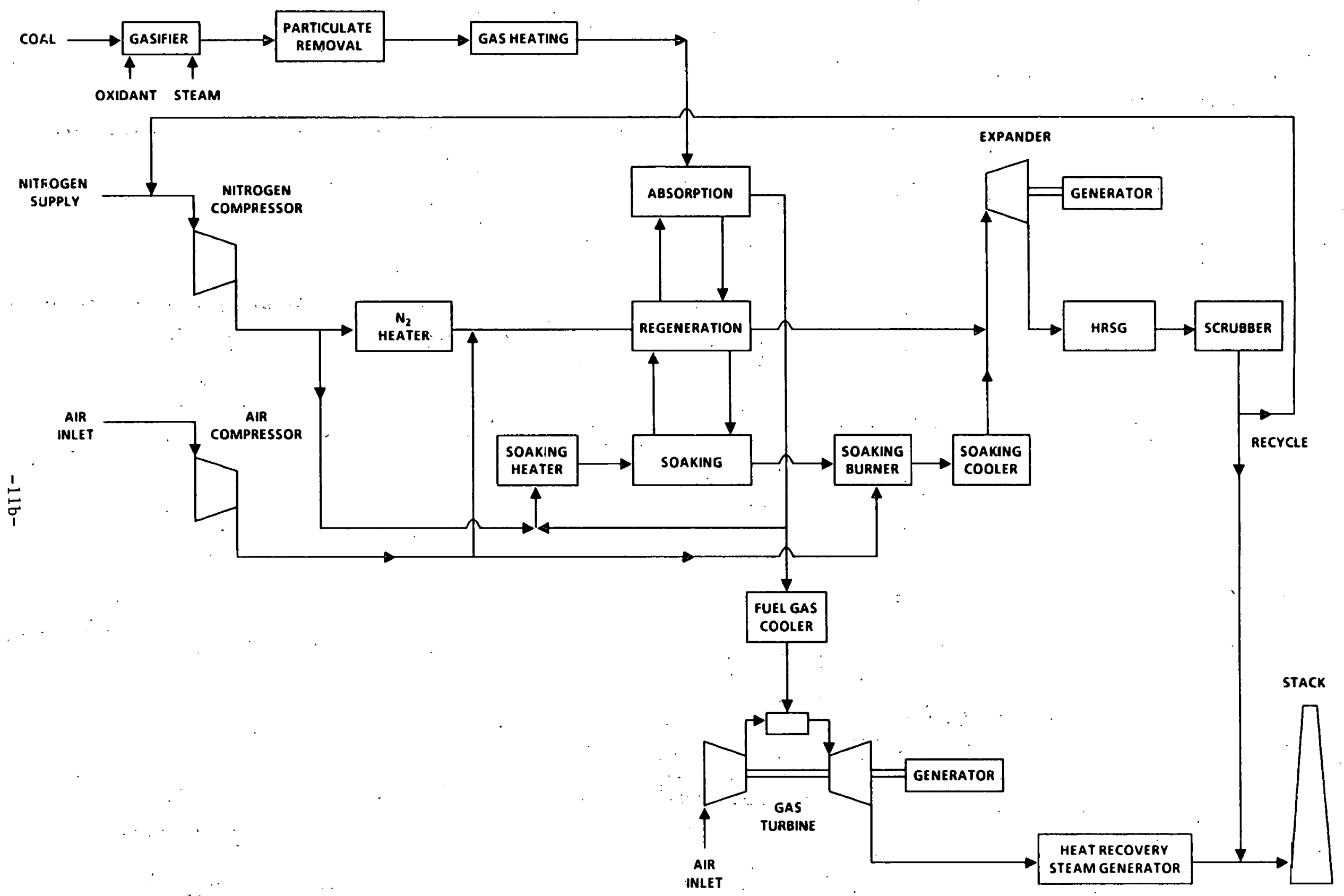

FIGURE 2-2 IGCC SYSTEM BASED ON THE METC ZINC FERRITE PROCESS 


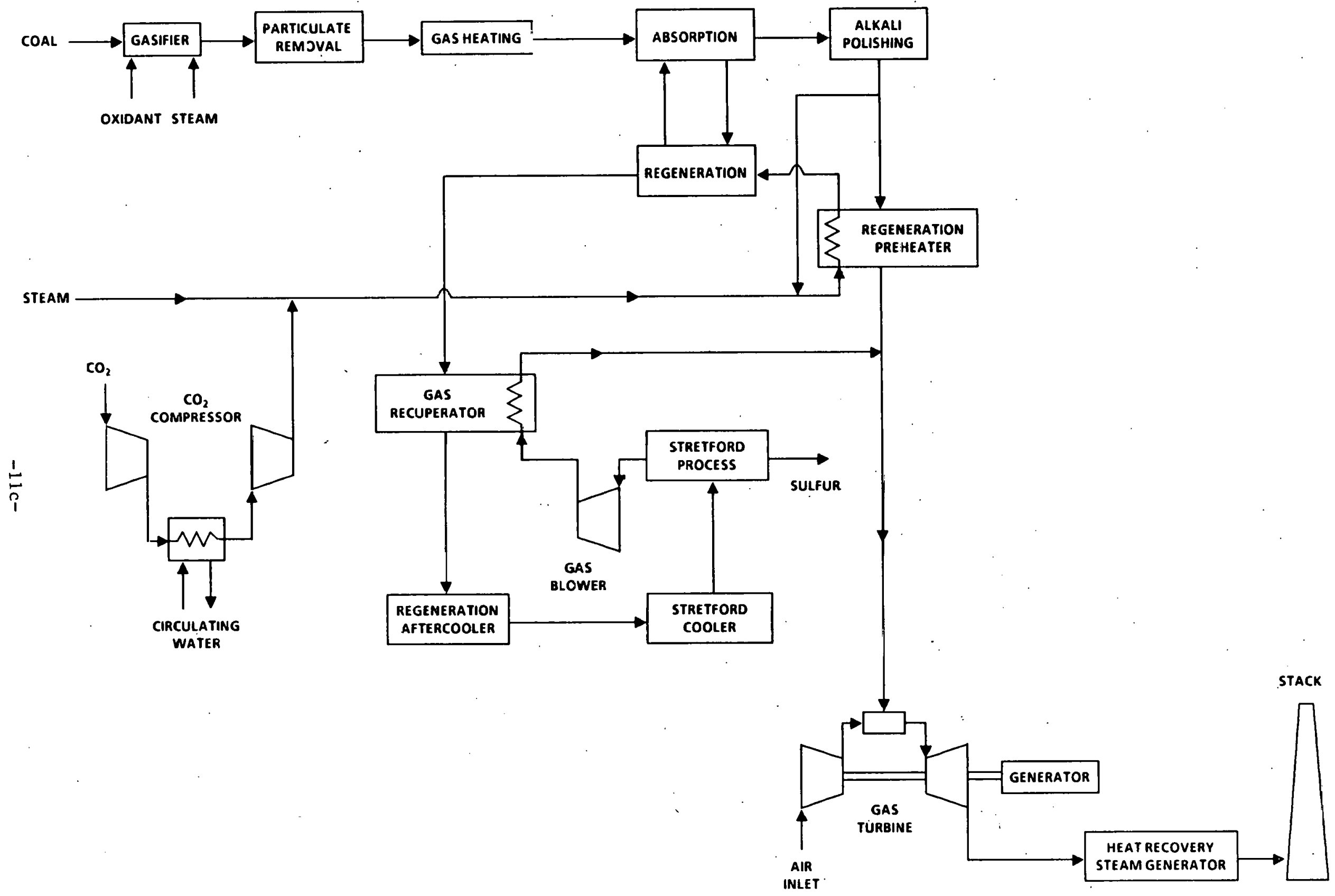

FIGURE 2.3 IGCC SYSTEM BASED ON THE BATTELLE SOLID SUPPORTED MOLTEN SALT PROCESS 


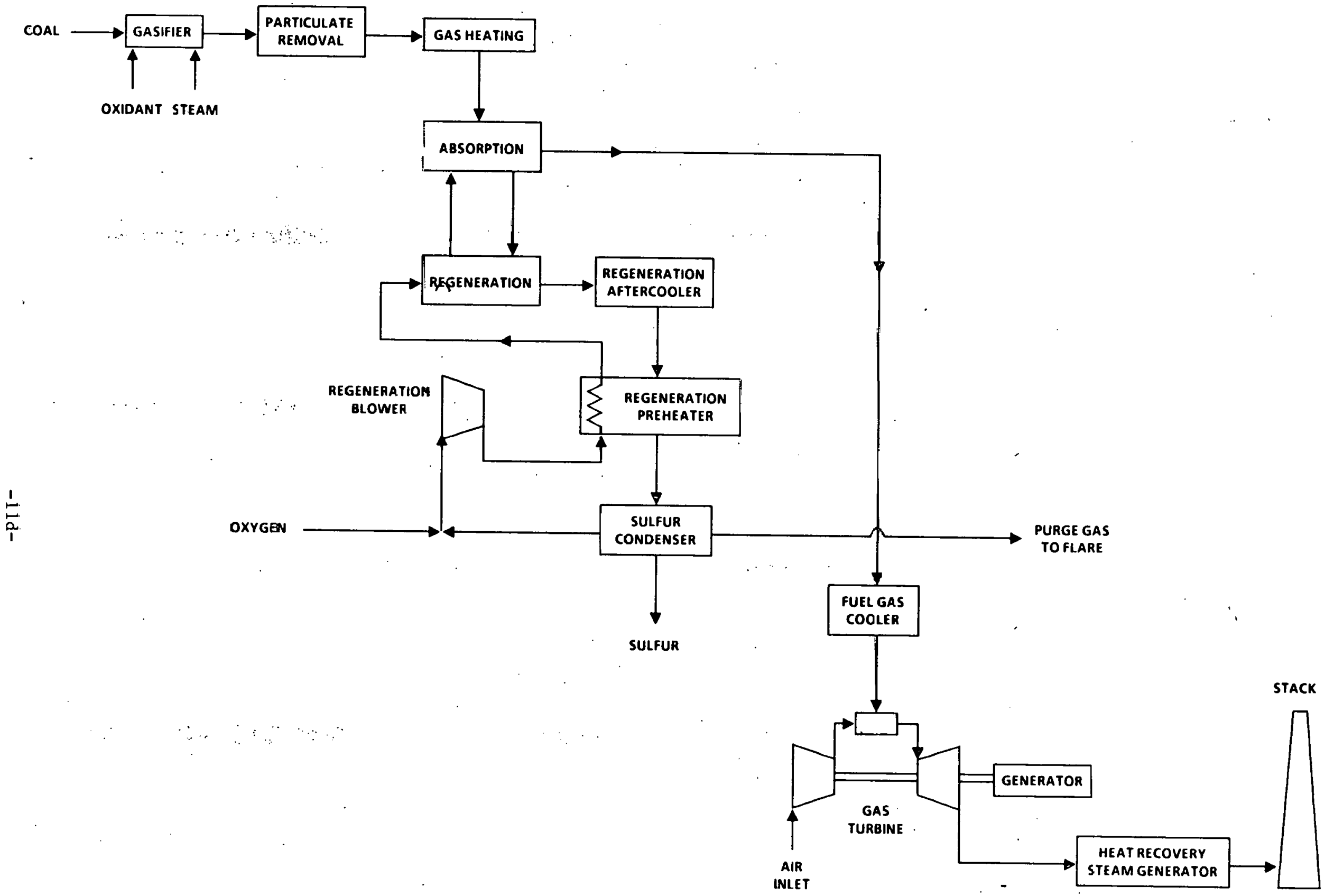

FIGURE 2-4 IGCC SYSTEM BASED ON THE IGT MIXED METAL OXIDE PROCESS 
The IGT Mixed Metal Oxide Process is based on the use of an elemental sulfur producing metal oxide sorbent combined with a high sulfur affinity metal oxide. After the metal oxide is fully loaded, it is regenerated using a mixture of oxygen and tail gas. The gas from the bed undergoing regeneration consists of $\mathrm{N}_{2}, \mathrm{SO}_{2}$ and elemental sulfur. After the elemental sulfur is removed, the tail gas is recycled through the same bed.

Instruments and control needs for the gas turbine, steam turbine, oxygen plant and balance-of-plant subsystems are not directly related to the DOE's gas stream cleanup program. For the purpose of this study, it has been assumed that the necessary new instruments will be provided as a result of the well established market demand for such systems.

\subsubsection{Contaminants Detrimental to Components}

Published information based on experience is not available which discusses in detail the interactions betwenn gasifiers, gas turbines and HRSG's in totally integrated coal gasification combined cycle plants. Nevertheless much past experience has been accumulated in operating all three on an individual basis. This experience will be outlined below and at the same $t$ ime the various detrimental contaminants associated with each system will be discussed. On the one hand this past experience implies that the problems can be solved, or (in the case of some power plants) may not even exist. On the other hand, in some areas, much uncertainty exists; for example, in the corrosion of turbine blade materials by hot alkali metal contaminants in the presence of sulfur.

\section{Past HRSG Experience}

In the case of coal and oil-fired boilers, ash deposits often settle on the heating surfaces and impair their performance. Salts of the alkali metals sodium and potassium volatilize in the process of combustion and condense as a sticky: substance at temperatures corresponding to superheater tubes, resulting in high-temperature corrosion. Fly-ash particles in the flue gases can melt and adhere to surfaces, and when fuel oil with vanadium is fired, vanadium pentoxide and complex vanadates are sometimes formed which lead to or accelerate high-temperature corrosion. Thus, based on the heat source, a provision for soot blowing is often made to remove the deposits. Since this extensive boiler experience is available to solve most problems that may arise, and since relatively clean coal gas will cause significantly fewer problems, HRSG corrosion, erosion and impaction should not be a cause for great concern.

\section{Turbine Section Corrosion Control}

Although there is little actual experience available on running gas turbines on medium Btu gas, a substantial amount of experience has been obtained with gas turbines operating on low Btu gas from blast furnaces. This gas is normally cooled and scrubbed with a two-stage wet scrubber prior to combustion. In some respects, 
blast furnace gas can be regarded as a worst case situation. Yet many plants have operated for long periods of time without problems. For example, Brown Boveri began designing gas turbine installations using blast furnace gas more than 25 years ago. At least 21 plants of this type have been put into service and some have operated for over 170,000 hours. 27

Hot corrosion and erosion generally is the life limiting factor in industrial gas turbines. This is believed to be an accelerated type of oxidation due to the presence of molten alkali metal sulphates on the surface of the component.28 It is believed that the process occurs in the following three steps:

- Pormation of a molten sulphate layer on the component surface

- Attack and penetration of the protective oxide layer.

- Rapid oxidation of the metal which is in direct contact with the molten sulphate.

In order to control hot corrosion it is necessary to modify the operating conditions by lowering the $\mathrm{Na}, \mathrm{K}, \mathrm{S}$ and $\mathrm{V}$ content of the fuel. Experience has shown that below a Na (and $K$ ) level of 1 ppm in the flue gas the corrosion rate is acceptable. A decrease in the $\mathbf{S}$ content may be considered, but additional studies are needed to clarify the mechanisms responsible for hot-corrosion 29 . Reduction of the $V$ content is very important because of its strong accelerating effect on the corrosion process. It has been found that an addition of $2 \mathrm{ppm} V$ to $5 \mathrm{ppm} \mathrm{Na}$ increased the corrosion rate three times with respect to $\mathrm{Na}$ alone. 30

New materials and coatings may significantly improve service performance in the future.

\section{Ranges of Allowable and Expected Contaminant Concentrations}

Based on the discussion of HRSG and gas turbine contamination in the previous section it follows that the expected contamination for the HRSG will be considerably lower than the allowable contamination. This will be the case for all combined cycle plants providing that the gas turbine is properly protected.

With regard to the gas turbines, fuel specifications from the major manufacturers are shown in Table 2.3. In general, sulfur specifications for the turbine are less stringent than environmental requirements and emission standards, which are shown at the end of Section 2.1, may set the sulfur clean-up requirements.

Early particulate tolerance levels expressed by gas turbine manufacturers were very $l o w$ and did not discriminate with respect to size distribution. Current limits in the low hundreds ppm range shown in Table 2.4 are higher and have been developed with more concern given to size distribution. These current limits are less 
stringent than environmental imits and therefore environmental limits will set the requirements for particulates also.

Metals, especially vanadium and alkali metals, have long been correlated with turbine blade, corrosion, and fuel specifications have limited concentration of these metals to very low levels. In the case of cold gas cleanup, this is not a serious problem because all of the alkali compounds are water soluble and will therefore be removed in the cleanup system. However, there exists the possibility that some alkali metal compounds may be carried over as entrainment from the cold cleanup system. In the case of hot gas cleanup, it may be necessary to reduce the one or two ppm of alkali that may be contained in the raw coal gas to 250 ppb using, for example, a bed of pelletized bauxite. 
Table 2.3

CONVENTIONAL GAS TURBINE FUEL SPECIFICATIONS

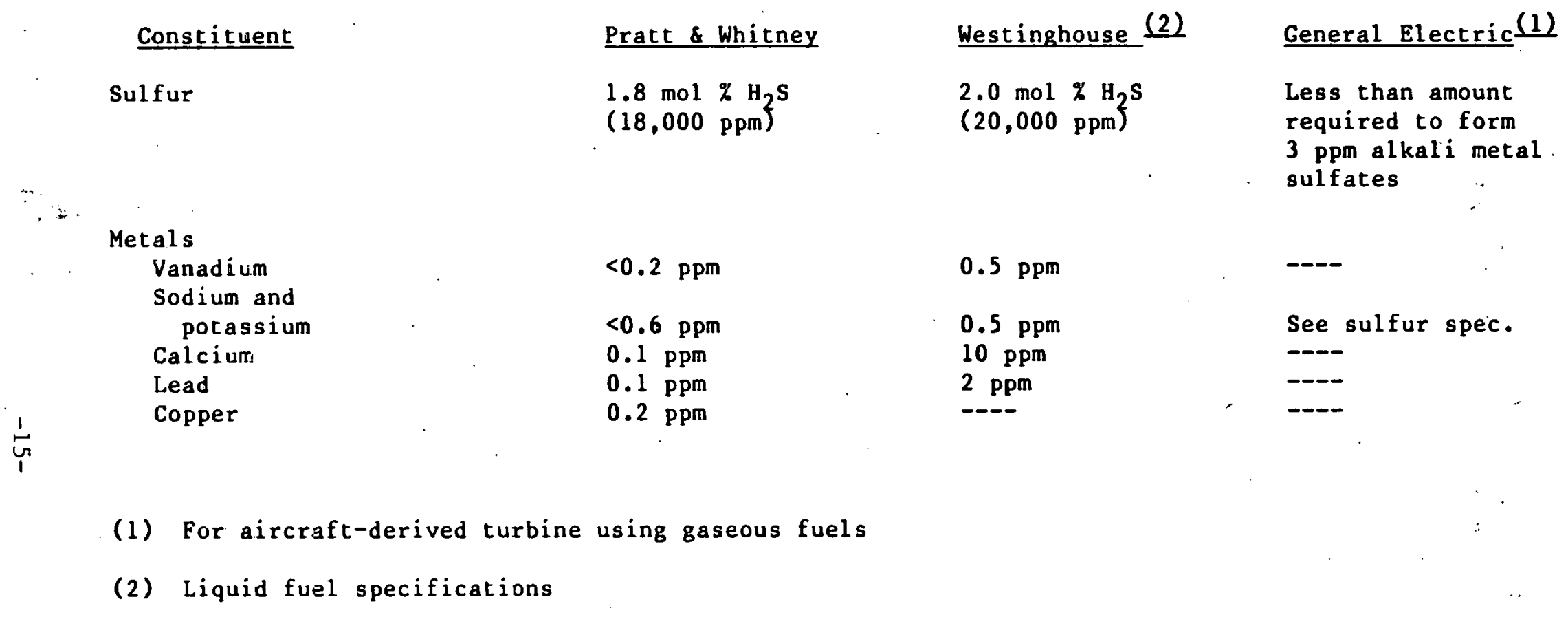


Table 2.4

CURRENT RESEARCH TURBINE TOLERANCE LIMITS

FOR PARTICULATE MATERIAL

Projected

Interval Limits

General Electric

1 ppm $>12.7$ micron

$4 \mathrm{ppm}>8.0 \mathrm{micron}<12.7$

$8 \mathrm{ppm}>5.0$ micron < 8.0

Westinghouse

(Curl distribution)

40-100 ppm

Stal-Laval

$12 \mathrm{ppm}>5.0$ micron

200 ppm 


\subsection{PFBC POWER SYSTEM}

\subsubsection{Power System Description}

\subsubsection{Introduction}

Of the three power generation systems covered by this study, the PFBC system offers significant potential for immediate commercialization, but somewhat less near-term potential than the IGCC system due to the fact that some technological enhancements are needed in order to promote more widespread acceptance of the technology.

The reference configuration to be described is based on the GE steam cooled cycle.31. This system is described briefly in this section and in more detail in Appendix $B$. Other configurations have been considered briefly in order to cover a range of instrumentation requirement possibilities.

In describing the selected PFBC plant, emphasis was placed on descriptive material needed to discuss gas clean-up instrumentation needs. A process flow diagram (Figure $B-1$ ) is included in Appendix $B$ and a simplified version of that diagram is included in this section as Figure 2.5. Figure B-1 has been assigned stream numbers as a means of tabulating stream conditions required for discussing instrumentation needs.

\subsubsection{Basis for Reference Plant Selection}

Electric utility companies are interested in coal burning technologies which are economical, reliable and able to meet emission standards. By comparison with conventional coal-fired boiler technology, AFBC technology is attractive and commercially available for many applications. PFBC has several advantages over $A F B C$ including higher combustion efficiency, higher volumetric heat release rate, higher heat-flux, fewer coal feed points, improved $\mathrm{SO}_{2}$ capture, and suitability to application in a turbine combined cycle. However, this suitability is not universally acknowledged due to the need for several technological enhancements.

An electric utility selecting PFBC technology today would probably insist on the use of equipment having an established performance history. For this reason, a PFBC reference system has been selected for this study which reflects this utility preference. The selected system is based on the GE steam cooled cycle, but has been modified in some areas to emphasize commercial availability.

The GE system was selected as the basis for the reference system due to the following advantages:

- Highest power plant efficiency in the combustor temperature range of interest, 
- Reduced combustor/steam generator corrosion potential because of low fluidized bed tube temperature (as compared to the air cooled cycle),

- Reduced hot gas cleanup flow rate (as compared to the adiabatic combustor cycle), and

- Increased turbine bucket life from improved material protection systems.

2.3.1.3 Reference Plant Description

The steam cooled PFBC is characterized by the use of a conventional steam boiler cycle with the steam generated in a tube bundle immersed in the fluidized bed. Some power is derived from the expansion of flue gas through a gas turbine. Several investigators have favored the steam cooled PFBC concept including GE, Westinghouse, AEP/Stal-Laval, CURL and others. Bed pressures for the proposed steam cooled PFBC concept range from 10 to 16 atmospheres and bed temperatures from 1550 to $1750^{\circ} \mathrm{F}$. The GE concept has been developed under DOE contract. It is representative of several designs and is well documented.

The steam cooled PFBC concept is illustrated in Figure 2-5, and the GE configuration is described in Appendix B. In the GE system, pressurized air supplied at the discharge of gas turbine compressors is ducted to the pressure vessel of pressurized fluidized bed combustor steam generator modules. Each module encloses two rectangular cross section fluidized bed combustors. The air is introduced in parallel to the beds, entering through distribution grids beneath each bed. The principal constituent of the fluidized beds is dolomite $\left(\mathrm{CaCO}_{3} \cdot \mathrm{MgCO}_{3}\right)$ which combines and reacts with $\mathrm{SO}_{2}$. Steam generation tubes are buried within the beds and are also arranged as membrane tube walls enclosing the four sides. Crushed coal is pneumatically fed at locations just above the air inlet grids at the bottom of each bed. Nolomite is similarly fed to the individual beds.

The combustion gases leave the beds at a temperature in the range of 1400 to $1750^{\circ} \mathrm{F}$, depending upon the plant load, and combustion heat is transferred from the bed to the steam generation tubes. The steam circuitry is the supercritical once through type. Steam is generated at $3500 \mathrm{psia}$ and $1000^{\circ} \mathrm{F}$ and is reheated to $1000^{\circ} \mathrm{F}$ after expansion through the high pressure section of the steam turbine.

The exhaust gases from the fluidized beds, which entrain a high percentage of the coal ash as well as dolomite fines, are ducted to conventional cyclones before being admitted to the gas turbine.

Heat is transferred from the gas turbine exhaust and from the hot fine solids to the steam cycle feed water in the stack gas coolers and fine solids cooler heat exchangers. This heat recovery process 


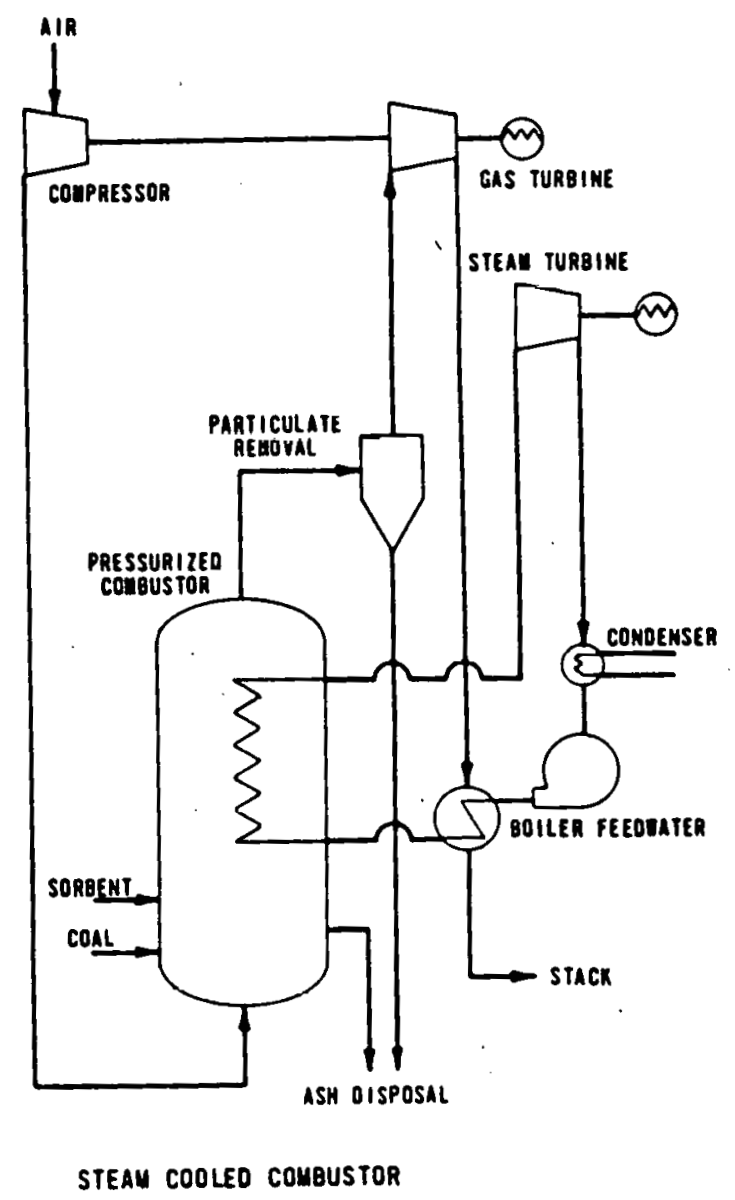

FIGURE 2.5 TYPICAL STEAM COOLED PFBC CONFIGURATION 
is integrated with and supplemented by extraction steam from the steam turbine to heat the feedwater before it enters the PFBC.

The GE reference design employs three gas turbines, each coupled with one PFBC module. The total power level for this plant is $646 \mathrm{MW}$. The gas turbines produce 153 MWe which is 24 percent of the plant output. Control of the plant is coordinated by a master controller, which regulates plant load by automatically balancing steam generator demand and steam turbine and gas turbine loads. Variations in steam system demand result in changes in the coal firing rate and in the fluidized bed temperature.

The fluidized bed effluent contains a high concentration of particles which must be reduced prior to expansion in the gas turbine. Although several approaches have been proposed or tried for particle removal from high temperature and high pressure gases, only cyclones have been used in continuous duty. However, because of the inherent limitations of cyclones, their use for hot gas clean-up requires that the flue gas downstream of the gas turbines be treated to meet the NSPS for particulates. Because of the fine particulate size distribution, low inlet grain loadings, and large gas volumes to be processed, a standard reverse air baghouse was selected.

\subsubsection{Other PFBC Power Plant Configurations}

FBC systems may be categorized according to the presence or absence of heat transfer surfaces in the bed, the cooling medium used within the heat transfer surfaces, and the conditions of operation (including the system pressure). The Department of Energy has considered PFBC designs with and without in-bed heat transfer tube surfaces. For the in-bed heat transfer case, both air and water/steam cooling mediums have been considered. In all cases the bed operating pressures have been different. Three PFBC systems have been investigated by DOE. 32 The other two are shown in Figure 2-6.

\section{Adiabatic Combustor}

In the adiabatic combustor concept, there are no heat exchanger tubes within the combustor. Bed temperatures are maintained in the 1500 to $1800^{\circ} \mathrm{F}$ range by means of high airflows (near 300 percent excess air). The high airflow per MWe output dictates a larger combustor size than that projected by a steam or air cooled concept. A version of this cycle was demonstrated at a $9 \mathrm{MW}_{t}$ scale by Combustion Power Company in Menlo Park, California. Their system operated at 4 atmospheres pressure, but could conceivably be much higher. The cycle, as illustrated in Figure 2-6, consists of a gas turbine and a steam bottoming cycle, with approximately 20 percent of the total power being generated by the steam turbine. The primary advantage of this cycle is the simplicity of the combustor. The primary disadvantages are the larger components (combustor and cleanup train) required and the potentially higher NOx emissions due the high excess air requirement. The adiabatic 


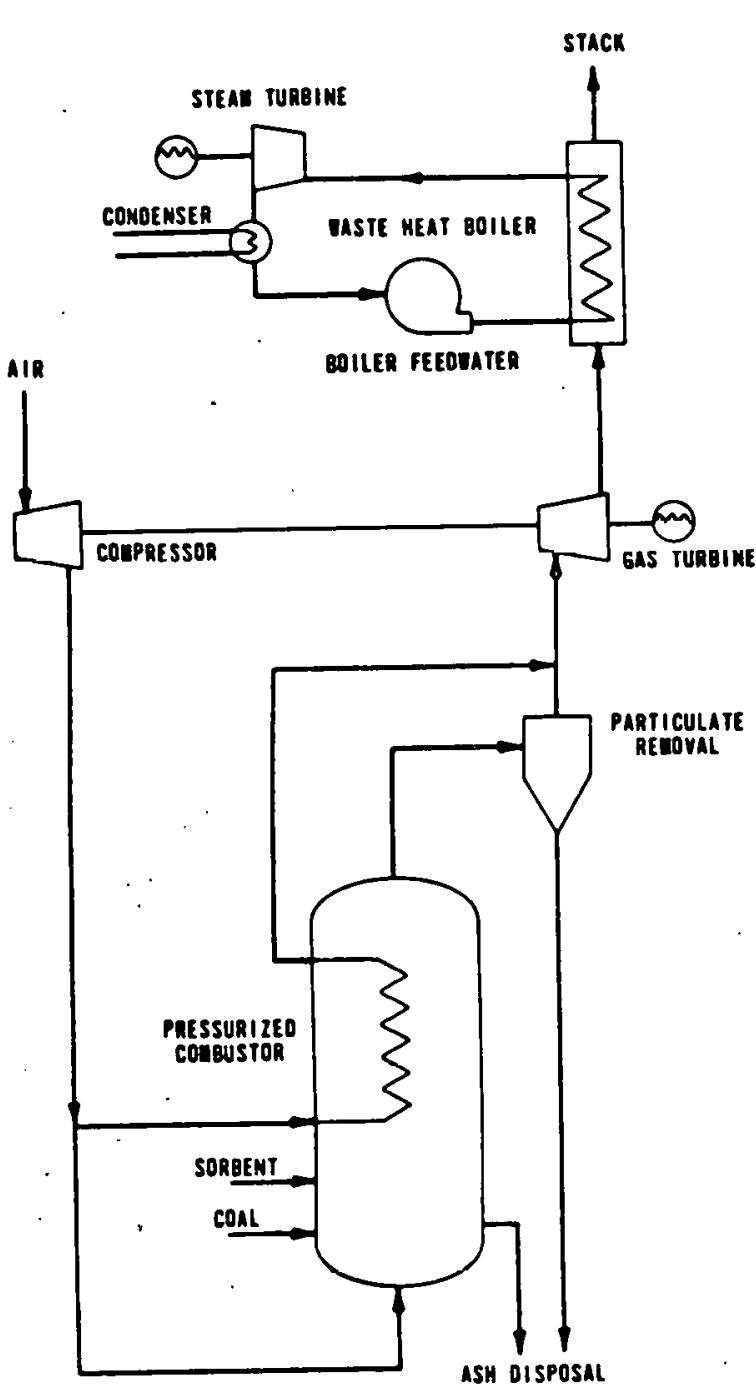

AIR COOLED COMBUSTOR

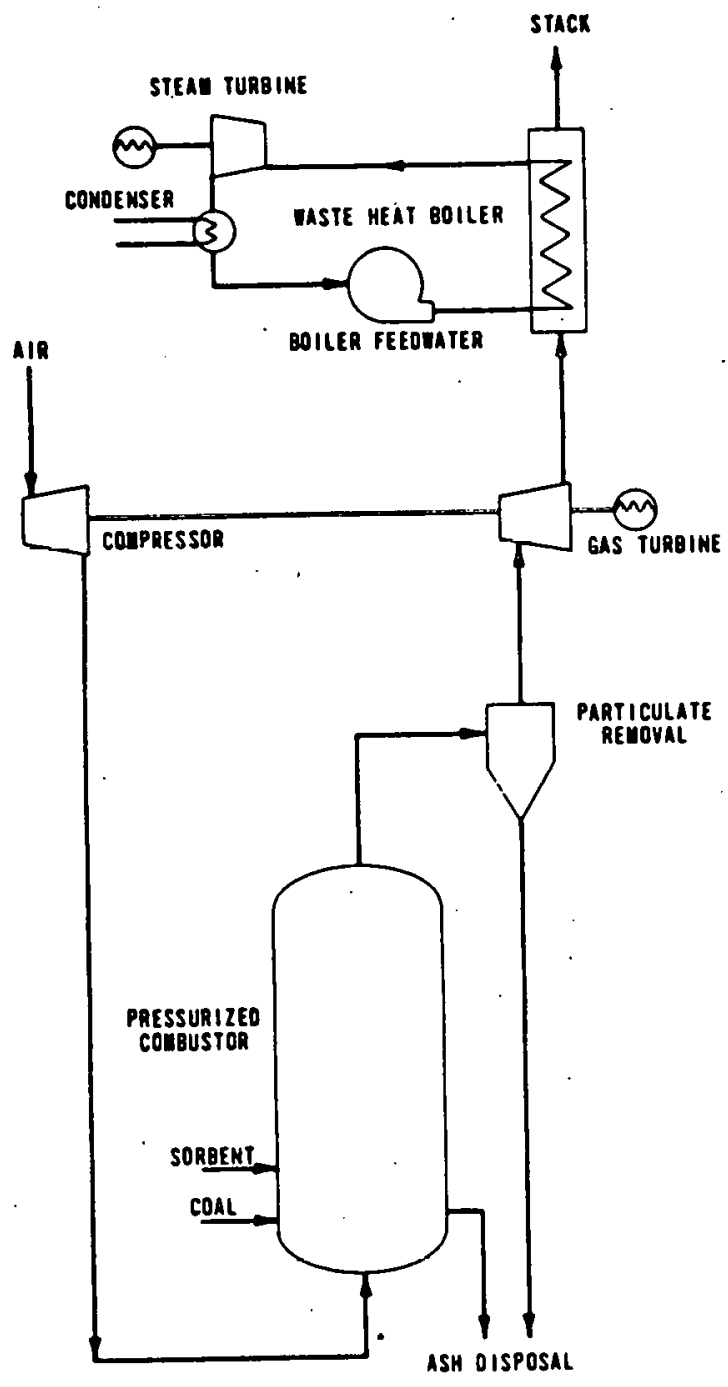

AOIABATIC COMBUSTOR

FIGURE 2.6 OTHER PFBC CONFIGURATIONS 
combustor may find application in a "first generation" PFBC plant because of its inherent simplicity.

Air Cooled PFBC

The installation of an air cooled heat exchanger in the bed is actually a variation of the adiabatic concept in the sense that the majority of the excess air is indirectly. heated and not involved in the combustion process. As a result, the gas cleanup devices are smaller since only the combustion gas must be cleaned of particulates. The combustor will also be somewhat smaller because of the high air velocity in the air cooling tubes. Two "air cooled" conceptual designs have been studied: One by Burns \& Roe/United Technologies at 16 atmospheres pressure and one by Curtis-Wright/Dorr-Oliver/Stone \& Webster at 7 atmospheres. The first design was a second generation design involving an AFBC reheat in the exhaust of the PFBC turbine. This cycle achieved a 43 percent cycle efficiency.

A simplified flow diagram of the air cooled PFBC combined cycle is shown in Figure 2-6. Approximately one-third of the air from the gas turbine's compressor is used to fluidize the dolomite bed and to support combustion of coal at a temperature of $1650^{\circ} \mathrm{F}$. The remaining two-thirds of the compressor air is indirectly heated to $1575^{\circ} \mathrm{F}$, within a heat exchanger which is fully immersed in the bed. The hot combustion gases flow through several stages of particulate cleanup before joining the clean heated air from the in-bed heat exchanger. The mixed flow expands through the gas turbine to drive the compressor. It then expands through a free power turbine, coupled to a generator to produce electric power. The hot exhaust gas leaving the power turbine enters a waste heat recovery boiler which raises steam to power a steam turbine generator set, producing additional electric power. About 60 pereent of the total plant power is provided by the gas turbine, and 40 percent by the steam turbine.

\subsubsection{Other Cleanup Systems}

One of the major advantages of the fluidized bed combustion process is that $\mathrm{SO}_{2}$ emissions can be cortrolled by carrying out the rnal. combustion reactions in the presence of limestone or dolomite. Another advantage is that NOX emissions are low due to the low combustion temperature. Both of these gas cleanup advantages are inherent advantages of the PFBC process itself. Therefore there are no alternative gas cleanup sysleins in the anme sense that alternative gas stream cleanup processes exist for use in the IGCC and MCFC power generation systems.

Many particulate removal devices (such as ceramic cross-flow filters, ceramic bag filters and electrostatic precipitators, some of which are referenced in Section 3.3.2) are being considered for use in PFBC power plants. Each device is provided with an instrumentation and control system which varies according to the collection technology used. These systems are installed in order 
to operate each device. The problem of measuring inlet and outlet dust loadings and distributions is one of significant importance, but this problem is common to all particulate removal. systems.

\subsubsection{Other Power Generation and Balance-of-Plant Systems}

Instrumentation and control needs for the gas turbine, steam system and materials handling systems are not directly related to the DOE gas stream cleanup program. It may become feasible to monitor coal and dolomite composition on a continuous basis. However, at present this monitorng is performed on an intermittent basis using plant laboratory instrumentation.

\subsubsection{Contaminants Detrimental to Components}

The major PFBC components which are subject to damage by contaminants are the gas turbines; and the corrosion and erosion problems involved have already been discussed in section 2.2.2.

The abrasive nature of the PFBC bed material itself will be detrimental to the heat exchanger surfaces immersed in the fluidized bed and to the operation of the hot gas valve which may be needed to facilitate start-up and shutdown or to guard against turbine overspeed in the event of loss of electrical load. Instrumentation may be needed to monitor heat exchanger surface erosion.

The allowable ranges of sulfur, alkali metal and other trace metals have been discussed in Section 2.2.2. Since the allowable ranges are established by the turbine manufacturers, they are dependent upon the power system in which they are used. Expected contaminant release ranges were considered during the contaminant identification study described in Section 2.1 .

2.4 MCFC POWER SYSTEM

2.4.1 Power System Description

MCFC power systems are unlike IGCC and PFBC systems in that few integrated power plants have been designed, even at the conceptual level. Most MCEC hardware development work has been carried out by United Technologies, but additional work is needed to achieve acceptable scale-up and 1 ifetime goals. Although the General Electric researchers are no longer developing MCFC technology, their reference plant design was based on an intensive three year study on feasible combinations of alternative subsystems considering such factors as efficiency, complexity, development status and cost.

Major materials investigations are continuing, but with the exception of recent work on hot gas clean-up which has been covered in Section 2.2.1, no new subsystem designs have emerged which would 
suggest instrumentation needs significantly different from those required for the GE system.

The base case Molten Carbonate Fuel Cell electric power generation plant described in this report is based on the General Electric(34) cycle which is descried in more detail in Appendix C. This system employs the coal preparation, oxidant feed, gasification, gas cooling, acid gas removal and power generation sections shown schematically on Figure 2.7. A contaminant control and monitoring strategy was not selected as the initial step. Rather, required limits for the important contaminants were specified, and then the final system emerged in the form of a preferred strategy after imposing the appropriate economic and operational constraints.

Since available technologies, economic considerations, operational requirements and user preferences all change with $t i m e$, and since coal composition changes significantly from one location to another, it follows that each application should be treated separately as an integraced study. However, in view of the limited scope of this project, it has been necessary to treat each gas cleanup process as a unit operation. Very little attention has been paid to the important question of load-following for MCFC power plants. In the absense of this information, MCFC gas cleanup instrumentation response times will be assumed to be the same as those based on IGCC load-following considerations.

The contaminants of major concern in MCFC power plants are discussed in Section 2.4.2 and appropriate low temperature and hot gas cleanup processes are discussed in section 3.3.1. The hot gas cleanup processes which are not yet commercially. available, will permit the sensible heat in the gas to be used without heat exchange. Low temperature processes have the advantage that they have been commercially proven, but the overall advantages and disadvantages of the two approaches are still under investigation.

The molten carbonate fuel cell is attractive because it has a high electrochemical conversion efficiency, and because it can operate at a high temperature and consequently power an efficient Carnot limited bottoming cycle.

The GE study was based on a thorough analysis of eight cycle concepts, and the final selection was made from four of these. The preferred system was finally selected on the basis of the relative cost of electricity.

2.4.2 Contaminants Detrimental to Components 20,39

The molten carbonate fuel cell power plant requires the purest fuel gas of the plants considered here. As previously mentioned, practically all naturally occurring elements occur in roal and hence, they and their compounds may appear in the raw fuel gas. Cell damage in the form of degraded output or structural failure can result from their presence if they are not removed to sufficiently low levels. While the damage mechanisms of some 


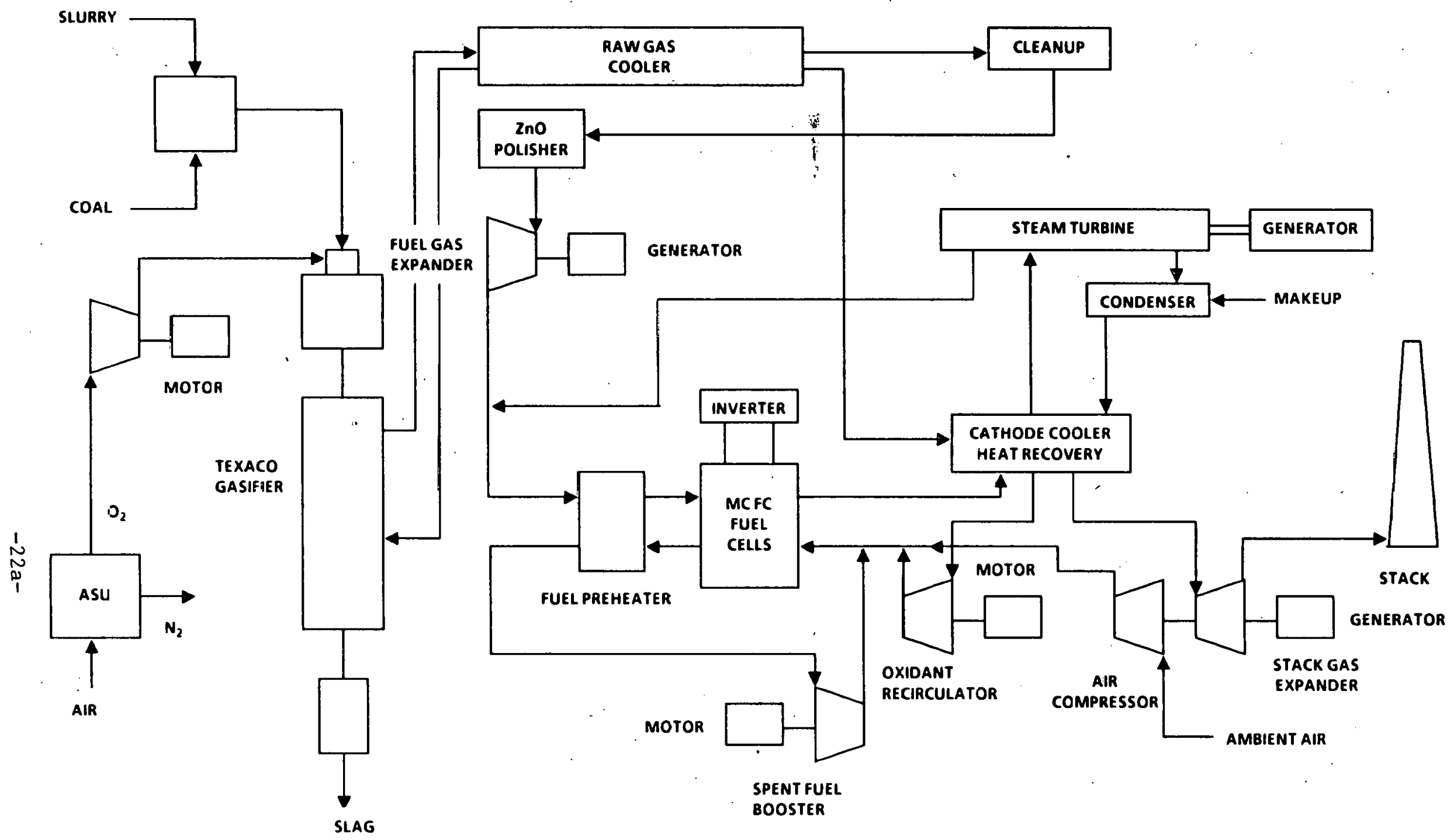

FIGURE 2-7 THE MCFC REFERENCE POWER SYSTEM 
contaminants such as sulfur and halogen compounds are known, very little is known about the damage mechanisms for other contaminants such as metals.

Sulfur compounds, due to their high concentration (see Table 2.2, Range of Gas Composition from Illinois 非 Coal), are of the most prominent concern. After gas cleanup, $\mathrm{H}_{2} \mathrm{~S}$ and $\mathrm{COS}$ will still be present in the fuel gas to the anode of the fuel cell. The anode exhaust gas is combusted with excess air before going to the cathode, so that $\mathrm{SO}_{2}$ will be present there. The molten carbonate electrolyte can react with these sulfur compounds to form sulfates and sulfides, thus, all active cell components can be affected by sulfur with possible reduction in electrical output or internal corrosion which later may increase internal cell resistance or cause structural failure.

Halogen acids can poison electrocatalytic sites of the cathode and cause internal cell corrosion. Hydrogen chloride can cause stress corrosion cracking of stainless steel stack hardware. It can also react with the electrolyte to form volatile alkali chlorides which reduce electrolyte level and activity and thus cell output.

Ammonia, like nitrogen, acts only as a diluent without direct effect on cell performance. In fact, the anode may decompose ammonia to nitrogen and hydrogen with the latter being useful as fuel. Any unreacted ammonia can be converted to $\mathrm{NO}_{\mathbf{x}}$ during anode exhaust gas combustion which may form alkali nitrates with the electrolytes.

Metallic and trace elements in the fuel gas are potentially damaging contaminants since they may adsorb on the electrodes, increasing internal cell resistance. Electrolyte reactions may result in deleterious changes in physical properties. Only arsenic, cadmium, lead, mercury, tin and titanium have been studied theoretically. Practically no experimental data are available for these elements or their compounds.

Hydrocarbons are not catalyst poisons. Simple, light hydrocarbons act as diluents while more complex organics are cracked or reformed to provide some fuel value21. Carbon plugging of gas passages can be prevented by adding steam to the fuel gas which also promotes reforming.

Coal-derived fuel gas may contain particulate matter, even after cleanup, in sufficient amount to be troublesome. Typical nickel electrode pores are less than ten micrometers in diameter, thus micrometer and sub-mirrometer particles which are difficult to remove by any cleaning method can diffuse into and plug the pores with resulting loss of activity. This may be more of a problem at the cathode than at the anode so that oxidant or cathode gas may require an additional stage of particulate removal. 
Table 2.5 from reference 20 summarizes what little is currently known about the effects and limits of contaminants in coal-derived fuel gas. 
Table 2.5

SUMMARY OF THE EFFECT OF IMPURITIES AND TOLERANCE LIMITS20

\begin{tabular}{|c|c|c|}
\hline Impurity & Possible Effect & Operating Limits \\
\hline $\begin{array}{l}\text { Sulfur compounds } \\
\left(\mathrm{H}_{2} \mathrm{~s}, \mathrm{COS}, \mathrm{Cs}_{2}, \mathrm{SO}_{2}\right)\end{array}$ & $\begin{array}{l}\text { - Sulfation of carbonates } \\
\text { and increase in } \\
\text { overpotentials } \\
\text { - Deactivation of anode by } \\
\text { chemisorption } \\
\text { Sulfation of anode } \\
\text { materials sintering } \\
\text { - Sulfidation of cell } \\
\text { hardware loss of strength } \\
\text { and increase of ohmic } \\
\text { resistance }\end{array}$ & Less than $1 \mathrm{ppm}$ \\
\hline $\begin{array}{l}\text { Halogen Compounds } \\
\text { ( } \mathrm{Cl}_{2} \mathrm{HCl}, \text { alkali } \\
\text { halides) }\end{array}$ & $\begin{array}{l}\text { - Severe performance loss } \\
\text { at cathode } \\
\text { - Eormation of chlorides } \\
\text { and hardware corrosion }\end{array}$ & $\begin{array}{l}100 \mathrm{ppm} \text { in fuel } \\
10 \mathrm{ppm} \text { in oxidant (a) }\end{array}$ \\
\hline $\begin{array}{l}\text { Nitrogen Compounds } \\
\left(\mathrm{NH}_{3}, \mathrm{NO}_{\mathrm{x}}\right)\end{array}$ & $\begin{array}{l}\text { Electrolyte composition } \\
\text { changes }\end{array}$ & Very large for $\mathrm{NH}_{3}$ \\
\hline $\begin{array}{l}\text { Metals ( } \mathrm{Fe}, \mathrm{Cu}, \mathrm{As}) \\
\text { Heavy metals ( } \mathrm{Hg}, \\
\mathrm{Sn} \text {, As) }\end{array}$ & $\begin{array}{l}\text { - Deactivation and plugging } \\
\text { - Corrosion, alloying and } \\
\text { structural damages }\end{array}$ & $\begin{array}{l}\text { (b) } \\
\text { (b) }\end{array}$ \\
\hline $\begin{array}{l}\text { Hydrocarbons } \\
\text { Tar and Oil }\end{array}$ & $\begin{array}{l}\text { - Carbon formation } \\
\text { - Deactivation, mechanical } \\
\text { problems. }\end{array}$ & $\begin{array}{l}\text { Lees than } 1 \text { mol\% } \\
\text { (b) }\end{array}$ \\
\hline Particulates & $\begin{array}{l}\text { - Diffusion problems, } \\
\text { blockage of flow passages }\end{array}$ & $0.0056 \mathrm{gr} / \mathrm{ft}^{3}, \mathrm{~d}<2 \mu \mathrm{m}$ \\
\hline
\end{tabular}

(a) TRW analysis shows $0.2 \mathrm{ppmV}$ tolerance for $\mathrm{HCl}$ and $100 \mathrm{ppmV}$ fur HF. 22

(b) Very low tolerance expected in IGT's Handbook of Fuel Cell Performance. 23 
3.1 CLASSIFICATION OF POWER PLANT INSTRUMENTATION NEEDS

3.1.1 Introduction

The need for continuous automated nonintrusive analysis instrumentation for fossil energy applications has been well established. However, the development work required to support that need has not yet been completed. Meanwhile, advanced power plants are being planned based largely on conventional, off-the-shelf instrumentation. In order to discuss future instrumentation requirements, it is necessary to take several different needs into consideration. For this reason it was decided to categorize instrumentation requirements as follows:

- Operational Needs

- Research Needs

- Environmental Needs based on Existing and Pnssible Future Regulations

These categories are discussed below.

\subsubsection{Operational Needs}

From an operational point of view, the ideal variable to measure is one that can be used to regulate the process in the presence of disturbing forces and can be monitored easily, inexpensively, quickly and accurately. The variables that usually meet these qualifications are pressure, temperature, level, voltage, speed and weight. Otten, the values of other variables are obtained from measurements of these. For example, flow rate is otten determined by measuring pressure differential across a constriction in a pipeline. However, the correlation between pressure drop and flow is also affected by changes in fluid density, pressure and composition. Therefore, if there exists the need for a more accurate measurement, then this would require the use of additional sensing devices as well as additional computational capabilities. This would result in an increase in cost and complexity which is often unwarranted unless the increase in capability is needed to solve some specific operational problem. For example, when an IGCC power system based on conventional technology must respond to a sudden increase in the demand for more electricity, the flow rate of the lean solution to the $\mathrm{H}_{2} \mathrm{~S}$ absorber is automatically increased to provide the additional $\mathrm{H}_{2} \mathrm{~S}$ removal capability. An $\mathrm{H}_{2} \mathrm{~S}$ analyzer is certainly needed, but from a purely operational point of view, it would not play a critically important role in-dynamically controlling the gas clean-up system.

Throughout this study there will arise situations where low cost solutions based on past operational practice will differ from solutions needed for optimization or development purposes. In many 
cases, the conventional approach will be satisfactory. In other cases, instrumentation previously restricted to research may now be available for operational purposes, and may be necessary.

\subsubsection{Research Needs}

Accurate process measurements are made with various objectives in mind. The term "research need" has been selected to describe any engineering-oriented need which falls outside the range of standard I\&C engineering practice, and which is not required for plant operation or normal monitoring.

In terms of the flow example discussed in the previous subsection it is probable that for "research" purposes, additional variables would be measured or else a more accurate flow-measuring instrument would be selected. If it is standard practice to use a specific instrument, and if (due to harsh conditions, improved accuracy or similar reasons) an improved version of that instrument is needed, then, for the purpose of this study, the improved instrument will be assumed to be satisfying a research need.

In some cases, a research need can be defined in terms of a specific research objective, such as, to check out a specific scale-up correlation. In other cases (as may be the case for a demonstration plant), there may merely exist a need to close all energy and mass balances to demonstrate performance or to provide good data for analysis work to be performed later.

Most of the higher priority DOE/METC research and development concerns relative to IGCC system commercialization are listed in terms of measurement, characterization or monitoring objectives 47 :

- Characterize the toxicity of oxidizer spent sorbent/ash (fluidized bed only).

- Measure the fate of non- $\mathrm{H}_{2} \mathrm{~S}$ reduced sulfur compounds in a zinc ferrite bed.

- Characterize and measure fixed nitrogen compound generation in an air-blown fixed-bed gasifier, and in an air-blown fluidized-bed gasifier with in-bed sorbent.

- Measure fixed nitrogen capture and release during regeneration in a zinc ferrite system.

- Characterize the toxicity of cyclone and tertiary filter fines.

- Characterize the toxicity of spent zinc ferrite and zinc ferrite fines.

- Measure the effects of trace elements on the long term performance of the zinc ferrite system. 
- Measure the effects of trace elements on the long term performance of the zinc ferrite system.

- Measure the toxicity of the spent material from a fixed bed $\mathrm{SO}_{2}$ removal system.

- Measure the toxicity of oxidizer spent sorbent and ash (fluidized bed).

- Measure the impact of fixed bed tar/oil on zinc ferrite bed and advanced filter performance.

- Measure fines production during zinc ferrite regeneration, and characterize the impact of fines on gasifier/SO 2 removal systems.

- Measure the impact of tar/oil nitrogen and fines on zinc ferrite sulfidation performance.

- Monitor alkali volatilization in fluidized bed gasifiers.

- Characterize fouling and deposition of alkalis downstream of a gasifier and upstream of a zinc ferrite bed (fluidized bed).

- Measure points of exit of alkalis from a fluidized bed system.

- Measure the amount of alkalis passing through a zinc ferrite fluidized bed system.

Based on the above DOE/METC concerns, it must be anticipated that contaminant monitoring needs will continue to provide a major incentive for developing research-oriented instruments for analyzing cóal-derlved gas screams.

3.1.4 Environmental Needs Based on Existing and Púsible Future Regulations

\subsubsection{Introduction}

The measurement requirements 1 isted in the previous section emphasize hot gas cleanup, fluidized bed gasification and emissions assessment activities. After the indicated process development work has been completed, it will be necessary to install instruments in response to process control and regulatory driving forces. The purpose of the following discussion is to assess regulatory impact on future instrumentation design to the extent to which such assessments are possible.

\subsubsection{Discussion}

The U.S. may very well see more stringent requirements to address the acid rain issue. Pending acid rain legislation may have an increasing impact as utilities begin expansion plans. Legislation has been proposed that calls for a reduction of $\mathrm{SO}_{2}$ emissions by 
eight to twelve million tons/yr along with smaller NO $_{x}$ reductions. This will put extreme pressure on utilities to either upgrade existing plants with the necessary controls, retire existing plants and replace with new capacity, or utilize low sulfur fuels. Retrofitting existing plants is an ideal application for the technologies being considered. A site specific application could favor any of the three new technologies, depending on the situation, but higher efficiency technologies complying to the same limits will result in less total emissions per MWe.

Table 3.1 summarizes some environmental concerns and attempts to show, by subjectivity assigned rating numbers, the relative capabilities of the technologies considered here. A pulverized coal burning plant equipped with flue gas scrubbing and particulate control has been selected as the baseline for comparison. 
TABLE 3.1

ENVIRONMENTAL CONCERNS ADDRESSED BY VARIOUS TECHNOLOGIES

Environmental Issue/Concern PC/FGD PFBC IGCC MCFC

Pending severe acid rain legislation

5

3

3

2

requiring significant reductions in

existing emission levels

Tightened PSD limits for new sitings

5

53

Shorter emission averaging periods

5

3

Solid waste disposal

5

Liquid waste discharge

5

5

3

3

4

Water usage

$\begin{array}{lll}3 & 6 & 3 \\ 4 & 3 & 4\end{array}$

Key: 5 is nominal, assigned to baseline technology.

Below 5 is more favorable, 1 is most favorable, above 5 is less favorable, 10 is least. favorable, and the ICCC rating is for low temperature gas cleanup.

Regulations under National Emissions Standards for Hazardous Air Pollutants (NESHAPS), Toxic Substance Control Act (TSCA), Clean Air Act (CAA), Clean Water Act (CWA) and Resource Conservation and Recovery Act (RCRA) may be developed, more tightly controlling presently regulated emisgions or controlling presently unregulated emissions and effluents. These regulatory changes would affect other energy conversion technologies as well as those considered here.

Air emissions that may become subject to limitations under the CAA or NESHAPS include:

- Respirable particulate, PM

- Polycyclic organic materials, POM

- Trace metals: $\mathrm{AS}, \mathrm{Be}, \mathrm{Hg}, \mathrm{Ni}, \mathrm{Pb}, \mathrm{Se}$, etc.

- Reactive or toxic species: $F_{2}, B$, etc.

Respirable particulate emissions represent a measurable fraction of the total particulate emitted. Ongoing research indicates 40-50 percent of the cotal particulace emicced is in the respirable range. However, studies are inconclusive in demonstrating what fraction of the toxic metals are actually emitted and whether they are in a form that is biologically mobile.

Measurements at PFBC plants indicate that emissions to the atmosphere for $\mathrm{As}, \mathrm{Be}, \mathrm{Cd}, \mathrm{Hg}, \mathrm{Pb}, \mathrm{Sb}$, Se and $\mathrm{Te}$ are well below the Minimum Acute Toxicity Effluent (MATE) values used by EPA to assess 
aggregate multi-media effects35. Less complete data exist for gasifiers, although raw gas may contain higher. concentrations.

Conventional technology also creates similar concerns with respect to toxic metals in exit flue gas. It is known that FGD scrubbing techniques are not very effective in reducing volatile, toxic metal forms, particularly $\mathrm{Be}, \mathrm{Hg}$, and $\mathrm{Se}$.

Polycyclic organic material (POM), which is produced by incomplete combustion and includes polynuclear aromatic hydrocarbons (PAH), may become subject to CAA, NESHAPS or TOSCA 1 imitations in the future. POMs have been detected in the exhaust gas from PFBC pilot plants at levels well below the MATE values used by EPA.

Table 3.2 shows that all the alternative technologies considered here can be controlled to meet current environmental regulations. Note that the emissions from MCFC are set by the electrochemical cell requirements rather than by regulations. A PFBC or IGCC (cold gas cleanup) plant emits less NOX than present regulations allow, thus such plants could easily comply with more stringent NOX regulations.

TABLE 3.2

EMISSION RATES FROM COAL CONVERTORS 7

$(1 \mathrm{~b} / 106 \mathrm{Btu})$

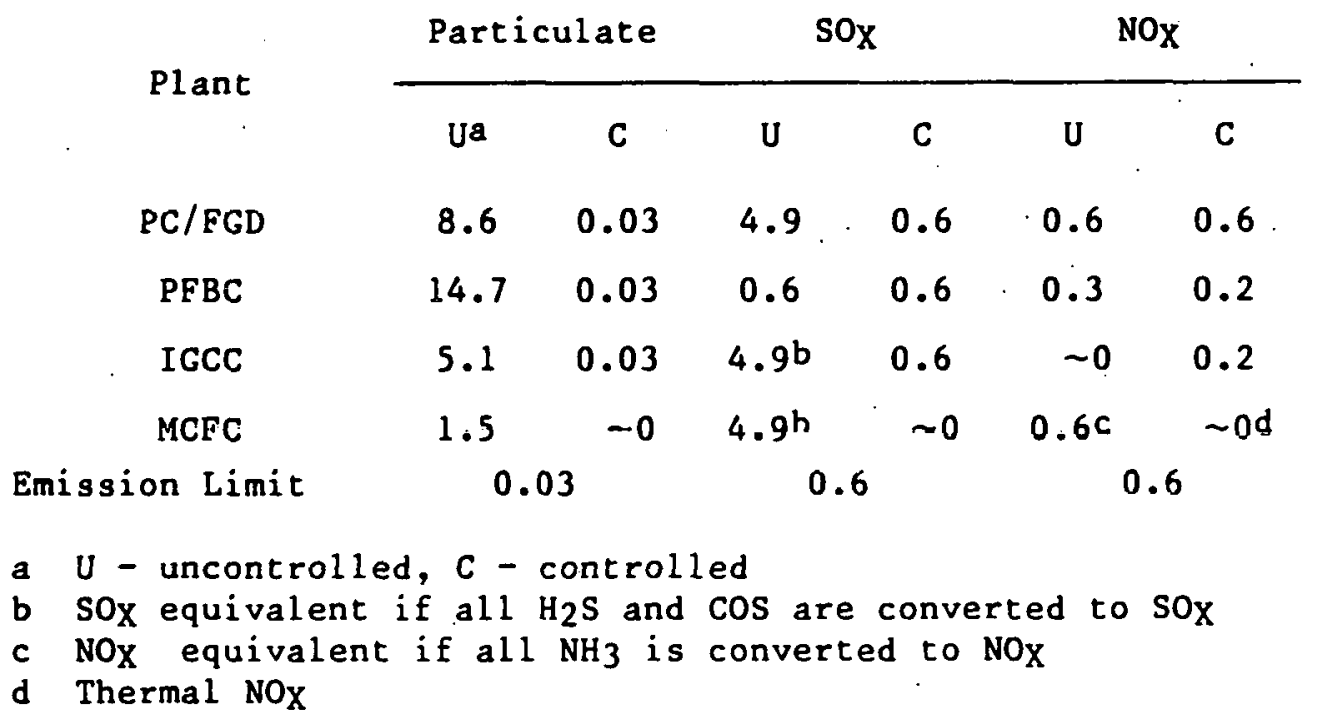

Wastewater effluents from hoth PC/FGD and PFBC units originate from similar, secondary sources that are not likely to have a new 1 imit on new species or pollutant categories imposed in the foreseeable future. However, since these sources are very similar, new limits will have equal effects on either technology. Gasifier limits may 
be set based on other criteria, but probably will not be more strict than combustion effluent limits.

Future regulations under RCRA may complicate disposal options which would equally affect conventional technology's ash and sludge disposal facilities. Such regulatory changes could result in an expanded definition of hazardous properties and/or more rigorous specifications for disposal facility performance. Since most states have policies that are presently requiring new ash and sludge disposal sites to meet standards analogous to those for hazardous wastes, no significant dislocation due to RCRA revisions are anticipated at this time.

Relative impacts on water usage and therefore generation of wastewater are shown in Table 3.3. These data show that these technologies will result in reduced pollutant mass loadings, (suspended solids, dissolved solids, oils and grease, $\mathrm{Cr}, \mathrm{Zn}, \mathrm{Cu}$ ) on receiving waters due to the lesser quantities of wastewater being released from the plant sites. Consumptive usage of water, which presumably reduces the availability of this resource for alternative use, appears particularly low for MCFC technology. The PC/FGD plant has an additional penalty due to water use in the FGD system and for ash sluicing.

Treatment applied to $\mathrm{PC} / \mathrm{FGD}$ and $\mathrm{PFBC}$ wastewaters are standard technologies that have been in use in power plants for many years. Alternatively, gasification wastewater streams have high organic loadings which require application of more complex treatment techniques that are not common to utility power plants, having primary use in the chemical and petrochemical industries. In the case of IGCC systems with low temperature gas cleanup, there are additional concerns that these wastewaters contain toxic species that may need more rigorous specific treatment of technologies than are presently available on a commercial basis. The hot gas cleanup option would avoid these concerns.

A comparison of solid waste generation is also shown in Table 3.3. These data show that on an energy output basis, PFBC and IGCC technologies generate less solid waste than PC/FGD, while MCFC technology is conspicuously lower; which, over a period of time, will significantly reduce the solid waste loadings on the environment.

Table 3.3 shows that, in the aggregate, the alternative technologies have slightly lower commitments of resources necessary to produce equivalent outputs. The reduced need for water and coal is especially advantageous since these resources are 1 ikely to experience supply constraints and their exploitation creates secondary environmental impacts that are likely to be of increasing concern.

The foregoing demonstrates that existing regulations can be met by the applications at various levels of available control techniques. When or if regulations become more stringent, available techniques 
can be applied at higher levels, such as increasing the $\mathrm{Ca} / \mathrm{S}$ ratios in PFBC, going to larger liquid to gas ratios or higher pressure drops in scrubbers, designing larger specific collection areas in electrostatic precipitators or using baghouses, etc. Additionally, new techniques such as tertiary wastewater treatment or carbon absorption can be applied. The fact that MCFC emissions can be brought to low ppm levels shows that any regulation or requirement can be met with the expenditure of sufficient money and energy. Better efficiencies in some technologies permit easier controls. None of the technologies has inherent limitations that would prevent lowering emissions.

TABLE 3.3

RESOURCE COMMITMENTS \& WASTE PRODUCTS FOR VARIOUS TECHNOLOGIES

TECHNOLOGY

\begin{tabular}{|c|c|c|c|c|}
\hline . & PFBC 36 & $\mathrm{PC} / \mathrm{FGD} 36$ & IGCC36 & $\operatorname{MCFC} 7,37,38$ \\
\hline $\begin{array}{l}\text { Water Consumption } \\
\text { gal } / \mathrm{kWh}\end{array}$ & 0.66 & 0.52 & 0.60 & 0.23 \\
\hline $\begin{array}{l}\text { Wastewater Requiring } \\
\text { Treatment gal/kWh }\end{array}$ & 0.33 & 0.26 & 0.28 & 0.02 \\
\hline $\begin{array}{l}\text { Coal } \\
1 \mathrm{~b} / \mathrm{kWh}\end{array}$ & 0.96 & 0.86 & 0.92 & 0.57 \\
\hline $\begin{array}{l}\text { Sorbent } \\
1 \mathrm{~b} / \mathrm{kWh}\end{array}$ & 0.13 & 0.27 & -- & - \\
\hline $\begin{array}{l}\text { Land, acres/MW, } \\
\text { plant site } \\
\text { off-site disposal }\end{array}$ & $\begin{array}{l}0.80 \\
0.48 \\
\end{array}$ & $\begin{array}{l}0.70 \\
0.52 \\
\end{array}$ & $\begin{array}{l}0.80 \\
0.28 \\
\end{array}$ & $\begin{array}{l}1.10 \\
0.35 \\
\end{array}$ \\
\hline Total & 1.28 & 1.22 & 1.08 & 1.45 \\
\hline $\begin{array}{l}\text { Solid Waste } \\
\mathrm{Lb} / \mathrm{kWh}\end{array}$ & 0.46 & 0.36 & 0.20 & .08 \\
\hline
\end{tabular}

3.1.4.3 Conclusions

Based on the above discussion it is concluded that air emissions may become'subject to more stringent regulations for the following:

- Respiratory particulate

- Polycyclic organic materials

- Träce metals 
Some liquid and solid waste impacts will be experienced, but it is probable that conventional laboratory analysis techniques will be satisfactory.

Since on-line real-time elemental analysis techniques will be required for equipment protection purposes, it follows that it would be cost-effective to use similar technology for monitoring gas stream contaminants.

Although it has been concluded that existing processes could be used to satisfy tighter regulations, and existing process analyzers could be used for process control purposes, there exists a problem in that the capital and operating costs for the commercially available analyzers and sample conditioning systems, and the higher efficiency conventional cleanup processes, may be prohibitively high.

3.2 METHODOLOGY FOR COMPARING INSTRUMENTATION REQUIREMENTS WITH INSTRUMENTS AVAILABLE

During the initial phase of the study, several attempts were made to develop an instrumentation need assessment methodology based primarily on quantitative considerations. The objective was to specify contaminant levels and cleanup process dynamic response times, and select instruments based primarily on these factors. the work progressed, it became increasingly apparent that this approach would have to be revised for the following reasons:

1. Based: on previous experience in dealing with typicai disturbances, instruments had al ready been selected for the commercially available processes, and it appeared unnecessary to refevaluate these selections.

2. Diffieult-to-quantify fcaturce cuch as those related to malfunction detection, case of maintenance, ease of calibration and communications interface compatibility have become increasingly important.

3. Miniaturization trends and analyzer component improvements have led to response time reductions at the same time that advanced gas cleanup processes are being developed, which are less sensitive to load changes.

In view of considerations such as these, only the more important quantitative factors were tabulated for each instrument need, and the less quantitative factoors were taken into consideration by referencing a set of appropriate application notes. The resulting instrumentation needs are listed in Section 3.5 .

A 1 ist of quantitative factors and related instrumentation characterization factors were compiled during the execution of Task 3 , and then the two lists were compared and discussed during the execution of Task 4. During the execution of Task 4, the question of instrumentation improvements was addressed. 
Improvements are always possible, and some may contribute significantly to reductions in instrument maintenance costs.

The selected methodology may be summarized as follows:

Instrumentation Requirements (Task 2)

1. Describe an equipment configuration and some typical configuration variations for each power plant type.

2. Generate process flow diagrams for the various possibilities using numbered flow streams.

3. Review each stream (primarily gas streams) for instrumentation needs based on the following classification system:

- Operational Needs

- Research Needs

- Environmental Needs based on Existing Regulations

- Environmental Needs based on Possible Future Regulations

4. Exclude most streams for which instrumentation based on current commercial I\&C engineering practice is known to be satisfactory.

5. Generate a list of quantitative factors related to each instrument need. Emphasize gas stream cleanup and reference notes on related less quantitative factors.

\section{Instrumentation Available (Task 3)}

1. Generate a list of instruments available based on DOE/METC, G/C and published information.

2. Generate a list of quantitative factors (such as accuracy, range and response time) for each instrument available and combine them with related less quantitative factors and constraints.

Comparison of Instrumentation Requirements and Availabilities (Task 4)

1. Compare requirements with availabilities based on engineering judgement and cost-effectiveness considerations and identify the deficiencies in available instruments.

2. Identify the instrumentation that should be developed for monitoring gas streams in future power systems. 
IGCC Power Systems were discussed in Section 2.2.1, and some discussions of the gas clean-up systems were included. The purpose of this section is to analyze the IGCC gas processing options in more detail.

Clean-up of gaseous fuel derived from coal for gas turbines is necessary to prevent corrosion of, deposition on and erosion of turbine materials and to meet environmental requirements for emissions to the atmosphere. The contaminants encountered in IGCC power systems have been identified in Sections 2.1 and 2.2.2.

Two general methods for cleaning coal gases are available. The first approach entails cooling the gas to below $300^{\circ} \mathrm{F}$ (to a temperature compatible with the absorber solvent) and then cleaning the gas. The low temperature cleanup option is based on commercially available processes. The second approach entails cleaning the gas as hot as possible $\left(1000-1500^{\circ} \mathrm{F}\right)$, thus making use of as much sensible heat as possible in the gas turbine.

In cold gas cleanup, tars and oils, if present, are scrubbed from the fuel gas in the quench/particulate removal process. The ability to recycle tars and oils back to the gasifier thus becomes an important consideration. In hot gas cleanup, any tars and oils present pass through the cleanup train and are combusted in the gas turbine directly. Likewise, ammonia and water soluble trace elements, especially the alkali metals, are removed during the quench/scrubbing step of low temperature scrubbing. In high temperature cleanup, they either pass through to the turbine or are removed in separate processes.

Hot gas cleanup processes for particulate removal, sulfur removal and trace metal removal are all in the early stages of development and require additional laboratory, pilot, and demonstration work before both the technical and economic feasibility of these processes can be assured.

In the area of hot gas cleanup, many operational problems have been experienced which are process control problems only in the sense that reliable composition analysis information has not been available. This has been partially due to deficiencies in existing analytical techniques, but primarily due to numerous problems which have been caused by poor performance of the gas sampling systems which are used with high temperature and pressure gas streams which contain particulate materials.

\subsubsection{Cold Gas Cleanup Processes}

The cold gas cleanup option offers the availability of commercial technology. However, the specific design of the cleanup system for a coal gasification plant can vary widely depending on the gasifier 
type, the end use of the gas, and the environmental standards that apply at a specific location.

Many processes exist for the removal of sulfur compounds from fuel gases. Most of the available processes operate in the temperature range of $-100^{\circ}$ to $230^{\circ} \mathrm{F}$. These fuel gas desulfurization processes can generally be categorized into one of four basic types:

1. Chemical solvent processes

2. Physical solvent processes

3. Direct Conversion processes

4. Hybrid Physical/Chemical processes

A basic description of the characteristics of each type follows.

\section{Chemical Solvent Processes}

The two major types of chemical solvent systems.include amine-based systems and the alkali salt-based systems.

Amine-based systems are based on the forming of a complex of $\mathrm{H}_{2} \mathrm{~S}$ with amine-type compounds in an aqueous solution. Some $\mathrm{CO}_{2}$ is also complexed. Amines that have been used include monoethanolamine, diethanolamine, diglycolamine, methyldiethanolamine and di-isopropanolamine. Regeneration of these amine solutions is generally accomplished by applying heat to the solution and stripping off the $\mathrm{H}_{2} \mathrm{~S}$ and $\mathrm{CO}_{2}$ in a regeneration tower. The ratio of $\mathrm{H}_{2} \mathrm{~S}$. $\mathrm{CO}_{2} \mathrm{CO}_{2}$ removed depends upon the specific amine. Generally, tertiary amines and secondary amines offer more selectivity toward $\mathrm{H}_{2} \mathrm{~S}$ removal. Examples of amine-based systems include the recently developed DOW methyldiethanolamine, EXXON Flexsorb SE and Union Carbide Uearsol-HS processes.

Alkali salt systems remove $\mathrm{H}_{2} \mathrm{~S}$ by the reaction of $\mathrm{H}_{2} \mathrm{~S}$ with dissolved alkali salts, such as potassium carbonate. Many do so in the presence of amines and activators or potassium salts of organic acids. The $\mathrm{H}_{2} \mathrm{~S}$ is then recovered by flashing or steam stripping. Examples of modern alkali salt systems are the Alkazid process, the Catacarb process, and the Benfield process.

\section{Physical Solvent Processes}

Physical solvent systems remove sulfur compounds from raw gas streams by physical absorption in an organic solvent without a chemical reaction. These solvents can be regenerated by heat, pressure reduction, or gas stripping and require much less energy than do amine-based systems when applied to high-pressure gas streams.

One of the advantages of using physical solvent systems is that a high degree of selectivity toward $\mathrm{H}_{2} \mathrm{~S}$ can be achieved. This makes 
it possible to produce a concentrated stream of $\mathrm{H}_{2} \mathrm{~S}$, which is more easily converted to an environmentally acceptable form such as elemental sulfur. Physical solvent systems include the Rectisol process (methano1), the Selexol process. (dimethylethers of polyethylene glycol), and the Purisol process (n-methyl-2pyrrolidone). Physical solvent systems also remove many of the minor impurities in the gas stream because of the dissolution that occurs in the solvent.

\section{Direct Conversion Processes}

Liquid-phase oxidation processes are generally employed to purify gas streams containing low concentrations of hydrogen sulfide. In the liquid-phase oxidation processes, $\mathrm{H}_{2} \mathrm{~S}$ is absorbed selectively from the gas by an aqueous salt solution. The dissolved $\mathrm{H}_{2} \mathrm{~S}$ is then oxidized to elemental sulfur by oxygen carriers dissolved or suspended in the liquid media. The oxygen carriers are then regenerated by contact with air. Examples of available 1 iquid-phase oxidation processes include the Stretford, Giammarco-Vetrocoke, Takahax, and Lo-Cat processes.

Liquid-phase oxidation processes generally operate at temperatures between $70^{\circ} \mathrm{F}$ and $110^{\circ} \mathrm{F}$ and essentially remove all of the $\mathrm{H}_{2} \mathrm{~S}$ present. But these processes do not remove $\operatorname{Cos}$ and $\mathrm{CS}_{2}$, and impurities such as hydrogen cyanide irreversibly react with the sulfides present in the solution to form stable thiocyanate salts that eventually must be purged from the system.

\section{Hybrid Physical/Chemical Solvent Processes}

By mixing a physical absorption solvent with a chemical absorption solvent, the range of $\mathrm{H}_{2} \mathrm{~S}$ levels that are suitable for removal is expanded from low to moderately high. Typical of the hybrid solvent is the Sulfinol process.

The Sulfinol process can effectively remove $\mathrm{H}_{2} \mathrm{~S}, \mathrm{CO}_{2}, \mathrm{COS}, \mathrm{CS}_{2}$, mercaptans and organic sulfides and disulfides from feed gas streams. Plants are in operation that remove $\mathrm{H}_{2} \mathrm{~S}$ and $\cos$ from partial oxidation gas in hydrogen generating plants and remove $\mathrm{CO}_{2}$ from crude hydrogen for ammonia synthesis or for use in a hydrofining process.

The Sulfinol process combines physical absorption in sulfolane and chemical absorption in di-isopropanolamine. Thus, the solvent permits high acid gas loading at high pressure. Alternatively, because of the chemical absorbent, the process can be designed for use at low pressures.

\section{Application to IGCC Power Systems}

The purpose of this study is not to recommend clean-up systems, but rather to review the various options available in order to arrive 
at an instrumentation requirements specification based on the more comnercially viable control/monitoring strategies.

The sulfur removal processes outlined in the last section cover sulfur removal in general. However, for coal gas clean-up applications, processes have been developed and improved over a long period of time. Consequently, to a large extent, the necessary analysis work has already been carried out as a result of past experience. In situations where coal gas is produced at high pressure (as in combined cycle applications) considerations such as the following are important:

- Processes should minimize the need for excessive gas cooling.

- A high enthalpy, high mass flow should be maintained to the expansion turbine.

- Separate crude gas cooling equipment should not be required.

However, in the final analysis, cycle efficiency and overall economic considerations dominate. The economically attractive Lurgi hot potassium carbonate process is used in conjunction with other clean-up processes ( $\mathrm{Cl}$ aus and Beavon-Stretford) for the selected reference system described in Appendix $A$.

The gas cleanup system flow diagram included in the appendix (Eigure $A-2$ ) is based on the system described in the EPRI Report 25. It was beyond the scope of this study to provide a detailed description of all of the process streams and to provide stream condition information beyond that originally published; therefore, a simplified diagram was prepared which is shown in Figure 3.1 and the corresponding stream conditions are shown in Table 3.4. This figure will be used to reference stream conditions for instrument selection purposes.

3.3.1.2 Hot Gas Cleanup Processes

The purpose of the DOE/METC hot gas cleanup program is to eliminate the need for heat recovery and gas-liquor/tar/dust separation systems, and to avoid the efficiency losses associated with these systems.

The following hot gas cleanup systems are presently being investigated:

- METC Zinc Ferrite Process

- IGT Mixed Metal Oxides Process

- Battelle Solid-Supported Molten Salt System

Descriptions of these three processes follow. 


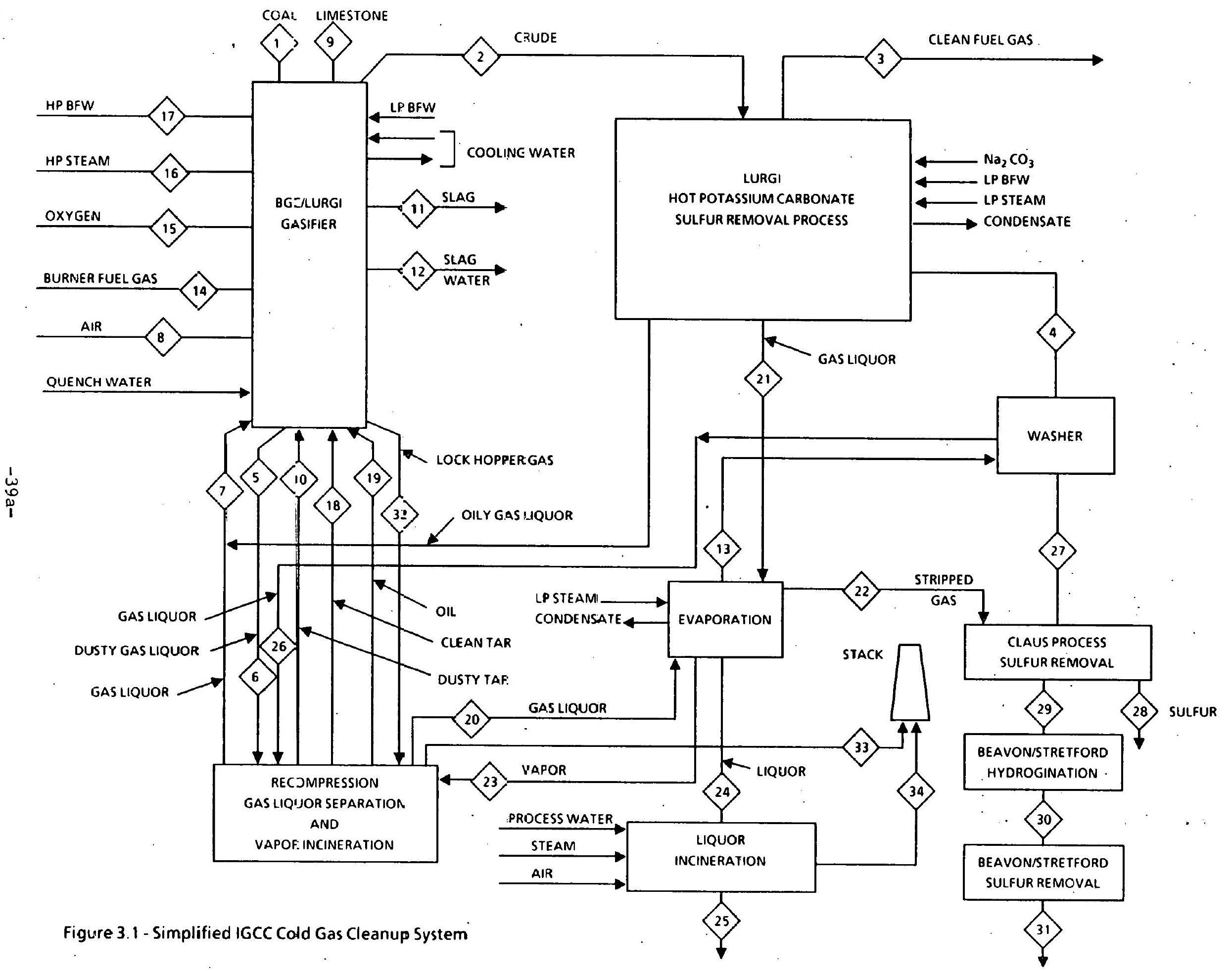




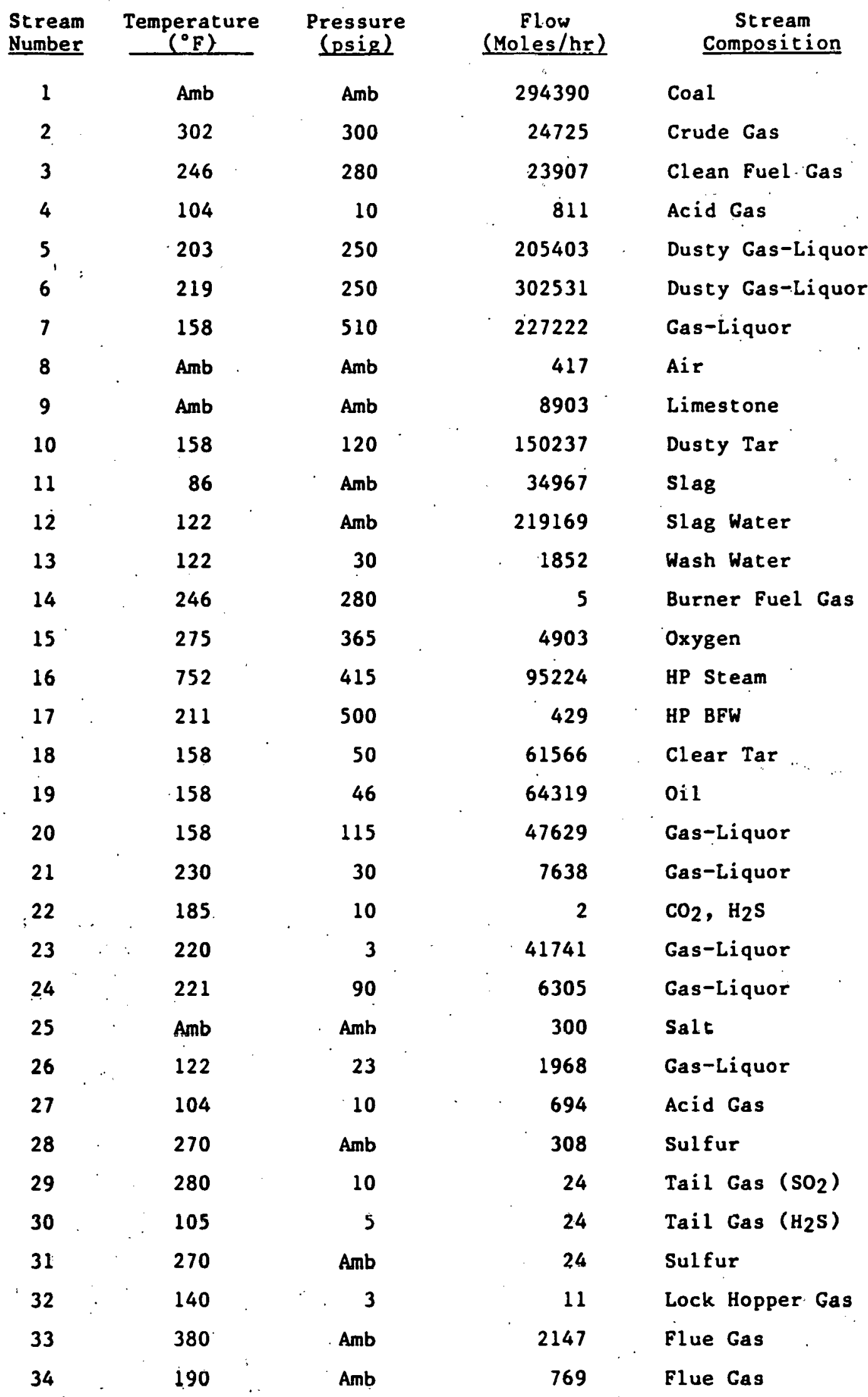

Table 3.1 ICCC Cold Gas Cleanup Stieain Cunditions 
The METC project to investigate zinc oxide-containing sorbents for hot coal gas desulfurization is an outgrowth of previous work based on the use of iron oxide. It was found that iron oxide as a sorbent was somewhat 1 imited in its ability to remove sulfur compounds, specifically hydrogen sulfide, at high temperatures. Zinc oxide has the capability of removing $\mathrm{H}_{2} \mathrm{~S}$ to a level about two orders of magnitude lower than that which can be achieved using iron oxide.

Both iron oxide and zinc oxide, in their sulfided form, can be regenerated by roasting with air or oxygen, and diluted with inert gases such as steam and nitrogen to moderate the high temperature which can result from the exothermic oxidation reaction. The compound zinc ferrite, $\mathrm{ZnFe}_{2} \mathrm{O}_{4}$, which is formed by heating a mixture of zinc and iron oxides, tends to combine the high sulfur affinity of zinc oxide with the good regenerability of iron oxide. The chemical changes taking place during sulfidation and regeneration may be represented-as follows:

$\begin{array}{lll}\text { Sulfidation } & 3 \mathrm{ZnFe}_{2} \mathrm{O}_{4}+\mathrm{H}_{2} & \rightarrow \mathrm{ZnO}+2 \mathrm{Fe}_{3} \mathrm{O}_{4}+\mathrm{H}_{2} \mathrm{O} \\ & \mathrm{Fe}_{3} \mathrm{O}_{4}+3 \mathrm{H}_{2} \mathrm{~S}+\mathrm{H}_{2} & \rightarrow 3 \mathrm{FeS}+4 \mathrm{H}_{2} \mathrm{O} \\ \mathrm{ZnO}+\mathrm{H}_{2} \mathrm{~S} & \rightarrow \mathrm{ZnS}+\mathrm{H}_{2} \mathrm{O} \\ \text { Regeneration } & 2 \mathrm{FeS}+7 / \mathrm{2O}_{2} & \rightarrow \mathrm{Fe}_{2} \mathrm{O}_{3}+2 \mathrm{SO}_{2} \\ & \mathrm{ZnS}+3 \mathrm{IO}_{2} & \rightarrow \mathrm{ZnO}+\mathrm{SO}_{2} \\ & \mathrm{ZnO}+\mathrm{Fe}_{2} \mathrm{O}_{3} & \rightarrow \mathrm{ZnFe}_{2} \mathrm{O}_{4}\end{array}$

The sulfur dioxide in the regeneration tail gas can be recovered or scrubbed out by commercially available processes. To prevent sintering of the zinc ferrite, regeneration is carried out at a temperature that permits a significant degree of sulfate formation. The presence of sulfates not only reduces the capacity of the sorbent, but also could lead to the introduction of secondary contaminants during the absorption cycle if the sulfates are not first reduced. Initial experiments indicate that the zinc sulfate formed can be reduced by gases such as $\mathrm{H}_{2}$ and $\mathrm{CO}$.

The zinc ferrite process should operate at gas conditions where magnetite, $\mathrm{Fe}_{3} \mathrm{O}_{4}$, which is formed from zinc ferrite, is stable. If the zinc ferrite system operates outside this region, species other than magnetite will be present in the absorption bed. These other iron species, i.e., iron/iron carbides and wustite (Feo), have adverse effects on the performance of the zinc ferrite process.

The METC Zinc Ferrite Process is shown in Figure 3.2 and the corresponding stream conditions are 1 isted in Table 3.5. The raw fuel gas at $1000^{\circ} \mathrm{F}$ and 250 psia is valued to one of the two vessels operating in the absorption mode. When the gas contacts the 
RECYCLE

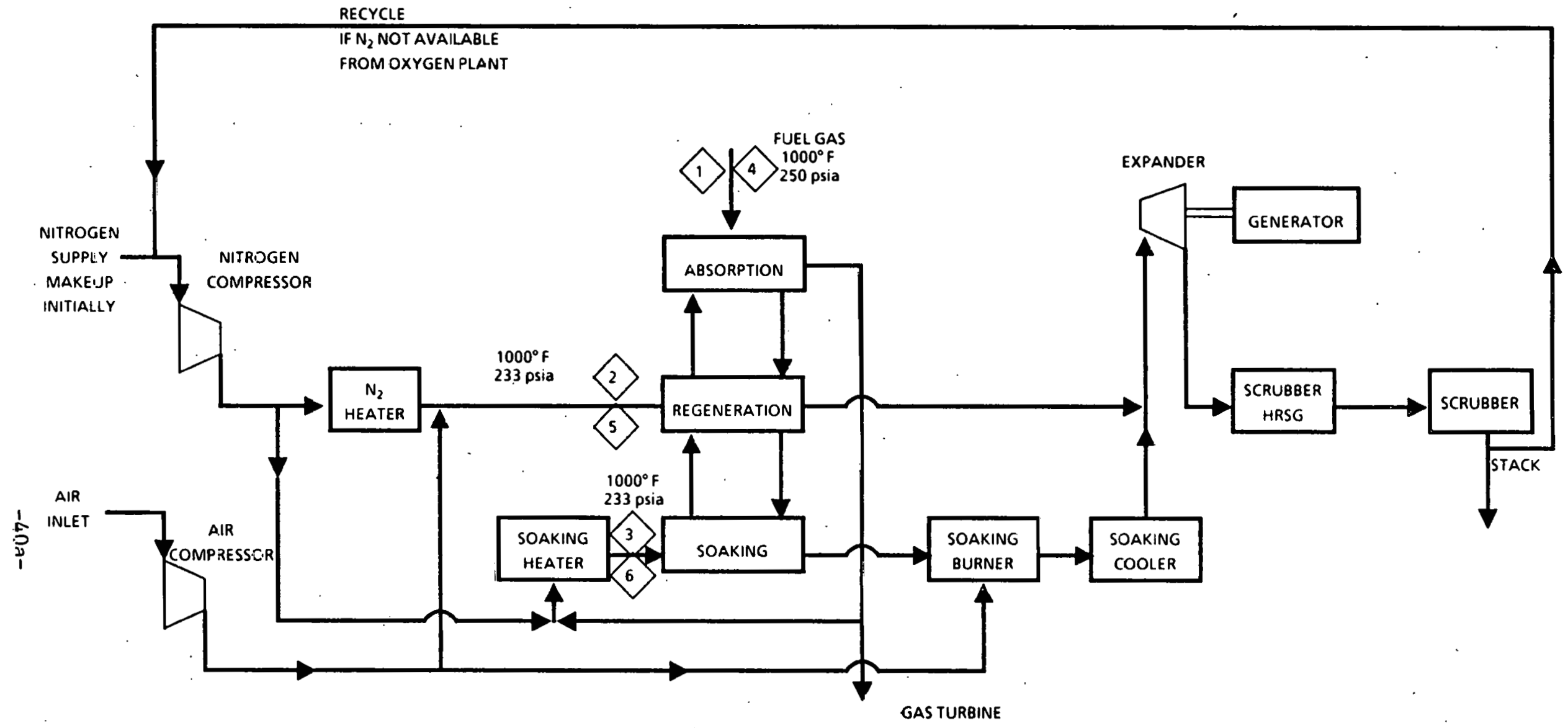

Figure 3.2 METC Zinc Ferrite Process 
sorbent, the exothermic water gas shift and absorption reactions occur, causing the bed and fuel gas to heat up slightly. Gas flow and absorption continues until the bed becomes saturated and breakthrough occurs which indicates the bed is ready for regeneration. The raw fuel gas is switched to another absorber and regeneration begins.

Regeneration of the sorbent bed is carried out in a two stage process. The oxidizing air and nitrogen gas mixture is used initially to drive off $\mathrm{SO}_{2}$. This is followed by a soaking period with a mixture of fuel gas and nitrogen to reduce any sulfates that have formed. Nitrogen from the oxygen plant is compressed and piped to the desulfurization area where it is heated and sent to the regeneration gas header. The regeneration gas at $1000^{\circ} \mathrm{F}$ and 233 psia is valved to the vessel being regenerated. The regeneration gas flow is introduced in the opposite direction of the absorption gas flow. Oxidation proceeds through the bed, creating a moving hot zone. Bed temperature is controlled by using a Low oxygen content regeneration gas and controlling the temperature of the regeneration gas. The regeneration tail gases are collected in the regeneration tail gas header, mixed with any soaking tail gases and piped to the HRSG and expander before exhausting to the sulfur recovery units. 
Table 3-5 METC Process Gas Streams

Gas Stream (mole $\%$ )

\begin{tabular}{lrrrrrr}
\cline { 2 - 6 } \multicolumn{1}{c}{ Species } & 1 & 2 & 3 & 4 & \multicolumn{1}{c}{5} & 6 \\
$\mathrm{O}_{2}$ & & 2.1 & & & 2.4 & \\
$\mathrm{~N}_{2}+\mathrm{Ar}$ & 0.2 & 97.4 & 80.0 & 0.5 & 97.3 & 80.1 \\
$\mathrm{H}_{2} \mathrm{O}$ & 50.5 & 0.5 & 9.2 & 49.8 & 0.2 & 6.5 \\
$\mathrm{CO}_{2}$ & 15.3 & & 4.1 & 5.1 & & 4.7 \\
$\mathrm{CO}$ & 7.5 & & 0.5 & 25.1 & & 1.3 \\
$\mathrm{H}_{2}$ & 20.9 & & 5.1 & 16.7 & & 6.9 \\
$\mathrm{CH}_{4}+\mathrm{C}_{2}$ & 4.6 & & 0.8 & 2.5 & & 0.5 \\
$\mathrm{H}_{2} \mathrm{~S}$ & 0.59 & & & 0.61 & & \\
$\mathrm{COS}$ & 0.03 & & & 0.06 & & \\
$\mathrm{NH}_{3}$ & 0.4 & & 0.3 & & &
\end{tabular}
Key: 1 Absorber Inlet, Lurgi System
2 Regenerator Inlet (Air/N2), Lurgi System
3 Regenerator Inlet (Fuel/N2), Lurgi System
4 Absorber Inlet, KRW System
5 Regenerator Inlet, KRW System
6 Regenerator Inlet, KRW System

During soaking, a reducing mixture of at least $10 \% \mathrm{CO}$ and $\mathrm{H}_{2}$ is necessary to reduce sulfate formed during regeneration. Nitrogen and fuel gas are mixed and heated and sent to a soaking gas header. The soaking gas at $1000^{\circ} \mathrm{F}$-and 233 psia is valved to the vessel being soaked. The soaking gas reduces any sulfates that have formed and cools the bed to $1000^{\circ} \mathrm{F}$ prior to the absorption cycle. The soaking tail gases are collected in a header, combusted and piped to the HRSG and expander before exhausting to the sulfur recovery unit.

The Battelle Solid-Supported Molten Salt Process

The reversible reaction of $\mathrm{H}_{2} \mathrm{~S}$ with molten carbonates has been under study at Battelle Northwest since 1974:

$$
\mathrm{MCO}_{3}(1 \mathrm{iq})+\mathrm{H}_{2} \mathrm{~S}(\text { gas }) \longleftrightarrow \mathrm{MS}(1 \mathrm{iq})+\mathrm{H}_{2} \mathrm{O}(\mathrm{g})+\mathrm{CO}_{2}(\text { gas }),
$$

where "M" represents $\mathrm{Li} 2, \mathrm{Na2}, \mathrm{K}_{2}$, or $\mathrm{Ca}$. 
The process was first developed based on continuous, countercurrent gas liquid contacting.

The solid supported molten salt (SSMS) concept was developed as a practical means for handling the corrosive molten carbonates. Several ceramics were investigated as potential supports. Lithium aluminate was chosen for chemical stability and for ease of fabrication into strong, porous pellets. Although the pellets could be fluidized, use in a fixed-bed avoided possible agglomeration problems and still allowed the advantages of a gas-liquid equilibrium system to be exploited.

Regeneration with carbon dioxide in a steam-rich stream releases $\mathrm{H}_{2} \mathrm{~S}$ at a higher concentration, facilitating recovery of elemental sulfur. It was found that $\mathrm{H}_{2}$ or $\mathrm{CO}$ had to be included in the regeneration feed gas to avoid leaving traces of oxidized sulfur in the bed that would be reduced during the subsequent absorption, contaminating the product gas before breakthrough.

The SSMS system being developed by Battelle differs from other hot gas cleanup systems under study for integrated coal

gasification/MCFC power plants in that $\mathrm{HCl}$ and sulfur compounds can be removed with a single sorbent, resulting in less complexity. However, $\mathrm{HCl}$ cannot be easily regenerated and thus the sorbent must be discarded when saturated with $\mathrm{HCl}$. Because the reaction product is dissolved in the molten carbonate matrix a theoretically unlimited extent of contaminant removal is possible. If only a solid product is formed, removal cannot proceed below the level at which the contaminant in the cleanup gas is in equilibrium with that solid. Therefore, at the clean end of an SSMS fixed bed absorber, the concentration of contaminants in the cleaned gas can approach zero. The approach is 1 imited only by the size of the bed, mass transfer efficiency and the degree of regeneration.

During absorption, as shown in Figure 3.3, raw fuel gas from the gas expansion turbine is piped to the raw gas header. The raw fuel gas at $1472^{\circ} \mathrm{F}$ and 255 psia is valved to one of the vessels operating in the ahsorption mode. When the gas contacto the sorbent, the exothermic water gas shift reaction and the endothermic absorption reaction occur, resulting in net generation of heat and a slight heating of the bed. The clean fuel gas is collected in the clean gas header, piped to the polisher vessel to ensure alkali metal levels below a few $\mathrm{ppm}$ and then piped to the gas turbine area.

Gas flow and absorption continues until the bed becomes saturated and breakthrough orcurs which indicates the bed is ready for regeneration. The raw fuel gas is then switched to another absorber.

The stream conditions corresponding to the stream numbers shown in Figure 3.3 are 1 isted in Table 3.6 . 


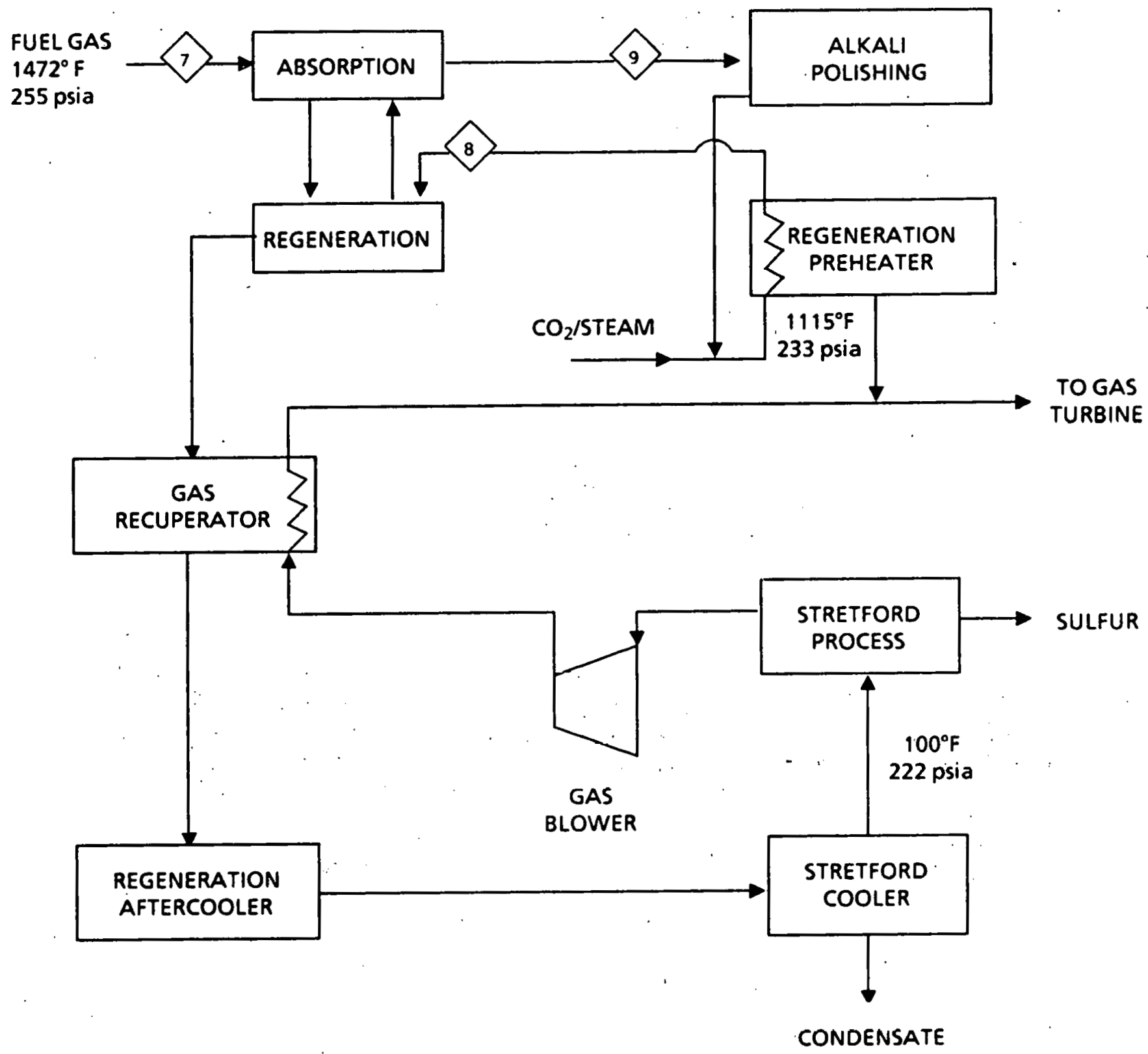

Figure 3.3 - Battelle Solid Supported Molten Salt Process 
Table 3-6 Battelle Process Gas Streams

\begin{tabular}{|c|c|c|c|}
\hline \multirow[b]{2}{*}{ Species } & \multicolumn{3}{|c|}{ Gas Stream (mole 7 ) } \\
\hline & 7 & 8 & 9 \\
\hline $\mathrm{N}_{2}+\mathbf{A r}$ & 0.8 & 0.1 & 0.8 \\
\hline $\mathrm{H}_{2} \mathrm{O}$ & 9.5 & 51.0 & 6.2 \\
\hline $\mathrm{CO}_{2}$ & 9.0 & 37.2 & 14.5 \\
\hline $\mathrm{CO}$ & 45.0 & 6.0 & 40.2 \\
\hline $\mathrm{H}_{2}$ & 30.0 & 5.0 & 33.9 \\
\hline $\mathrm{CH}_{4}+\mathrm{C}_{2}$ & 4.5 & 0.6 & 4.5 \\
\hline $\mathrm{H}_{2} \mathrm{~S}$ & 1.1 & & $1 \mathrm{ppm}$ \\
\hline $\cos$ & 0.1 & - & \\
\hline 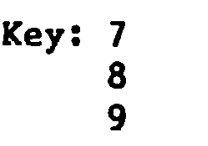 & $\begin{array}{l}\text { Absorber } \\
\text { Regenerat } \\
\text { Polisher }\end{array}$ & $\begin{array}{l}\text { Inlet, KR! } \\
\text { or Inlet, } \\
\text { Inlet, KRt }\end{array}$ & $\begin{array}{l}\text { System } \\
\text { KRW System } \\
\text { System }\end{array}$ \\
\hline
\end{tabular}

Regeneracion of the sorbent bed is carried out with a mixture of $\mathrm{CO}_{2}$ recovered from the gas turbine exhaust, steam and clean fuel gas. The $\mathrm{CO}_{2}$ and steam are piped to the desulfurization area, mixed with the clean fuel gas, heated and sent to the regeneration gas header. The regeneration gas is valved to the vessel being regenerated and introduced in the opposite direction of the absorption gas flow. The exothermic regeneration reaction creates a moving hot zone through the bed. The regeneration gas cools the bed and removes excess heat. After regeneration, the gases are collected in a header and sent to the sulfur recovery unit.

The IGT Mixed Metal Oxide Process

In the Mixed Metal Oxide process, a mixture of metal oxide-containing sorbents removes the sulfur-containing compounds from hot $\left(>1000^{\circ} \mathrm{F}\right)$ fuel gases by a chemical reaction. The sulfided sorbents are then regenerated with on oxygen-containing gas to produce elemental sulfur. The primary incentive for development of the IGT mixed metal oxide process is that with the proper selection of sorbents it is expected that the process will not only be able to reduce the sulfur content of the coal-derived fuel gas to low ppm(v) levels, but more importantly, it will be able to recover this sulfur as elemental sulfur without the need for a reductant such as fuel gas or coke. 
The mixed metal oxide process was first conceived by IGT researchers in the late $1970^{\prime} \mathrm{s}$. The overall reaction mechanism is:

$$
\begin{aligned}
& 2 \mathrm{MS}+3 \mathrm{O}_{2} \longleftrightarrow 2 \mathrm{MO}+2 \mathrm{SO}_{2} \\
& 4 \mathrm{MS}+2 \mathrm{SO}_{2} \longleftrightarrow 4 \mathrm{MO}+3 \mathrm{~S}_{2}
\end{aligned}
$$

where $M O$ is the metal oxide and MS is the corresponding metal sulfide. It was found that metal oxides that had this ability to produce elemental sulfur had a low affinity for sulfur. The lower the reaction equilibrium constant for the reaction between $\mathrm{H}_{2} \mathrm{~S}$ and the metal oxide, i.e.

$$
\mathrm{MO}+\mathrm{H}_{2} \mathrm{~S} \longleftrightarrow \mathrm{MS}+\mathrm{H}_{2} \mathrm{O}
$$

the greater the yield of elemental sulfur upon regeneration.

This relationship between elemental sulfur production and the sorbent sulfidation reaction equilibrium posed a potential obstacle to the use of the discovered elemental sulfur producing sorbents in a high temperature fuel gas desulfurization process, especially when steam represented a significant fraction of the fuel gas (such as in coal gasification fuel gases). To overcome this limitation, IGT conceived the mixed metal oxide process. In this process, rather than using only one type of metal oxide-containing sorbent, a mixture would be used. An elemental sulfur producing metal oxide-containing sorbent would be mixed with a high sulfur affinity metal oxide-containing sorbent such as zinc oxide. The elemental sulfur producing sorbent would remove about $70 \%$ to $80 \%$ of the fuel gas sulfur while the high affinity sorbent would remove the rest. During regeneration, the sulfided high affinity sorbent would react with $\mathrm{O}_{2}$ to produce $\mathrm{SO}_{2}$, which in turn would react with the sulfided low affinity sorbent to produce elemental sulfur.

The mixed metal oxide process, as originally conceived, had another attractive feature. Since the low affinity, elemental sulfur producing sorbent could be regenerated with $\mathrm{SO}_{2}$, any $\mathrm{SO}_{2}$ remaining in the regeneration product gas could be recycled to the sorbent bed undergoing regeneration. With quantitative $\mathrm{SO}_{2}$ recycle, elemental sulfur production could also be made quantitative.

In this concept, sulfur is absorbed by a mixture of metal oxides contained in a fixed-bed reactor. After the mixture is fully loaded, it is regenerated. Regeneration is accomplished using a mixture of oxygen and tail gas from the regeneration. The product gas from the fixed bed undergoing regeneration, which is a mixture of $\mathrm{N}_{2}, \mathrm{SO}_{2}$, and elemental sulfur, is partially cooled and then sent to elemental sulfur recovery. The elemental sulfur is removed from the gas in a sulfur condenser. After elemental sulfur recovery, the tail gas is recycled directly back to the bed undergoing regeneration.

As shown in Figure 3.4, during absorption, raw fuel gas from the gas expansion turbine is piped to the raw gas header. The raw fuel 


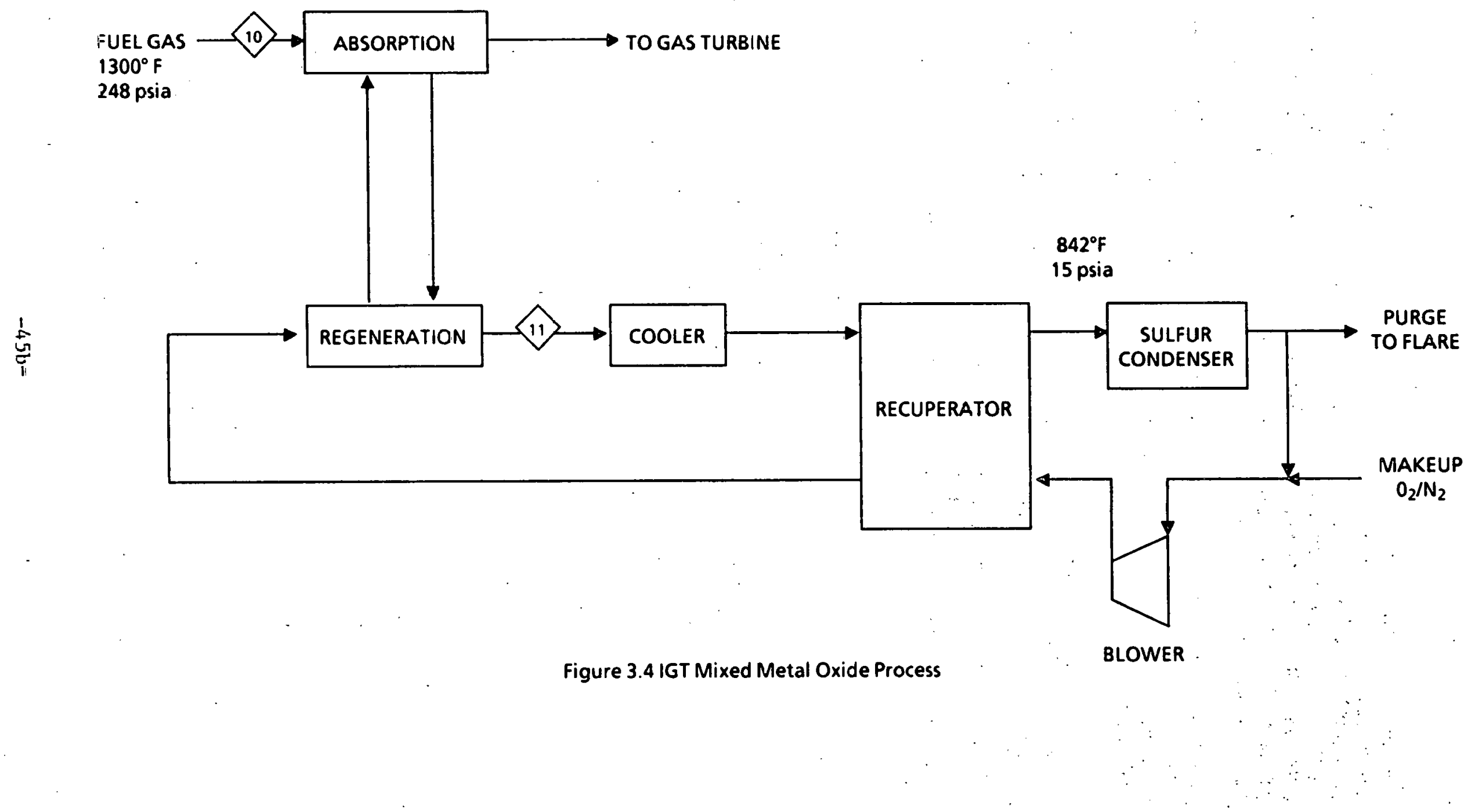


gas at $1300^{\circ} \mathrm{F}$ and $248 \mathrm{psia}$ is valved to one of the vessels operating in the absorption mode. When the gas contacts the sorbent, the exothermic water gas shift reaction and the endothermic absorption reaction occur, resulting in net generation of heat and a slight heating of the bed. The clean fuel gas is collected in the clean gas header, and then piped to the gas turbine area.

Gas flow and absorption continue until the bed becomes saturated and breakthrough occurs, which indicates the bed is ready for regeneration. The raw fuel gas is then switched to another absorber.

During regeneration, gases are valved from the regeneration gas header to the vessel being regenerated and introduced in the opposite direction of the absorption gas flow. The exothermic regeneration reaction creates a hot zone moving through the bed. The average bed temperature is maintained below $2000^{\circ} \mathrm{F}$ by the cooling action of the regeneration gas. After regeneration, the tail gases are collected in a header and sent to the sulfur condenser to remove elemental sulfur.

Table 3-7 IGT Process Gas Streams

Gas Stream (mole $\%$ )

Species

02

$\mathrm{N}_{2}+\mathrm{Ar}$

$\mathrm{H}_{2} \mathrm{O}$

$\mathrm{CO}_{2}$

CO

$\mathrm{SO}_{2}$

$\mathrm{H}_{2}$

$$
\mathrm{CH}_{4}+\mathrm{C}_{2}
$$

$\mathrm{H}_{2} \mathrm{~S}$

$\cos$

45.0

30.0

4.5

1.1

0.1 Key: $10 \quad \begin{aligned} & \text { Absorber Inlet, KRW } \\ & \text { System }\end{aligned}$

11 Regenerator Outlet, KRW System 
The tail gas from the condenser is recycled back to the regeneration gas header. Oxygen is added for regeneration and a small $1^{r}$ purge is taken to the flare to restrict the buildup of inerts. Nitrogen is initially added to the recycle stream to achieve the desired $\mathrm{H}_{2}$ concentration in the loop.

The stream conditions corresponding to the stream numbers shown in Figure 3.4 are 1 isted in Table 3.7 .

\subsubsection{PFBC Power Systems}

In the case of PFBC power systems, no chemical cleanup system exists in the sense that there are a variety of unit operations and process streams to be considered. Primarily, there exists an inlet stream containing contaminants released by the combustion process, a particulate removal system, and an outlet stream which is normally passed to a gas turbine. The heat recovery and steam generation equipment downstream of the gas turbine may need some instrumentation for corrosion and erosion monitoring purposes. However, if necessary, these requirements can be satisfied by commercially available instrumentation used in normal power plant boiler practice.

In the gas stream entering the gas turbine, the contaminants of primary importance are $\mathrm{SO}_{2}$, alkali metals and particulates. The gas cleanup approaches associated with these contaminants are discussed briefly below.

\section{$\underline{\text { SO2 }}$ Removal}

Although theoretical methods exist to investigate gas absorption kinetics in fixed and fluidized beds, they are seldom used in practice for process design or control purposes. Instead, empirical methods are employed. In the case of PFBC it is usual to quantify sulfur retention in terms of some simple empirical function of the calcium to sulfur ratio. If sulfur retention is inadequate, then either a more reactive absorbent is sought, or else the calcium to sulfur ratio is increased. Therefore, control of $\mathrm{SO}_{2}$ removal is achieved by monitoring the $\mathrm{SO}_{2}$ concentration of the gas leaving the fluidized bed and by making appropriate adjustments to the calcium to sulfur ratio.

\section{Alkali Removal}

Alkali release has been considered in Sections 2.1 and 2.2 .2 . In a PFBC system, alkali compounds in the exhaust gas stream at the inlet to the gas turbine are present in solid, aerosol and vapor form. At the present time it is not clear how significant the form of alkali compounds is in influencing blade corrosion once the metal oxide layer has been penetrated. It is probable that turbine blade fouling is most significantly influenced by the fraction of aerosol and vapor present, and since these fractions represent a small fraction of the total alkali released, the need for alkali removal systems in commercial power plants has not been subjected 
to detailed economic evaluation. Alkali measurement, however, is a high priority item for research purposes.

\section{Particulate Removal}

In the case of $\mathrm{PFBC}$, a variety of particulate removal systems are either available or are under development. The more important systems which are under development are as follows:

- Electrostatic Precipitator - Cottrell Environmental Sciences

- Ceramic Woven Filter - Acurex Corp:

- Ceramic Cross Flow Filter - Westinghouse

- Moving Granular Bed Filter - Combustion Power Co.

- Acoustic Agglomerator - Aerojet/Pennsylvania State University

- Ceramic Bag Filter - Acurex/3M/Carborundum

- Porous Ceramic Candle Filter - Westinghouse-Schumacher/ Didier - Industrial Pump and Filter

Each device or system has reached a different stage of development, and each uses a different design approach. Also, each system is provided with its own operational instrumentation.

Most particulate removal system developers have little choice other than to rely upon conventional sampling techniques at the inlet and outlet of their devices. These measurements are based on the use of sampling and particle size analysis techniques which are frustrating to use and tend to produce inaccurate or, variable results. Consequently, from an instrumentation point of view, all these devices are similar in the sense that they all use standard instrumentation internally and they all need better inlet and outlet particulate loading and particle size distribution instrumentation. In a commercial plant, a reliable device which detects and reacts instantly to upsets or breakthroughs is essential to protect the turbine, since severe turbine damage could occur if large amounts of particulates reach the turbine.

3.3.3 MCFC Power Systems

3.3.3.1 Cold Gas Cleanup

The cold gas cleanup option uses available technology, but the specific design of the cleanup system for a coal gasification plant depends upon the gasifier type, the end use of the gas and the applicable environmental standards 33 . Conventional high efficiency cyclones are usually adequate for particulate removal before heat recovery. After heat recovery, quenching/scrubbing is the usual practice for fine particulate and tar/oil removal. During 
quenching/scrubbing, water soluble halogen, nitrogen and trace metal compounds are also removed.

Many processes exist for the removal of sulfur compounds from fuel gases. These processes have already been described in

Section 3.3.1.1, and a typical cold gas cleanup system is shown in Figure 3.5. This figure will be used in conjunction with Table 3.8 in order to estimate stream conditions for instrument selection purposes. This information is based on the reference system design described in Appendix $C$.

Table 3.8 MCFC Cold Gas Cleanup Stream Conditions

\begin{tabular}{|c|c|c|c|}
\hline Stream Name & $\begin{array}{c}\text { Pressure } \\
\text { (psig) }\end{array}$ & $\begin{array}{l}\text { Temperature } \\
\left({ }^{\circ} \mathrm{F}\right)\end{array}$ & $\begin{array}{c}\text { Flow } \\
(1 \mathrm{~b} / \mathrm{hr})\end{array}$ \\
\hline 1. \#1 L.P. Steam Generator Inlet & 585 & 800 & 25,774 \\
\hline 2. \$2 Regen. HX Inlet & 585 & 800 & 96,950 \\
\hline 3. Particulate Scrubber Inlet & 570 & 357 & 122,724 \\
\hline 4. Particulate Scrubber Outlet & 562 & 330 & 122,724 \\
\hline 5. \#2 L.P. Steam Generator Inlet & 562 & 330 & 89,589 \\
\hline 6. \#1 Regen. HX Inlet & 562 & 330 & 33,135 \\
\hline 7. Gas Cooler Inlet & 555 & 280 & 112,848 \\
\hline 8. $\mathrm{NH}_{3}$ Scrubber Inlet & 547 & 105 & 103,319 \\
\hline 9. Acid Gas Removal Inlet & 540 & 100 & 103,084 \\
\hline 10. Acid Gas Removal Outlet & 521 & 75 & 97,810 \\
\hline 11. \#1 Regen. HX Outlet & 514 & 275 & 97,810 \\
\hline 12. \$2 Regen. HX Outlet & 507 & 750 & 97,810 \\
\hline 13. Zno Unit Outlet & 500 & 750 & 97,810 \\
\hline 14. Acid Base Outlet & 7 & 120 & 5,274 \\
\hline 15. Liquid sulfur & 15 & 265 & 2,076 \\
\hline 16. Hydrogen & - & - & 19 \\
\hline
\end{tabular}

3.3.3.2 Hot Gas Cleanup Processes

Most of the control techniques required for MCFC power systems have already been discussed in Section 3.3.1 (IGCC Power Systems) or Section 3.3.2 (PFBC Power Systems), and these discussions need not be repeated here. In this section, the IGCC and-PFBC discussions were referenced and more detailed information on specific MCFC 


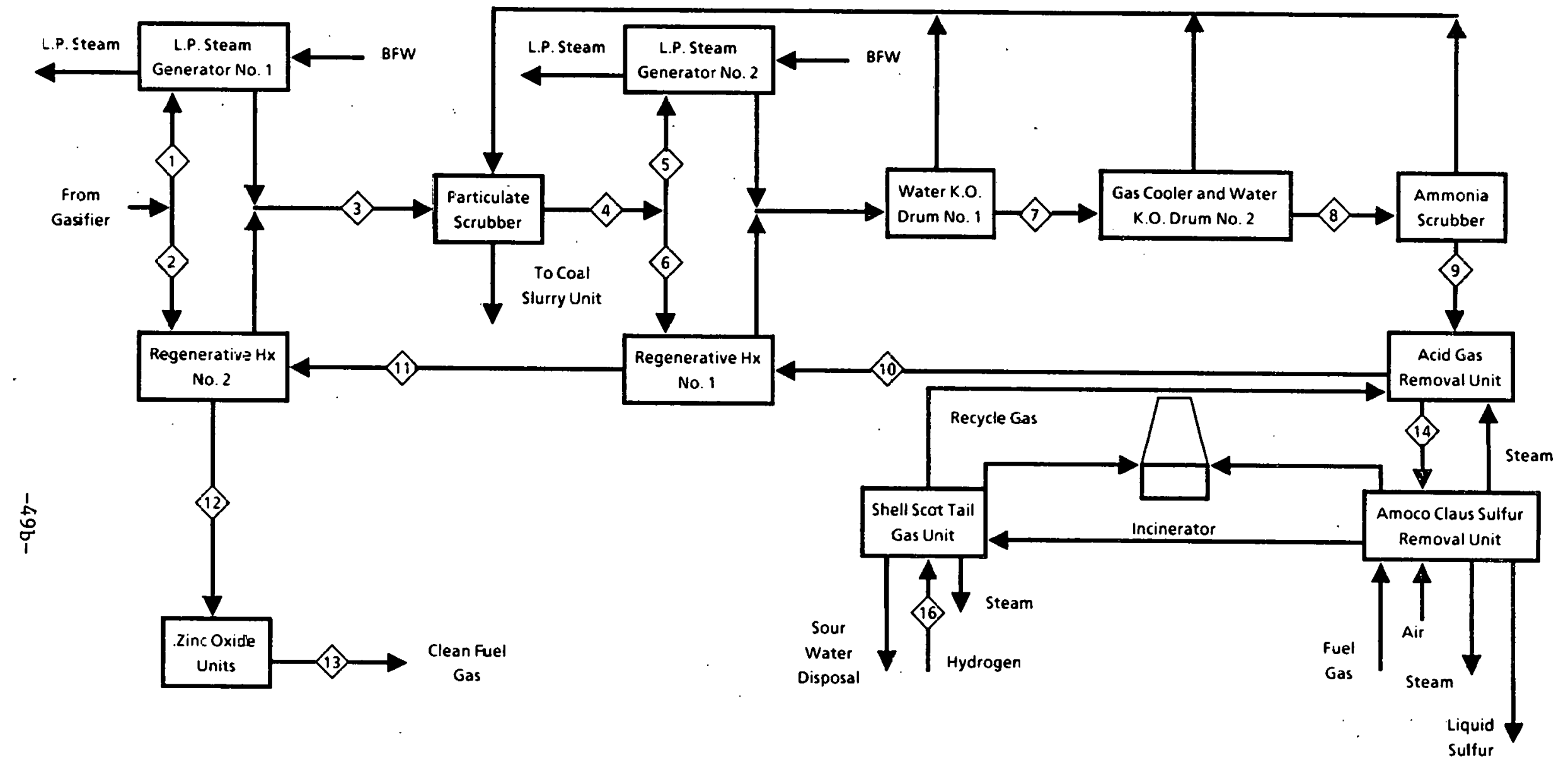

Figure 3.5 Simplified MCFC Cold Gas Cleanup System 
process control requirements were generated during the Task 2 study.

A number of particulate removal devices are being developed primarily for use in pressurized fluidized bed combustion. These devices have been 1 isted in Section 3.3.2, and will be available for use in MCFC Power Plants.

Hot gas cleanup processes for removing sulfur compounds are being developed with the objective of simplifying IGCC and MCFC power systems and improving their overall efficiencies. These processes have been described in Section 3.3.1.2.

The prime MCFC contaminant is sulfur which poisons the anode catalyst. Even $0.1 \mathrm{ppm}$ of sulfur may degrade the performance of a fuel cell and reduce its 1 ife considerably. Most sulfur removal processes can be designed to reduce sulfur down to this low level. The problem is that higher capital and/or operating costs are necessary. Therefore, to a large extent, a sulfur removal process must be selected on the basis of economic considerations. 
3.4.1 System Dynamic and Load Following Considerations

3.4.1.1 Introduction

IGCC and PFBC power plants include one or more gas turbines each discharging gas through an HRSG. Usually, the several HRSG's steam output feed one steam turbine. A comnercially viable integrated gasification combined cycle plant is described in Appendix A. Using this plant as an example, some general observations can be made about combined cycle plant response times.

Steam turbines are slower to respond than gas turbines because of the slow response of the HRSG's. To a large extent, the gas turbines can compensate, but, for the integrated plant, much depends on the design of the overall system. For example, the oxygen plant may need to be sized and designed to permit satisfactory load following. The clean-up system may need to be designed to tolerate a significant change in flow rate and/or a specific depressurization during load excursions. Also, the plant may have the capability to use natural gas to satisfy peak load demands.

In specifying instrumentation response times, it is more appropriate to study the load following capability of the plant as a whole (due to the fact that the plant imposes load-following design requirements on the clean-up system) rather than to derive response times for specific clean-up units.

Usually, tolerance limits for the major contaminants are established based on power system component requirements, and then various commercially appropriate processes are designed on the basis of economic considerations, load-following conditions and utility company preferences. As a result, contaminant control becomes a function of contaminant tolerance levels and various site-specific economic and operational constraints.

Experience in dealing with random disturbances is accumulated when the process is developed. Consequently, a suitable control system for this purpose invariably exists as a result of the normal process development work which was needed to develop the process in the first place. In contrast, set point changes and response times due to load following needs are directly or indirectly specified by the electric utility company, and these are included in a design requirements document.

To meet the requirements for daily load following, many utilities would like base load units to go from $100 \%$ power during the day to $60 \%$ power at night and they would like to move these units under manual or automatic control at rates of $1 \%$ to $2 \%$ per minute. It follows that from 50 to 25 minutes would be available to accomplish these changes. Most startup procedures include brief delay periods. Consequently, in order to achieve an overall response rate of $2 \%$, a $5 \%$ per minute rate should be assumed for instrument specification purposes. However, this $5 \%$ system response rate can not easily be related to analyzer response rate. Analyzers are frequently used for set point adjustment purposes, and the 
adjustment strategy is usually established on the basis of operator experience.

It is probable that the gasifier and some of the power system components can meet or exceed this requirement, but a delayed response may be encountered from other subsystems; the steam turbine, oxygen plant and gas cleanup systems in particular.

\subsubsection{Gas-Liquid Systems}

Based on economic and operational factors, it has been established that the Rectisol, Selexol and Stretford processes are good candidates for low temperature gas cleanup applications. They are preferred because of their low steam consumptions, favorable solution stabilities and corrosion characteristics. All of these processes require the use of an absorber and stripper.

The absorber will be discussed as an example. These units, in common with many similar process units, have three major capacities, consequently three major lags determine their dynamic behavior. The largest is the concentration lag arising from the capacities of liquid on the trays. The next largest is the lag in liquid flow rate due to change in liquid holdup. The third 1 ag is that associated with the gas phase, and this can usually be neglected. The instrumentation for a typical absorber is shown in Figure 3.6. Load changes are normally handled by controlling the flow of the lean solution based on the gas flow rate. It is standard practice to monitor gas composition at the inlet and outlet of the absorber and to adjust the setpoint of the flow controller accordingly. The absorber inlet and outlet gas analyzer signals would be available to a distributed system, as would a feed-forward demand signal from a station controller. These inputs would be used to make appropriate adjustmenls to the setpoint for the lean solution flow controller if necessary.

The concentration lag could be analyzed theoretically on a tray-by-tray basis. However, such an analysis would be time-consuming and would require design infotmacion which is not readily available. For the purpose of this study, it is satisfactory to assume a liquid hold-up and to calculate an approximate lag on the basis of the absorber lean solution flow rate. If necessary, the adequacy of this calculation can be checked by obtaining performance information from the cleanup system vendor. For the IGCC cleanup system described in Appendix A, the inlet flow is about $103,000 \mathrm{lbs} / \mathrm{hr}$. or about 2100 $\mathrm{ft} 3 / \mathrm{hr}$. Assuming 5 trays each $6 \mathrm{ft}$. in dia., and assuming $3-1 / 2$ inches of liquid per tray, it follows that the liquid hold up for the tray section will be $5(n / 4) 62(3.5 / 12)=41.2 \mathrm{ft}^{3}$. Consequently, the corresponding $\mathrm{Lag}$ will be approximately $41.2(60 / 2100)=1.2$ minutes. Assuming a factor of four to allow for other capacities and lags in the cleanup system, it follows that the total 1 ag would be approximately 5 minutes. The $5 \%$ per minute load following response rate could be a problem if it were necessary to use $\mathrm{H}_{2} \mathrm{~S}$ concentration rather than lean solution flow rate for load-following purposes. 


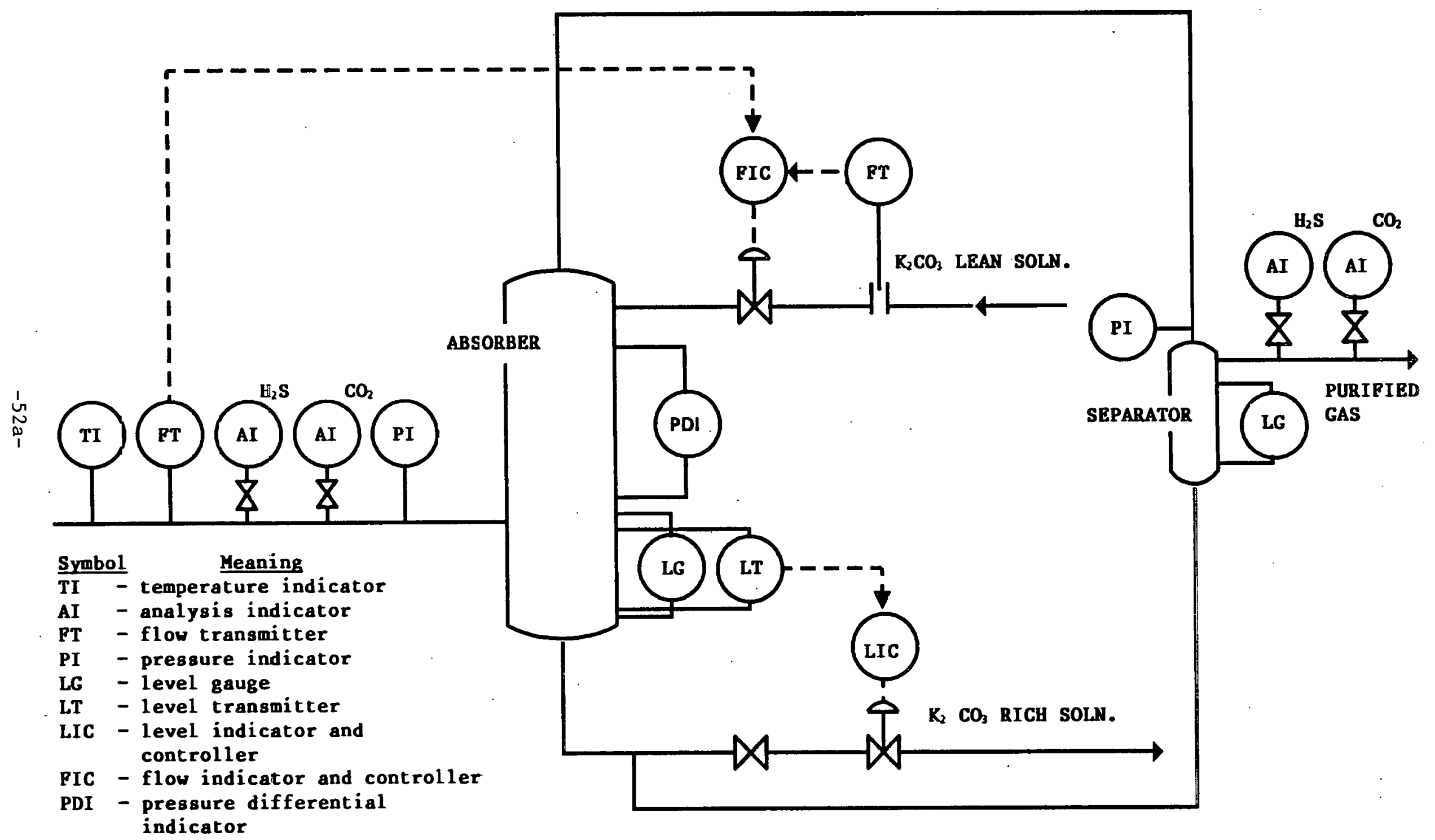

FICURE 3-6 TYPICAL ABSORBER INSTRUMENTATION 
In general, gas-solid sorption equipment can be based on the use of static, moving or fluidized beds, or else the solid phase can be dispersed in the gas. For economic and operational reasons most fuel gas cleanup processes are based on the use of static beds. Therefore, in the discussion which follows, a static bed will be as sumed.

Sorption involves contacting the gas with a rigid and durable particulate phase which can take up and store one or more species originally contained in the gas. Also; an economically attractive sorption mechanism is usually selected which can be reversed using a desorption or regeneration process.

Usually, the contaminant undergoing sorption is removed continuously from the fuel gas stream and accumulated in the solid phase. A sorption wave moves through the bed at a rate very much slower than the linear velocity of the gas. Near the start, the effluent concentration is substantially zero. The wave then moves through the bed until a break through point is reached at which time the allowable 1 imit in contaminant concentration is monitored until a predetermined contaminant level is detected. Depending upon the nature of the process, either a forward or reverse flow of regeneration gas is usually used to pass a desorption wave through the bed. A typical contaminant removal process uses two beds such that one is operating in the sorption mode at the same time that the other is being regenerated.

Intermittent monitoring based on composition analysis is usually desirable for correlating breakthrough point information with contaminant concentration. However, for process control purposes, it is sometimes possible to monitor the location of the sorption or desorption waves within the bed by means of temperature measurements, or to predict breakthrough on the basis of past sorption/desorption cycles.

From the above discussion, it follows that most gas-solid contaminant removal systems are not difficult to control because rapid load changes do not lead to the existence of outlet concentration transients and therefore instrument selection problems.

\subsubsection{IGCC Power System}

\subsection{2:1 Cold Gas Cleanup}

In the case of the IGCC Power System cold gas cleanup option, the control/monitoring strategies have been established on the basis of past technical, operational and economic experience. As indicated on Figure A-2 the contaminant control system is as follows:

- Complete separation of tars and oils from water and their recycle to the gasifier. 
- Strip ammonia and sulfur compounds from the gas-liquor prior to incineration.

- Use low grade heat from the gasifier to evaporate the major portion of the gas-liquor.

- Burn the remaining liquid portion of the gas-liquor.

- For economic and technical reasons use the hot potassium carbonate acid gas removal process.

- The primary sulfur recovery unit controls will be a standard ratio controller (air to acid gas), and the usual catalyst temperature controls.

- Use the basic Claus process for sulfur recovery. This is a demonstrated system with superior economics.

- Use the commercially demonstrated Beavon sulfur removal system for treating the tail gas from the Claus process.

- Careful control of the Beavon process air/fuel gas will be essential. The hydrogenation reactor must be carefully controlled to maximize sulfur conversion.

- The Stretford solution circulation rates must be carefully controlled for maximum $\mathrm{H}_{2} \mathrm{~S}$ removal. Also, the solution chemical concentrations must be maintained at the proper levels.

\section{Operational Needs}

In general, the liquid levels, flows, temperatures and pressures for the entire clean-up system can be measured using standard commercially available instrumentation. No special requirements for analyzers are anticipated beyond those included in the instrumentation and control systems specified by the various process manufacturers.

Typically, for maximum flexibility and integrity, an integrated total plant distributed control system will be installed. Measurements will be made throughout the plant in order to adequately control start-up/shutdown sequences, plant load following, module coordination, and to provide protection during upsets and off-design conditions. The operator will have all of the information at his disposal, primarily in the form of video displays, to effectively control the plant. Also, full or partial manual control will be available at all times. Control loops will be configured such that if any sensor information is not available, no major disturbance will be caused; that is, the loop will hold the current set point so that the operator can take the appropriate manual action. Also, the system will be provided with means for the operator to safely control and shutdown the plant under emergency conditions.

A modern distributed control system will be used, the integrity of which will be enhanced by redundant control elements and backup for 
sensors where necessary. For example, the multiplexed data transmission of plant control parameters will be achieved by a data highway system (an optical fiber or coaxial cable communication system) with fault checking and redundant backup. This will provide communication among all distributed components. An uninterruptible power supply will be provided for the essential instrumentation and control equipment which will be capable of supporting control system operation for sufficient time to supervise an orderly shutdown. Redundancy for the operator interface functions will be provided by the multiple monitors and keyboards which will be used for control, display and alarm purposes.

\section{Instrumentation Needs for Research Purposes}

Throughout this study process instrumentation needs have been divided into operational and research needs. Operational needs have been selected on the basis of needs which have been established by commercial practice, and all other needs (other than those related primarily to environmental considerations) have been classified as research needs.

There exists a general need for analyzers which operate in a fully continuous manner. For IGCC applications, semi-continuous or intermediate readings have been satisfactory since system dynamic requirements have been satisfied using standard liquid flow control. From a response time point of view, aralyzers similar to those used for cold gas cleanup applications would be satisfactory for high temperature and pressure gas streams except that suitable sampling and gas conditioning system would be needed.

For hot gas cleanup applications (see Section 3.4.2.2, below), research analyzers without samplers which operate in a fully continuous unattended manner would be preferable, because sampling systems lead to high maintenance costs and they often interfere with the gas composition measurements. Similar research instruments may be preferred for cold gas clean up applications if they become available. Meanwhile, it is probable that gas chromatographs will continue to be preferred for research purposes.

\section{Instrumentation Needs Based on Environmental Regulations}

In order to satisfy existing environmental regulations, no requirements for analyzers are anticipated beyond those included in the instrumentation and control systems specified by the various process manufacturers.

Instrumentation needs based on possible future regulations have been discussed in section 3.1.4. If envirumental regulations become more stringent, commercially available processes may be used except that the cleanup system will have to be designed to meet the tighter specifications. In the case of IGCC plants with cold gas cleanup systems, no problems will be encountered in meeting tighter NO $x$ regulations. New sulfur regulations can be met by conventional means; that is, by using larger liquid to gas ratios and/or higher pressure drops in the acid gas removal and tail gas cleanup systems. Existing technology should be satisfactory for removing particulates, but new techniques in wastewater treatment (such as 
carbon absorption) may lead to a requirement for improved laboratory analyzers.

Environmental regulations have had a major impact on market demand, and market demand has provided instrument manufacturers with a major incentive to develop lower cost instruments with higher reliabilities and fewer operating problems. Many of these instruments could be used in cold gas cleanup applications.

\subsubsection{Hot Gas Clean-Up}

It is characteristic of all fixed bed desulfurization processes that the capacity of sorbent decreases as the number of sorptionregeneration cycles increases. In the case of the METC and IGT processes, the cycle time is expected to decrease from about 100 hours with fresh sorbent to less than 50 hours. In the case of the Battelle process, the cycle time is expected to decrease from about 2 hours to about 30 minutes.

Assuming a cycle time as low as 30 minutes a gas analyzer with a low response time ( 1 minute or less) would be preferred. The primary purpose of the analyzer would be to detect sulfur break-through, but since break-chrough does nul uccur suddenly, then there should be no problem in using a commercial analyzer with a fast response time providing that a similarly fast sampling loop is installed.

Standard instrumentation would be satisfactory for measuring flow rates, temperatures, and pressure drops.

Depending upon the specific process used, there could be a significant temperature rise at the wave front where the regeneration reactions take place. This temperature increase would be useful in that it would provide a means of monitoring the regeneration process. Depending upon the system employed, it may bo necessary to control the rerirrulation of gas through the bed in order to maintain bed temperature helow a specified level.

Operational Needs

It is anticipated that commercially available instrumentation could be used to satisfy all hot gas cleanup needs. All of the proposed hot gas cleanup processes use reactor technology, which has been well developed for such units as reformers, and crackers in the petroleum industry. However, the sampling system necessary for use with high temperature, high pressure and dirty gas streams may lead to unacceptable reliability problems, high maintenance costs and high time lags.

It is anticipated that an on-line model will be required to generate optimum sorption-regeneration information for the Battelle Process. This type of need is referenced in Section 5.3.5.

\section{Research Needs}

Since all of the hot gas cleanup processes are still under development, it follows that commercialization will proceed through 
the PDU, pilot and demonstration stages. It is expected that most of the demonstration plant instrumentation will be commercially available. Significant use may be made of in situ, on-line instrumentation which is presently near commercial, under development or planned. Current availabilities are discussed in Section 4 and some recommended development projects are discussed in Section 5 .

\section{Environmental Needs}

The existing environmental regulations for new power plants were listed in Section 2.1. The hot gas cleanup processes would be designed to meet the same regulations, consequently they would be developed to at least compete with the cold gas cleanup processes on the basis of economic and operational considerations.

It is anticipated that all instrumentation needed to demonstrate compliance with existing environmental regulations would be commercially available.

The current DOE/METC gas cleanup research projects emphasize the characterization of effluent streams from gasifiers and gas cleanup processes. Much of this emphasis has been due to the role that environmental regulations have played in focusing attention on contaminant monitoring. Although it is not possible to list the contaminants which will be covered by future regulations, it is possible to develop some appreciation for the magnitude of the problem in terms of component development or research measurement requirements. Later, after the component development or research measurement programs have been completed, the anticipated environmental regulations will supply the necessary cost reduction and maintainability driving forces which are normally absent in research studies.

Many of the comments made in connection with the cold gas cleanup option also apply to hot gas cleanup with the exception that the hot gas cleanup option may lead to a $\mathrm{NO}_{x}$ emissions problem. It is expected that tighter sulfur regulations would merely lead to an increase in capital and operating costs for the hot gas cleanup process. Possible tighter particulate regulations would also result in cost increases, but the technology should be available as a result of current DOE supported development work on new particulate removal equipment and instruments for $P F B C$ power systems.

More stringent regulations for waste water disposal may lead to a significant increase in capital and operating costs for the cold gas cleanup option. If so, the hot gas cleanup option may become increasingly attractive and there will be a reduction in the need for wastewater analysis systems.

\subsubsection{PFBC Power Systems}

In the case of $P F B C$ power systems, it is difficult to separate gas cleanup control from other process control functions. For a typical fluidized bed, the coal, dolomite, feedwater and waste solids removal control systems are all somewhat integrated. Typically, a bed temperature sensor (or an average signal from a 
number of such sensors) is used to control coal flow. The bed temperature set point is normally trimmed on the basis of load demand and steam temperature. Dolomite flow is then ratioed to coal flow and an $\mathrm{SO}_{2}$ sensor signal is used to modify the dolomite/coal (i.e., the calcium/sulfur) ratio.

Cyclones are normally used to remove particulate material down to a level corresponding to the limitations of cyclone technology: Then a fine particulate removal system is used. Cyclones require no process control instrumentation other than that used for lock hopper control, the instrumentation needed for the fine particulate removal system depends upon the system selected. A standard reverse air baghouse or an electrostatic precipitator may be used downstream of the gas turbine, but improved fine particulate removal systems are under development which may be used upstream of the turbine.

As indicated in Section 3.4.3 there exists a need for on-line instrumentation which is capable of measuring particulate loadings at the inlets and outlets of the various particulate removal systems which are available or under development.

Many research-oriented PFB process development units are well instrumented for data acquisition purposes, but only a $f e w$ automatic controllers are used. During the process development phase, manual adjustments based on operator experience are often preferred. Analytical instruments are frequently sophisticated, but the information which they provide is used by the plant operator only on an intermittent basis. These instruments are usually installed to provide information for off-line performance analysis purposes.

3.4.4 MCEC Power Systems

Much of the process control discussion in Section 3.4 .2 also applies to MCFC power systems. Some discussion related more specifically to MCFC power systems follows.

\subsubsection{Cold Gas Cleanup}

Cold gas cleanup control/monitoring strategies for MCFC power systems have been based on similar strategies to those previously proposed for IGCC power systems. The contaminant control strategy for the reference system shown in Figure $C-2$ is as follows:

- Raw gas from the Texaco gasifier is cooled in a series of heat exchangers.

- Condensate, together with effluent from the ammonia scrubber is used by the particulate scrubber to remove the last traces of coal, ash and dust.

- Fffluent from the particulate scrubber is recycled to the coal. slurrying unit. 
Sulfur compounds are reduced to $2 \mathrm{ppm}$ in the Norton Selexol unit.

- Sulfur compounds are reduced to less than .1 ppm in the zinc oxide unit.

- An Amoco Claus process is used to separate elemental sulfur from the acid gas stream.

- The Shell Scot tail gas unit is used to treat the sulfur removal plant off gas so that it is environmentally acceptable.

- The exhaust gas from the fuel cells is passed through a catalytic combustor.

- A waste disposal system is provided to collect, store and then transfer to an evaporation pond, all wastes, sludges and drains from the plant.

\section{Operational Needs}

As in the case of the IGCC power system, the liquid levels, flows, temperatures and pressures for the entire cleanup system can be measured using commercially available instrumentation, and no analyzers are expected to be required beyond those normally supplied by the various cleanup system vendors or developers.

\section{Research Needs}

The research needs for MCFC power systems are similar to those already out ined for IGCC systems. There always exists a need for improved instrumentation for use in research and demonstration plants, but in the case of MCFC systems there exists an on-going need for process analyzers capable of measuring low concentrations of coal-derived contaminants.

\section{Envi ronmental Needs}

Molten carbonate fuel cell power plants require extremely pure fuel gas in order to avoid cell damage which may lead to degraded output or structural failure. As a result of these stringent

requirements, it is anticipated that no gas cleanup control will be needed to satisfy current or future environmental needs. It is probable that additional analytical instrumentation will be required to monitor future waste disposal systems. 
This section contains a list of instrument requirements, including response times, accuracies, measurement ranges and application notes.

Each need has been assigned a requirement number as indicated in Tables 3.9 and 3.10 . This number is basically a reference number which is used later (in Table 4.1) to reference instrument requirements in terms of ingtrument availabilities. Table 3.9 summarizes the gas cleanup needs which have been selected, and Table 3.10 summarizes other needs which are important but which are less directly related to gas cleanup.

It was not possible to quantify all of the factors which were considered to be important in specifying instrumentation needs, therefore some additional notes were generated and have been assembled in section 3.5.5. Most of these notes apply to more than one instrument, therefore each note has been allocated a single letter which has been used as a reference where appropriate.

Most of the instrument needs 1 isted in this section pertain to the hot gas cleanup option since low temperature gas cleanup systems are commercially available for steady-state operation. In the case of power plants which require load-following cleanup systems, commercial availability still needs to be confirmed for the cold gas cleanup option. Therefore, cold gas cleanup instrumentation requirements for load-following purposes have been included in this assessment.

Early in the project, it was recognized that it would be impossible to identify the bcot analyzer for a given gas stream on the basis of a few easily quantifiable parameters. In addition, due to scope and need definition problems it was recognized that the less quantifiable factors would be difficult to evaluate. A compromise was necessary and lie lullowing was adopted:

- Select a limited set of quantifiable factors

- Select a limited set of qualitative factors

- Perform a preliminary screening of instrumenation available based on the above factors.

The purpose of this section is to document the results of the first two steps. Success has been somewhat limited due to methodology and information availability problems. 
Table 3.9 Summary of Gas Cleanup Instrumentation Needs

(requirement number/type of unit/primary measurement)

\begin{tabular}{|c|c|c|c|c|c|c|c|c|}
\hline \multirow{2}{*}{$\begin{array}{l}\text { POWER } \\
\text { SYSTEM }\end{array}$} & \multirow[b]{2}{*}{$\begin{array}{c}\text { GAS } \\
\text { TEMPERATURE }\end{array}$} & \multirow{2}{*}{$\begin{array}{l}\text { CLEANUP } \\
\text { PROCESS }\end{array}$} & \multicolumn{6}{|c|}{ UNIT OPERATION } \\
\hline & & & $\begin{array}{l}\text { GASIFICATION/ } \\
\text { COMBUSTION }\end{array}$ & SORPTION & $\begin{array}{l}\text { REGENERATION } \\
\text { (1ST STAGE) }\end{array}$ & $\begin{array}{c}\text { REGENERATION } \\
\text { (2ND STAGE) }\end{array}$ & COLLECTION & OTHER \\
\hline \multirow{4}{*}{ IGCC } & LOW & LURGI & & $1 / 9 / \mathrm{H}_{2} \mathrm{~S}$ & & & & \\
\hline & \multirow{3}{*}{$\mathrm{HIGH}$} & METC & $2 / 8 / \mathrm{H}_{2} \mathrm{~S}$ & $\begin{array}{l}3 / 1 / \mathrm{H}_{2} \mathrm{~S} \\
6 / 2 / \mathrm{H}_{2} \mathrm{~S} \\
\end{array}$ & $\begin{array}{l}4 / 1 / \mathrm{SO}_{2} \\
7 / 2 / \mathrm{SO}_{2}\end{array}$ & $\begin{array}{l}5 / 1 / \mathrm{H}_{2} \mathrm{~S} \\
8 / 2 / \mathrm{H}_{2} \mathrm{~S}\end{array}$ & $\begin{array}{l}9 / 11 / \text { Fine } \\
\text { Particulates }\end{array}$ & $\begin{array}{l}10 / 3 / \\
\text { Alkali Metals }\end{array}$ \\
\hline & & BATTELLE & & $11 / 1 / \mathrm{H}_{2} \mathrm{~S}$ & $12 / 1 / \mathrm{H}_{2} \mathrm{~S}$ & & & $\begin{array}{l}13 / 3 / \\
\text { Alkali Metals }\end{array}$ \\
\hline & & IGT & & $14 / 1 / \mathrm{H}_{2} \mathrm{~S}$ & $15 / 1 / \mathrm{SO}_{2}$ & & & $16 / 4 / \mathrm{N} 2$ \\
\hline \multirow{5}{*}{ MCFC } & \multicolumn{2}{|l|}{ PFBC } & $17 / 2 / \mathrm{SO}_{2}$ & . & . & & \begin{tabular}{|l|} 
18/10/Coarse \\
Particulates \\
$19 / 11$ ifine \\
Particulates \\
\end{tabular} & $\begin{array}{l}20 / 3 / \\
\text { Alkali Metals }\end{array}$ \\
\hline & LOW & SELEXOL & & $\begin{array}{l}23 / 9 / \mathrm{H}_{2} \mathrm{~S} \\
24 / 1 / \mathrm{H}_{2} \mathrm{~S}\end{array}$ & & & & $\begin{array}{l}21 / 11 / \text { hydro- } \\
\text { carbons } \\
22 / 6 / \mathrm{NH}_{3}\end{array}$ \\
\hline & \multirow[t]{3}{*}{$\mathrm{HIGH}$} & METC & $2 \mathrm{~S} / 8 / \mathrm{H}_{2} \mathrm{~S}$ & \begin{tabular}{|l}
$26 / 1 / \mathrm{H}_{2} \mathrm{~S}$ \\
$29 / 2 / \mathrm{H}_{2} \mathrm{~S}$ \\
$33 / 1,7 / \mathrm{H}_{2} \mathrm{~S}$ \\
$34 / 2,7 / \mathrm{H}_{2} \mathrm{~S}$ \\
\end{tabular} & $\begin{array}{l}27 / 1, \mathrm{SO}_{2} \\
30 / 2, \mathrm{SO}_{2}\end{array}$ & $\begin{array}{l}28 / 1 / \mathrm{H}_{2} \mathrm{~S} \\
31 / 2 / \mathrm{H}_{2} \mathrm{~S}\end{array}$ & $\begin{array}{l}32 / 11 / \text { Fine } \\
\text { Particulate }\end{array}$ & \\
\hline & & BATTELLE & . & $\begin{array}{l}35 / 1 / \mathrm{H}_{2} \mathrm{~S} \\
37 / 1,7 / \mathrm{H}_{2} \mathrm{~S}\end{array}$ & $36 / 1 / \mathrm{H}_{2} \mathrm{~S}$ &. & & . \\
\hline & & IGT & & $\begin{array}{l}38 / 1 / \mathrm{H}_{2} \mathrm{~S} \\
40 / 1,7 / \mathrm{H}_{2} \mathrm{~S}\end{array}$ & $39 / 1 / \mathrm{SO}_{2}$ & & & \\
\hline
\end{tabular}

Types of Units: 1. Fixed Bed Unit

2. Fluidized Bed Unit

3. Alkali Polisher

4. Sulfur Condenser
5. Tar Cracker

6. Ammonia Stripper

7. $\mathrm{H}_{2} \mathrm{~S}$ Polisher

8. In-bed Desulfurization
9. Gas-liquid Unit

10. Cyclone

11. Not Specified 
Table 3.10 Other Instrumentation Needs

(requirement number/measurement or need)

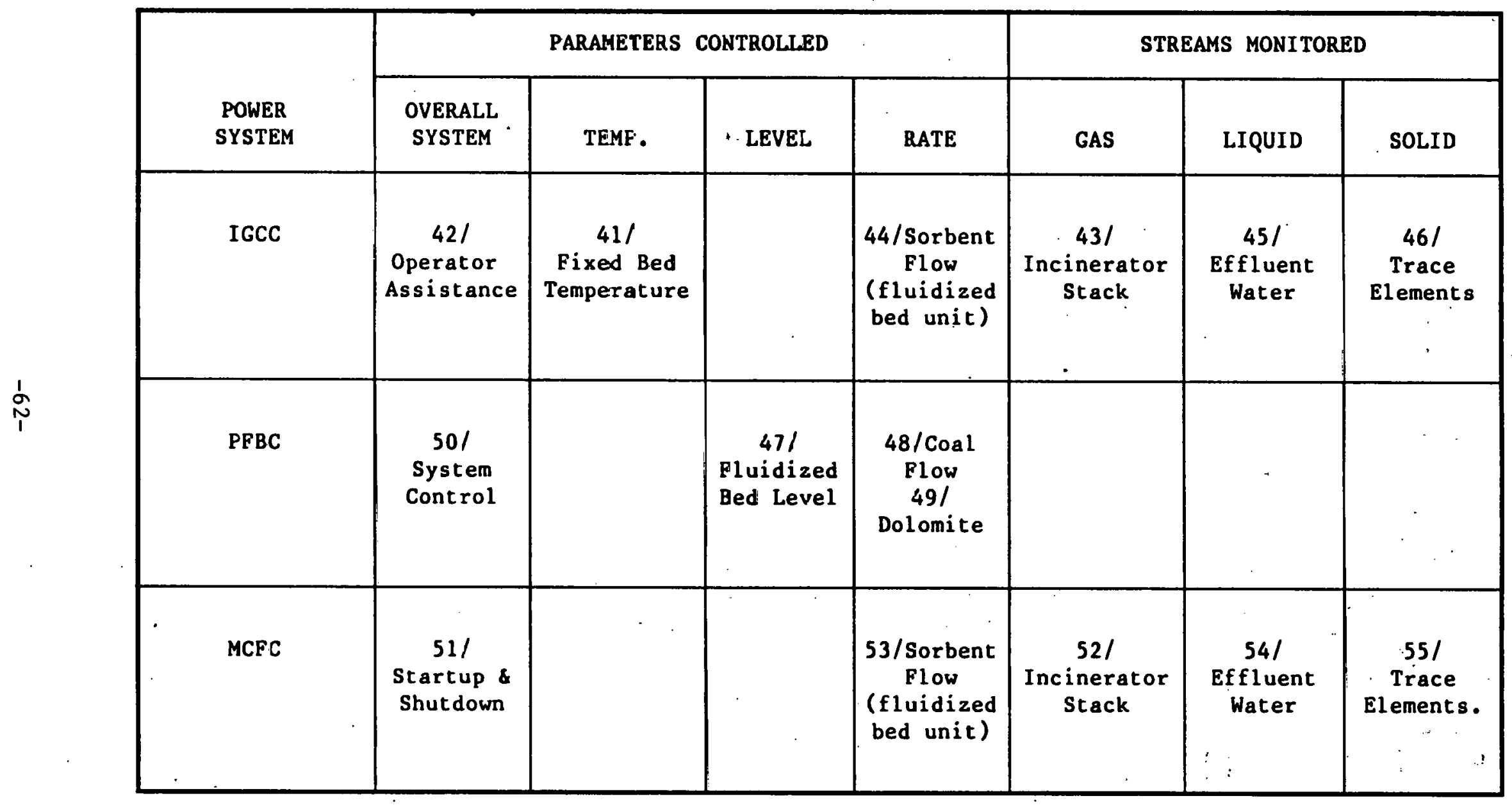




\subsubsection{IGCC Gas Cleanup System Requirements}

The IGCC instrument requirements are based primarily upon Figures $3.2,3.3$ and 3.4 , and their related Tables $3.5,3.6$ and 3.7. Figure 3.1 and Table 3.4 describe a typical low temperature cleanup approach. Instruments for the cold gas cleanup processes are available, but recent instrumentation advances and electric utility load-following requirement trends have made it necessary to include them in this assessment.

Figures $3.2,3.3,3.4$ and their related tables deal with the hot gas cleanup processes which are under development. It is possible that commercially available instruments could be used to control these processes. However, depending upon the specific application, some loss of responsiveness and/or high maintenance costs may be incurred which should be avoided if possible.

A list of instrumentation requirements for the IGCC gas cleanup processes follows.

3.5.1.1 Req. No. 1 - Downstream of $\mathrm{H}_{2} \mathrm{~S}$ Absorber

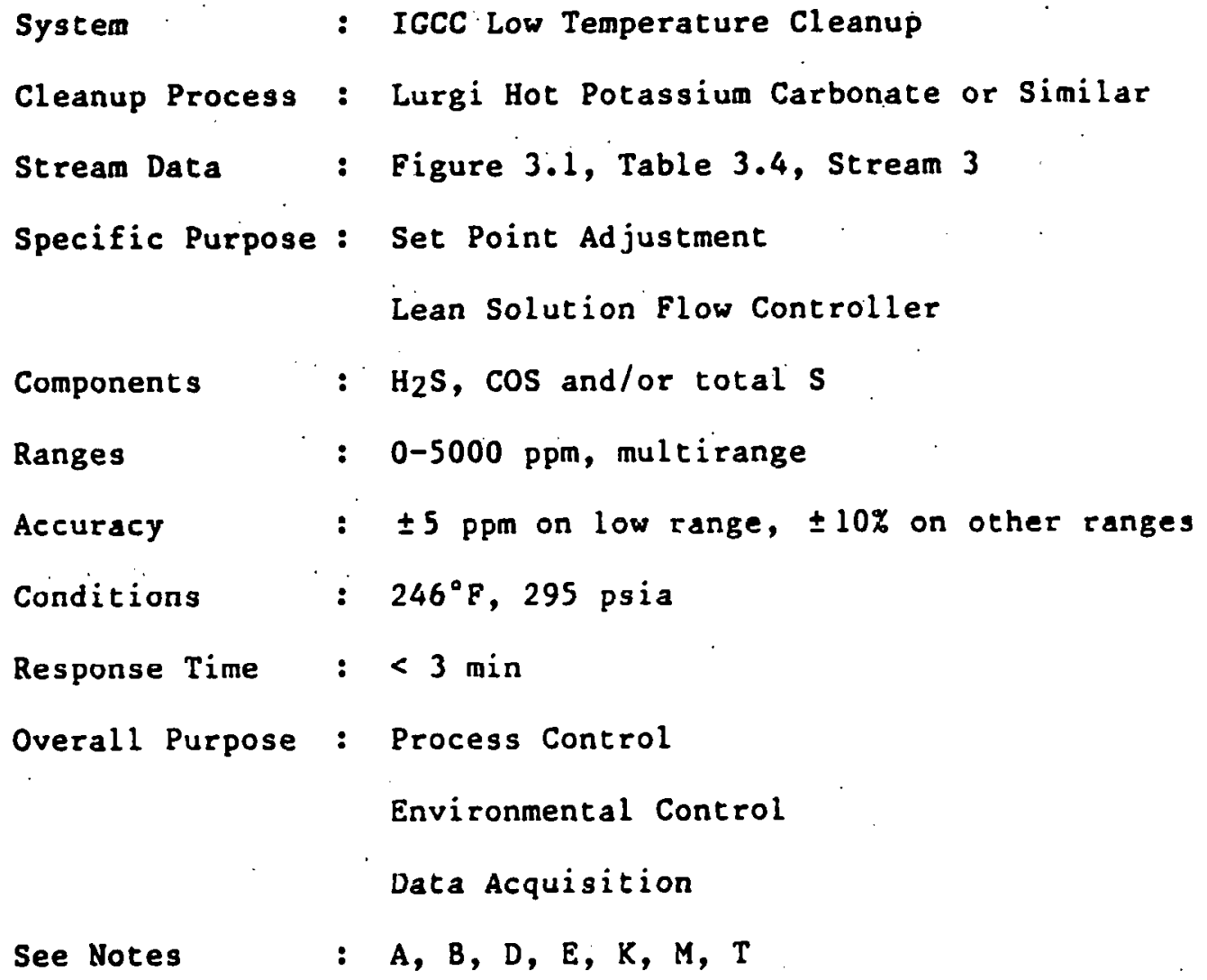

Req. No. 2 - Downstream of Gasifier 


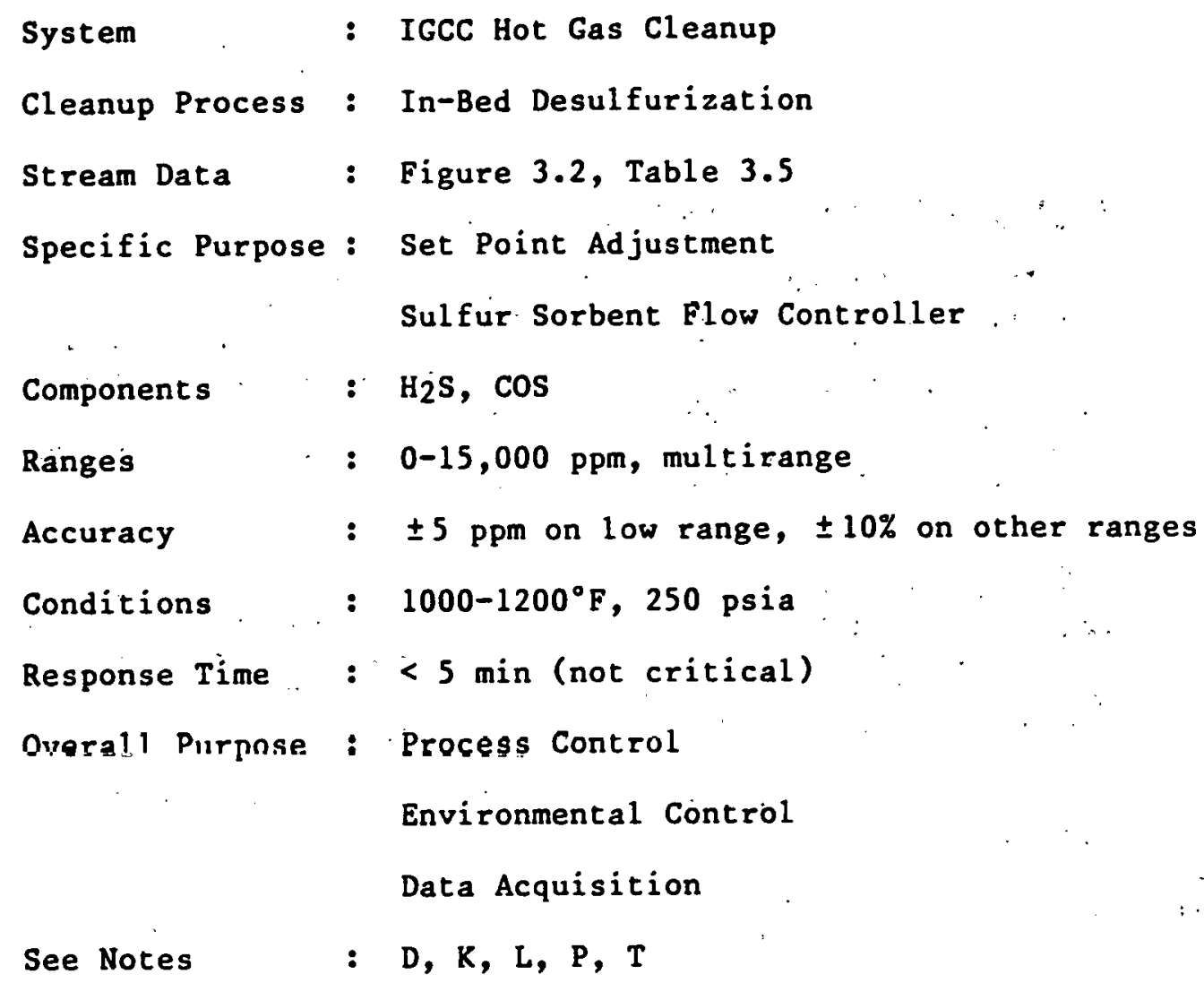


Req. No. 4 - Downstream of Regenerator

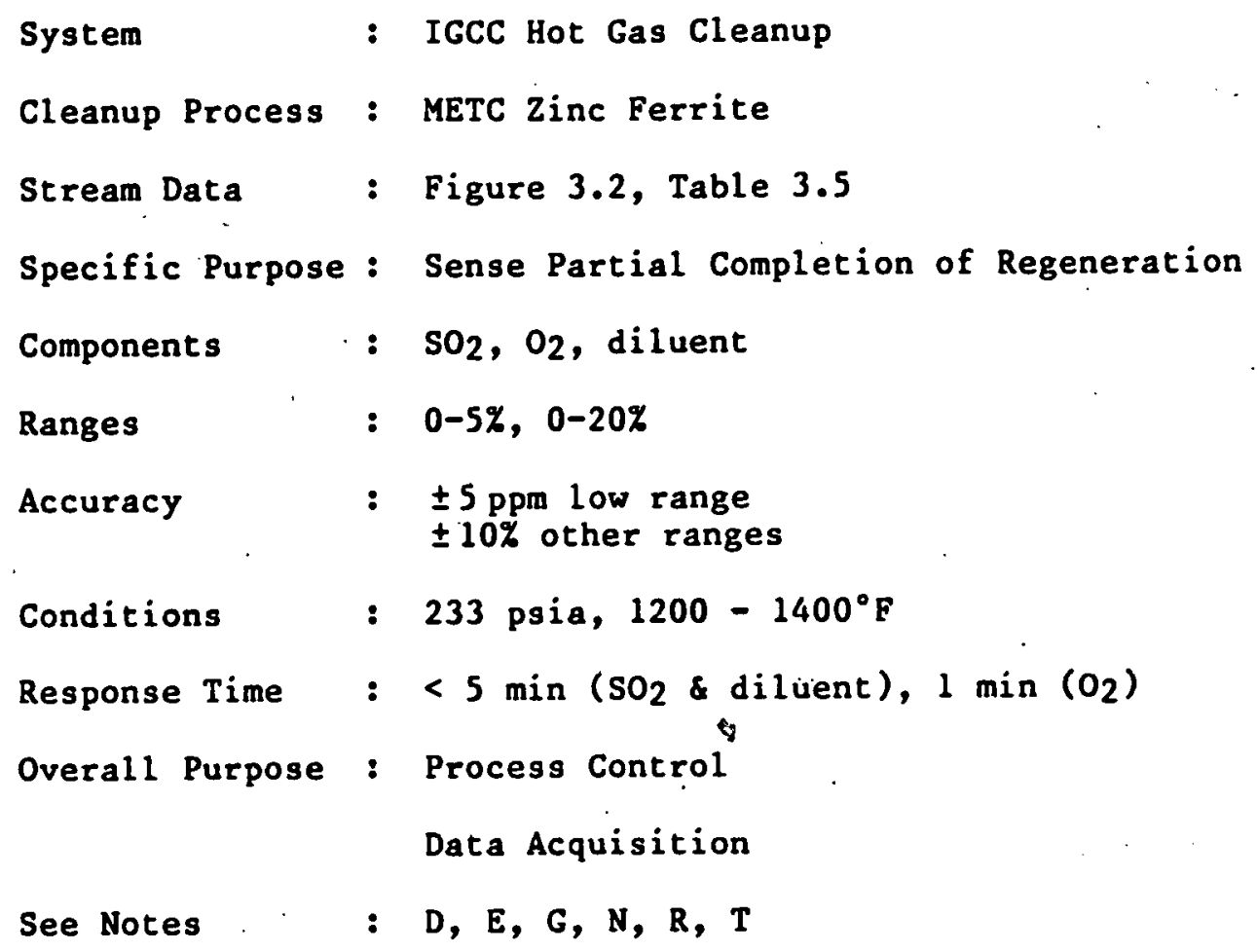

Req. No. 5 - Downstream Reductive Regeneration Unit

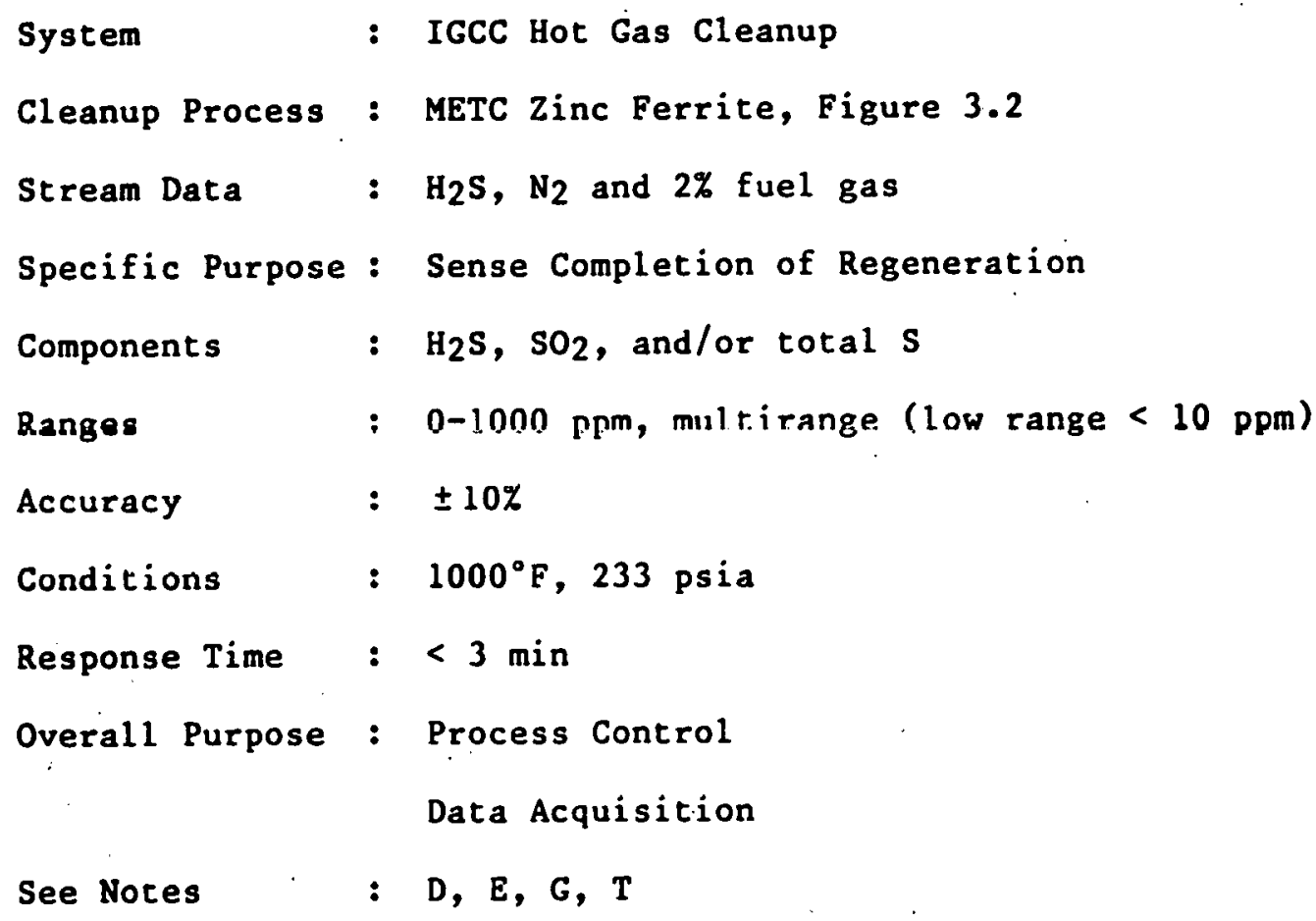


Req. No. 6 - Downstream of $\mathrm{H}_{2} \mathrm{~S}$ Absorber

$\begin{array}{ll}\text { System } & \text { : IGCC Hot Gas Cleanup } \\ \text { Cleanup Process } & : \text { METC Zinc Ferrite, Fluidized Bed }\end{array}$

Note : Gas analysis requirements are essentially the same as listed in Req. No. 3\%: See note $P$.

Req. No. 7 - Downstream of Regenerator

$\begin{array}{ll}\text { System } & : \text { IGCC Hot Gas Cleanup } \\ \text { Cleanup Process : METC Zinc Ferrite, Fluidized Bed }\end{array}$

Note $\quad$ Cao analycic requirements are essentially the same as listed in Req. No. 4. See note $P$.

Req. No. 8 - Downstream of Reductive Regeneration Unit

$\begin{array}{ll}\text { System } & \text { : IGCC Hot Gas Cleanup } \\ \text { Cleanup Process : METC Zinc Ferrite, Fluidized Bed }\end{array}$

Note : Gas analysis requirements are essentially the same as listed in Req. No. 5. See note $P$.

Req. No. 9 - Downotroam of $\mathrm{H}_{2} \mathrm{~S}$ Absorber

System $\quad$ IGCC Hot Gas Cleanup
Cleanup Process : METC Zinc Ferrite, Fluidized Bed
Specific Purpose: Particulate Control

Note : Gas composition and conditions as referenced ill Rey. No. 2 except for the presence of particulates from the fluidized bed. Particulate measurements needed for loading down to $200 \mathrm{ppm}$ and an average particle size below 10 micrometers.

Req. No. 10 - Downstream of Alkali Polisher 


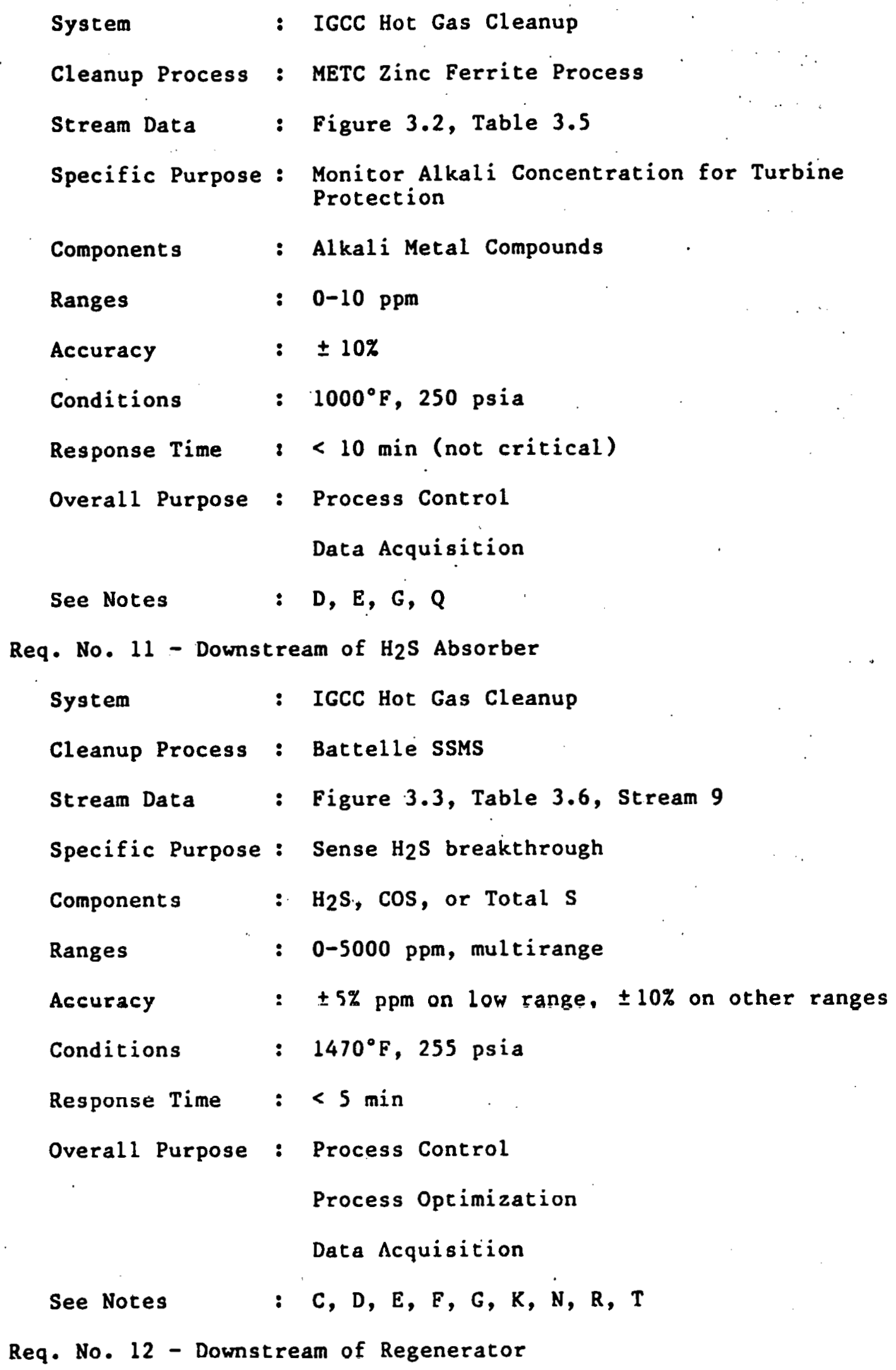




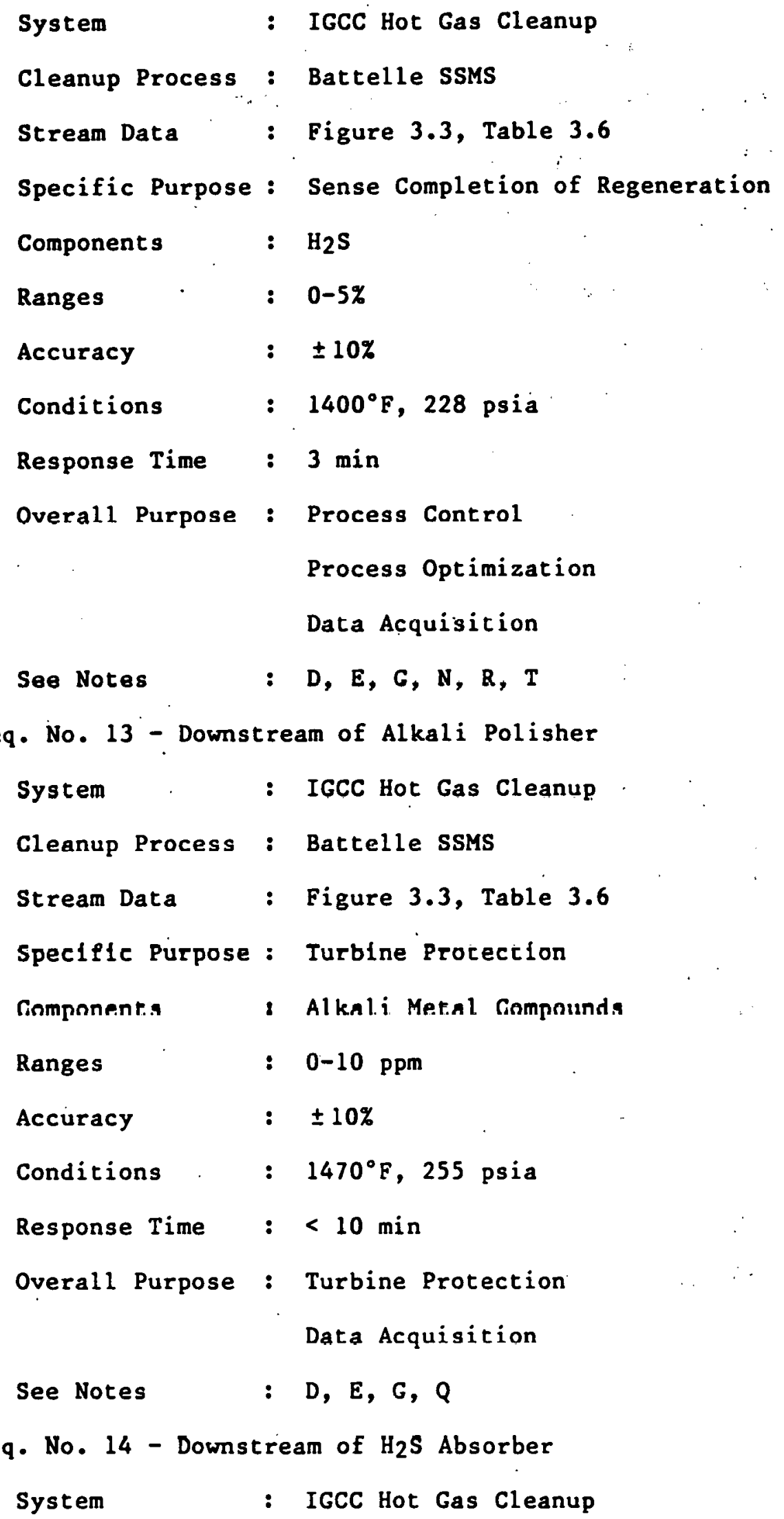




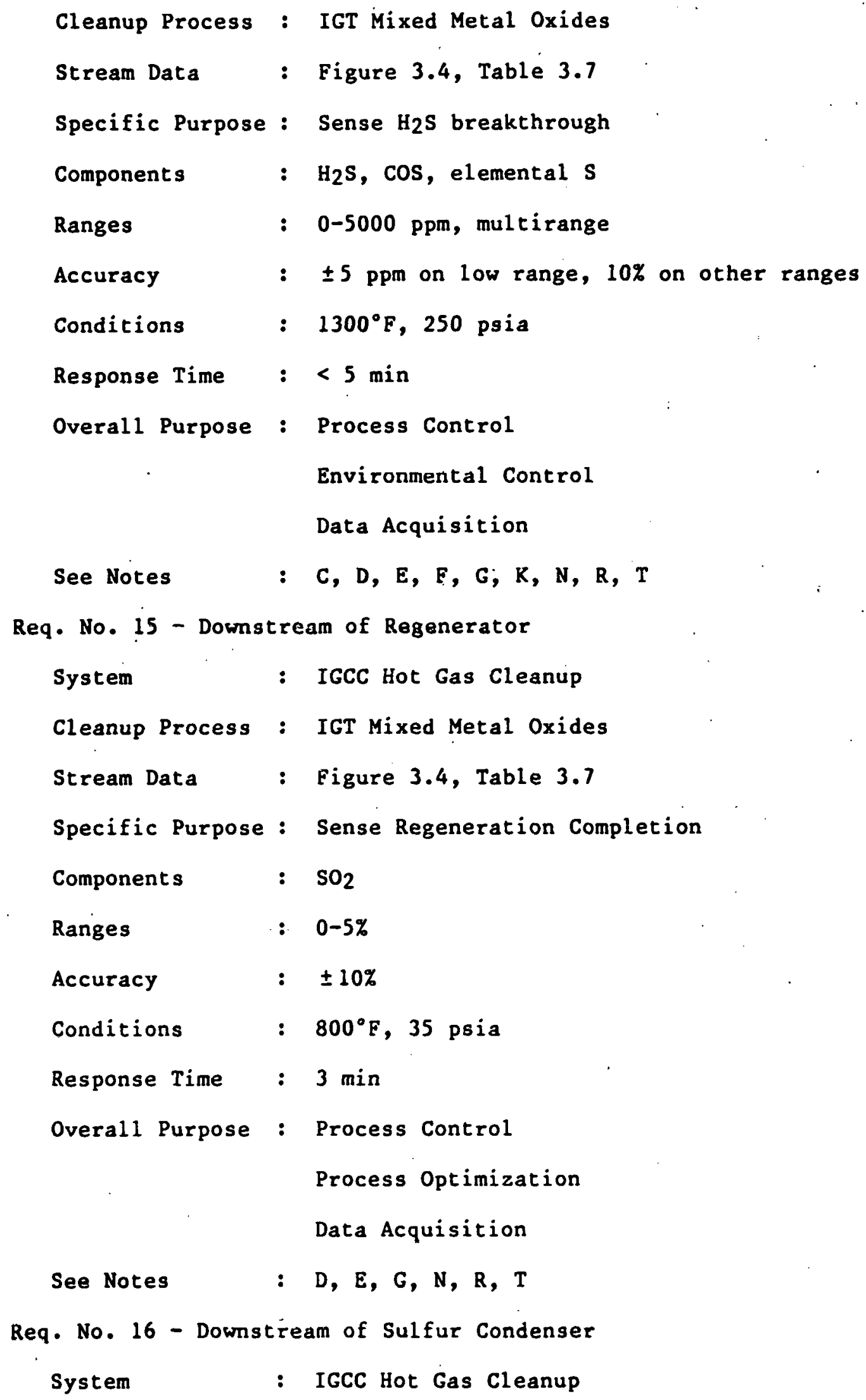




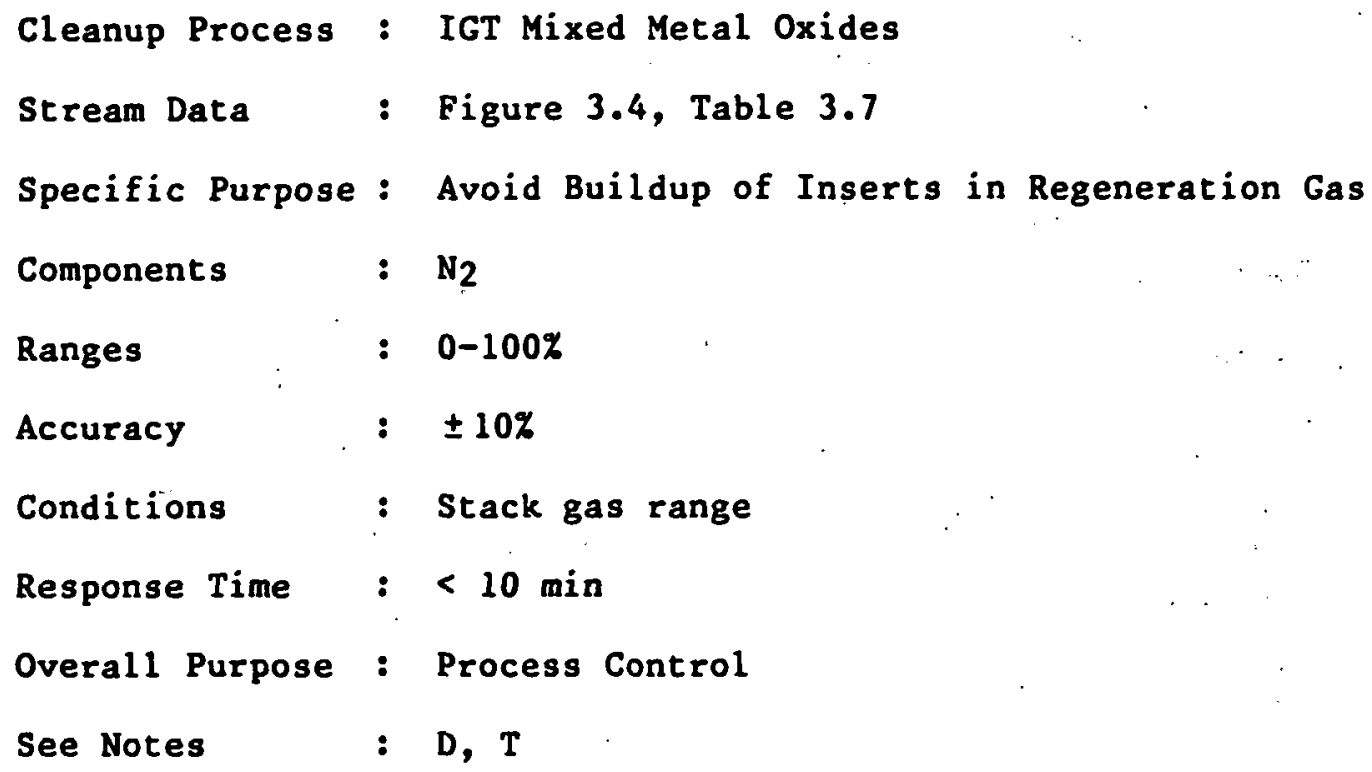

3.5.2 PFBC Gas Cleanup Requirements

The instrumentation requirements listed in this section are based upon the process control requirements discussed in Section 3.4.3. Stream conditions are based upon Figure B-1 and Table B-3.

Req. No. 17 - Downstream of Combustor

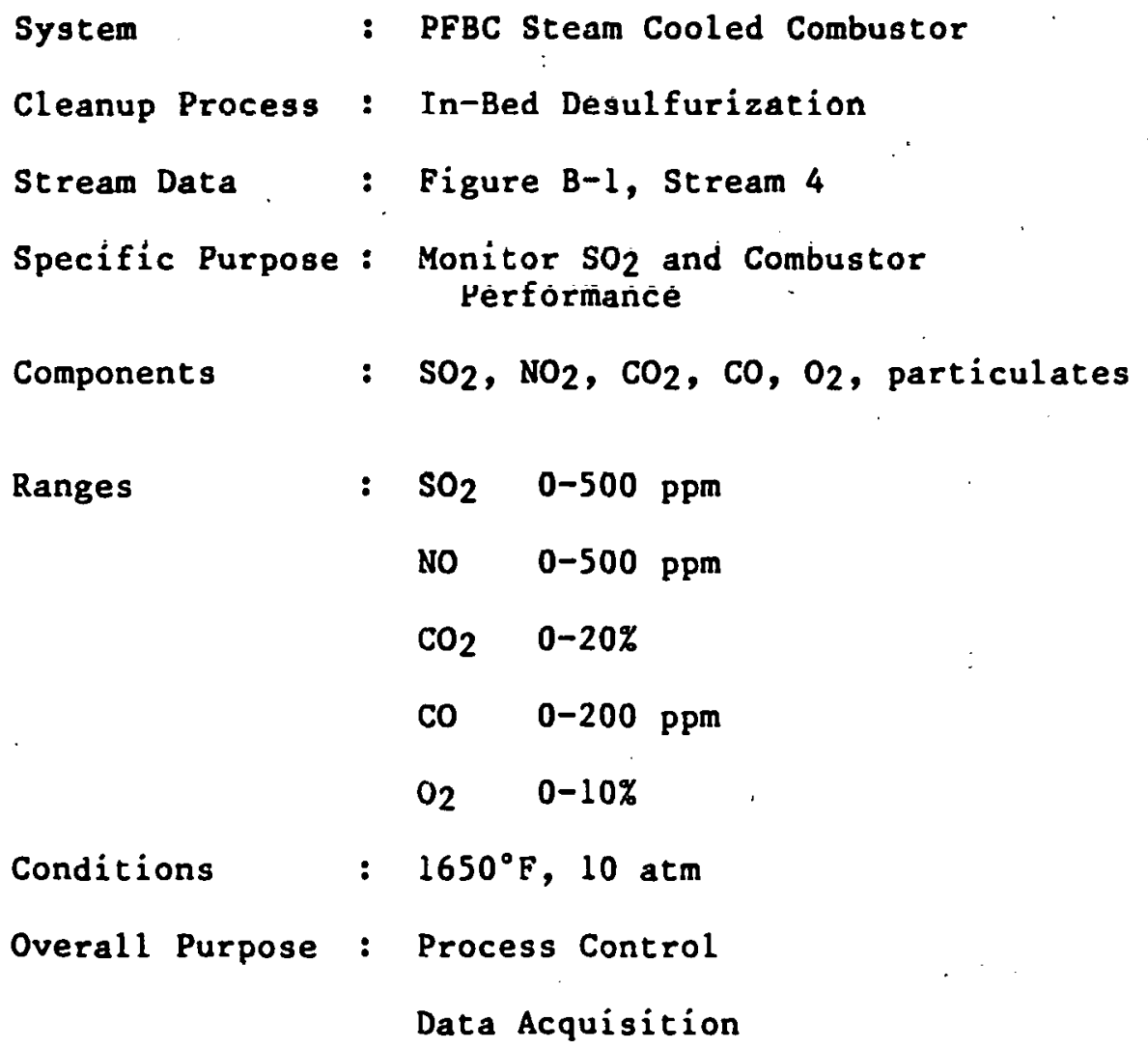


See Notes : D, E, G, K, L, R

Req. No. 18 - Downstream of Cyclones

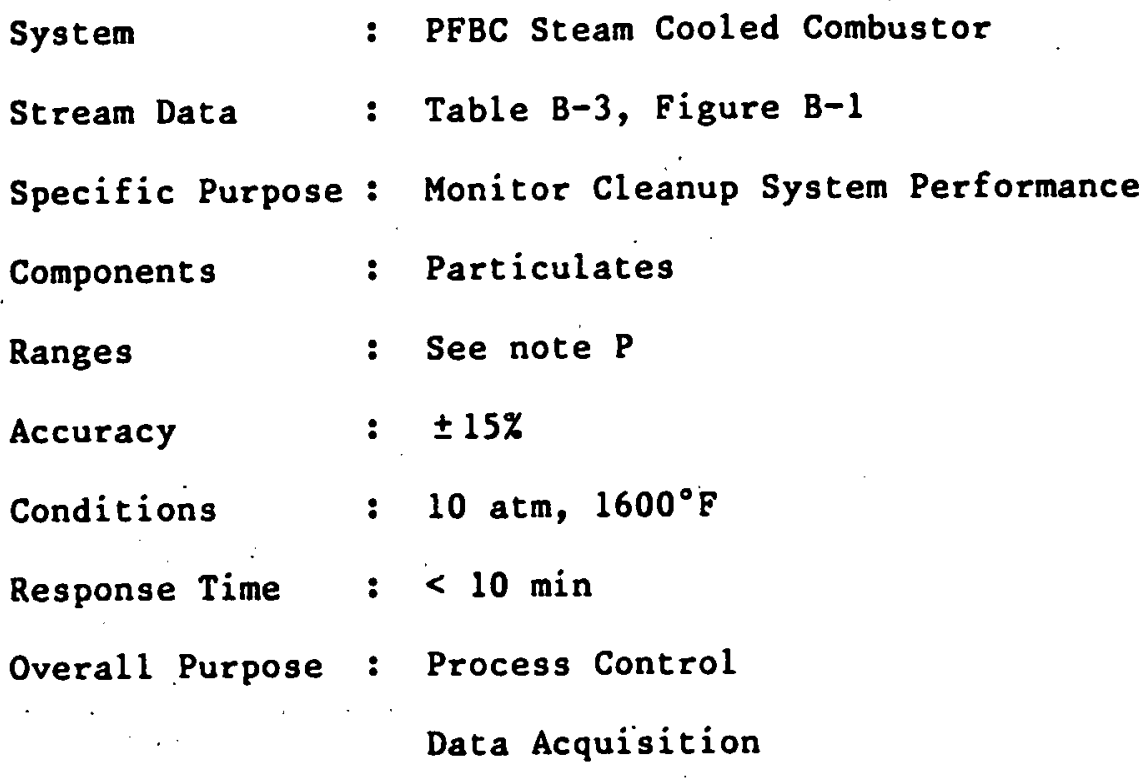

See Notes : E, H

Req. No. 19 - Downstream of Fine Particle Cleanup Device

$\begin{array}{ll}\text { System } & : \text { PFBC Steam Cooled Combustor } \\ \text { Stream Data } & : \text { Table B-3, Figure B-1 } \\ \text { Specific Purpose : Gas Turbine/Environmental } \\ \text { Components } & : \text { Particulates } \\ \text { Ranges } & : \text { See note P } \\ \text { Accuracy } & : 15 \% \\ \text { Conditions } & :<10 \mathrm{~min}, 1600^{\circ} \mathrm{F} \\ \text { Response Time } & : \text { Process Control } \\ \text { Overall Purpose } & \text { Data Acquisition } \\ & \text { : D, E, S }\end{array}$

Req. No. 20 - Downstream of Alkali Absorption Unit

System : PFBC Steam Cooled Combustor

Specific Purpose: Gas Turbine Protection 


$\begin{array}{ll}\text { Components } & : \mathrm{Na}, \mathrm{K} \\ \text { Ranges } & : 0-10 \mathrm{ppm} \\ \text { Accuracy } & \pm 10 \% \\ \text { Conditions } & : 10 \mathrm{~atm}, 1600^{\circ} \mathrm{F} \\ \text { Response Time : } & <10 \mathrm{~min} \\ \text { Overall Purpose } & : \text { Process Control } \\ & \text { : Data Acquisition } \\ \text { See Notes } & \text { : D, E, Q }\end{array}$

3.5.3 MCFC Gas Cleanup Requirements

The instrument requirements 1 isted in this section are based on Figures $3.2,3.3,3.4$ and 3.1 . Figure 3.1 and Table 3.4 describe some typical low temperature cleanup processes. Instrument needs for these processes can be satisfied by vendor supplied instruments, but recent instrumentation advances have made it necessary to include some of these instrumentation needs in the assessment.

Figures $3.2,3.3,3.4$ and their corresponding tables $(3.5,3.6$, 3.7) deal with the hot gas processes which are under development. Commercially available instruments may be satisfactory for controlling these processes. However, depending upon the specific application, some loss of responsiveness and/or high maintenance costs may be incurred which should be avoided if possible.

A list of instrumentation requirements for the MCFC gas cleanup processes follows.

Req. No. 21 - Downstream of the Tar Craoker

$\begin{array}{ll}\text { System } & : \text { MCFC High Temperature Cleanup } \\ \text { Cleanup Process : Any hot gas cleanup process used with the } \\ \text { Lurgi gasifier } \\ \text { Stream Data } \\ \text { Specific Purpose: Mable } 3.5 \text {, Stream } 1 \text { plus tars and oils } \\ \text { Components } & : \text { Total Hydrocarbons } \\ \text { Ranges } & : 0-10 \text { ppm } \\ \text { Accuracy } & : \pm 10 \% \\ \text { Conditions.. } & : 225 \text { psia, } 1472^{\circ} \mathrm{F}\end{array}$


Response Time : < 10 min (not critical)

Overall Purpose : Fuel Cell Protection

Process Control

Data Acquisition

See Notes : D, G

Req. No. 22 - Downstream of Ammonia Scrubber

System : MCFC Low Temperature Cleanup

Cleanup Process : Texaco Gasifier/Selexol

Stream Data : Figure C-2, Stream 9

Specific Purpose : Monitor Scrubber Performance

Components $\quad: \quad \mathrm{NH}_{3}$

Ranges : $\quad 0-1000 \mathrm{ppm}, 0-10 \%$

Accuracy : $\pm 10 \%$

Conditions $\quad: 540 \mathrm{psig}, 100^{\circ} \mathrm{F}$

Response Time : $<5 \mathrm{~min}$

Overall Purpose : Process Control

See Notes : D, T

Req. No. 23 - Downstream of Absorber

$\begin{array}{ll}\text { System } & \text { MCFC Low Temperature Cleanup } \\ \text { Cleanup Process } & : \text { Norton Selexol } \\ \text { Stream Data } & \text { : Figure } 3.1 \text {, Stream } 14 \\ \text { Specific Purpose : } & \text { Set Point Adjustment } \\ & \text { Lean Solution Flow Controller } \\ \text { Components } & : \text { Primarily } \mathrm{H}_{2} \mathrm{~S} \\ \text { Ranges } & : 0-5000 \mathrm{ppm} \text { multirange } \\ \text { Accuracy } & \pm 5 \mathrm{ppm} \text { on low range, } \pm 10 \% \text { on other ranges } \\ \text { Conditions } & : 120^{\circ} \mathrm{F}, 7 \mathrm{psig} \\ \text { Response Time } & :<3 \mathrm{~min}\end{array}$


Overall Purpose : Process Control

Process Optimization

Data Acquisition

See Notes

: A, B, D, E, K, M, T

Req. No. 24 - Downstream of Zinc Oxide Unit

System : MCFC Low Temperature Cleanup

Cleanup Process : Texaco Gasifier/Selexol

Stream Data : Figure C2, Stream 12

Specific Purpose : Fuel Cell Protection

Components : $\mathrm{H}_{2} \mathrm{~S}$

Ranges $\quad$ : $0-1$ pyuI

Accuracy : $\pm 10 \%$

Conditions : $500 \mathrm{psig}, 750^{\circ} \mathrm{F}$

Response Time : $<3 \mathrm{~min}$

Overall Purpose : Process Control

Process Optimization

Data Acquisition

See Notes : $\bar{B}, E, T$

Req. No. 25 - Downstreañ of Gasifler

System : MCFC Hot Gas Cleanup

Cleanup Process : In-Bed Desulfurization

See Req. No. 2

Req. No. 26 - Downstream of Absorber

System : MCFC Hot Gas Cleanup

Cleanup Process : METC Zinc Ferrite, Fixed Bed

See Req. No. 3

Req. No. 27 - Downstream of Regenerator

System : MCFC Hot Gas Cleanup 
Cleanup Process : METC Zinc Ferrite

See Req. No. 4

Req. No. 28 - Downstream of Soaking Unit

System : MCFC Hot Gas Cleanup

Cleanup Process : METC Zinc Ferrite

See Req. No. 5

Req. No. 29 - Downstream of $\mathrm{H}_{2} \mathrm{~S}$ Absorber

System : MCFC Hot Gas Cleanup

Cleanup Process : METC Zinc Ferrite, Fluidized Bed

See Req. No. 6

Req. No. 30 - Downstrean of Regenerator

System : MCFC Hot Gas Cleanup

Cleanup Process : METC Zinc Ferrite, Fluidized Bed

See Req. No. 7

Req. No. 31 - Downstream of Soaking Unit

System $\quad:$ MCFC Hot Gas Cleanup

Cleanup Process : METC Zinc Ferrite, Fluidized Bed

See Req. No. 8

Req. No. 32 - Downstream of Particulate Removal Device

System : MCFC Hot Gas Cleanup

Cleanup Process : METC Zinc Ferrite, Fluidized Bed

See Req. No. 9

Req. No. 33 - Downstream of $\mathrm{H}_{2} \mathrm{~S}$ Polisher

System : MCFC Hot Gas Cleanup

Cleanup Process : METC Zinc Ferrite, Fixed Bed

Stream Data : Table 3.5, Stream 4

Specific Purpose : Fuel Cell Protection

Components $\quad \because \mathrm{H} 2 \mathrm{~S}, \mathrm{COS}$ 


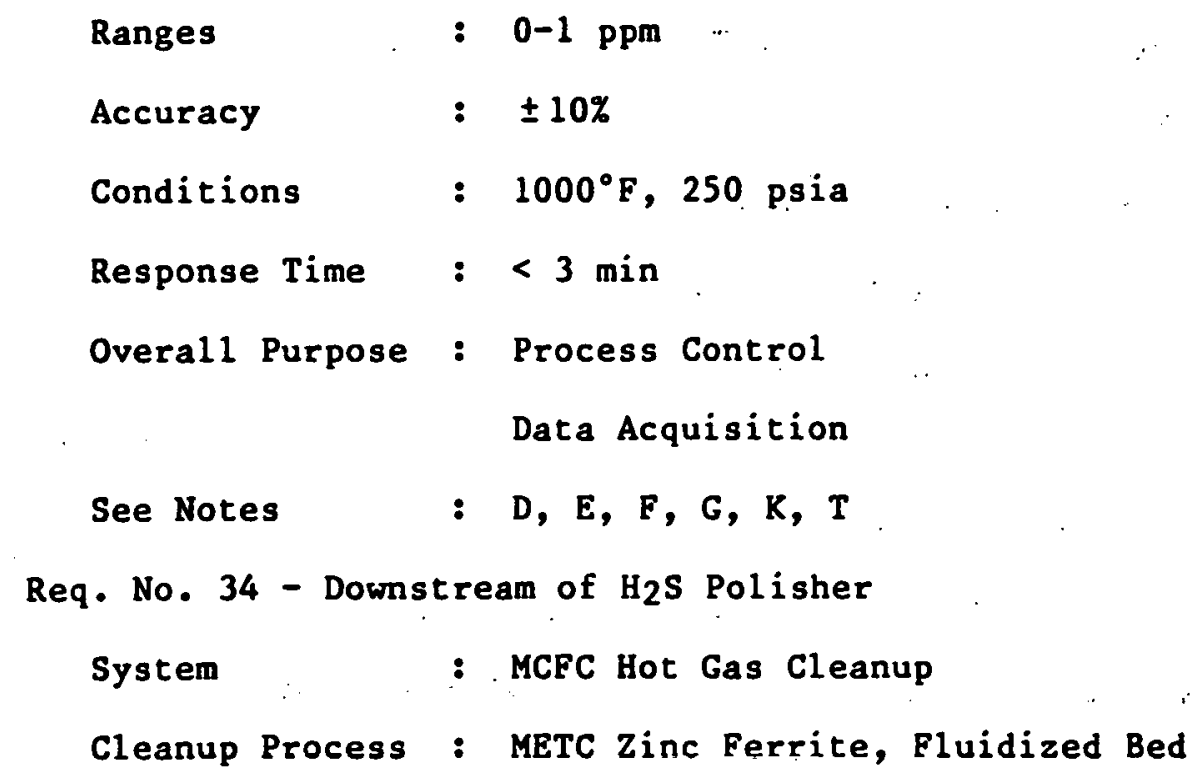

Note: This instrumentation need will be essentially the same as that described above (Req. No. 33) except that a gas conditioning system will have to be provided to filter out particulate material which is carried over from the fluidized bed.

Req. No. 35 - Downstream of $\mathrm{H}_{2} \mathrm{~S}$ Absorber

System : MCFC Hot Gas Cleanup

Cleanup Process : Battelle SSMS

See Rey. Nu. 11

Req. No. 36 - Downstream Regenerator

System : MCFC Hot Gas Cleanup

Cleanup Process : Battelle SSMS

See Req. No. 12

Req. No. 37 - Downstream of $\mathrm{H}_{2} \mathrm{~S}$ Polisher

System : MCFC Hot Gas Cleanup

Cleanup Process : Battelle SSMS

Stream Data : Figure 3.3, Table 3.6, Stream 4

Specific Purpose : Fuel Cell Procection

Components : $\mathrm{H}_{2} \mathrm{~S}$ 


$\begin{array}{ll}\text { Ranges } & : 0-1 \mathrm{ppm} \\ \text { Accuracy } & : \pm 10 \% \\ \text { Conditions } & : 170 \mathrm{psia}, 1400^{\circ} \mathrm{F} \\ \text { Response Time }:<3 \mathrm{~min} \\ \text { Overall Purpose : Process Control } \\ & \text { Data Acquisition }\end{array}$

See Notes: $\quad: \quad D, E, F, G, K, T$

Req. No. 39 - Downstream $\mathrm{H}_{2} \mathrm{~S}$ Absorber

System : MCFC Hot Gas Cleanup

Cleanup Process : IGT Mixed Metal Oxides

See Req. No. 14

Req. No. 39 - Downstream Regenerator

System : MCFC Hot Gas Cleanup

Cleanup Process : IGT Mixed Metal Oxides

See Req. No. 15

Req. No. 40 - Downstream of $\mathrm{H}_{2} \mathrm{~S}$ Polisher

\begin{tabular}{|c|c|c|}
\hline System & : & MCFC Hot Gas Cleanup \\
\hline Cleanup Process & $:$ & IGT Mixed Metal Oxides \\
\hline Stream Data & : & Figure 3.4 , Table 3.7 , stream 9 \\
\hline Specific Purpose & : & Fuel Cell Protection \\
\hline Components & : & $\mathrm{H}_{2} \mathrm{~S}, \mathrm{COS}$ \\
\hline Ranges & : & $0-1 \mathrm{ppm}$ \\
\hline Accuracy & : & $\pm 10 \%$ \\
\hline Conditions & : & $170 \mathrm{psia}, 1300^{\circ} \mathrm{F}$ \\
\hline Response Time & : & $<5 \mathrm{~min}$ \\
\hline Overall Purpose & : & Process Control \\
\hline & & Data Acquisition \\
\hline
\end{tabular}




\subsubsection{Other Instrumentation Requirements.}

\subsubsection{IGCC Requirements}

Req. No. 41 - Gasifier Temperature Measurement

In the past, difficulties have been experienced in measuring high temperatures in gasifiers and combustors. Thermocouples or other devices are needed which are capable of resisting corrosion; erosion and large temperature excursions over long periods of time. See note $L$.

Req. No. 42 - Fixed Bed Gasifier Startup and Shutdown

In general, fixed bed gasifiers are controlled by experienced operators who are able to infer conditions within the bed from external measurements. This capability to manually monitor gasifier behavior is particularly important during cold startup. Consideration should be given to combining a simple on-line model with expert systems technology in order to better automate gasifier concrol. See hule $\mathrm{K}$.

Req. No. 43 - Incinerator Stack Monitoring

Some IGCC power systems use low temperature gas cleanup systems which recycle various contaminated'streams back to the gasifier. An example of this approach is shown in Figure $A-1$. For such systems, a stack gas analyzer should be installed to monitor the effluent stream or streams being discharged to the atmosphere. Assuming the incinerator is operating correctly, the trace components of possible concern should be $\mathrm{SO}_{2}, \mathrm{CO}, \mathrm{NO}_{x}$ and $\mathrm{H}_{2} \mathrm{~S}$ together with small quaritities of dust and organics. See notes $D . E$, and $J$.

Rey. No. 44 3orbent Flow Measurement

System: IGCC Hot Gas Cleanup

Cleanup Process: In-Bed Desulfurization

Commercially available flow meters which are mostly of the intrusive type have not performed well. For in-bed desulfurization applications, the measurement of $\mathrm{H}_{2} \mathrm{~S}$ at the outlet of the fluidized bed gasifier poses less of a problem than the measurement of sorbent flow rate. There is a need for improved solids flow rate measurements for all fluidized bed applications. See note L.

Req. No. 45 - Effluent Water Analysis

System: IGCC Cold Gas Cleanup

The base case IGCC cold gas cleanup system differs from that referenced in Req. NO. 54 in that all liquid effluents are recycled: however, in general, most power systems which employ low temperature cleanup techniques require instrumentation for performing effluent water analyses. See Req. No. 59 and Note J. 
Req. No. 46 - Trace Element Analysis

Atomic spectrographic techniques are used to measure trace elements. Over the past few years, inductively coupled plasma (ICP) spectrometry has become generally accepted for routine analysis purposes. ICP is a multi-element measuring technique and would be suitable for most research instrumentation needs. Based on current operational needs, no on-line measurements of trace elements are necessary other than those related to alkali monitoring, and these needs have been covered by Req. Nos. 10, 13, 20, and 34. However, for research purposes, real-time on-line trace element analysis methods are required for a variety of data acquisition and data analysis applications. See also Req. No. 55 and note $\mathrm{J}$.

\subsubsection{PFBC Reguirements}

Req No. 47 - Bed Level Measurement

Bed height is usually monitored by measuring pressure drop across the bed. Sight glasses are usually installed and are frequently needed due to the poor performance of typical pressure measuring elements. Major problems are usually experienced in keeping the pressure probes free of particulate material. There exists an urgent need for improved bed level measuring instrumentation. See notes $E$, $L$.

Req. No. 48 - Coal Feed Rate

The accurate measurement of coal flow feed rate has been a problem at most PFBC facilities. Rotary feeders are often used for process control purposes, but they are less accurate than desired. Over a period of time the total mass flow rate of coal can be monitored by means of weigh cells, but there exists a need for improved methods of making on-line measurements for process control purposes. See notes $E$, L.

Req. No. 49. - Dolomite Feed Rate

The same problems as discussed under "Coal Feed Rate" also apply to the measurement of dolomite flow. However, since changes in dolomite flow rate do not cause unstable combustor operation, the need for improved dolomite flow control is not as great. See notes $E$, $L$.

Req. No. 50 - Overall Plant Control

Test rigs and pilot plants provide an ideal environment for the development of process control systems, yet some coal conversion test rigs are controlled manually. This is particularly true of PFB combustors. Most operational difficulties are related to solids handling, erosion or plugging problems caused by a combination of high temperatures, pressures and solids concentrations. Therefore automatic control studies are often deferred until other operational problems have been solved, and control system development work tends to be neglected. As a 
result, there exists a need to develop and publish integrated control strategies for typical PFBC power systems. See note K.

\subsubsection{MCFC Requirements}

Req. No. 51 - Overall System

The start-up of an MCFC plant will require the careful development of a schedule based on maximum heat-up rates for the refractory and other materials used for the gasifier, fuel cell, steam turbine and hot gas cleanup systems. Some important instrumentation needs will emerge as a result of conducting such a study.

Req. No. 52 - Incinerator Stack Monitor

In the case of the MCFC power system shown in Figure C-1, no gas or liquor streams are recycled back to the gasifier. Instead, all of the flue gases from the incinerator are exposed to a sufficiently high temperature to ensure that all of the combustible substances present are incinerated. Some components of concern, however, may be present and should be monitored. These include $\mathrm{SO}_{2}, \mathrm{CO}, \mathrm{NO}_{\mathrm{x}}$, $\mathrm{H}_{2} \mathrm{~S}$ and small quantities of organics and dust. In addition to stack gas monitoring for environmental protection purposes, the incinerator effluent analyses will contribute information on overall cycle efficiency and the effectiveness of the cleanup systems. See note J.

Req. No. 53 - Sorbent Flow Measurement

System: MCFC hot gas cleanup

Cleanup Process: In-Bed Desulfurization

See Req. No. 44

Req. No. 54 - Effluent Water Analysis

Using the MCFC plant shown in Figure $\mathrm{C}-1$ as an example, water from the gasification plant clarifier is first contacted with steam in the $\mathrm{H}_{2} \mathrm{~S}$ stripper. The stripper water is then sent to a biological treating system where undesirable contaminants are removed to the following levels:

$\begin{array}{ll}\text { Sulfides } & <1 \mathrm{ppm} \\ \text { Ammonia } & <25 \mathrm{ppm} \\ \text { Formates } & <10 \mathrm{ppm} \\ \text { Cyanides } & <3 \mathrm{ppm}\end{array}$

Analytical instrumentation will be required to monitor the concentrations of these effluents to make sure that they comply with environmental regulations. See note J.

Req. No. 55 - Trace Element Analysis 
The contaminants detrimental to fuel cell power plant components were discussed in Section 2.4.2. As shown in Table 2.5, the contaminants of concern which have not yet been considered in this section are the following:

- Halogen compounds

- Metals ( $\mathrm{Fe}, \mathrm{Cu}$ and $\mathrm{As}$ )

- Heavy metals ( $\mathrm{Hg}$ and $\mathrm{Sn}$ )

In addition, the TRW study 22 lists selenium hydride as a contaminant of concern which should be monitored.

$\mathrm{Hg}$ and $\mathrm{HF}$ are known catalyst poisons and may need to be controlled. However, at the present time there is insufficient information in the technical literature to clearly indicate that an $\mathrm{Hg}$ and $\mathrm{HF}$ absorption unit should be included in a commercial power plant configuration. For this reason, it will be assumed that $\mathrm{Hg}$ and $\mathrm{HF}$ concentrations will be monitored but not controlled.

Power plant performance measurements will be needed during future developmental and demonstration programs. Therefore analytical instrumentation for such plants will be required. For all coal fired power plants, and fuel cell plants in particular, there exists a definite need for process analyzers capable of measuring trace concentrations of a wide range of species.

These should be microprocessor controlled instruments capable of being connected to the integrated control system for the plant so that appropriate alarms can be incorporated into the overall plant control system. Such alarms can be easily added or deleted on the basis of normal pilot or demonstration plant operations experience and need not be called out as a requirement at this stage in the development of fuel cell technology.

The TRW report recommended that an emergency flare system be installed to protect the fuel cell in the event of gas cleanup system failure. The GE design did not include such a requirement. A flare system will exist for gasifier start-up purposes, and a computer system capable of analyzing and issuing alarms will also exist. A highly responsive $\mathrm{H}_{2} \mathrm{~S}$ monitor may be needed to initiate the flaring of contaminated fuel gas. This need will be factored into the instrument availability portion of the study, but the development of a specific control strategy should be based on a more detailed dynamic study than can be undertaken at this time.

See also note $J$.

3.5.5 Instrument Application Notes

The following notes are referenced in sectiors 3.5.1 to 3.5.4:

A - Cold Gas Cleanup Processes

Other cold gas cleanup processes may be equally suitable. A wide variety of processes available for $\mathrm{H}_{2} \mathrm{~S}$ removal have been 
discussed in section 3.3.1.1. Each vendor or engineering firm has one or more preferred proprietary processes, many of which also remove $\mathrm{CO}_{2}$. They were developed for use with natural gas feed streams.

B - Absorber Inlet and Outlet Gas Compositions (Cold Gas Cleanup)

The types of gasifiers shown in Table 2.2 may be used with a large number of low temperature gas cleanup processes. It follows that the gas composition downstream of the $\mathrm{H}_{2} \mathrm{~S}$ absorber could vary over a wide range. For the purpose of informing instrument suppliers of the gas species present, the following ranges will be assumed:

$\begin{array}{ll}\mathrm{H}_{2} & 20-35 \% \\ \mathrm{CO} & 10-55 \% \\ \mathrm{CO}_{2} & 10-20 \% \\ \mathrm{H}_{2} \mathrm{O} & 5-35 \% \\ \mathrm{H}_{2} \mathrm{~S} & 0.5-1.5 \% \quad \text { (inlet) } \\ \mathrm{COS} & 0.001-0.05 \% \text { (inlet) } \\ \mathrm{H}_{2} \mathrm{~S}+\mathrm{COS} & 0-5000 \mathrm{ppm} \text { (outlet) }\end{array}$

The sulfur compounds likely to be present in the gas stream are primarily $\mathrm{H}_{2} \mathrm{~S}$ and $\mathrm{COS}$, but $\mathrm{CS}_{2}$ and mercaptans may be present. Either the major component $\left(\mathrm{H}_{2} \mathrm{~S}\right)$ or total sulfur may be measured.

C - Absorber Outlet Gas Composition (Hot Gas Cleanup)

Composition information was not available for all gas cleanup process streams. Where absorber or polisher outlet stream compositions have not been reported, it has been assumed that the outlet composition is the same as the inlet composition except for the species absorbed which are listed under "components."

D - Operational Requirement Trends

To an increasing extent, microprocessor-based analyzers are being used to monitor and control more operating parameters. For example, they are being used to perform automatic calibrations, implement better diagnostics and thereby achieve higher reliabilities. Improved reliability and freedom from analytical instrumentation maintenance will contribute to the acceptance of chemical processes by the electric utilities, and this objective should be factored into the assessment.

E - Research Instrumentation and Data Acquisition

A research or data acquisition need can of ten be defined in terms of a specific research objective: for example, the 
validation of a specific performance model or scale-up correlation. In other situations (as may be the case for a demonstration plant), there may exist a need to close all energy and mass balances to demonstrate performance or to provide good data for analysis work to be initiated later. Frequently, such research needs require the use of more sophisticated analytical instrumentation than can be justified on an economic basis for process control purposes. However, having made such an investment, the more expensive instrument would probably be used for process control purposes depending upon instrument response time, communications protocol, and availability for process control purposes.

Most of the advanced coal conversion processes and gas cleanup systems will advance through a demonstration phase for which research instrumentation must be available. This is an important phase and is one which will be needed for selection or development of instruments and control strategies for commercial application.

In order to arrive at availability estimates for such instruments, the instrument 1 ists contained in this section (which are oriented to operation needs) will also be used to investigate the availability of instruments with enhanced accuracies, selectivities and other capabilities needed for research purposes. These selections will be made on the basis of engineering judgement and vendor recommendations.

\section{F - Hot Gas Cleanup Processes}

From a process control point of view, the hot gas cleanup processes considered in this study are similar. Ideally, the control system should have the capability to monitor the progress of an S-shaped concentration profile through a stationary bed, and measure sulfur breakthrough which does not occur suddenly. In contrast to a cold gas cleanup system, load-following requirements are easily satisfied because the sulfur sorption capacity of the bed depends upon the integrated sulfur flow rate rather than on the dynamic response of the system to change in that rate.

\section{G - High Temperatures and Pressures}

The temperatures and pressures 1 isted are those in the gas stream. Their listing does not imply that a sensor must be found which will operate under these conditions. In most cases a sampling system will be required which will be capable of cooling and conditioning the gas stream using a suitable sampling lonp. In situations where an in situ instrument may also exist, the in situ and sampling loop approaches should be evaluated on an economic basis.

H - Particulate Loading Measurements

At this location, an on-line instrument is needed to monitor dust loadings and (if possible) particle size distributions. This should be an inexpensive and easy-to-maintain instrument. on-line instruments are available for research purposes, but 
they are expensive and not well suited for operational use. off-line approaches are available which require the manual manipulation of filters or cascade impactors, but these methods are troublesome to use and maintain.

\section{J - Effluents}

Coal is a heterogeneous mixture of many minerals. As a result many of its constituents are contained in the effluent streams from a typical power plant. For research and environmental protection purposes it is important to have analytical methods available to measure many of these constituents accurately. Usually, on-1ine measurements are not performed due to a combination of instrument availability and economic considerations. Instead, off-line measurements are performed using plant laboratory instruments.

The availability of on-line instrumentation capable of measuring trace concentrations of multiple components should be included in the study in order to satisfy research and contaminant monitoring requirements for demonstration plants.

$\mathrm{K}$ - Integrated Control Systems

To an increasing extent, analytical instruments and their sampling systems are being integrated with overall plant control systems. In order to design such a system, it is necessary to install a hierarchical structure of control strategies. Using such an approach, instrument needs emerge as a result of the top-down design activity involved. In the past there has been a tendency for instrument needs to be egtablished using a bottom-up approach. That is, the control engineer is presented with a completed design at the 1 nwer level and is expected to develop a control scheme for the overall system. This approach should be avoided.

L - Temperature, Pressure, Level and Solids Flow Rate Measurements

A number of on-going instrument needs exist for processes which operate at high temperatures and pressures, and have gas streams with high particulate concentrations.

Given the requisite economic incentive to build an IGCC or PFBC power plant, it is unlikely that instrumentation availability alone would have much impact on the build or no-build decision. Nevertheless, measurements in the instrumentation areas referenced above have proven sufficiently troublesome during past coal conversion process test programs that they should be included in this assessment. Improved measurement systems in these areas are needed to efficiently control all of the hot gas cleanup processes covered in this assessment.

\section{M - Load-Following Considerations (Cold Gas Cleanup)}

The instrumentation needed for a typical gas/liquid absorber is shown in Figure 3.6. Although the purpose of the absorber is to remove $\mathrm{H}_{2} \mathrm{~S}$, the load-following capability of the system 
does not depend upon the responsiveness of the $\mathrm{H}_{2} \mathrm{~S}$ analyzer, but rather on the lean solution flow control system and the liquid holdup in the absorber. An analytical instrument on the outlet gas stream is highly desirable, but is not of critical importance from a purely operational point of view because the power plant can continue to operate during periods during which $\mathrm{H}_{2} \mathrm{~S}$ measurements may not be available.

N - Regeneration

For some of the hot gas cleanup processes, there exists the possibility that the bed temperature may exceed the maximum allowable temperature for the absorbent. Bed temperature control is not expected to necessitate any instrumentation beyond that which is commercially available, nevertheless, there exists a need. for improvement as mentioned in note $\mathrm{L}$.

\section{P - Fluidized Bed Cleanup Processes}

The analytical instrumentation needed for use with fluidized bed absorbers and regenerators can be the same as that used with fixed bed units, except that a more sophisticated sampling loop and gas conditioning system will be required. Fluidized bed combustion and gasification experience can be applied, but improved gas conditioning systems and/or improved in situ analytical methods are needed in all areas.

Q - Alkali Metal Monitor

There is a need for an on-line monitor to measure total sodium and total potassium for PFBC and other power systems where gas turbines must be protected against alkali attack. Previous attempts to satisfy this need have resulted in equipment which is too expensive and too sophisticated for use in a typical power plant environment.

\section{R - Process Optimization}

Optimizing control is becoming cost-effective as a means of minimizing the cost of electricity. In order to produce a vialle optimisation result it is usually necessary to develop a simple representation (an on-line mathematical model) of the process. If such a model were implemented for hot gas cleanup, then it is probable that some process control. benefits would follow. For example, using this approach, it would be possible to infer temperatures and compositions throughout the length of a fixed bed absorber on the basis of measurements obtained for previous absorption/regeneration cycles, and in this way avoid problems due to temporary failure or lack of responsiveness (if any) of the analytical instruments or their sampling systems.

S - PFBC Particulate Removal.

The particle size distribution from a typical PFB combustor is such that approximately $90 \%$ of the material is less than 250 micrometers in diameter and $10 \%$ of the material below 
10 microns. A typical cyclone inlet loading is $5-10 \mathrm{gr} / \mathrm{scf}$ and a typical outlet loading less than $1 \mathrm{gr} / \mathrm{scf}$.

Many previously proposed PFB plants have employed fine particle removal devices downstream of the gas turbine, but most future designs will employ a hot gas cleanup device upstream of the turbine. In order to meet NSPS requirements the particulate loading at the stack must be less than approximately $0.015 \mathrm{gr} / \mathrm{scf}$.

T - For the purpose of this study, a single parameter analyzer was specified at most process flow diagram locations. Measurement of more than one component may be preferred, in which case a multi-parameter or general purpose instrument may be installed.

In some cases, different process flow diagram locations have been specified even though they all correspond to one physical location. In such cases, it has been assumed that a microprocessor-controlled multi-parameter instrument would be provided. The feasibility of this assumption will have to be checked out on an application-by-application basis. The alternative would be to use a general purpose instrument such as a gas chromatograph.

3.6.1 Introduction

In general, excluding economic considerations, it is preferable to eliminate all sampling systems by locating appropriate analyzers directly in process streams. Such in situ designs are becoming increasingly available, and it is an important objective of this study to evaluate all applicable in situ designs that may exist or may be available in the near future. This study deals with high efficiency power generation systems and coal-derived gas streams. High efficiency systems require high temperatures and pressures, and coal-derived gas streams contain not only dust, but possibly condensable liquids including water, hydrocarbon oils, viscous tars and alkali compounds. It follows that a sampling system should be included as a competitive option for most IGCC, PFBC and MCFC gas stream analysis applications.

Once a sample has been taken and properly conditioned, compositional analysis can of ten be done with standard equipment such as individual component analyzers, gas chromatographs or mass spectrometers. Although there may exist a preferable solution, the standard instrument/sampling system combination should be evaluated first in order to generate a base-case approach against which all potentially preferable analytical systems can be compared.

\subsubsection{Typical Sampling System Components}

It is not possible to specify a sampling system which can be used for all applications. The important components needed for a typical sampling system may be selected from those shown in 
Figure 3.7, but not all of the components shown will be required for use with a given analyzer.

This discussion has been 1 imited to sampling systems used for gas streams. Most of the gas composition analysis systems presently in use involve sampling, and therefore have all of the problems inherent in sampling: that is, high labor costs, uncertainty about sample integrity, and large time lags. For this reason, the most important aspect of analyzer application is very often the sampling system rather than the analyzer itself.

Usually, gas is withdrawn through a probe. When the gas sample contains particulate material, the system may need to be designed to accept gas under isokinetic conditions (that is, under such conditions that the gas velocities inside and outside of the probe tip are the same). On the other hand, depending upon the application, it may be preferable to point the probe tip downstream in order to avoid collecting particulate material.

In some applications the system must be designed to quench homogeneous gas phase reactions by cooling or expanding the gas. Also, it may be necessary to avoid introducing catalytic surfaces which may support heterogeneous reactions. In other applications, quenching must be avoided by keeping the probe and part of the sampling system hot. It is not possible to specify a sampling system which can be used for all applications. It is possible to indicate some of the most common features found in gas sampling systems, and this is the purpose of Figure 3.7 .

A first cut at designing a sampling system can usually be made by selecting appropriate materials of construction for a given application, selecting the important components from figure 3.7, and by adding any additional instrumentation needed for operational and purging purposes.

The bypass shown in Figure 3.7 is often needed in order to maintain a high sample transport velocity so that transportation 1 ag can be minimized. Some form of filtration system is invariably needed, but cyclone separators are not always required. Cyclones are needed, for example, at the inlet to the particulate removal device for a PFBC power system, but are not practical at the outlet due to the low outlet dust loading.

In Section 3.5 analytical needs were established in preliminary form and, where appropriate, reference was made to this section for further information on the sampling system needs. In Section 3.7, information was included to indicate the extent to which current clean up system designs successfully use sampling systems and standard instruments.

Much of the supporting instrumentation has not been shown in Figure 3.7. It is necessary, for example, to purge and leak test most sampling systems quite frequently. These additional components and the necessary maintenance procedures add significantly to the cost of the sampling system/standard instrument approach, and this is one reason why in situ analyzers are preferred if they are practical and available. In order to estimate the relative merit of the newer analytical approaches 

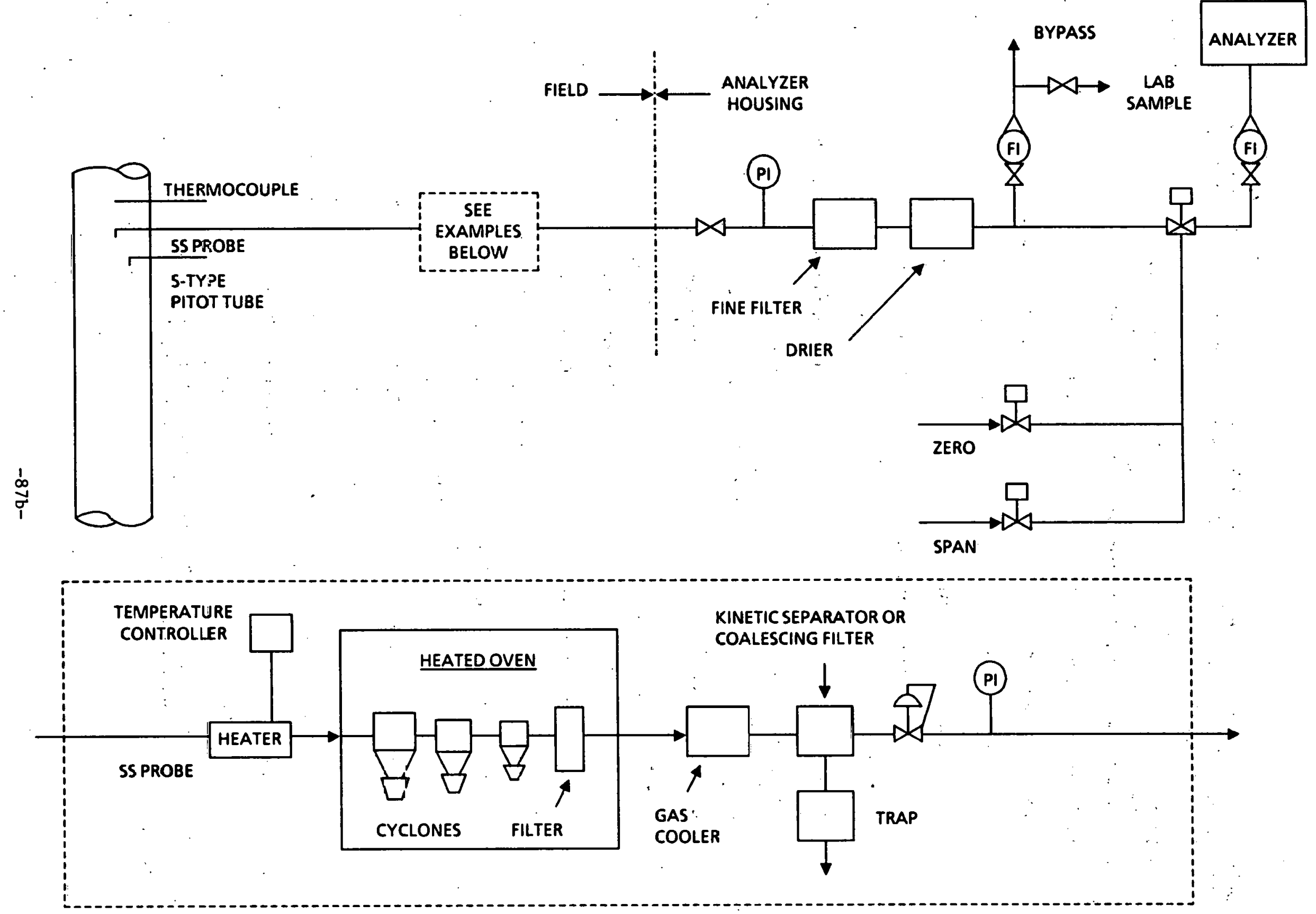

FIGURE 3.7 SOME TYPICAL SAMPLING SYSTEM COMPONENTS 
which are available or under development, it was decided to use the sampling system/standard instrument approach for cost/performance comparison purposes.

The problem with documenting each sampling technique is that so many variables must be considered which change from one application to another. Some of these variables are listed below.

- Take-off location

- Sample transport

- Single-1ine

- Bypass (no return)

- Bypass (with return)

- Hashing

- Vaporizing

- Heating

- Cooling

- Back flushing

- Filtration

$$
\begin{array}{ll}
-\quad \text { Cyclone } \\
\text { - } \quad \text { Filter cartridge } \\
\text { - Coalescer. } \\
\text { - Selective permeation }
\end{array}
$$

- Chemical Treatment

$$
\text { - numerous types }
$$

- Maintenance

- Type of operation

- Manual

- Automatic
- Pumps

- Temperature controls

- Control valves

- Sensors

- Temperature

- Pressure

- Differential pressure

- Blow

- Contamination by:

- Permeation

- Diffusion

- Adsorption

- Desorption

- Water vapor content

- Desiccation

- Multi-stream switching

- Purging

- $\quad$ Testing

- Calibration

- Sample disposal

- Enclosure design

A manual of guidelines for building sampling systems could and should be developed, but the level of effort involved was tou great to be included in this study. 


\subsubsection{Introduction}

Gas/liquid cleanup systems are typical of many chemical processes in that they are controlled by measuring and manipulating temperature, pressure, position (e.g., level) and flow. Similar variables are used to control gas/solid systems when the solid phase flows through the unit. The solid phase is usually in the form of a packed bed, and regeneration cycle time is employed instead of a solids flow rate. Gas/liquid and gas/solid systems are frequently monitored by measuring chemical composition.

The term "monitoring" requires further discussion. Usually, gas eleanup systems are designed to operate at a specific full load, and can be turned down when necessary to perform satisfactorily under part load conditions. Such load changes are often accommodated by making changes to the liquid flow rate (in the case of gas/liquid systems) or to the cycle time (in the case of gas/solid systems). When a power plant is operating at its design conditions (either part or full load), composition analyses are usually not critically important unless they are needed for closed loop control (as opposed to adjustment) purposes. Also, since the plant was designed to go from full to part load in a specified time, the parameters which determine its dynamic performance are usually known; however, it cannot be guaranteed that the predicted behavior will be followed over the life of the process or even for a few hours; therefore, periodically, the operator (or a supervising computer system) must note the composition of each important stream so that steps can be taken to change some of the process variables as necessary. In this report, the term "monitoring" has been used in the above sense.

When process analyzers are used for monitoring purposes, it is difficult to specify upper and lower limits for response time. Although the dynamic response of the cleanup system may be known and may be less than (say) one minute, the dynamic response for the analyzer can be much larger. For hot or cold gas cleanup applications, a two minute response time may be preferable (ignoring economic considerations), but a ten minute response time (or longer) may be quite acceptable.

It has been well established that sampling systems account for most analyzer system problems, and that they can only be developed on an application-by-application basis. For this reason, a general section on sampling systems (Section 3.6) was included in this report in preparation for soliciting user and vendor input information on sampling systems experience as part of the ingtrumentation needs study.

\subsubsection{Operational Experience}

Some actual user/vendor experiences are documented below:

Great Plains Coal Gasification Project, Beulah, MD

Instrumentation and control in the Rectisol Unit is extensive and elaborace. The basic philosophy is that the gas flow to the unit 
is pressure-controlled and the methanol circulation is controlled by a combination of level control and flow control. Both absorption and regeneration require strict temperature control.

The Rectisol Unit is guaranteed to deliver a clean gas with less than a $0.2 \mathrm{ppm}$ of total residual sulfur. The product gas stream is frequently analyzed and the results monitored. In addition to the product gas, a number of other streams are analyzed. The purpose of the analysis of these sidestreams is to monitor their composition thereby alerting the operators in case equilibrium conditions are upset and equilibrium distributions changed.

Several non-dispersive infrared instruments are used to measure $C O$, $\mathrm{CO}_{2}$ and methane in the raw and mixed gas streams. Thermal conductivity instruments are used to measure hydrogen and a solid state instrument is used to measure $\mathrm{H}_{2} \mathrm{~S}$. Some difficulty has been experienced in measuring $\mathrm{H}_{2} \mathrm{~S}$ concentrations below $100 \mathrm{ppb}$.

In addition to the single parameter instruments mentioned above, several gas chromatographs are used some of which (depending upon the manufacturer) require high maintenance.

All samples are conditioned before analysis by cooling, cleaning and pressure reduction. The problems of obtaining analyses have been directly a function of the ability to sample and condition the various gas streams.

\section{KRW Gasification And Hot Gas Cleanup Project, Madison, PA}

The METC hot gas cleanup method is being tested at the KRW Energy Systems, Inc. process development unit facility. This is a research and development unit which gasifies approximately one ton of coal per hour.

The major process control functions include pressure, temperature, flow and level control. Differential pressure measurements and blowback cycle time control are used for the sintered metal filter unit.

Process gas chromatographs which use thermal conductivity and flame photometric detectors, are employed to perform gas composition analyses along the centerline and at the wall of the absorber. In addition, $\mathrm{H}_{2} \mathrm{~S}$ is monitored at the inlet and outlet of the desulfurizer vessel and this measurement is used as an indication that the sulfur absorption cycle is nearing completion. The gas chromatographs use different detectors depending upon the sensitivity and selectivity required for a given application. The species measured are $\mathrm{CO}, \mathrm{CO}_{2}, \mathrm{H}_{2}, \mathrm{~N}_{2}, \mathrm{CH}_{4}, \mathrm{H}_{2} \mathrm{O}, \mathrm{H}_{2} \mathrm{~S}, \mathrm{CO}_{2}$, and $\mathrm{COS}$. One gas chromatographs used to measure ammonia and two single parameter stack gas analyzers are used to measure $\mathrm{O}_{2}$ and $\mathrm{SO}_{2}$.

A mass spectrometer has been purchased recently but no information was available on its applicability.

The gas chromatograph analysis times vary from five to ten minutes per gas stream. 
Analyzer maintenance experience at the facility has been typical. The single parameter stack gas analyzers present few maintenance problems whereas the gas chromatographs require considerable rout ine maintenance.

All is Chalmers Kilngas Proiect, Milwaukee, WI

The Kilngas process is in the demonstration stage. Both process and plant laboratory analyses are performed using gas chromatography and mass spectrometry techniques. A calorimeter is also used. The instruments function in a satisfactory manner, but strict routine maintenance and calibration is essential.

The sampling systems are all housed in a controlled sampling building, and each sampling system was purchased as a package from a sampling system vendor. Extensive modification of these systems was necessary: not because of any vendor problems, but simply because the majority of sampling systems for coal conversion process environments have to be custom-tailored for each application. In particular, the hot gas sampling systems have to be frequently backflushed and purged with steam and nitrogen in order to avoid tar and particulate buildup in the sample lines.

\subsubsection{Conclusions}

The review outlined above was initiated in an attempt to confirm instrumentation requirements in terms of response time. It was established that instruments needed for gas cleanup systems can be divided into two categories; those needed for measuring temperature, pressure, position and flow, and those needed for measuring composition. Further, it was established that the former instruments (which are largely available) strongly impact cleanup system response time, whereas the latter instruments (which are always in need of further development) are usually needed for applications where responsiveness is not a major factor. The analysis also confirmed that measurement systems comprise analyzers and sampling systems, and that it is the sampling systems which are responsible for most of measurement systems problems.

\subsection{PLANT LABORATORY INSTRUMENTATION}

\subsubsection{Introduction}

The plant laboratory is primarily a quality control laboratory. As such, it contains all of the off-line instruments needed to determine whether the products and raw materials meet their specifications, and whether.all the waste streams meet the criteria set by the applicable local, federal, and state regulations. In the case of pilot or demonstration plant facilities, the laboratory also contains the instruments needed to satisfy the research and developinent ubjectives of the project. The planc laboratory can be regarded as a separate technical and organizational entity from that needed to handle operational instrumentation and control problems. It is staffed by analytical chemists and laboratory technicians, whereas the instrumentation and control department is staffed by instrument and control engineers and instrument technicians. Although it is feasible and sometimes necessary to transmit information from the plant sensors to the laboratory, many 
of the laboratory analyses are initiated by taking samples manually. The laboratory usually contains a variety of analytical instruments such as those shown in Table 3.11 , and it usually plays an important role in contaminant monitoring.

This study has focused on instrument and control engineering, but some study of plant laboratory instruments has been essential. These instruments have been described in general terms in this section, and a corresponding section was generated during the instrument availabilities phase of the study which discusses the extent to which the necessary laboratory instruments were commercially available or under development. In practice, an analytical chemist selects the type of instruments which are required in a plant laboratory, and this selection process reflects the problems and needs associated with the plant under consideration and its geographic location.

3.8.2 Power Plant Problems

Since late 1971, when the EPA revised the new source performance ybaindards to include power $\mathrm{plants,}$ there has been a change in the role that chemical technology must play in the day-to-day operation of a power plant. This trend, which is not always well received by the utility industry, is one which is likely to continue as the more advanced systems become available.

Much relevant plant laboratory experience has been accumulated in other industries which deal with highly contaminated gas streams. The petroleum and petrochemicals, coal and coke, iron and steel, lime, cement, glass and gypsum industries, for example, have accumulated much experience which can be applied to coal conversion process monitoring problems. Most plant laboratories contain general purpose instruments. Primarily they are used to implement analytical procedures which have become accepted as standard methods; however, in spite of this experience and standardization, problems exist in many of these industries due to the difficulties which are frequently encountered in handling mulliphase gas and liquid streams. For the power plants covered under this study, the problems will be especially severe for the Lurgi-based systems which generate significant quantities of condensible compounds, hydrocarbon vapors and particulate matter. This was a factor which was considered when the Lurgi gasifier was selected for the base case IGCC system. It was decided that a useful range of instrumentation needs would be covered by selecting a worst case situation.

In the area of quality control, the recovery and analysis of extractable and purgeable organics and trace element analyses are areas of concern, and many species must be detected at levels below or near the procedural detection limits. As a result, instrumentation improvements are continually being sought. These instrumentation problems are usually not problems in the sense that they will impact power system commercialization. Rather, they are problems that cause mainlenance difficultics which need to be minimized by suitable research--such as the development of in situ methods which require no sampling systems, or by a continuing emphasis on instrument and sampling system automation. 
To a large extent, the methods used in a typical plant laboratory will be selected on the basis of the many environmental, public health and other standards which have been established, and are described in documents such as the following:

Environmental Monitoring Reference Manual for Synthetic Fuels Facilities, EPA-600/8-83-027, July 1983

Code of Federal Regulations

NIOSH Manual of Analytical Methods, U.S. Department of Health, Education and Welfare

American Public Health Association Standard Methods for the Examination of Waste and Wastewater

American Society for Testing and Materials, Annual book of Standards. Parts 26 and 31

U.S. Envi ronmental Protection Agency Methods for Chemical Analyses of Water and Wastes

Federal Register

Test Methods for Evaluation of Solid Waste, 7 U.S. EPA, 1982, Sampling and Analyses Methods for Hazardous Waste Incineration, U.S. EPA, February 1982.

The standard methods described in these documents largely establish the environmental, health and safety instrumentation needs for the facility. A selection of appropriate methods is made at the time that the power plant is designed. This selection is based on many coal, process and site-specific factors.

The analytical objective for the plant laboratory will vary considerably according to the type of need (operational or research). For operational purposes, it is probably that a small laboratory will be selected, and that emphasis will be placed on satisfying regulatory requirements. On the other hand, for pilot and demonstration plant activities, ic is anticipated that a variety of instruments will be needed to satisfy specific research requirements or to ensure that all energy and mass balances are closed to the maximum extent possible.

Some typical process streams are listed in Table 3.12. The major gas stream species are usually monitored using gas chromatographs with thermal conductivity detectors. Flame ionization photometric detectors are also used, particularly for determining the sulfur species. Volatile hydrocarbon determinations are of ten made using an adsorption train followed by extraction and GC-MS analysis. 
Trace element analyses are usually conducted on aqueous and organic concentrates. Atomic absorption spectrophotometry can be used for some trace elements and inductively coupled argon plasma emission spectrometry for others.

Solid samples are usually analyzed for the usual proximate and ultimate analysis species, sulfur species, extractable organics and trace elements.

Some infrequent measurements (such as corrosion and erosion measurements on in-bed heat exchanger tubes, refractory materials, hot gas valves and turbine blades) could be performed by an outside service organization as could other measurements requiring the use of unusual or costly instruments.

The necessary on-line process analyzers have been discussed in Section 3.5. Most contaminant level measurements need not be made on-line by the instrument and control system. Rather, they are made off-ine in the plent laboratory using general purpose instruments such as those listed in Table 3.11 .

Some typical process streams are shown in Table 3.12. For a given power plant, many standard methods could be implemented using the Table 3.11 instruments. This instrument selection process is usually carried out by an expert or team of experts having experience in matching plant laboratory needs with the instruments available and/or by discussing the functional requirements for the laboratory with system vendors.

No major problems should be encountered in selecting appropriate quality and environmental control instruments for a specific power plant. However, it is probable that some sampling system, detection limit and cost constraint problems would emerge.

During Tasks 3 and 4, some of the more important existing and encrging plant laboratory measurement rechniques were evaluated relative to their potential for monitoring the performance of present and future gas cleanup systems for IGCC, PFBC and MCFC Power Systems. 
Table 3.11 Common Plant Laboratory Instruments

Gas Chromatography/Thermal Conductivity Detection (GC-TCD)

Gas Chromatography/Flame Ionization Detection (GC-FID)

Gas Chromatography/Electron Capture Detection (GC-ECD)

Gas Chromatography/Flame Photometric Detection (GC-FPD)

Extraction/GC-FID

Thermal Desorption/GC-FID

Gas Chromatography/Mass Spectrometry (GC-MS)

Extraction/GC-MS

Ion Chromatography

Specific. Ion Electrode

Atomic Absorption

Flameless Atomic Absorption

Atomic Emission Spectroscopy

High Performance Liquid Chromatography

$\mathrm{X}$-Ray Fluorescence

Infrared

Colorimetric

Electrometric

$X$-Ray Diffraction

Table 3.12 Primary Process Streams Monitored

Gas

Liquid

Solid

Raw Fuel Gas

Desulfurized Gas

Sulfur Removal off-Gas

Gas to Incinerator

Incinerator Products

Baghouse Emissions

Holding Tank Vents

Pond Emissions

Ambient Air
Sulfur Removal Condensates Cooling Tower Water

Raw Hater

Water with Slag

Evaporation Ponds
Sulfur

Coal Feed

Filter Cakes

Spent Catalysts

siag 


\subsection{TASK 3 - INSTRUMENTATION AVAILABILITIES \\ 4.1 CHARACTERIZATION OF INSTRUMENTATION AVAILABILITIES}

The requirements and constraints for the power system and cleanup systems under consideration were discussed in Sections 2 and 3. The purpose of Task 3 was to characterize and select the instruments which were available for satisfying the identified requirements.

First, the requirements 1 isted in Section 3 were divided into two groups--system requirements and user requirements. The system requirements were primary component, range, accuracy and response time. The user requirements were operational needs, research needs and two levels of environmental needs. Next, some system constraints and uger constraints were added. The system constraints considered were temperature, pressure, other components to be measured, and any interfering components. The user constraints considered were cost, reliability, maintainability and communications compatibility. Finally, the available instruments were categorized as follows:

\section{In Situ Measurements}

Most instruments which are manufactured for in situ applications use optical techniques. In particular, the absorption of infrared or ultraviolet radiation by gases has been useful for the in situ measurement of gas compositions. Today's infrared and ultraviolet analyzers have benefited significantly from recent improvements in radiation source assemblies, optical filters and solid state photodetectors. Many of the in situ optical analyzers use a split architecture construction such that the source assembly resides in an enclosure which is separate from the detector assembly. This architecture permits the sample cell to be located so that the optics and electronics can be protected from potentially harsh envi ronments.

For the purpose of this study, instruments of this type have been characterized as in situ instruments even though gas cleanup temperature and/or pressure considerations may prevent the commercial instrument from being used in the in situ mode for a particular application. That is, the term in situ has been used to characterize any split architecture instrument advertized for in situ use.

The question of whether or not an available in situ instrument could satisfy the gas cleanup system requirements and constraints was addressed during the execution of lask 4. Even though an instrument may be advertized as being of the in situ type, it is sometimes necessary to use that instrument with some kind of gas conditioning system. 
Extractive Systems

Today, there is a growing tendency for analyzer manufacturers to market integrated analyzer systems. Such a system consists of an analyzer integrated with an appropriate sampling system.

Until recently, analyzer manufacturers were reluctant to solve sampling problems. Fortunately, users were capable of building and maintaining their own systems because the earlier analyzers and sampling systems were manufacturered using readily available and easily understood switches, valves, relays and analog logic elements. Today, this is no longer the case. Most analyzers and sampling systems are integrated with microprocessors to such an extent that they can not easily be serviced in the traditional manner. Many plant managers prefer this trend and are insisting upon maintenance-free vendor-serviced systems which have built-in diagnostics capabilities.

For the purpose of this study, any system which requires a user designed sampling system or includes a vendor-supplied sampling system, will also be designated as an extractive system.

\section{Single Parameter Measurements}

Many analyzers in industrial use operate in the UV, visible, or near IR regions. To measure more than one component, more wave lengths are employed and the various optical and detector systems are changed automatically. Frequently, essentially the same instrument can be purchased to measure only one component.

For the purpose of this study, where only one component has been specified in the availabilities table, the instrument has been characterized as a single parameter type even though the manufacturer may be able to provide a multi-parameter capability if requested to do so.

\section{Multi-Parameter Measurements}

As indicated under the heading of single parameter measurements, many analyzers are modular in that they can be purchased with additional optical or other subsystems which can be selected automatically under microprocessor control. In this study, such an analyzer has been characterized as being of the multi-parameter type.

The term multi-parameter has not been used to describe an instrument such as a gas chromatograph, which is normally used to measure more than one component.

\section{General Purpose Instruments}

General purpose on-stream analyzers can take many forms, and are frequently based on their plant laboratory counterparts. Chromatographs are the most widely used general purpose on-stream instruments. They are capable of analyzing one or more streams for numerous individual components and they usually have response times in the range of 1 to 20 minutes. Mass spectrometers are comparable 
to gas chromatographs in terms of general usefulness. They are faster but more expensive than chromatographs.

A general purpose instrument will be considered to be a chromatograph or mass spectrometer or other general purpose instrument capable of serving essentially the same purpose as one or both of these instruments.

Sampling systems were introduced in Section 3.6. Since very few sampling systems are alike (other than for identical applications), it has not been possible to characterize them or to generate detailed guidelines for building them. For pressurized fluidized bed combustion, gasification and hot gas cleanup applications, it is necessary to develop each sampling system over the same period of time that the pilot or demonstration plant studies are performed.

In general, sampling systems perform very poorly and are responsible for up to $95 \%$ of all analyzer prnblems. It is probable that the current trend toward highly automated and vendor-supplied systems will continue where a sufficient demand exists. However, for advanced coal conversion applications, the first sampling systems will have to be developed by the user or by sampling system consultants. Some analyzer manufacturer's have developed gas conditioning systems which are suitable for some applications. These systems can frequently be used to build an initial system which can then be further modified on the basis of experience.

Some vendors of special sample system components such as filters and probes can be very helpful in making sample system design recommendations.

\subsection{IDENTIFICATION OF AVAILABLE PROCESS ANALYZERS}

At the time that the TRW study 22 was performed, there were tewer single and multi-parameter optical instrumencs un Llie maiket, and the general purpose instruments (for example, the process gas chromatographs) had not been integrated with reliable low cost microprocessors. Also, fewer listings of process analyzers had been published.

Today, process analyzer usage trends are better established and documented. For gas stream applications, gas chromatographs are used primarily for set point adjustment, quality control and process optimization purposes, whereas the optical instruments are used primarily for closed loop control.

In 1979, the EPA published performance standards for new electric-utility steam generators that addressed the question of emissions limits for units capable of firing more than 250 million $\mathrm{Btu} / \mathrm{hr}$ of fossil fuel. As a result of this EPA continuous emissions program, the analyzer business expanded and analyzer technology improved. Numerous nondispersive infrared analyzers are available for measuring $\mathrm{CO}$ and $\mathrm{CO}_{2}$, pulsed fluoresence analyzers for measuring $\mathrm{SO}_{2}$, and chemiluminescence analyzers for the measurements of $\mathrm{NO} / \mathrm{NO}_{\mathrm{X}}$. Although these analyzers have been 
designed for a stack gas monitoring, the technological advances associated with their widespread introduction have led to significant improvements in reliability, accuracy, and maintenance for all applications.

For this study, the method used to identify appropriate analyzers was based on the characterization scheme described in Section 4.1, and the requirements identified in Section 3.5. The procedure, which is out lined in Figure 4-1, was used to generate a preliminary set of instrument availabilities. This procedure should be used iteratively on an application-by-application basis, but it was beyond the scope of this study to perform all of the iterations for all of the instrumentation requirements for all three power systems. The primary objective here was to perform a sufficient number of iterations to permit the assessment study to proceed, and to identify any instrumentation deficiencies for gas stream cleanup applications.

No commercially proven in situ instruments could be identified which were capable of being employed at the high temperatures and pressures used for the hot gas cleanup applications. Most available in situ instruments can not be used for gas streams hotter than $700^{\circ} \mathrm{F}$; consequently, it was assumed that the commercially available instruments would have to be used with gas conditioning systems.

It was decided to select a single parameter optical or probe type instrument as a first choice in order to minimize capital cost, maintenance, and response time. For many of the hot gas cleanup applications, $\mathrm{H}_{2} \mathrm{~S}$ was selected as the primary component of interest, and it was assumed that this measurement alone could be used to implement the sulfur absorption strategies described in Section 3.4. Similarly, the components listed in section 3.5 were used to select appropriate single or multi-component analyzers. The selected analyzers are shown in Table 4.1 .

A list of commercially competitive instruments and measurement methods was not included. Such a list of candidate instruments already exists which is organized by application and measurement method.41 This available list was used to help generate Table 4.1. Although Table 4.1 emphasizes the use of optical instruments, the general purpose analyzers based on chromatography and mass spectroscopy can not be ignored. Indeed, for research (e.g., demonstration and pilot plant) purposes, the use of general purpose instruments may be preferred. The general purpose instruments may also be preferred for process optimization purposes. For such applications, the advantages of gas chromatography would probably compensate for the increase in response time, but the capital and maintenance costs would also be higher.

Many instrument vendor representatives were contacted by telephone or were invited to discuss process analyzer availabilities at the Gilbert/Commonwealth, Inc. facility. However, for the purpose of documenting a representative list of instruments, it was decided to use information which would be readily available to any analyzer 
<smiles>C1CCCCC1</smiles>

System Requirements and Constraints

- Primary Component to be Measured

- Temperature

- Pressure

- Minimum Range

- Accuracy

- Response Time

- Other Components to be Measured

- Interferring Components

\section{User Requirements and Constraints}

- Operational Need

- Research Need

- Environmental Need (Current Regulations)

- Environmental Need (Possible Future Regulations)

- Capital Cost

- Operating Cost

- Reliability

- Maintainability

- Communications Compatibility

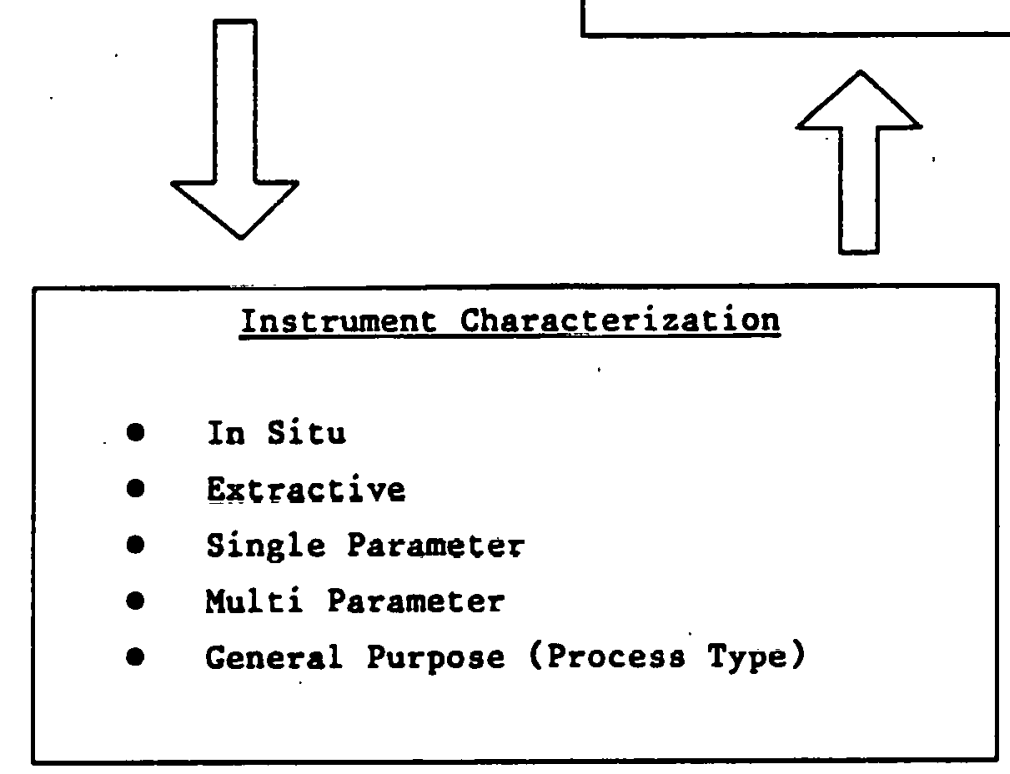

Figure 4-1 Instrumentation Selection Procedure 
Table 4-1. Summary of Process Analyzer Availabilities.

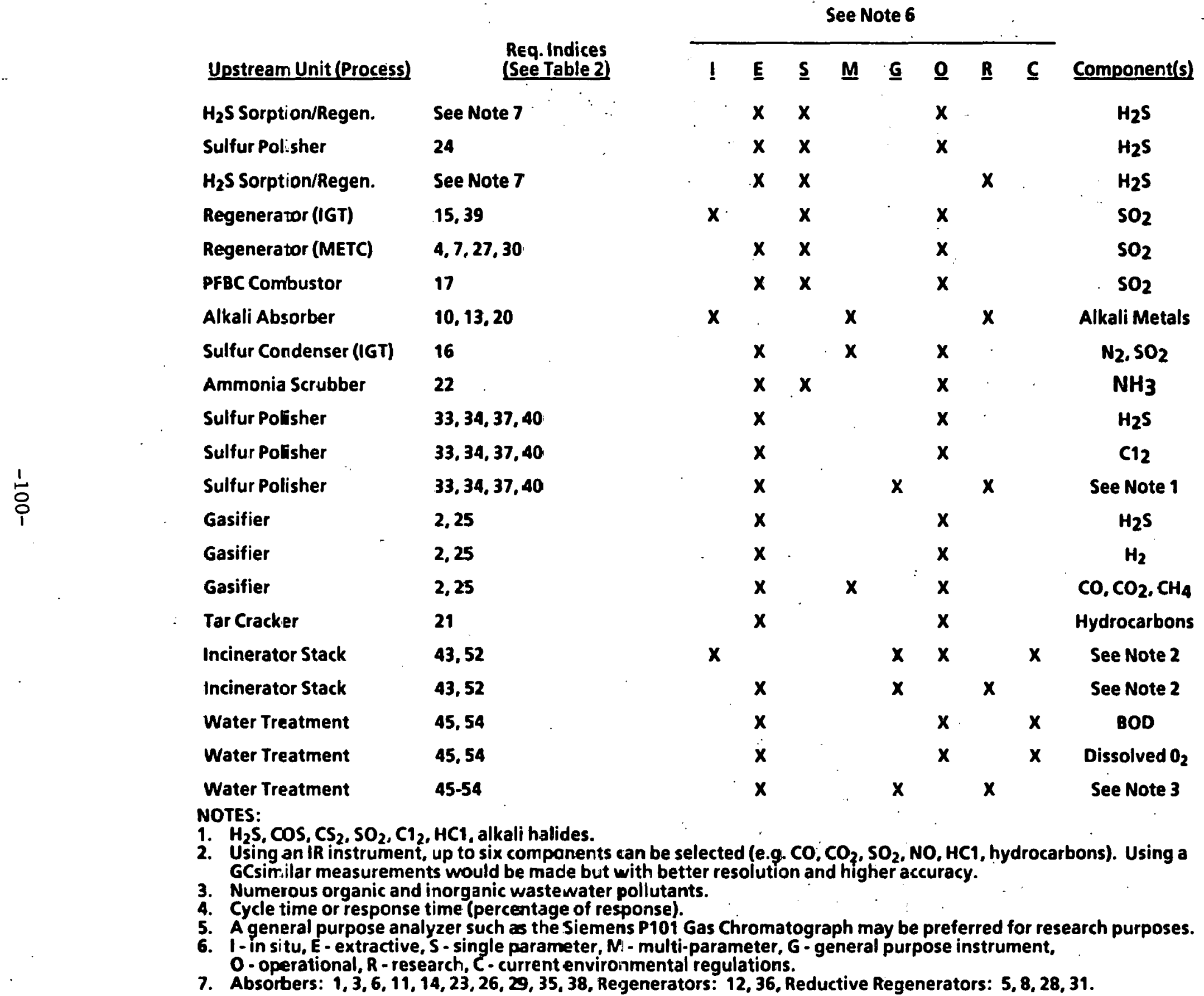


Table 4-1. Summary of Process Analyzer Availabilities (Cont'd).

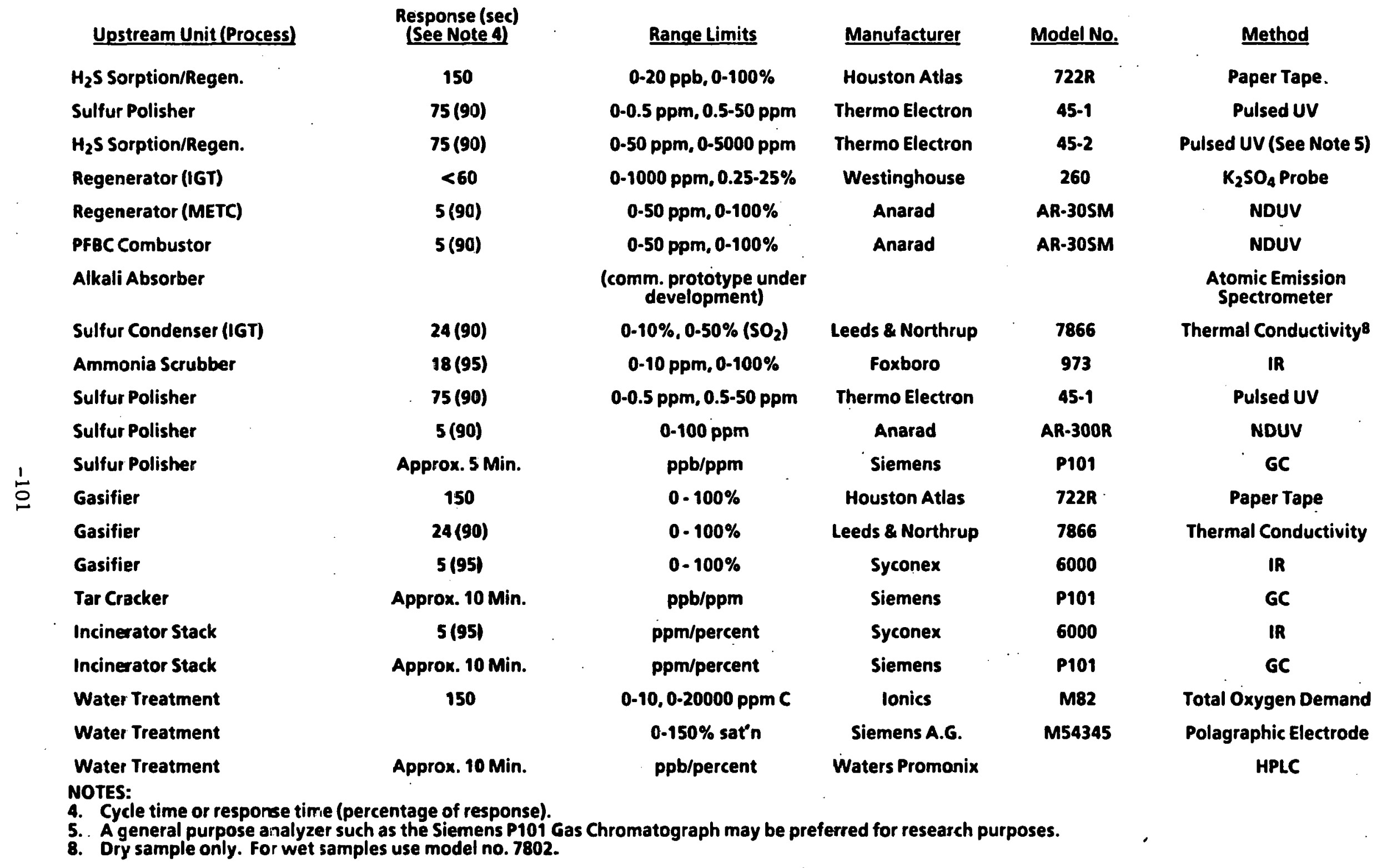


engineer. For this reason, the Anadata Process Measurement Encyclopedia 41 was used to develop Table 4.1. This table was not intended as a firm set of recommendations, but rather as an indication of commercial status.

The consensus of opinion of the various vendors surveyed was that on-stream analyzers for coal conversion system contaminant control purposes are available at present or are scheduled for early implementation. They were not able to comment on hot gas cleanup analyzer availability on the basis of experience, but they expressed confidence that analyzers with sampling systems could be provided on the basis of experience in supplying similar analyzer systems for similar applications. In contrast, published user surveys continue to indicate that many currently available analyzer systems (extractive and in situ types) are extremely difficult to maintain. Because of the uncertainties involved, all final selections should be made by soliciting inputs from several suppliers, and by evaluating those inputs in relation to the specific requirements and constraints which apply for each analyzer application.

4.4 IDENTIFICATION OF AVAILABLE LABORATORY ANALYZERS 42, 43

The analytical techniques described in this section are typical of those required for the routine analysis of coal conversion process streams. They cover the following:

- Standard Coal Analyses

- Standard Ash Analyses

- Polynuclear Aromatic Hydrocarbon Analyses

- Gas Analysis

- Particulate Analyses

- Trace Metal Analyses

- Water Analyses

For research purposes, many advanced instruments are available, but it was beyond the scope of this study to suggest solutions for research measurement problems. For routine analytical purposes, the methods described in this section are adequate, and commercial laboratory instruments are readily available to implement them.

\section{Standard Coal Analyses (ASTM)}

Ultimate Analysis - C, H, N, S, O

Proximate Analysis - Moisture, Heating Value, Ash, Fixed Carbon, Volatiles 
Sulfur - Total Sulfur; Pyritic Sulfur, Sulfates, Organic Sulfur Chlorides

Standard Ash Analysis (ASTM)

$\mathrm{SiO2}, \mathrm{Al} 203, \mathrm{Fe} 203, \mathrm{Ti02}, \mathrm{P} 205, \mathrm{CaO}, \mathrm{MgO}, \mathrm{Na} 20, \mathrm{~K}_{2} \mathrm{O}$

\section{Polynuclear Aromatic Hydrocarbon Analyses}

Temperature-programmed 1 iquid chromatography, liquid chromatography, ultraviolet, infrared, florimetry and nuclear magnetic resonance measurements are frequently used for measuring hydrocarbons in the aromatic, nitrogen, phenols and sulfur classes. Another generally applicable procedure is gas chromatography in combination with mass spectrometry.

\section{Gas Analyses}

Gas bomb and trap samples are usually analyzed using a gas chromatograph with temperature programing and various detection systems. Sulfur containing components are usually detected using a flame photometer.

\section{Particulate Analyses}

Coulter techniques, which employ an electrical sensing zone to generate particle size dependent voltage pulses, are used in many industries, and cascade impactors are frequently used in air pollution and inhalation studies. Laser-based instruments such as the Malvern 2600c or 3600Ec are widely used in food, chemicals, pigments, plastics and pharmaceutical industry laboratories, and the Malvern Master Sizer can be used to make in situ measurements at temperatures up to approximately $200^{\circ} \mathrm{F}$ and pressures up to a few atmospheres.

The analysis of airborne particulate for polynuclear aromatic hydrocarbon compounds is often carried out using gas chromatography and ultraviolet spectrometry or gas chromatography and mass spectrometry.

\section{Trace Metal Analyses}

A suitably prepared solution can be analyzed directly by atomic absorption spectroscopy for $\mathrm{Ba}, \mathrm{Be}, \mathrm{Ca}, \mathrm{Cd}, \mathrm{Cr}, \mathrm{Cu}, \mathrm{Mn}, \mathrm{Ni}, \mathrm{Pb}, \mathrm{Sr}$, and $\mathrm{Zn}$. Related analytical procedures are also available for measuring As, $\mathrm{F}, \mathrm{Hg}, \mathrm{Sb}$ and $\mathrm{Se}$.

\section{Water Analyses}

In water analysis, ion exchangers are frequently used to remove interfering ions, determine total ion content, concentrate trace quantities of cations and separate anions from cations. Many procedures depend upon matching colors, either by eye or by using a photometric instrument. Tall-form nessler tubes provide a $30 \mathrm{~cm}$ light path. They are inexpensive, their use does not require much training, they are not subject to mechanical or electrical failure 
and they are still satisfactory for much routine work. Photometric instruments are more accurate and less subject to personal bias. However, testing, maintaining and repairing such instruments requires specialized experience.

Atomic absorption spectrometry can be applied to the determination of metals in water without the need for prior concentration or extensive sample pretreatment, and flame photometry is used to determine sodium, potassium, 1 ithium, and strontium. Arc-spark emission instruments can be used to carry out trace analyses which are not easily performed by any other method. Inductively coupled plasma instruments are replacing the older arc-spark instruments and they are useful for scanning power plant wastes for various metal ions, especially where colorimetric interferences exist.

Various polarographic techniques are available for the determination of heavy metals, and amperometric titration, which is related to polarography, is suitable for determining residual chlorine, chlorine dioxide and iodine. Ion chromatography is also available for anion or cation determinations using ion exchange and conductivity, amperometric or colorimetric detectors. Several autumated continuous flow techniques are available for measuring chlorides, fluorides, ammonia, nitrates, phosphates, silica, and sulfaces.

Many titrimetric methods can be performed potentiometrically by using a pH meter or a millivolt meter with suitable electrodes. Selective ion electrodes are available for measuring ammonia, cadmium, calcium, copper, hardness, lead, potassium, silver, sodium, bromide, chloride, cyanide, fluoride, iodide, nitrate, perchlorate, and sulfide ions: Also, various commercially available probes are available for measuring dissolved oxygen.

\section{Temperature Measurement}

A promising spectroscopic thermometry technique is based on Coherent Anti-stokes Raman Spectroscopy (CARS). Essentlally, a pump laser beam at one frequency and a second beam at another are used to generate a strong resonance-based response which varies with temperature. This method is not yet suitable for operational use, but it is important because of the potential offered by CARS and related techniques for performing in situ analyses of gasifier effluent streams. Temperature can be measured simultaneously. CARS measurements are based on fundamental constants rather than on empirical calibrations; consequently, they can be used to monitor temperatures and specie concentrations at specific locations and times.

A promising commercially available approach for measuring high temperatures in hostile environments is based on the use of $f$ iber optics. For example, optical fiber sensors are available from Accufiber, Inc. They are considered to be superior in performance to thermocouples. These optical fiber sensors are now being used in ceramics, metals, combustion, glass, annealing and other 
industrial processes. However, unlike CARS, they are not capable of measuring gas phase temperatures.

\section{Gasifier Startup and Shutdown}

In general, computer-controlled startup and shutdown has resulted in plants that are safer, more responsive, and have fewer operators. Combined cycle power plants which use coal gasifiers may be troublesome to startup and shutdown. Many utility companies will not readily accept present gasifier startup and shutdown procedures because they depend heavily upon expertise in estimating conditions within the gasifier based on a few temperature, pressure and process analyzer readings and considerable operator experience. In recent years, expert system building techniques have become available which could be used to alleviate some of these problems and significantly help IGCC power plant commercialization.

\section{Incinerator Stack Monitoring}

Instruments suitable for stack gas monitoring have been greatly improved in recent years, but growing concerns about acid rain have placed renewed emphasis on controlling air pollution, particularly that coming from utility and industrial stacks. These continuing concerns will generate the need for monitoring systems which must be sensitive to much lower concentrations of contaminants. This need is addressed in Section 5.3.2.6.

\section{Bed Level Measurement}

Bed levels in fluidized beds are usually inferred from differential pressure measurements. Purged pressure taps are usually used. Although various noncontacting methods have been proposed and are still being investigated, no entirely satisfactory method is available at the present time.

\section{Mixed Phase Flow}

Coal and dolomite flow measurements can be made by supporting the coal or dolomite hopper from several load cells. The weight signal generated by the load cells is then used in conjunction with a star feeder or similar device which is employed for real time control purposes.

Various improved flow metering systems are still under development, but no satisfactory systems are commercially proven at the present time.

\section{Overall Plant Control}

In order for IGCC, PFBC, and MCFC power systems to become effective power generating units, each must have the capability to produce a desired response in a stable manner for different operating conditions.

The IGCC and PFBC plant control philosophies will be similar to the standard utility coordinated turbine-boiler control approach, but major differences will exist because of the modular nature of the 
major differences will exist because of the modular nature of the gasifier and combustor sections of the IGCC and PFBC plants.

Ideally, the desired response for the plant as a whole should be used to generate desired responses for the gasifiers or combustors and their associated cleanup systems. This information should then be used to derive response times and further define instrumentation needs.

The necessary distributed control systems are available physically, but the control logic needed to implement integrated control strategies required for ICCC and PFBC power plants is not readily available in such a form that response times can be established for gas cleanup process analyzers. Similarly, control strategies are not readily available for designing load-following MCFC systems.

\section{Effluent Water Analysis}

Effluent water analysis will be the responsibility of the plant laboratory. This subject is discussed in Section 4.4. For pilot or demonstration plant studies, it is possible that an on-stream analyzer (such as a process type high performance liquid chromatograph) would be useful.

\section{Trace Element Analysis}

In the past, trace element analysis has been the responsibility of the plant laboratory. This subject is discussed further in Sections 4.4 and 5.3.2. Due to component protection considerations, it is probable that some trace element analyzers will be required in process analyzer form. 
Prior to comparing instrument requirements with instrument availabilities, it is necessary to compare cleanup system requirements with their availabilities. Many low temperature gas cleanup processes were designed as steady state systems. That is, they were based on the assumption that all operating and environmental factors would be held constant or nearly constant. Because of this steady state emphasis it is not clear that the low temperature processes have been well-designed for power plant applications.

The instrumentation system for a power plant includes measurements that can be made easily, inexpensively and quickly (such as pressure, temperature, level, voltage, speed, and weight), and measurements (such as gas compositions) which often require less responsive instruments. Also, a responsive control loop based on the use of a process analyzer can have a high maintenance cost and an installed cost ten or more times greater than the cost of a control loop based on temperature or flow. For cost and maintenance reasons alone, there is a need to avoid using a composition measurement if an other-than-composition measurement will serve the same process control purpose.

Control strategies are usually developed during test rig or pilot scale testing activities. During this period, operational observations are accumulated which are translated into appropriate set-point adjustment experience for different input stream compositions. For some processes, the adjustments can be performed periodically but infrequently, even though the control loop being adjusted may have a small time constant. For other processes, the adjustments must be performed continually, even though the control loop may have a much larger time constant. The permissible adjustment frequency, which will determine analyzer response time, will depend on the response times of the power system components which are integrated with the cleanup systems. Therefore, the various startup, load-following and shutdown requirements for a proposed power system should be specified and used to firm-up gas cleanup system instrumentation needs.

The instrumentation availabilities sumnarized in Table 4.1 were based on a mixture of engineering judgement and analysis. The engineering judgement led to the conclusion that optical analyzers should be selected on the basis of probable load-following needs combined with cost, maintenance, and other considerations discussed in Section 3.5. Load-following studies, however, should be performed for the various power system configurations. The 1 imited dynamic analysis work which was carried out for this study indicated that the high and low temperature cleanup processes should be able to use optical analyzers or gas chromatographs.

In making this decision, much depends upon the importance of operational need relative to research need, and this ratio will change from one application to another. 
The early optical analyzers had serious limitations: radiation sources were unreliable, sample cells were difficult to replace and align, and detectors were difficult to manufacture and were not sufficiently robust for industrial environments. Also, the early optical filters were not sufficiently selective. Today's systems have evolved due to improvements in the various components. This evolution will and should continue. For typical applications, deficiencies exist, but they are primarily deficiencies in the sense that evolutionary improvements are still needed.

The optical analyzers included in Table 4.1 are primarily those listed in readily available catalogs or reviews of commercial process analyzers used for typical process control purposes. However, compositions of process streams from fossil energy conversion/utilization processes are required for environmental studies, process dynamic studies, calculation of mass balances, development of protection strategies for downstream components, component performance evaluation, and for confirmation of chemistry, kinetics and thermodynamics of the conversion processes. The temperature, pressure and mixed phase characteristics of coal conversion process gas streams are not typical, and the reasons for installing research instruments are not typical. As a result, research and development work should continue in order to develop instruments which, in the near term, are capable of satisfying research needs and in the long term, are capable of being installed in a commercial plant environment.

Sampling systems have always been troublesome. Recently, the instrument manufacturers have become interested in providing integrated analyzer systems which include sampling systems. Because of power system demand considerations, this trend may not lead to the early availability analyzer systems specifically designed for hot gas cleanup applications. Therefore, hot gas cleanup technology deficiencies will continue to exist in the sampling system area until suitable in situ measurement techniques can be developed.

A systems analysis deficiency exists in the sense that a greater emphasis should be placed on planning for gas cleanup system instrumentation needs. Contaminant control must be implemented from the lowest levels and proceed upward; however, all levels of the power plant control scheme should be designed at the same time with appropriate emphasis on load-following requirements and topdown planning.

An instrumentation needs assessment methodology does not exist which is capable of taking into consideration the difference between instrumentation needs for cleanup system process control, contaminant monitoring, research and process optimization purposes. These different needs have been neglected in previous studies. Some methodology development work should be carried out in this area. An interactive data base would be helpful which should have some built-in expert system capabilities to assist the user in selecting an appropriate process analyzer. 


\subsection{RESEARCH AND DEVELOPMENT NEEDS}

\subsubsection{Process Analyzers}

\subsubsection{Introduction}

Almost any physical property which is characteristic of a particular element or compound can be made the basis of an analytical method; however, for process control purposes, chromatography, which is based on the dynamic interaction between two immiscible phases, provides one large class of methods, and absorption of radiation in the ultraviolet, visible and infrared regions forms another. These two classes of methods have been emphasized because they are so important in gas cleanup applications.

New principles of measurement are usually developed in academic, government, or industrial research laboratories. Only after working instruments have been constructed for laboratory use have instrument manufacturers entered the picture. The laboratory instrument manufacturer contributes the engineering expertise which is appropriate for the laboratory environment. Typically, only after the laboratory instrument has been commercialized do process analyzer manufacturers step in and contribute the engineering expertise required for the process environment.

In some cases, it is necessary to proceed directly from the research stage to the development of a process instrument. This is the situation in the case of hot gas cleanup applications. There are few situations in the laboratory where it is necessary to measure gas stream compositions at $1200^{\circ} \mathrm{F}$ using an in situ technique, consequently the usual commercial incentives do not apply.

Many process analyzers are essentially electronic-based laboratory instruments which have been hardened for hot and corrosive industrial environments. Typically, laboratory instruments are sensitive and costly, but they are more difficult to maintain. Process instruments, on the other hand, should be inexpensive, robust, and easy to maintain. One of the problems in using a hardened laboratory instrument is that they frequently require almost as much attention when used in the plant as they do in the laboratory. This is because the attention required is a function of the measurement method which is essentially the same for both environments. More attention should be paid to the development of measurement methods which are developed from scratch for process analysis applications.

The single component nondispersive infrared (NDIR) instrument is an example of an analyzer which has been developed specifically for process use; however, the technique is most sensitive and selective for small molecules whose spectral line structure is best resolved under ambient conditions. The need exists to continue research and development work on in situ instruments which can be used at high temperatures. This need is addressed in Section 5.3.1.4.

To a large extent process analyzer development work for typical commercial applications is evolutionary. Deficiencies exist in the 
sense that radiation sources, optical filters, and radiation detectors are still being improved. As these improvements are adopted, they will lead to corresponding improvements in analyzer availabilities for the more important gas stream components encountered in the gas cleanup systems covered by this study. However, due to market demand considerations, it is unlikely that these evolutionary forces will provide satisfactory process analyzers for demonstration plant applications. This need is addressed in Section 5.3.2. Meanwhile, for operational purposes, sampling systems will continue to be required for many years, and it would be helpful if a set of guidelines could be developed, and made available for general use, until the necessary new instruments can be developed.

\subsubsection{Thermodynamic Considerations}

Instruments which are capable of making measurements at the conditions of the process stream are preferred by instrument engineers and research scientists alike, but the instrument engineer is often constrained, by cost, reliability and availability considerations, to solve problems differently. For example, there are many situations where gas compositions can change significantly with temperature and pressure. The $\mathrm{H}_{2} \mathrm{~S} / \mathrm{COS} / \mathrm{CO}, \mathrm{CO} / \mathrm{CO}_{2} / \mathrm{H}_{2} \mathrm{O}$ and $\mathrm{NH}_{3} / \mathrm{NO}_{\mathrm{x}}$ systems are all subject to composition changes as process conditions change due to sample conditioning or for any other reason. The instrument engineer is often constrained to use an available low temperature, low pressure analyzer; to measure temperature and pressure, and perhaps other compositions; and then compensate for shifts in equilibrium by means of appropriate non-linear function generators. This adds cost and complexity to the instrumentation and control system which further compounds the problem of high maintenance costs due to the presence of troublesome sampling systems. If possible, these additional costs and complications are avoided by using in situ analyzers which measure the concentration of the component of interest directly.

In the case of hot gas cleanup applications, this type of problem occurs quite frequently. As a result, an instrument development incentive exists which is not present in the case of the cold gas cleanup option.

\subsubsection{Sampling Systems.}

It is generally agreed that sampling and gas conditioning systems are responsible for most analyzer system problems. It is also generally agreed that they are presently necessary. In situ systems are currently not available for gas streams which are at a higher temperature than approximately $100^{\circ} \mathrm{F}$, consequently the commercially advertized in situ systems can not be used without gas conditioning.

For gas streams below $700^{\circ} \mathrm{F}$, in situ systems have replaced many extractive systems, but there is still no well-defined consensus of opinion as to which type is more reliable. In situ optical beams are frequently obscured by process dust, soot, or condensed liquids even when gas purge systems are used to keep the lenses clean. 
Although additional development work on lens cleaning systems is needed, the potential for improving analyzer system reliabilities by eliminating sampling systems is high. At the same time, some development work should be carried out on sampling systems. In particular, there exists a need for a set of guidelines which could be used to design a sampling system from scratch or to correct deficiencies in an almost satisfactory commercially available system.

One major deficiency within the analyzer engineering community is that sampling system operating costs are not researched and reported. Without this information, it is virtually impossible to compare one approach with another. For example, as indicated in the introduction to this section, the non-dispersive infrared and ultraviolet analyzers have been developed to the point that they are extremely reliable, but can not be used at high temperatures. In the absence of suitable maintenance cost information, it is impossible to choose between the following:

- Use of a well-proven, low cost, low maintenance NDIR analyzer with a low cost but high maintenance sampling system.

- Use of partially-proven, high cost, higher maintenance, laser-based analyzer without a sampling system.

In the absence of the information needed to make assessments of this nature, it will be difficult to advance any partially-proven but technically attractive analyzer system to the commercial stage.

\subsubsection{Laser-Based Systems}

At the present time, lasers are used for analytical purposes primarily for localized heating and as excitation sources in Raman and fluoresence spectroscopy. Diode lasers are tunable over the region used by laboratory infrared spectrophotometers. They have high spectral resolution and good power output, but they require complex supporting equipment and therefore have not yet been used for process work except in a few isolated cases. In general, lasers have not been used to a great extent commercially because manufacturers have not been exposed to the market incentives which are needed to promote the development of "small field of view" spectroscopic techniques. These techniques are desirable for analyzing gas streams in coal conversion pilot and demonstration plants.

Extensive laboratory studies and field tests at METC 46 have indicated that Coherent Anti-Stokes Raman Spectroscopy (CARS) and several related techniques are effective and have potential for development into useful.process analyzer systems particularly for satisfying research needs. Current DOE emphasis is on instrumentation for research purposes; however, in the instrumentation business, present research needs tend to be transformed into operational needs rather quickly. Furthermore, due to the impact of solid state and microprocessor-based electronics, electric utility companies are finding that significant improvements in overall power plant operation can be 
achieved quickly for relatively small capital investments in new instrumentation.

Extractive and in situ laser-based techniques are needed for use in demonstration plant applications. These needs are discussed in Section 5.3.2 under the heading of "Research Instrumentation."

Some of these requirements are being planned 48 and it is important that this work should continue as a means of transferring less troublesome analyzer technology to the power generation industry as quickly as possible.

As indicated in Section 5.3.2.2, it is difficult to compare in situ and extractive systems because capital and operating cost information is not readily available. In order to evaluate the more advanced laser-based techniques, studies which project commercial possibilities for these techniques should include some capital and operating cost estimates for a commercial version of the proposed instrument.

\subsubsection{Research Instrumentation}

\subsubsection{Introduction}

At the beginning of this study it was anticipated that difficulties would be encountered in correlating plant instrumentation and control objectives with research instrumentation objectives. These difficulties stem from the fact that instrument engineers and research scientists have different responsibilities and different priorities.

In order to address this situation it was decided to partition the instrumentation needs into two categories - an engineering oriented category and a research-oriented category. In the first category, operational needs and needs based on current environmental regulations were emphasised.

In the research-oriented category it was assumed that some instruments would be required to support component performance evaluation, process scale up, mass balance development and similar activities, and that others would be requited to support various environmental and gas stream characterization studies.

In 1975, when EPA first promulgated their performance specifications for $\mathrm{SO}_{2}$, $\mathrm{NO}_{x}$ and particulate emissions, some instruments were available, but they were expensive to buy, operate, and maintain. The existing EPA regulations have provided a tremendous driving force for instrument research and development work.

Based on this experience, it was assumed that future environmental regulations will play an important role in providing similar incentives for the development of future gas stream monitoring inst ruments.

Historically, analytical instrumentation developments have followed the introduction of new measurement methods (e.g., gravimetric, 
volumetric, electrical, electromagnetic techniques based on conventional energy sources, chromatographic and nuclear). new energy sources have led to the development of improved electromagnetic methods.

Given an elemental or molecular specie of interest and some gas conditions information (e.g., temperature, pressure, concentration and presence of interfering substances) it is usualiy possible for an analytical chemist to select a preferred analyzer. However, in view of the large number of species of interest in different types of coal-derived gas streams, it was not possible to follow this procedure. For contaminant characterization and toxicity assessment studies, the number of species of interest is very large. In order to suggest a generally useful instrumentation development program, it was considered advisable to concentrate on the development of one or two generally useful analytical methods capable of being used (or easily modified) to measure a large number of species of interest.

Nearly all molecules with covalent bonds show some degree of infrared absorption, and for those diatomic molecules that do not (e.g., $\mathrm{H}_{2}, \mathrm{~N}_{2}$ and $\mathrm{O}_{2}$ ) satisfactory commercial instruments are available. Also, under suitable excitation, most elements emit radiations of characteristic wave lengths. As a result, these methods can be used for many gas stream characterization studies.

In the area of hot gas cleanup, high temperatures and pressures are encountered; and, under these conditions, the more recently introduced energy sources (inductively coupled radio frequencies and lasers) are more appropriate than their more conventional predecessors.

The near term research suggestions contained in this section were based primarily on the above considerations, and the longer term suggestions were based on the need to integrate the resulting analyzers into practical instrument and control systems for power plant applications.

5.3.2.2 On-Line Elemental Analysis

Elemental analyses are most frequently performed using atomic emission techniques. In recent years it has become practical and preferable to use laser or radio frequency energy sources for excitation purposes. The laser energy is used directly, and the radio frequency energy is used to heat up an inert gas such as argon which excites the atoms contained in a sample of the substance to be analyzed.

\section{In Situ Analysis}

Laser-induced breakdown spectroscopy (LIBS) is an excellent technique for providing real-time elemental analysis of process streams. It does not require sample extraction, and is applicable to virtually every element in the periodic table. Laser-induced fluorescence (LIF) is a related technique which can enhance the sensitivity and selectivity of LIBS. 


\section{Extractive Analysis}

Inductively Coupled Plasma (ICP) technology is also a useful general purpose method for measuring multi-element trace metals in gas streams from coal gasifiers. The ICP excitation source is an electrodeless plasma usually operated at atmospheric pressure and sustained by inductive coupling to a radio frequency magnetic field.

Until recently, the ICP method has been limited to laboratory applications. Today, there is an increasing tendency to use ICP instruments as process stream monitors for trace elements. For hot gas cleanup applications it is necessary to extract the gas sample from the process stream at a high sample flow rate in order to keep the particles and the gas conditions unchanged. Also, gas streams containing high nitrogen percentages are frequently encountered in hot gas cleanup studies, and high nitrogen percentages cause plasma quenching. Previous investigations at METC have indicated that these problems can be solved by developing improved plasma torch configurations, and these results have paved the way for further advances which will include field testing activities.

\subsubsection{On-Line Molecular Analysis}

Many current methods available for measuring trace molecular species use infrared energy sources. Many in situ analyzers are available, but none are capable of operating at the high temperature and pressure conditions which are necessary for hot gas cleanup applications. Laser energy sources are much more suitable for use under the higher temperature and pressure conditions; however, due to lack of market demand, the instrument manufacturers have been reluctant to make the necessary research and development investments to use lasers instead of conventional infrared sources.

The following molecular analysis methods should be developed for on-1ine use:

\section{Laser-Based Infrared Analysis}

The primary objective of this research should be to investigate the applicability of laser-based techniques for vapor-phase constituents and particles in hot particulate-laden process streams typical of those generated by IGCC, PFBC and MCFC power systems. Initially, the approach should be to provide techniques which are capable of providing chemical kinetic and process dynamic information for gas cleanup system research and development activities.

A responsive $\mathrm{H}_{2} \mathrm{~S}$ analyzer will also be required to monicor the concentration of $\mathrm{H}_{2} \mathrm{~S}$ in the fuel supplied to the molten carbonate fuel cell; so that the cell can be protected against cleanup system malfunction as discussed in Section 3.5.4.3. Also, a more responsive $\mathrm{H}_{2} \mathrm{~S}$ analyzer would be preferred for breakthrough detection purposes in hot gas cleanup applications. Since many molecules of interest absorb a useful amount of infrared radiation, it follows that the method development effort required to develop 
an improved $\mathrm{H}_{2} \mathrm{~S}$ analyzer would significantly accelerate the commercialization of many other analyzers.

\section{CARS Spectroscopy}

The CARS techniques which are referenced in Section 5.3 .1 .4 have been proven to be capable of making temperature and composition measurements at a specific position and time in hostile environments. These techniques are well suited for near term research instrumentation applications, and have potential for use as commercial systems where critical power system components must be protected against sudden changes in temperature and chemical composition.

\subsubsection{Alkali Monitor Development}

The alkali content of process streams may be required for a variety of reasons such as for process control purposes, protection of downstream components and for studying the chemical reactions taking place in coal conversion processes. The following systems should be developed:

- A system capable of being used to measure total alkali in situations where high reliability and low maintenance are of prime importance.

- A research-oriented alkali measuring system capable of measuring the fraction of total alkali which is in the vapor phase.

\subsubsection{On-Line Particle Characterization}

On-line optical devices for measuring particle size distributions and loads tend to be too sophisticated for operational use. A desirable approach would be to develop a simple, low cost, low maintenance device for process control purposes, and a more sophisticated device for making research measurements. The research device should be capable of calculating loadings and size distributions for densely loaded streams.

5.3.2.6 On-Line Detection of Polyaromatic Hydrocarbons

Present laboratory methods of polyaromatic hydrocarbon (PAH) sampling and analysis require several days to complete. Laser-based methods such as laser-induced fluorescence offer potential for reducing this analysis time. In particular, there exists the possibility of using laser-based techniques in conjunction with a currently available mass spectrometer or gas chromatograph to develop an improved overall approach. The primary objective should be to develop and field test the improved approach for use in making demonstration plant measurements on incinerator stack effluents.

5.3.2.7 Gas Chromatograph Development

Gas chromatographs are frequently used for gas analysis purposes in pilot and demonstration plant applications, but single parameter 
infrared and ultraviolet instruments are of ten preferred for process control applications because of their better response times and lower maintenance characteristics.

The increased use of less complex gas chromatographs should be investigated. By using microbore capillary columns and by developing suitably fast detectors, it would be possible to significantly reduce response time. Also, by developing a simple system for each application, it may be possible to reduce maintenance cost and response time for an acceptable increase in capital cost.

\subsubsection{Laboratory Analyzers}

Deficiencies in laboratory analyzers will always exist in the sense that there has always been a continuing search for better ways to determine the composition of materials in terms of the elements or compounds contained in them.

In the molecular spectrometry area, the Fourier Transform Infrared (FTTR) spertrometry market rentinues to grnw at a rapid pare. The technique has revolutionized the field of infrared spectrometry. Such interferometric instruments, which use integrated computers to help the operator perform fast, high resolution analyses, have been widely accepted in both industrial and academic laboratories. There is a trend in industry toward the use of FTIR for process monitoring purpose.

In the atomic spectroscopy area, inductively coupled plasma (ICP) acomic emission spectrometry has sceadily gained popularity over the past seven or eight years. ICP has better sensitivity than flame atomic absorption for refractory elements, and is relatively free from chemical matrix effects. ICP also has a wide dynamic range.

There is a growing interest in integrating spectrophotometry with fiber optic systems which can be used to transmit the analyzing light from the analyzer, which may be located in the plant laboratory, to the on-line sampling point and back to the analyzer. Using this approach, no sample pretreatment or modification is required, and measurements can be made in real time under actual process conditions. Also, a single high-performance general purpose analyzer could be used to determine the composition at many locations. One approach would be to excite fluoresence in the sample and return the resolution response for analysis using a monochromator of the type used in Raman Spectroscopy.

Many process analyzers have been developed by repackaging laboracory instruments as process analyzers. This interaction between laboratory analyzer engineering and process analyzer engineering should be encouraged. Laboratory analyzer, process analyzer, and instrumentation and control technologies should be more closely integrated and planned using a systems approach.

5.3.4 Zinc Ferrite Process/IGCC Dynamic Study

A power system dynamic study is required to establish a control strategy for one or more IGCC power system configurations which use 
the METC zinc ferrite gas cleanup process. The purpose should be to establish the power system and gas cleanup system control strategies which will result in fast, stable, and smooth transitions between the operating points for several system configurations. The dynamic model should be based on a simple set of first-principle dynamic equations similar to those used to simulate other power systems 44 .

A major objective of the study should be to establish preferred dynamic response requirements for the zinc ferrite process based upon typical electric utility load-following needs. This study would provide valuable input information for the zinc ferrite process model which is presently under development 45. An electric utility load-following study would contribute design specification information to the zinc ferrite process development program, particularly to that part of the program which is concerned with the operational stage capabilities of the instrument and control system.

5.3.5 Analyzer Information Management

Recent advances in computer technology have resulted in a new generation of analytical instruments in which each instrument requires the computer to be an integral part of the system. A network of software-driven instruments integrated inco a laboratory information management system would be useful for any large research and development facility. The Fourier transform infrared spectrometer is a good example of a software-driven instrument. Indeed, the rapid growth in FTIR instrumentation can be directly attributed to the availability of suitable low-cost, computerdriven measurement systems; however, the revolution is still in its early stages.

Many analytical methods are based on the interaction of electromagnetic radiant energy with matter. Since the nature of this interaction depends upon the fundamental properties of matter, it can not change, therefore, instrument improvements are often based upon the use of new analog or digital information processing techniques.

As mentioned in the last section, there is a growing interest in integrating spectrophotometry with fiber optics. That is, there exists the potential to transmit atomic or molecular exitation energy to various process streams, and then returning each response to a centrally located analyzer. This approach should be extremely useful for contaminant monitoring purposes, but it may not be popular for process control applications because it would be in conflict with present control system preferences. At the present, thore is a process rontrol rendency to distribute intelligent sensors and local controllers throughout a plant or manufacturing facility.

The commercialization of instruments under development could be accelerated by the development of improved communication between the analyzer research scientists and the instrument engineers who are responsible for installing state-of-the-art commercial instruments and distributed systems. At the present time, an Ingtrument Society of America (ISA) committee (SPSO) is developing 
a draft field bus standard which will be released for general review and comments. This standard covers Programmable Logic Controllers (PLC's). Originally, PLC's were flexible, easily reprogrammed industrial computers that performed chains of simple commands. Today, they are of ten used in advanced process control, process monitoring and process optimizaiton applications. It is probable that future process analyzers will be required to conform to this developing standard. For this reason, current and future process analyzer development programs should address these integration issues.

In Section 3.5 , reference was made to the possibility of using a real-time model for process control purposes. It is sometimes preferable (on the basis of cost, reliability and maintenance considerations) to infer composition information by monitoring easy-to-measure process variables. Alternatively, by using a combination of inference and measurement, it is possible and desirable to report instrumentation failures. Research in this area should be carried out with the objective of establishing a set of functional specifications for the proposed analyzer information management system.

5.4 CURRENT OR RECENT RESEARCH AND DEVELOPMENT PROJECTS

Improvements in many components for the emerging IGCC, PFBC and MCFC power systems are needed because of the extreme operating conditions encountered. Some of the component needs listed during the course of this study have been discussed in previous studies. As a result, appropriate $R \& D$ projects have been initiated, some of which are listed in Table 5.1.

Many of these $R$ \& D projects are still active, and considerable progress has been made. As a result, a number of improved instruments have reached the commercialization planning stage. For this reason, it has been necessary to introduce an emphasis on Lulal syslem planning and cocal system Informaclon fintegration. Tho noxt otcp, ao indicaced in Eection $5: 3$, is to geneiate sume preliminary integration plans so that the instruments shüwilly satisfactory commercial potential can be functionally integrated with the communications networks used in today's distributed control systems. 


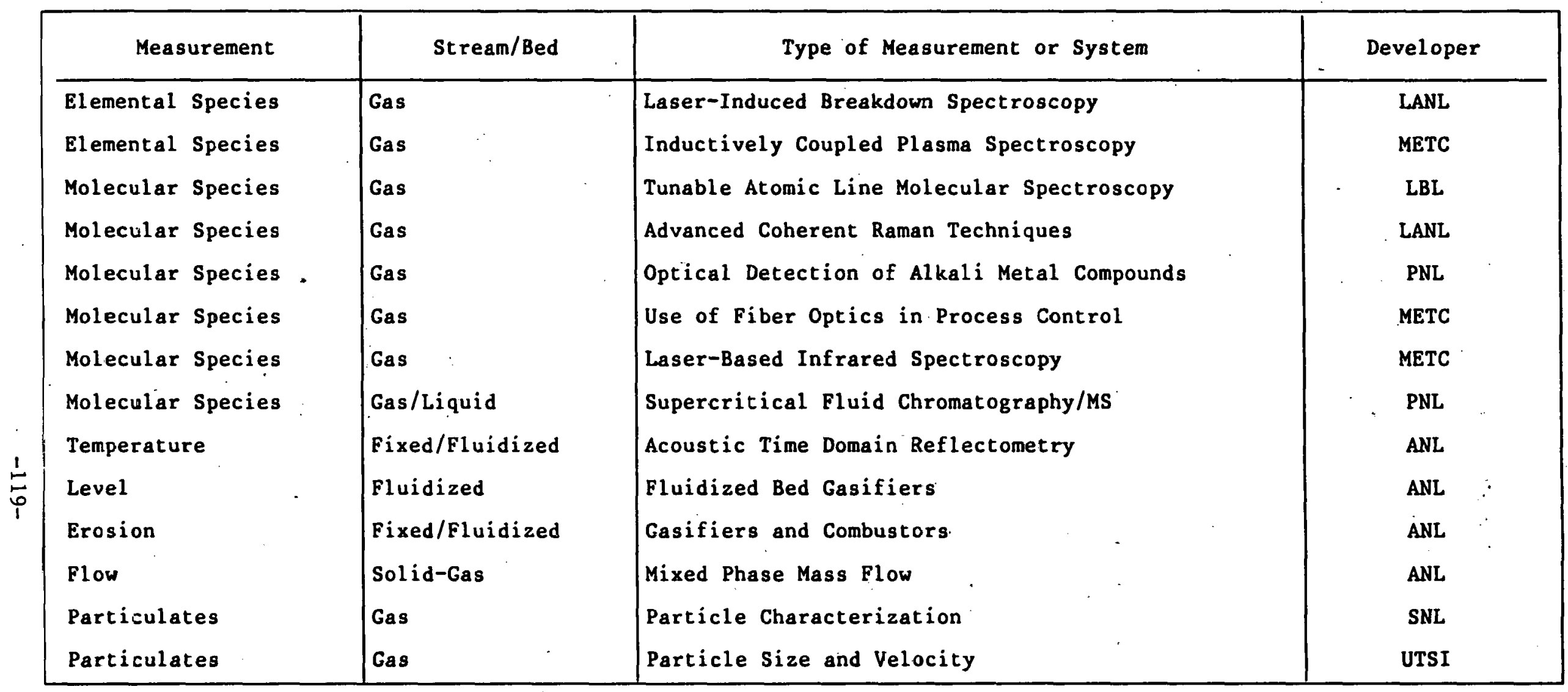

METC - Morgantown Energy Technology Center.

PNL - Pacific Northwest Laboratory

UTSI - University of Tennessee Space Institute

TABLE 5-1 CURRENT OR RECENT R \& D PROJECTS 


\begin{tabular}{|c|c|}
\hline AEP & American Electric Power \\
\hline AFBC & Atmospheric Fluidized Bed Combustion (Combustor) \\
\hline ANL & Argonne National Laboratory \\
\hline BGC & British Gas Corporation \\
\hline CAA & Clean Air Act \\
\hline COE & Cost of Electricity \\
\hline CURL & Coal Utilization Research Laboratory \\
\hline CWA & Clean Water Act \\
\hline DOE & United States Department of Energy \\
\hline EPA & Environmental Protection Agency \\
\hline EPRI & Electric Power Research Institute \\
\hline ESP & Electrostatic Precipitator \\
\hline FBC & Fluidized Bed Combustion (Combustor) \\
\hline G/C & Gilbert/Commonwealth \\
\hline GE & General Electric Company \\
\hline $\operatorname{gr} / \operatorname{scf}$ & Grains per Standard Cubic Foot \\
\hline HнV & Higher Heating Value \\
\hline $\mathrm{H} / \mathrm{O}$ & Hydrogen/Oxygen Ratio. \\
\hline HRSG & Heat Recovery Steam Generator \\
\hline HTHP & High Temperature High Pressure \\
\hline IGCC & Integrated Gasification Combined Cycle \\
\hline IGT & Institute of Gas Technology \\
\hline KRW & KRW Energy Systems \\
\hline $\mathbf{L} / \mathbf{G}$ & Liquid to Gas Ratio \\
\hline MCFC & Molten Carbonate Fuel Cell \\
\hline METC & Morgantown Energy Technology Center (DOE) \\
\hline NESHAPS & National Emissions Standards for Hazardous Air Pollutants \\
\hline NSPS & New Source Performance Standards (EPA) \\
\hline O\&M & Operation and Maintenance \\
\hline P\&ID & Process (or Piping) and Instrumentation Diagram \\
\hline PDU & Process Development Unit \\
\hline PFBC & Pressurized Fluidized Bed Combustion (Combustor) \\
\hline POM & Polycyclic Organic Material \\
\hline ppm & (or ppmv) Parts per Million by Volume \\
\hline ppmw & Parts per Million by Weight \\
\hline RCRA & Resource Conservation and Recovery Act \\
\hline
\end{tabular}


UTC United Technologies Corporation

SSMS Solid Supported Molten Salt

TSCA Toxic Substance Control Act

TRW . TRW Inc., Energy Systems Group

BSRP Beavan Sulfur Removal Process

\section{Response Time Definitions}

1. If, after a steady state period of one hour at $40 \%$ of the nameplate MW rating, a power system reaches full output in $T$ minutes; then, for the purpose of this report, $T$ has been termed the power system response time and $(100-40) / T$ the power system response rate.

2. For the purpose of this report, the response time of an analyzer has been defined as the time required for an output to change from. an initial value to $90 \%$ of the final steady state value (either before or in the absence of overshoot), plus any time required between initiating the input change and the start of the observable response. 


\section{REFERENCES}

1. Jones, "C. H., "Comparative Evaluation of High and Low Temperature Gas Cleaning for Coal Gasification--Combined Cycle Power Systems," EPRI AF-416, April 1977.

2. "Coal Derived Fuel Gases for Molten Carbonate Fuel Cells," TRW for Morgantown Energy Technology Center, Report No. DOE/METC/80850/6, November 1979.

3. "Coal Gasification Combined Cycle Component Assessment Study," Gilbert/Commonwealth, Reading, PA, GAI Rpt. No. 2617, April 1986.

4. Mulik, P.R., "High-Temperature Removal of Alkali, Vapors in Hot Gas Cleaning Systems," in Proc. 2nd Ann. Contractors Meeting on Contaminant Control in Hot Coal Derived Gas Streams, U.S. Dept. of Energy, Conf. 820208, February 1982, p. 438.

5. Meyer, J.'P., "Survey of Industrial Coal Conversion Equipment Capabilities: High-Temperature, High-Pressure Gas Purification," ORNL/TM-6072, June 1978.

6. Holland, R.F., "Infrared Analysis of Coal Gasifier Product Gases," in Proc. 1980 Symp. on Instrumentation and Control for Fossil Energy Processes, ANL-80-62 and CONF-800602, June 1980, p. 523.

7. Fischer, Wm. H., "Comparison of Environmental Intrusions of Various Power Plants", Preprints, Am. Chem. Soc., Div. Fuel Chem., 29 No. 6 1984.

8. Dillingham, E.W., "Enriched Air and Oxygen Gasification of Illinois No. 6 Coal in a Texaco Coal Gasification Unit," in Proc. 1st Ann. EPRI Contractors' Conf. on Coal Gasification, EPRI AF-2394, May 1982, P. 1-1. 
9. McDaniel, J., "EPRI Tests on Ruhrkohle/Ruhrchemie's 165 Ton per Day Texaco Coal Gasification Pilot Plant," in Proc. 1st Ann. EPRI Contractors' Conf. on Coal Gasification, EPRI AF-2394, May 1982, p. 2-1.

10. Roberts, S. L., "Shell Coal Gasífication Process," in Proc. Ist Ann. EPRI Contractors' Conf, on Coal Gasification, EPRI AF-2394, May 1982, p. 4-1.

11. Bonds, T. L., "Fuel Cell Power Plant Integrated Systems Evaluation," EPRI EM-1097, June 1979.

12. Ljungstrom, E., "Measurements of In-Bed Gas and Solid Composition in a Combustor Operating at Pressures up to $20 \mathrm{Bar}, "$ in Proc. 7th Intern. Conf. on Fluidized Bed Combustion, DOE/METC/83-48, January 1983, p. 465

13. Hoy, H. R., "Performance of a Small Combustor at Pressures up to $20 \mathrm{Atm}, "$ in Proc. 7th Intern. Conf. on Fluidized Bed Combustion, DOE/METC/83-84, January 1983; p. 473.

14. Friedman, M., "Gas Analysis Systems," presented at IEA Grimethorpe Technology. Transfer Workshop, U.S. Dept. of Energy, Office of Fossil Energy, Morgantown, WV, July 1984.

15. Roberts, A. G., "Fluidized Bed Combustion--1000 Hour Test Program," Vol. 1, DOE/ET/10423-1101, September 1981 .

16. Gluskotcr, H. J., et al., "Trace Elements in Coal: Occurrence and Distribution," Illinois State Geological Survey, Urbana, IL 61801, Circulạr 499, 1977, from Tables 2 through 7.

17. U. S. Dept. of Energy, "Coal Conversion Systems Techuical Data Book," 1982 ,m from Section IA.50.3.

18. King, J. M., "Energy Conversion Alternatives Study--ECAS--United Technologies Phase II Final Report," NASA CR 134955, 1976. 
19. Ham, D. 0., et. al., "Catalytic Cracking of Aromatic Hydrocarbons," in Cicero, D. C. and K. E. Markel (eds.) Proc. 5th Ann. Contractor's Meeting on Contaminant Control in Coal-Derived Gas Streams, DOE/METC-95-6025, 1985, PP. 395-404.

20. Jablonski, G., et. al., "Evaluation of Gasification and Gas Cleanup Processes for the Use in Molten Carbonate Fuel Cell Power Plants," Westinghouse R\&D Center for U. S. Dept. of Energy, DOE/MC/16220-1306 .

21. "Development of Molten Carbonate Fuel Cell Power Plant," General Electric Co. for U. S. Dept. of Energy, February 1983, DOE/ET/17019-11.

22. "Monitoring Contaminants in Coal-Derived Gas for Molten Carbonate Fuel Cells," TRW Energy Engineering Division, McLean, VA for Argonne National Laboratory, May 1981, DOE/METC--82-44.

23. Benjamin, T.G., et. al., "Handbook of Fuel Cell Performance," Institute of Gas Technology for U. S. Dept. of Energy, May 1980, C00-1545-T1.

24. Code of Federal Regulations, Title 40, Part 60, Subpart Da.

25. "Evaluation of the British Gas Corporation/Lurgi Slagging Gasifier in Gasification - Combined - Cycle Power Generation," Ralph M. Parsons Company for EPRI, AP-3980, Research Projects 2029-5 and 2029-6, March 1985.

26. "Conceptual Designs and Cost Estimates of High Temperature Desulfurization Processes", Gilbert/Commonwealth Inc. for the U. S. Department of Energy, Contract Number DE-AC21-84MC 21098, September 1986.

27. "Coal Gasification Systems: A Guide to Status, Applications, and Economics", EPRI Report AP-3109, June 1983. 
28. Tom A.J:A. and Kolkman, H.J., "Corrosion and Corrosion Control in Gas Turbines. Part II: The Turbine Section", 84-GT-256, ASME Gas Turbine Conference; Amsterdam, 1984

29.

Beltram, A.M. and Shores, D.A., "Hot Corrosion in the Superalloys", Ed. C. T. Sims and W. C. Hagel, John Wiley and Sons, 1972, pp. 317-339.

30. Lee, S. Y.,. "Laboratory Procedures for Evaluating High Temperature Corrosion Resistance of Gas Turbine Alloys", J. of Engin. for Power, July 19.71, pp. 313-320.

31. General Electric, "CFCC Development Program - Commercial Plant Stacked Combustor/Steam Generator Design Evaluation (Task 2.1), FE-2357-32, NTIS, June 1978.

32. Rubow, L. N. et. al., "Pressurized Fluidized Bed Combined Cycle Concept Evaluation," Gilbert/Commonwealth Inc. for DOE/METC, Contract DE-AC01-79ET11308, April 1982.

33. Klett, M. G., et. al., "Coal Gasification Cleanup Requirements and Practice", 1983 Energy Sources Terhnnlngy Conference and Exhibition, Houston, Texas, January 30 - February 3, 1983.

34. General Electric, "Development of Molten Carbonate Fuel Cell Power Plant," Work performed under Contract No. AC02-80ET17019, NITS, September 1982."

35. Castleman, J. M., "Process Performance of the TVA 20 MW Atmospheric Fluidized Bed Construction (AFBC) Pilot Plant," Proceedings of the Eight International Conference on Fluidized Bed Construction, Volume 1, DOE/METC, 85/6021, July 1985 .

36. Argonne National Laboratory, Design of Advanced Fossil Fuel Systems, Summary Report, ANL/FE-83-9, May 1983. 
37.

General Electric, Development of Molten Carbonate Fuel Cell Power Plant, Reference Plant Design, for DOE, DOE/ET/17019-T3, September 1982.

38. Gilbert/Commonwealth International, Inc., Molten Carbonate Fuel Cell Conceptual Design, Reading, PA, GC II Rpts. No. 2553, December 1984.

39. Patel, P. S., "Trace Contaminant Removal from Hot Coal Gas for Molten Carbonate Fuel Cell Application", Energy Research Corporation for DOE/METC, Contract No. DE-AC21-83MC20094.

40. Summit Technologies, Inc., "Topical Report: Review of State-of-the-Art Contaminant Sampling and Analytical Methodologies," Project DE-AT21-86MC23192 for DOE/METC, March 1987.

41. Measurementation, Inc., Anada Process Measurement Encyclopedia.

42. Hamersma, J. W. and Reynolds, S. L., "Tentative Procedures for Sampling and Analysis of Coal Gasification Process", TRW Systems Group for EPA, Contract No. 68-02-1412, Task Order No. 3, March 1975.

43. "Standard Methods for the Examination of Water and Wastewater", Sixteenth Edition, published jointly by the American Public Health Association, the American Water Works Association and the Water Pollution Control Federation, 1985.

44. R. B. Boulay, R. E. Weinstein, and J. C. Cutting, "A Simulation of the Dynamics of a Magnetohydrodynamic/Steam Power Plant", 19th SEAM, UTSI, Tullahoma, TN, June 15-17-1981.

45. D. P. Harrison, "Dynamic Simulation Models for High Temperature Desulfurization Process", METC Seventh Annual Gasification and Gas Stream Cleanup Systems Contractors Review Meeting, Morgantown, W.V., June 16-19, 1987. 
46. Los Alamos National Laboratory, "Advanced Coherent Raman Diagnostics for Coal Gasification Streams", METC Proceedings of the Instrumentation, Components, and Materials Contractors Meeting, Morgantown, W.V., Sept. 1986.

47. V. J. Kothari of DOE/METC, Personal Communication, April 1987.

48. J. K. Wachter of DOE/METC, Personal Communication, September 1987. 
Appendix A

IGCC Reference System

\section{Introduction}

Of the gasification; pressurized fluidized bed and molten carbonate fuel cell power generation systems covered by this study, the IGCC system offers: high potential for immediate commericalization. Emphasis on near-term commercialization was factored in to the published conceptual designs for two reasons; availability of technical information, and use of proven technology as preferred by the utility industry.

The selected reference system was based on the use of a BGC/Lurgi gasifier with cold gas cleanup. This system has been subjected to considerable study, particularly from the point of view of the system satisfying immediate utility requirements. The choice of the BGC/Lurgi gasifier and cleanup system does not imply any preference for this particular combination. The purpose of this study is to assess instrumentation need, therefore the selection was made on the basis of the amount and quality of the information available which could be used as a starting point for specifying instrumentation requirements. It was considered preferable to start with a solid base of system integration and system control information, than to start with the more advanced gas cleanup systems and then attempt to integrate them into optimized power generation systems for the level of effort available.

Since the hot gas cleanup processes are expected to be relatively easy to control from a load-following point of view, it was considered that the choice of the cold gas option would not seriously impact our assessment of hot gas cleanup instrumentation needs. Indeed, it was considered advantageous to provide a base case system against which the more advanced hot gas cleanup processes could be compared.

\section{Power Plant Description}

The description which follows is based upon the EPRI study 25 and an in-house study by $\mathrm{G} / \mathrm{C}$ in which sequential installation of the power generating equipment was assumed so that capacity addition increments can be spread out over a period of time to match load growth.

The power generating island is highly integrated with the gasifier system to absorb as much of the gasification and fuel gas desulfurization processes reject heat as possible. This high level of integration is required to maximize efficiency to compensate for the significant auxiliary load required by the gasifier system, particularly by the oxygen plant.

Three GE Frame 7E heavy duty industrial gas turbines were selected for this design so that the total combined cycle output would be in the 300-400 MW range. At the standard day site conditions of 14.4 psia and $60 \mathrm{~F}$, output was estimated to be $79,940 \mathrm{~kW}$ for each turbine on coal gas using Illinois 
No. 6 coal. Steam turbine output for the coal gas-fired mode was $157,060 \mathrm{~kW}$.

The total plant net output on coal gas is $356 \mathrm{MW}$, and the heat rate is 9317 Btu/kwh. Table A-1 summarizes the plant performance and Table A-2 shows state point information for the main process streams.

There is a slight mismatch between the gasifier and turbine unit capacities. Also, under some circumstances (hot ambient temperature days, for example) the gas turbine fuel requirements are reduced. To take advantage of this situation, supplemental fuel firing in a duct burner between the gas turbine exhaust and HRSG inlet was included. Since the gasifier operates at pressure, this fuel gas was reduced in pressure through an expander before being burned in the nearly atmospheric pressure duct burner. The expander produces an additional $2600 \mathrm{~kW}$ of electric power in the process.

As initially conceived, the coal gas is reheated after desulfurization to protect against fuel-gas water condensation and to transfer as much energy to the gas turbine cycle as possible in an effort to maximize efficiency. Heating is also required if the duct burner gas is to be throttled in an expander: This is due to the $360 \mathrm{~F}$ temperature drop that occurs when the fuel gas is expanded in the turbine. If the fuel gas was not heated, the expander exit temperature would be below the gas saturation temperature and condensation would occur in the expander. 


\section{TABLE $A-1$}

IGCC POWER PLANT PERFORMANCE SUMMARY

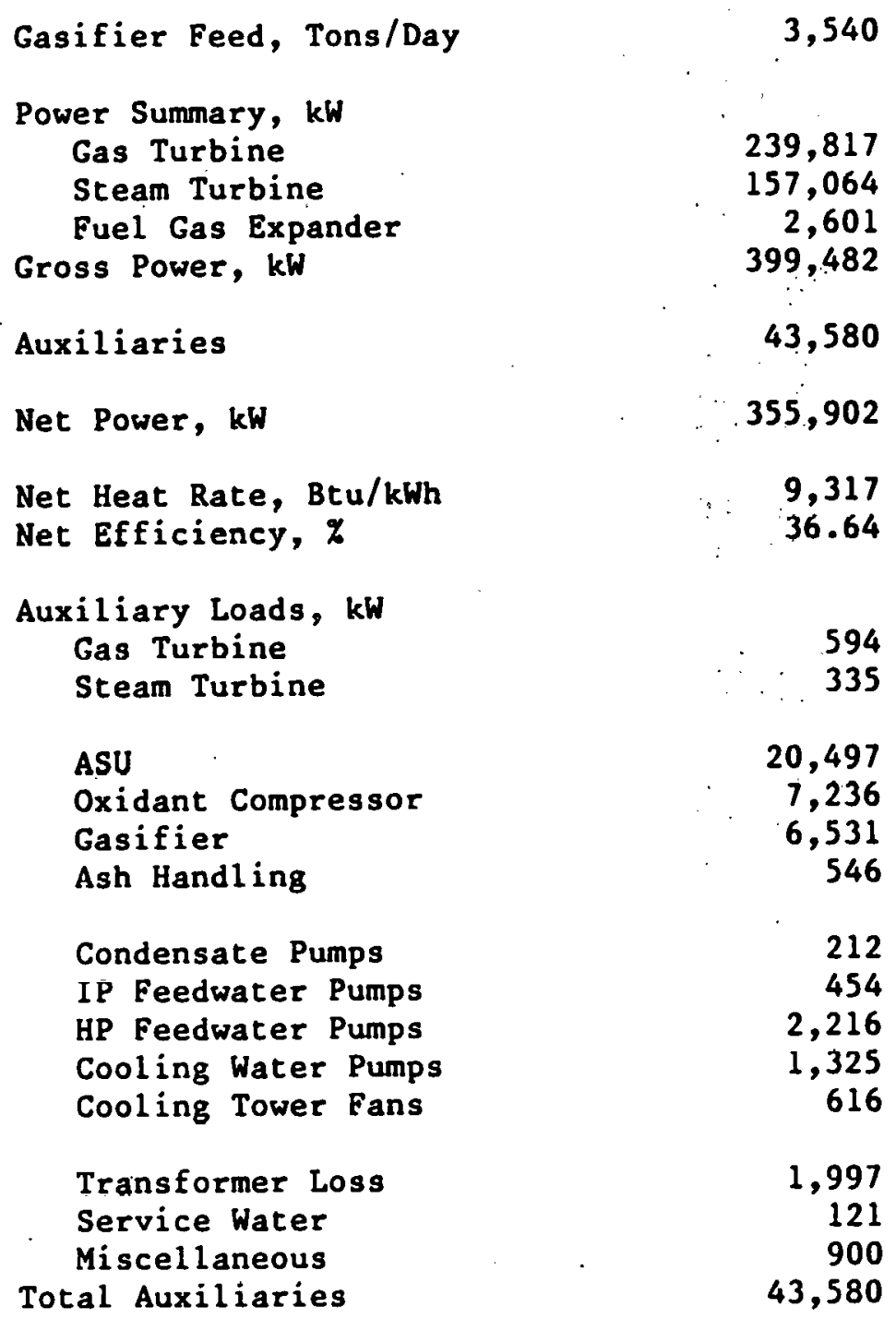


TABLE A-1 (Cont.)

IGCC POWER PLANT PERFORMANCE SUMMARY

$\begin{array}{lr}\text { Steam Turbine Data } & \\ \text { Throttle Pres., psia } & 1,814 \\ \text { Throttle Temp., F } & 1,000 \\ \text { Throttle Flow, pph } & 907,855 \\ & \\ \text { Hot Reheat Pres., psia } & 413 \\ \text { Hot Reheat Temp., F } & 997 \\ \text { Hot Reheat Flow, pph } & 853,647 \\ & \\ \text { Exhaust Hood Flow, pph } & 921,540 \\ \text { LP Steam Admission, pph } & 64,244 \\ \text { Turbine Back End } & \text { TC2F30 } \\ & \\ \text { Generator Rating, kVA } & 188,600 \\ \text { Gross T/G Output, kW } & 157,064\end{array}$

HRSG Gas Conditions

Gas to Duct Burner, pph

Gas Temp. C Burner Inlet

$6,756,511$

1,021

Burner Fuel, MMBtu/hr

299.3

Burner Exit Flow, pph

Burner Exit Temp., F

HRSG Exit Temp., F

$6,802,675$

1,160

317 
TABLE A-2 $\because$

IGCC POWER PLANT

PROCESS FLOW DIAGRAM STREAM CONDITIONS

\begin{tabular}{|c|c|c|c|c|c|}
\hline STREAM & STREAM & PRESSURE & TEMPERATURE & NUMBER : & TOTAL FLOW \\
\hline NUMBER & NAME & PSIA & DEG F & TRAINS & PPH \\
\hline 1 & As-Réceived Coal & - & 60 & 1 & 334,000 \\
\hline 2 & Coal Fines & - & 60 & $\therefore \quad 1$ & 39,000 \\
\hline 3 & Limestone & - & 60 & 7 & $\therefore \quad 7,900$ \\
\hline 4 & Clean Fuel Gas & 299 & 246 & $1 \cdots$ & 454,000 \\
\hline 5 & ÁSU Product (Oxygen) & 54.4 & 50 & 2 & 139,000 \\
\hline 6 & Gasifier Oxidant & 379 & 275 & 7 & 139,000 \\
\hline 7 & Gasifier Coal Feed & - & 60 & 7 & 295,000 \\
\hline 11 & GT AW Inlet & 14.4 & 60 & 3 & $6,235,000$ \\
\hline 12 & GT Fuel Gas & 282 & 500 & 3 & 408,000 \\
\hline 13 & GT Exhaust & 14.8 & 1021 & 3 & $6,756,000$ \\
\hline 14 & Duct Burner Fuel & 19.4 & 140 & 3 & 46,000 \\
\hline 15 & Gas Heater Exit & 281.9 & 500 & 1 & 454,000 \\
\hline 16 & Stack & 14.4 & 317 & 3 & $6,803,000$ \\
\hline 21 & Steam Turbine & 1.23 & 109 & 1 & 921,000 \\
\hline 22 & Water Makeup Exhaust & $\therefore \quad 14.4$ & 52 & 1 & 229,000 \\
\hline 23 & Condensate & 159 & 110 & 1 & $1,153,000$ \\
\hline
\end{tabular}




\section{TABLE A-2 (CONT.:)}

IGCC POWER PLANT

PROCESS FLOW DIAGRAM STREAM CONDITIONS

\begin{tabular}{|c|c|c|c|c|c|}
\hline STREAM & $\therefore$ STREAM & PRESSURE & TEMPERATURE & NUMBER & TOTAL FLOW \\
\hline NUMBER & NAME & PSIA & DEG $\mathbf{F}$ & TRAINS & PPH \\
\hline 24 & Acid Gas Coolant & 159 & 110 & 1 & 290,000 \\
\hline 25 & Acid Gas Coolant Return & 154 & 245 & 1 & 290,000 \\
\hline 26 & ASU Coolant & 159 & 110 & 2 & 561,000 \\
\hline 27 & ASU Coolant Return & 154 & 174 & 2 & 561,000 \\
\hline 28 & Compressor Coolant & 159 & 110 & 2 & 302,000 \\
\hline 29 & $\begin{array}{l}\text { Compressor Coolant } \\
\text { Return }\end{array}$ & 154 & 174 & 2 & 302,000 \\
\hline 30 & Deaerator Feed & 154.4 & 192 & 3 & $1,153,000$ \\
\hline 31 & Booster Pump Feed & 17.5 & 221 & 3 & $1,075,000$ \\
\hline 32 & HRSG IP Feed & 378 & 221 & 3 & $1,021,000$ \\
\hline 33 & IP Feedwater & 340 & 409 & 3 & $1 ; 021,000$ \\
\hline 34 & HP Economizer Feed & 2214 & 414 & 3 & 908,000 \\
\hline 35 & HP Throttle Steam & 1814 & 1000 & 1 & 908,000 \\
\hline 36 & Cold Reheat & 468 & 660 & 1 & 878,000 \\
\hline 37 & Gasifier HP Steam & 450 & 752 & 3 & $44 ; 900$ \\
\hline 38 & Hot Reheat & 413 & 1000 & 1 & 833,000 \\
\hline 39 & Gasifier LP steam & 44.4 & 274 & 3 & $64,200^{\circ}$ \\
\hline
\end{tabular}


TABLE A-2 (CONT.)

. IGCC POWER - PLANT

PROCESS FLOW DIAGRAM STREAM CONDITIONS

\begin{tabular}{rlcccc} 
STREAM & \multicolumn{1}{c}{ STREAM } & PRESSURE & TEMPERATURE & NUMBER & TOTAL FLOW \\
NUMBER & \multicolumn{1}{c}{ NAME } & PSIA & DEG F & TRAINS & PPH \\
40 & LP Steam Admission & 42.2 & 399 & 1 & 64,200 \\
41 & Anti-NOx Steam & 340 & 429 & 3 & 114,000 \\
42 & Gasifier LP FW & 22.5 & 221 & 3 & 133,000 \\
43 & Gasifier LP FW & 378 & 221 & 3 & 53,700 \\
44 & $\begin{array}{l}\text { Gasifier Condensate } \\
\text { Return }\end{array}$ & 44 & 273 & 3 & 52,900 \\
45 & LP Boiler Feed & 22.5 & 221 & 3 & 27,700 \\
46 & Deaerator Steam & 17. & 221 & 3 & 27,700
\end{tabular}




\section{Power Generation System Control}

In a combined cycle power plant, the steam,turbine generates power made available by steam produced through waste heat recovery from the gas turbine exhaust. It is, therefore, the HRSG's, which are responsible for recovering this heat, which are of primary importance from the point of view of designing a control system for the plant as a whole.

Previous IGCC studies and plant experience have established that the gas turbine-lead control mode is preferable to the gasifier-lead mode for meeting power system requirements. In this mode, the gas turbine fuel valve receives a command signal from the station controller to increase, decrease or maintain power plant output depending on the measured difference between megawatt demand and plant output.

Changes in power demand can be accommodated rapidly by the BGC/Lurgi slagging fixed-bed gasifier. Tests have shown that a $70 \%$ change in gas output can be made in 3 or 4 minutes. However, clean-up considerations may dictate that plant load changes be accomplished at a rate no greater than $5 \%$ per minute.

During start-up and shutdown, the three HRSG's will be capable of being operated in different control modes. In the steam turbine start-up mode, the HRSG control system will interface with a master control system to provide proper distribution of high pressure steam to the steam turbine. A bypass through the reheater will be used for heating and cooling the reheater, and for controlling steam to the HP turbine during start-up and steam blending. Also, a direct bypass to the condenser will be used during warming and start-up. During start-up, the reheater and its associated bypass pressure control loops will be used to control the superheat and reheat steam pressures. The load on the gas turbine will be gradually increased with water sprays being used to maintain required steam temperatures at the reheater and condenser. As pressure builds up in the cold reheat manifold, the condenser bypass will be switched to flow control with a setpoint equal to the high pressure bypass flow. Eventually, the bypass valves will be closed and will remain closed except for situations involving major load excursions.

The turndown approach for the system will be to reduce load on all three HRSG's simultaneously until it becomes more practical and economical to shut down one HRSG completely. The remaining two HRSG's will then be turned down until it is no longer economical or feasible to keep the steam turbine on line. One HRSG will be kept on line to provide high pressure steam for the gasification plant, and to receive low pressure steam for bypass to the condenser. These systems are of central importance in controlling the overall system.

\section{Gasifier Control}

The principal controls needed to support safe and balanced steady state operation are as follows. The oxygen and steam inputs have to be adjusted to maintain the required output capacity, and the oxygen/steam ratios have 
to be adjusted to maintain conditions such that slag will flow freely through the slag tap hole as required.

\section{Control System Implementation}

The IGCC plant will employ a fully integrated instrumentation and control system. A modern distributed system architecture and a modular implementation scheme will be required to provide the necessary flexibility of application needed to support the phased construction approach. The system will be such that the operator will have all of the information at his disposal, primarily in the form of video displays, to effectively control the plant. Also, full or partial manual control will be available at all times.

The basic elements of total distributed control are local subsystem controllers with controller files and input/output hardware. The controllers will provide all of the functions associated with conventional instrumentation devices and will interface with the central control room via a data highway.

\section{Fuel Gas Clean-up Systems}

A simplified process flow diagram for the fuel gas clean-up systems is shown in $\mathrm{Figure} \mathrm{A}-2$. The Lurgi hot potassium carbonate acid gas removal process represents the optimum process based on a variety of technical performance and economic considerations. It is interfaced primarily with the gasification, recompression and gas liquor separation systems, and produces. mainly $\mathrm{H}_{2} \mathrm{~S}$ which is converted to elemental sulfur in the Claus Process. The Beavon Sulfur Removal Process converts the tail gas from the $\mathrm{Claus}$ process to $\mathrm{H}_{2} \mathrm{~S}$ which is captured by the Stretford Process. Brief descriptions of these systems follow.

\section{Recompression}

The purpose of this unit is to wash, and recompress gases from the gasification unit and the gas liquor separation unit, and return them to the crude fuel gas stream.

\section{Gas-Liquor Separation}

The purpose of this unit is to cool, expand, and separate the gaseous, liquid and solid phases produced from the gas-liquor streams originating in the gasification unit, and from the subsequent crude fuel gas cooling steps in the acid gas removal unit. To avoid emissions caused by the breathing of vessels, all vents are connected to a header, and all equipment, including the drain system, is sealed from the atmosphere.

\section{Gas-Liquor Evaporation}

The purpose of this unit is to strip ammonia, hydrogen cyanide, and sulfur compounds from the gas-liquor and to evaporate part of the stripped gas-liquor. The major portion of the stripped gas is sent to the sulfur recovery unit. The balance is sent to the vapor incinerator in the gas-liquor incineration unit where organic components are destroyed 
thermally. The liquid blow-down stream is sent to a separate special liquid incinerator which is provided with salt recovery equipment. The gas-liquor evaporation unit is designed to strip the gas-liquor stream of gases and to evaporate most of the liquid. The remaining gas-liquor is routed as liquid blow-down to the liquid incineration unit. The amount of gas-liquor which is blown down and pumped to the liquid incinerator is set so that the concentration of organics in the liquid blow-down is adequate to support its combustion without supplementary fuel.

\section{Gas-Liquor Incineration}

This unit is designed to burn the various vapor streams in the vapor incinerator and the blow-down 1 iquid from the gas-liquid evaporation unit in the liquid incinerator. The flow of gaseous effluents, and fuel gas are constantly monitored and the air flow adjusted to ensure complete combustion. Combustion outlet temperatures are controlled by adjusting the fuel gas rate. The system is instrumented so that excessive combustion outlet temperatures will immediately start the flow of emergency ait to cool the combustors.

The purified flue gas is released into the atmosphere via a water droplet separator and flue gas stack.

\section{Acid Gas Removal}

The purpose of this unit is to selectively remove sulfur compounds generated in the BGC/Lurgi slagging gasifier which are contained in the crude fuel gas. This unit is designed to remove sulfur components down to 800 ppmv by selective chemical absorption in hot potassium carbonate solution. The carbon dioxide in the treated gas is kept at a maximum level by proper selection of operating conditions in order to keep the mass flow to the power plant gas turbines as high as possible.

\section{Sulfur Recovery}

The conversion of hydrogen sultide to sulfur is based on controlled combustion with air in which one-third of the hydrogen sulfide is burned to form sulfur dioxide. The sulfur dioxide reacts with the remaining two-thirds of the hydrogen sulfide to form sulfur and water vapor. The principal reactions are represented by the following simplified equations:

$$
\begin{aligned}
& \mathrm{H}_{2} \mathrm{~S}+3 / 2 \mathrm{O}_{2}=\mathrm{SO}_{2}+\mathrm{H}_{2} \mathrm{O}, \text { and } \\
& 2 \mathrm{H}_{2} \mathrm{~S}+\mathrm{SO}_{2}=3 \mathrm{~S}+2 \mathrm{H}_{2} \mathrm{O} .
\end{aligned}
$$

The reaction to form sulfur begins immediately in the combustion zone of the reaction furnace and is completed over a catalyst.

The tail gas from the final condenser is sent to the Beavon Sulfur Removal Process.

\section{Tail Gas Treatment}

The tail gas treating process employed is the Beavon Sulfur Removal Process (BSRP) and is displayed on Process Flow Diagram A-2. The BSRP involves the 
simultaneous catalytic hydrogenation and hydrolysis of sulfur and its compounds, contained in the tail gas from the sulfur recovery unit to hydrogen sulfide. The hydrogen sulfide is then converted to elemental sulfur using the Stretford Process, wherein the hydrogen sulfide is absorbed and oxidized to sulfur in an alkaline solution containing salts of vanadium oxide $\left(\mathrm{V}_{2} \mathrm{O}_{5}\right)$, and anthraquinone disulfonate. The sulfur is separated form the bulk of the solution by flotation, deaerated, filtered, washed and then melted under heat and pressure to produce molten sulfur. 


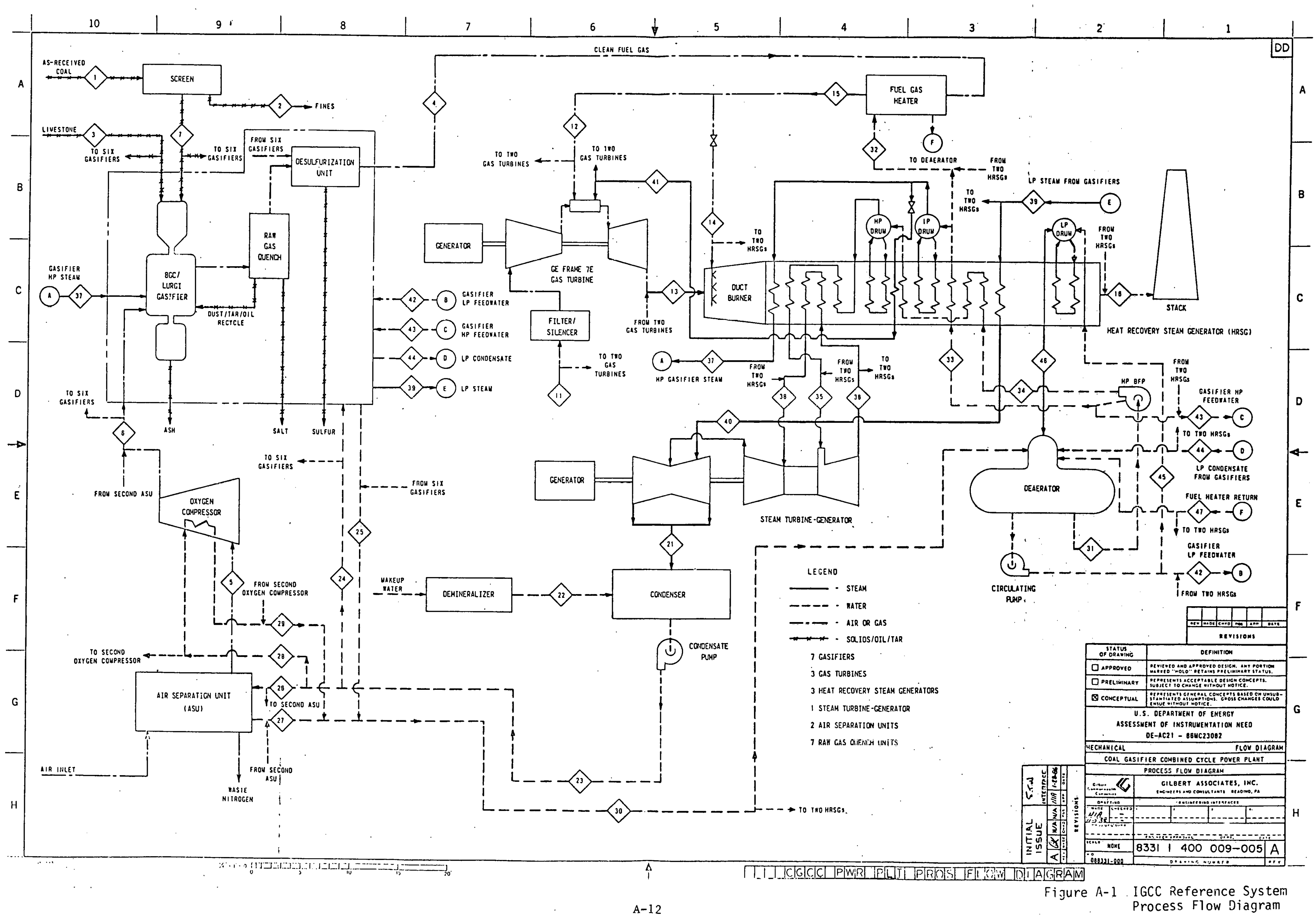




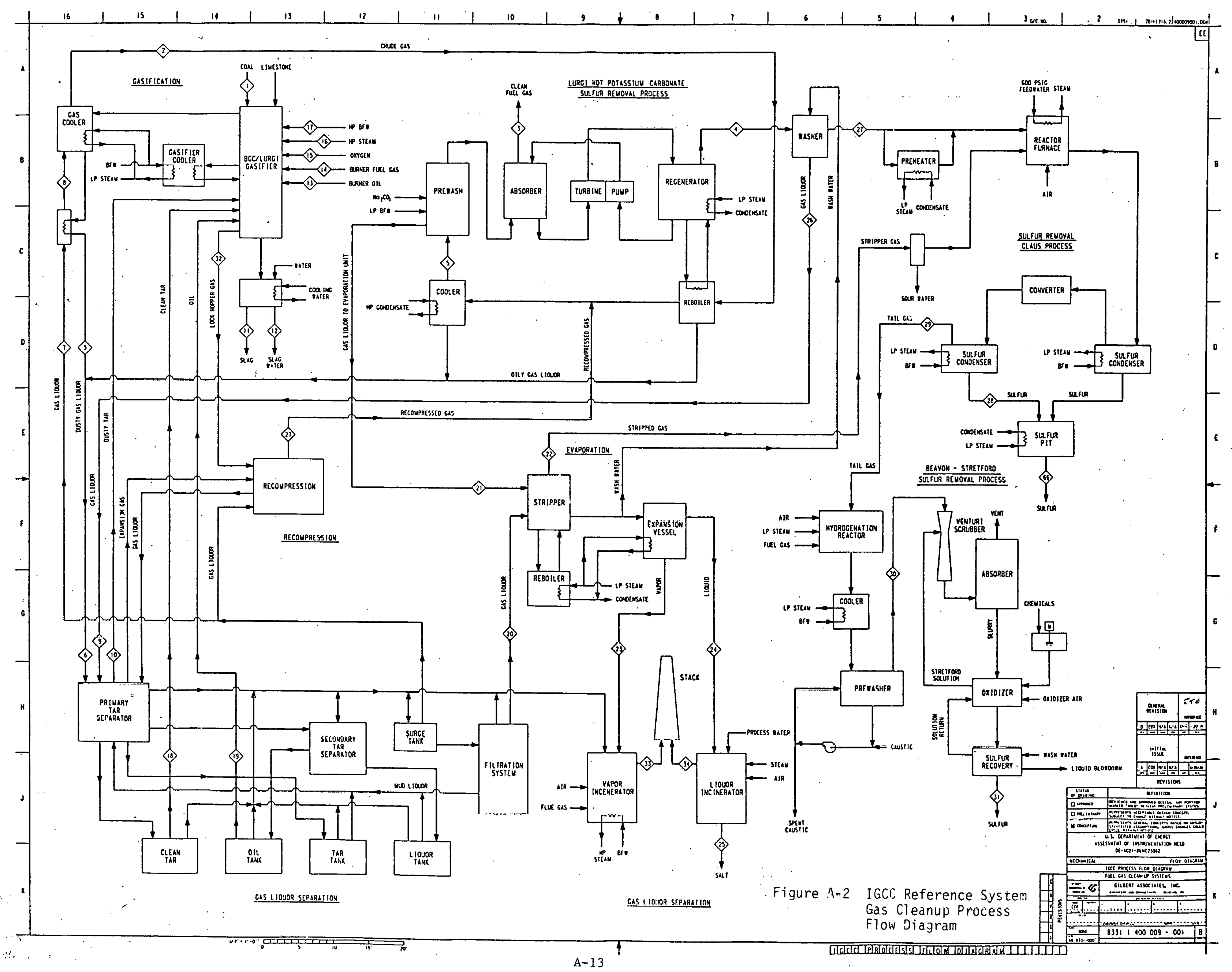


Appendix B

PFBC Reference System

\section{Introduction}

As indicated in the introduction to Appendix $A$, it was decided to select one commercially viable power system design for each power plant type, and to describe that plant in some detail, particularly in areas where instruments are needed to control or monitor contaminant concentrations.

As discussed in Section 2.3.1.2, PFBC systems may be categorized according to the presence or absence of heat transfer surfaces in the bed, the cooling medium used, and the operating conditions. Utilities are interested in pursuing coal burning technologies which will result in capacity additions which are economical, reliable, and able to meet emission standards. the selected reference system; the GE steam cooled PFBC, is one such system. It is characterized by the use of a conventional steam boiler cycle with the steam generated in a tube bundle immersed in the fluidized bed, and is generally considered to be one of the more acceptable systems from a utility requirements point of view.

Other PFBC power plant configurations are described in Section 2.3.

\section{Power Plant Description}

The "steam cooled" approach utilizes a combustor similar to a conventional boiler in function, but pressurized and more compact in design. The combustor is a horizontal cylindrical pressure vessel enveloping two rectangular waterwall fluidized bed subassemblies. Horizontal water/steam cooled tubes are immersed in each bed. An illustration of the vessel/waterwall arrangement is shown in Figure B-2. All of the air from the compressor is utilized in combustion at 20 percent excess air. Three combustors (six fluidized beds within three pressure vessels) combine to provide the total plant output. The combustion process is. "double contained," i.e., the waterwalls only contain a small pressure differential, while the vessel surrounding the rectangular fluidized bed contains the bulk of the pressure.

The steam cooled PFBC cleanup system consists of four cyclone trains per combustor. Each cyclone train consists of three advanced cyclones with no recycle. Also, in order to increase collection efficiency, a pressure drop of 6.9 psi has been taken across each cleanup train resulting in higher than normal inlet velocities in the cyclones ( 130 to $160 \mathrm{ft} / \mathrm{sec})$.

Coal and dolomite feeding systems are developmental items. Dense phase pneumatic injection is the only technique that has been used to date and Petrocarb Inc. has been the only manufacturer to develop an injection system. PFBC rigs have been able to run extended tests using underfed feeding. However, in general, coal feeding has always been a source of operation problems.

The waste heat recovery system consists of two separate economizers (stack gas coolers). The first is in parallel with the high pressure feedwater 
heaters. The second economizer heats the low pressure feedwater ahead of the deaerator.

Unit trains rotary dump to a grizzly bar arrangement below ground, then the coal is transferred to an aboveground stackout system. Stackout conveyors take coal to a transfer station and a radial stacker. Reclaim is by vibrating feeders in a tunnel onto conveyors which rise to a tripper belt over day silos. The silos feed crushers and dryers after which the sized, dried coal is sent to product storage bins for final feeding to the PFBC via the pneunatic injection system.

Dolomite is unloaded by the coal unloading equipment using a swinging boom stacker. Reclaim is via vibrating feeders and tunnel belt conveyors to silos, fluidized bed dryers, crushers and finally to the Petrocarb system.

Spent bed material is drained via refractory line pipes into refractory lined lockhoppers. A high temperature vibratory feeder empties the lockhopper into a fluidized bed cooler. The heated fluidizing air is cleaned by cyclones and used for drying coal and dolomite along with the gas turbine exhaust. Flyash is similarly collected and cooled in a fluidized bed containing a high pressure boiler feedwater tube bundle. The fluidizing air is cleaned by cyclones and used for drying along with the gas turbine exhaust. The cooled ashes are pneumatically conveyed to silos for loading into trucks for disposal offsite.

Since hot gas cleanup technology is still under development a series/parallel arrangement of cyclones was selected as the normalized hot gas cleanup system for the PFBC power plants. The series cyclone arrangement is the only commercially available technology available, at this time, that can remove particulates from high temperature and high pressure flue gas streams.

Because of the inherent limitations of cyclone technology, its use for hot gas cleanup requires that the flue gas downstream of the gas turbines be treated to meet the current NSPS for particulates. Because of the fine particulate size distribution ( $~ 60$ percent $\angle 2 \mu \mathrm{m})$, low inlet grain loadings, and large gas volumes to be processed, a standard reverse air baghouse is the most practical means of meeting NSPS.

The baghouses for both air and steam cooled PFBC with one compartment being cleaned have nominal air-to-cloth ratios of 2.3 for eastern coal and 2.2 for western. Both are typical values. The outlet loadings are $0.018 \mathrm{gr} / \mathrm{scf}$ on both eastern and western coals at a removal efficiency of 92 percent. The modular gas/steam generation units are capable of independent operation, and they independently supply steam to a single steam turbine. The principal thermodynamic cycle parameters for the reference design are summarized in Table B-1.

The physical size of the modular PFBC units is determined, for optimum values of pressure ratio and fluidized bed superficial velocity, primarily by the gas turbine air flow, and secondarily by the excess air ratio, which strongly affects the required steam generation surface and steam output. 
TABLE B-1

PRINCIPAL THERMODYNAMIC CYCLE PARAMETERS

57\% FULL LOAD
Gas Turbine (First Bucket
Inlet) Temperature

Gas Turbine (First Bucket
Inlet) Temperature

Range, ${ }^{\circ} \mathrm{F}$

Range, ${ }^{\circ} \mathrm{F}$ psia $/{ }^{\circ} \mathrm{F} /{ }^{\circ} \mathrm{F}$

Feed Water Temperature at

Bed Inlet, ${ }^{\circ} \mathrm{F}$

Combustor Excess Air, \%
$\mathrm{Ca} / \mathrm{S}$ Molar Feed Ratio

Combustor Excess Air, \%
$\mathrm{Ca} / \mathrm{S}$ Molar Feed Ratio

Gas Turbine Pressure Ratio

Fluidized Bed Operating
Temperature Range, ${ }^{\circ} \mathrm{F}$
10

1400

1327

$\begin{array}{cc}10 & 10 \\ 1400 & 1750 \\ 1327 & 1664 \\ 3500 / 1000 / 1000 & \\ 598 & 678 \\ 60 & 20 \\ 1.5 & 1.5\end{array}$

750
$100 \%$ FULL LOAD

10

1664

The GE reference design, with the cycle parameters of Table B-1. employs three MS7001E gas turbines, each coupled with one PFBC module.

The total power level of the proposed utility power plant is 646 MW for three gas turbine modules. The gas turbines produce 153 MW or 24 percent of the plant output; the steam turbine produces 76 percent. Table B-2 sumnarizes the plant performance and Table B-2 shows the state point information for the main process streams.

Control of the plant is coordinated by a master controller, which regulates plant load by automatically balancing steam generator demand and steam turbine and gas turbine loads. Variations in steam system demand result in changes in the coal firing rate and in the fluidized bed temperature ( and thus in the gas turbine firing temperature). Variation of bed (and gas turbine) temperature in the range of $1750^{\circ} \mathrm{F}$ ( $1658^{\circ} \mathrm{F}$ gas turbine) to $1400^{\circ} \mathrm{F}$ ( $1321^{\circ} \mathrm{F}$ gas turbine) produces a reduction in net plant output to approximately 57 percent. Total plant turndown below 57 percent of rated load is achievable through shutdown of one or more modules.

\section{Power Generation System Control}

The plant is controlled by an integrated plant control system which translates a plant load demand into steam generator and steam turbine demand signals. Variations in the steam system will result in changes in the coal firing rate and in the fluidized bed temperature.

The plant controller will also provide sequencing signals for startup and shutdown of the modular units. The vendor-supplied gas turbine and steam 
turbine control subsystems will be integrated with a control system for the steam generators.

The steam turbine-generator will immediately respond to changes in load demand caused by changes in setpoint and/or system frequency, and the gas turbines will operate in a turbine-follow mode with the compressor inlet guide vanes wide open. The air flow and bed temperature will vary with load turndown. The gas turbine power response will be delays by the 20-30 second time constant of the hot gas cleanup system. As the gas turbine load changes, the steam plant demand signal will be adjusted. The steam turbine will produce most of the load change, with the gas turbine acting as a delayed trim. This will be the reverse of the IGCC system where the gas. turbines will provide the initial response.

\section{Combustor Control}

The fuel demand from the master controller will be modified by any deviation of the feedwater temperature from normal. The resulting fuel demand will be limited by bed temperature measurement to prevent operation outside of the allowable temperature limits. Any error between measured fuel flow and fuel demand will change the demand signal to the coal injectors for the steam generation and super heat bed.

The fuel demand signal will also be combined with the reheat temperature error and limited by bed temperature. Any error between the demand and actual flow rates will modify the demand signal to the reheat bed coal in jectors.

Bed expansion will be controlled at a constant value by maintaining a constant air velocity through each bed. The pressure differential across a flow element will be measured, compared to a set point, and the difference used to adjust the position of the combustion air control damper for each bed.

Dolomite will be controlled by means of a three-element control system. The fuel flow signal will be used as a feed-forward signal for dolomite and the demand will be modified by a signal representing deviation of measured $\mathrm{SO}_{2}$ from the desired level.

Bed removal rate will be controlled using a three-element control system. The dolomite flow will be used as a feed-forward signal and the demand will establish the setpoint for the valve that controls the rate of bed draining.

The bed level will be calculated by measuring the pressure drop across an unknown bed height and a similarly measured known bed height

A hot gas intercept valve will be required to reduce the flow of combustion products from the pressurized combustor and its associated cleanup system. This valve is needed to prevent overspeed of the gas turbine in the event of sudden loss of electrical load. In addition, a hot gas blowoff valve should be provided upstream of the intercept valve. 
The PFBC plant will employ a fully integrated instrumentation and control system similar to that outlined in Appendix A for the IGCC plant.

Although no insurmountable control problems are anticipated, the integrated control system will be quite complex; consequently, a suitable dynamic simulation study should be initiated prior to developing a commercial design.

\section{$\underline{S O}_{2}$ Removal and NOx Formation}

One of the most important advantages of the fluidized bed combustion process is the capability of controlling $\mathrm{SO}_{2}$ emissions by burning the coal in the presence of limestone or dolomite. When dolomite or limestone are injected into the fluidized bed, calcination takes place and the calcium oxide reacts with sulfur dioxide to form calcium sulfate. Under PFBC conditions, sorbent effectiveness is not degraded by higher temperatures and tests have shown that dolomite required a lower $\mathrm{Ca} / \mathrm{S}$ ratio than 1 imestone.

$\mathrm{Ca} / \mathrm{S}$ ratios are usually established by reviewing test results obtained from the various $P F B C$ test rigs that have been operated using a variety of coals and test conditions.

Another primary advantage of fluidized bed combustion is the low NOx emitted by the combustor due to the low combustion temperature which limits the thermal fixation of nitrogen in the combustion air.

\section{Alkali Metal Compounds}

Alkali metal compounds, when combined with sulfur, cause corrosion and erosion of gas turbine blades and vanes. This problem has been discussed in Section 2.2.2.

Based on previous PFBC operating data, alkali concentrations tend to be slightly higher than the concentrations preferred by the gas turbine manufacturers. However, some previous chemical equilibrium composition studies have indicated that calculated alkali cocentrations are below the tolerance levels specified by the turbine manufacturers.

Due to the 1 imited quantity of variable test data which exist, and the uncertainties experienced in measuring alkali concentrations by means of currently available instrumentation, additional tests are required to establish reliable turbine tolerance guidelines for PFBC applications.

It is improbable that a PFBC commercialization plan which can be proven technically and economically viable with respect to all potential problem areas other than hot alkali corrosion, would have to be abandoned because of the alkali problem alone.

\section{Trace Element Emissions}

Since trace element emissions from fluidized bed combustors are comparable to or lower than trace emissions from conventional coal-fired plants, no 
trace element cleanup systems are needed to satisfy existing environmental regulations.

\section{Particulate Removal}

Cyclone performance data which have been collected to date have indicated that staged cyclones have been able to retain outlet loadings in PFBC facilities of less than $0.1 \mathrm{gr} / \mathrm{scf}$. However, loadings are still several times greater than EPA emission standards. Therefore a baghouse has been used in the reference plant design shown in Figure B2. 
Power Summary, MWe

Gas Turbine 143.1

Steam Turbine

Auxiliaries, MWe 10.7

Net Plant Efficiency, $\%$ 40.5

Gas Turbine

Compressor Efficiency; $\%$ (adiabatic)

88.5

Gas Turbine Generator Efficiency, $z$ 98.0

Fluidized Bed

Heat Loss, \% of fuel

0.39

Bed pressure drop

3.5

Bed Temperature 1650

Combustion Efficiency 98.9

$\mathrm{Ca} / \mathrm{S}$ Ratio

Hot Gas Cleanup

Pressure Drop, psi

Steam Turbine

Throttle Conditions, psia/ ${ }^{\circ} \mathrm{F}$

$3515 / 1000$

Reheat Temperature

1000

Turbine Exhaust Presure, inches $\mathrm{Hg}$

2.5

Turbine Efficiency, $\bar{z}$

$85.4-90.1$

Turbine Generator Efficiency, $\%$

98.4 
TABLE B-3

PFBC POWER PLANT

PROCESS FLOW DIAGRAM STREAM CONDITIONS

STREAM

NUMBER

STREAM
NAME

1 Coal Feed

2 Dolomite Feed

3 Air Supply

4 Combustor Exit

5 Ash (cyclone discharge)

6 Cyclone Outlet

7 Gas Turbine Outlet

8 Economizer Gas Outlet

9 Stack Gas Cooler Outlet

10. Feedwater (Hot)

11 H.P. Steam

12 Cold Reheat Steam

13 Hot Reheat steam

14 L.P. Steam (Turbine Inlet)

15 Feedwater (Deaerator Inlet)

16 L.P). Steam (turbine Exit)

17 Fluidized Bed

Temperature
PRESSURE

PSIA

TEMPERATURE

${ }^{\circ} \mathrm{F}$

TOTAL FLOW

PPH

472,739

213,563

14.7

50

1650

1650

$5,418,000$

139.2

$5,682,908$

109.27

132.3

1622

$5,573,636$

15.42

857

$5,898,716$

385.3

15.06

275

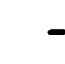

3500

675

607.6

120

169

206

664.4

$3,481,265$

1000

$3,481,265$

572.2

$3,054,543$

1000

$3,054,543$

$2,526,110$

$2,780,517$

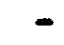

139.2

1650 


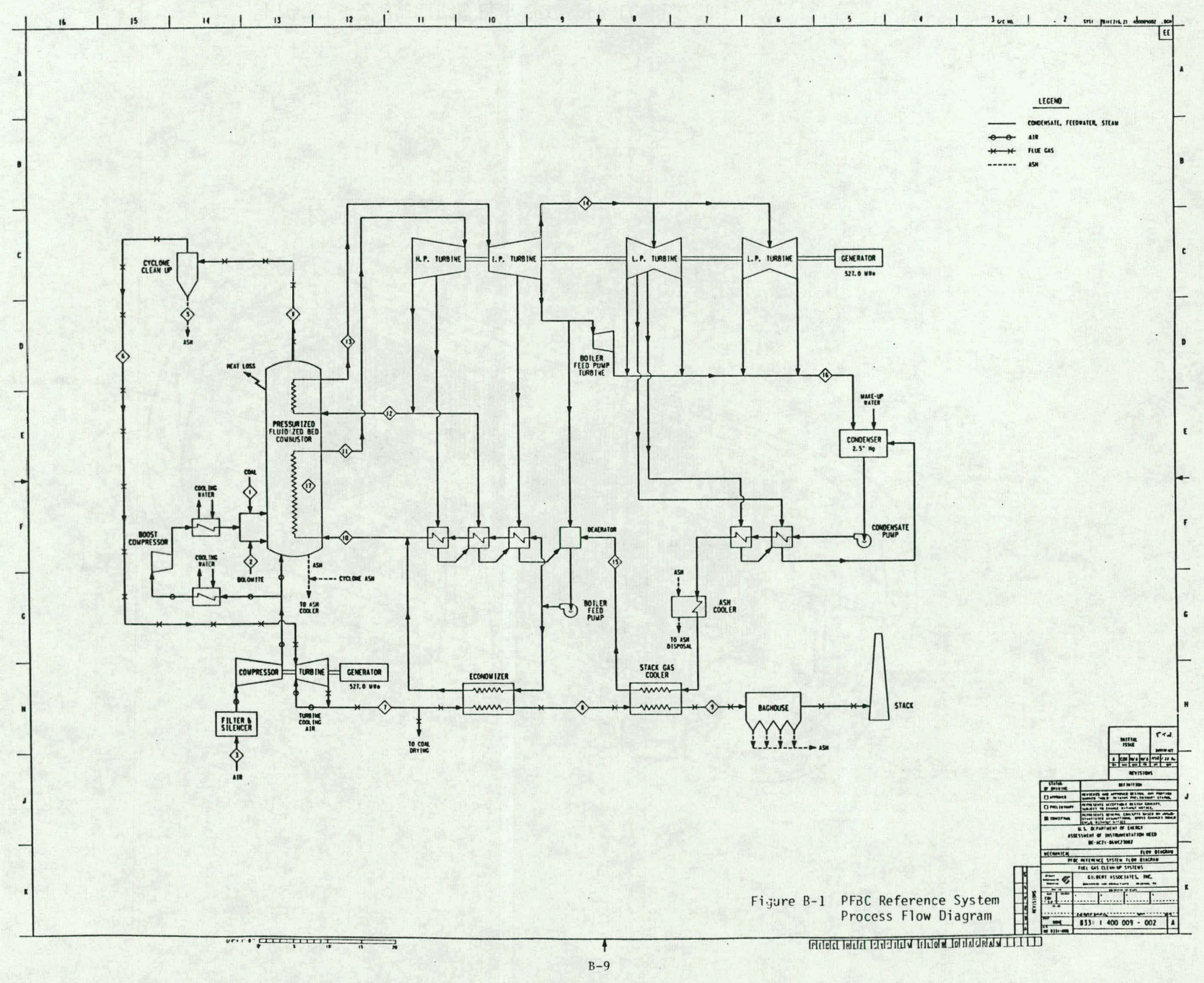




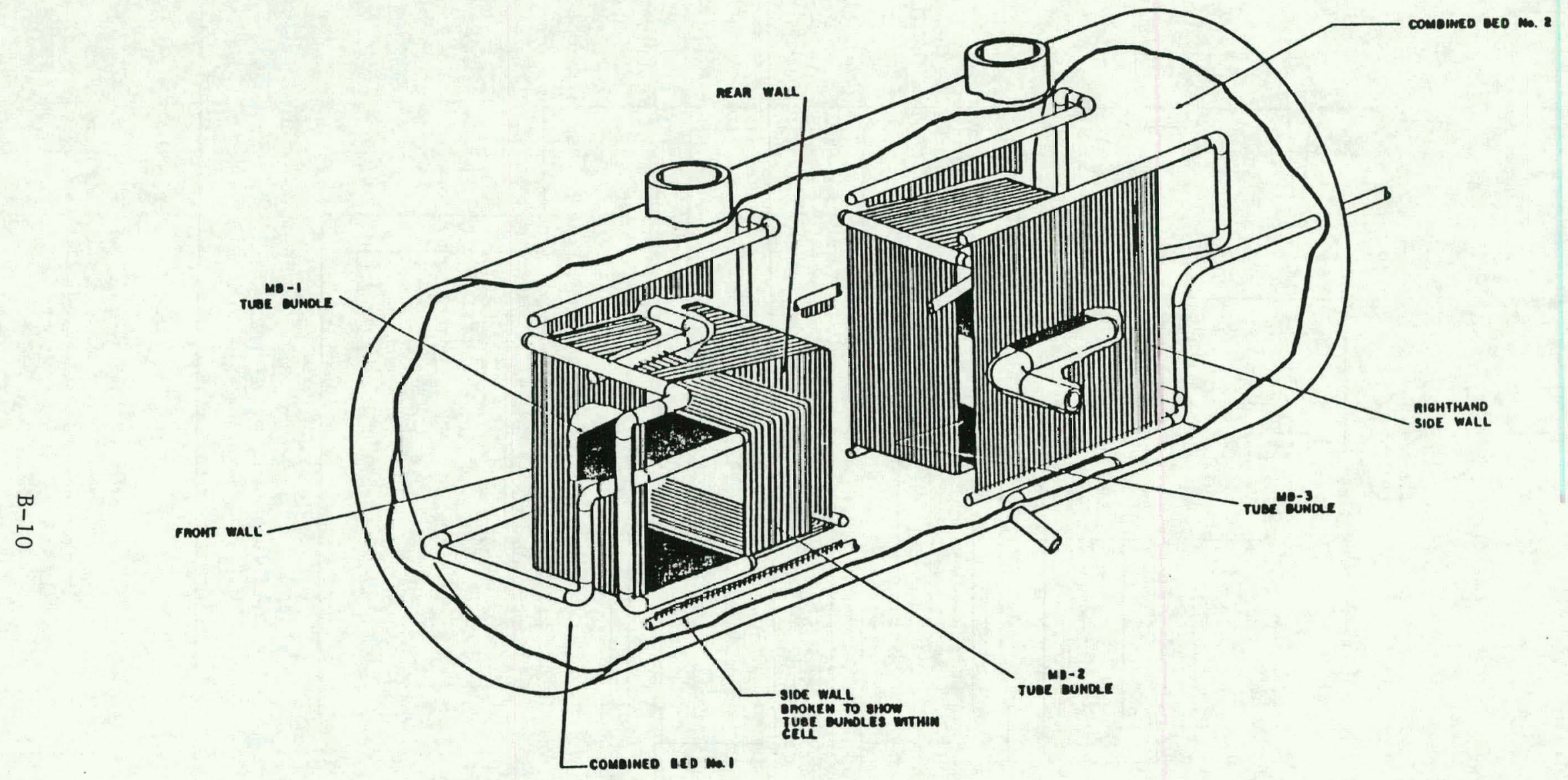

FIGURE B-2 GENERAL ELECTRIC PFB COMBUSTDR 


\section{APPENDIX C \\ MCFC REFERENCE SYSTEM}

\section{Introduction}

The General Electric 34 molten carbonate fuel cell power plant was selected as the reference systems for this study. Since fuel cell power plants cannot be selected based on commercial availability, emphasis was placed on simplicity and low cost of electricity. These are factors which will be assigned the highest priorities by a typical electric utility company.

The selected reference system, which uses an oxygen-blown Texaco gasifier is shown schematically in Figure C-1. Coal is fed to the gasifier in a water slurry containing $66.5 \mathrm{wt} \%$ coal along with $98 \%$ oxygen. Raw fuel gas exits the gasifier at $2200-2800^{\circ} \mathrm{F}$ and $600 \mathrm{psig}$ and is cooled in a heat recovery steam generator. Following the steam generator, where high pressure steam for the steam cycle is raised, the raw fuel gas is cooled in a series of low pressure steam generators, regenerative heat exchangers, and a water cooler. Particulates and ammonia compounds are removed in gas scrubbers and sulfur compounds are removed in an acid gas removal process. The clean fuel gas is reheated; passed through a $\mathrm{ZnO}$ bed for trace sulfur removal, reduced in pressure through an expansion turbine, and mixed with steam extracted from the steam turbine to provide a carbon-free gas to the fuel cells.

Power is generated by the fuel cell modules, the gas expansion turbines, and a conventional steam turbine.

Descriptions of the major sections of the power plant follow. Also, an introductory review of fuel electrode processes is included in order to provide a foundation for discussing contaminant impact on power plant performance.

\section{Coal Handling and Preparation}

The system description is based on an Illinois No. 6 coal having a higher heating value of $12235 \mathrm{Btu} / \mathrm{lb}$ and the following analyses by weight:

\section{Proximate Analysis}

Moisture

Ash

Fixed Carbon

Volatile Matter

$$
: 4.2
$$

9.6

52.0

34.2
Ultimate Analysis

Carbon

77.26

Hydrogen.

5.92

Oxygen $\quad 11.14$

Nitrogen

1.39

Sulfur

The coal is unloaded from 100 ton hopper cars into storage piles; and reclaimed to coal storage silos. It is then delivered by conveyor belt to the coal grinding facility. The coal is first powdered in a cage mill so 
that 80 percent will pass through 14 mesh. A rod mill is then employed to produce a water slurry containing approximately $65 \%$ solids. The slurry is pumped to either of two agitated mix tanks each having an 8-hour holdup capacity.

All of the equipment in this section of the plant is commercially available.

Oxygen Plant

The single train oxygen plant has a design capacity of 600 TPD so that excess oxygen can be stored and used in short duration shutdown periods.

All equipment in the oxygen plant is comnercially available and need not be described for the purpose of this study.

A 4000 gallon liquid nitrogen storage reservoir with a vaporizer is provided for plant cool down, purging and instrument air backup.

Coal Gasification and Ash Handling

In the proprietary Texaco coal gasification process, coal-water slurry and oxygen are reacted in a refractory-lined chamber at $24000 \mathrm{~F}$ to $26000 \mathrm{~F}$ and 600 psig to produce a gas having the constituents shown in Table $c-1$. Part of the coal burns with oxygen, providing energy need to vaporize the slurry water and support the endothermic steam/carbon reaction. Primarily, the hydrogen and carbon in the coal form $\mathrm{CO}, \mathrm{CO}_{2}, \mathrm{H}_{2}, \mathrm{H}_{2} \mathrm{O}$ and $\mathrm{CH}_{4}$; the sulfur from the coal forms $\mathrm{H}_{2} \mathrm{~S}$ and $\mathrm{COS}$; and nitrogen results in free nitrogen and ammonia. The ash in the coal melts to form slag.

The gas stream is initially cooled in the reactor by recycling cooled gas into the hot gas stream. This reduces the gas temperature sufficiently to solidify any entrained molten slag droplets which can then be separated and removed. It also results in a gas temperature compatible with the use of conventional gas cooling equipment. The gas is cooled furcher in a shell and tube type gas cooler by producing saturated steam from boiler feedwacer which is then superheated by fuel cell cathode waste heat. In this manner, essentially the full heating value of the coal feed is recovered and used. After cooling, the gas passes to the gas cleanup system which is shown in Figure C-2.

The ash in the coal which is melted into a slag in the gasification process is water quenched and withdrawn as gravel-like particles for disposal. After separating the slag from the water in the slag dewatering unit, the slag is conveyed to a bin located for truck loading. The slag is removed trom the site by truck and dumped at an approved solids disposal stre. Part of the separated water is recycled to the coal grinding and slurrying plant while the remaining blowdown is sent to the effluent water treatment plant for subsequent evaporation in ponds.

Water is also recycled to the coal grinding and slurrying plant from the particulate scrubber in the gas cooling and reheat unit. This water contains slag particles and ammonia scrubbed from the raw gas. 
The Texaco gasifier is essentially commercially available, but it is probable that some design changes may follow as a result of recent operating experience. 
Table C-1 Texaco Gasifier Effluents.

$\begin{array}{crr}\text { Effluent } & \underline{1 \mathrm{~b} / \mathrm{hr}} & \text { mole } \% \\ \mathrm{H} 2 & 3,535 & 28.84 \\ \mathrm{CO} & 72,292 & 42.45 \\ \mathrm{CH}_{4} & 78 & 0.08 \\ \mathrm{CO}_{2} & 23,303 & 8.71 \\ \mathrm{H}_{2} \mathrm{O} & 19,584 & 17.88 \\ \mathrm{~N}_{2} & 1,421 & 0.78 \\ \mathrm{H} 2 \mathrm{~S} & 2,086 & 1.01 \\ \mathrm{C} S \mathrm{~N} & 220 & 0.06 \\ \mathrm{NH} & \frac{205}{122,724} & 0.19 \\ & & 100.00\end{array}$


Gas Cooling, Acid Gas Removal and Gas Reheat

The major portion of the additional energy extracted from the gas stream is used to generate 50 psig stripping steam for the acid gas removal process and for regeneratively heating the clean fuel gas prior to passing through the zinc oxide units. The remainder of the energy is removed by cooling water in the raw gas cooler.

Water condensed out of the raw gas stream in the cooling process is mixed with the water effluent from the ammonia scrubber and the water mixture fed to the particulate scrubber, where the last traces of coal, ash and dust are removed. Effluent from the particulate scrubber is recycled to the coal grinding and slurrying unit. As shown in Figure $\mathrm{C}-2$, the cooled, scrubbed raw gas flows to the acid gas removal unit where sulfur compounds (primarily $\mathrm{H}_{2} \mathrm{~S}$ and $\mathrm{COS}$ ) are selectively removed in the Norton Selexol physical absorption solvent process.

Dry, ammonia-free raw gas enters the bottom of the acid gas absorber tower and flows countercurrent to the downward flowing Selexol solvent (dimethyl ether of polyethylene glycol). Acid gases dissolve in the solvent and the partially cleaned fuel gas leaves the top of the tower. Lean solvent is fed to the absorption tower. The clean fuel gas returns to the first regenerative heat exchanger in the gas cooling and reheat unit.

Acid gas-rich solvent leaves the bottom of the absorber and is sent to a series of flash tanks where the pressure is reduced. This causes desorption of the slightly soluble hydrocarbons which are recycled into the absorber. The acid gas-rich solvent exits from the last flash tank to the solvent stripper tower.

In the stripper tower, stripping steam regenerates the solvent by removing the acid gases, which are cooled and then flow to the sulfur removal unit. The lean solvent is then recycled to the absorber. Energy to generate stripping steam is provided by saturated 50 psig steam fed to the stripper reboiler. Steam for this purpose is generated in the low pressure steam generators, the sulfur removal plant, and in an auxiliary-fueled boiler.

The absorber/stripper system has not been shown in detail, but it is similar to the generic absorber/stripper referenced in Section 3.3.1.

After the clean fuel gas has been reheated in the two regenerative heat exchangers, it passes through a zinc oxide reactor in which the sulfur compounds are reacted and physically removed to a level less than 0.1 PPM by weight. When the $\mathrm{ZnO}$ unit is loaded to about $15 \mathrm{wt} \%$ sulfur, the material must be discharged and replaced. In order to allow continuous operation when this change is made, two vessels are installed in parallel with each capable of handling the full flow. From the 2 no units, the clean fuel gas goes to the fuel gas expansion turbine in the steam and power generation section.

The separation of elemental sulfur from the acid gas stream produced by the Selexol process is accomplished in a similar manner to that described in Appendix A. However, for the GE system the Amoco $\mathrm{Claus}$ sulfur removal, and Shell Scot tail gas cleanup units were selected. The Shell Scot unit 
catalytically hydrogenates all sulfur to $\mathrm{H}_{2} \mathrm{~S}$ which is then absorbed in an amine solvent.

The expected flow rates, gas compositions, temperatures and pressures for the power plant and gas cleanup systems are shown in Tables $\mathrm{C}-2$ and $\mathrm{C}-3$.

All equipment in the gas cleanup system is commercially available.

\section{Steam and Power Generation}

As shown in Figure C-1, clean fuel gas from the zinc oxide units is expanded to the fuel cell pressure level in the fuel gas expansion turbine. The fuel gas is fed to four parallel fuel cell islands. Steam extracted from the steam turbine cycle is injected into the fuel gas to prevent carbon formation. The gas is then heated to $10000 \mathrm{~F}$ in the anode gas preheater and introduced to the anodes of the four fuel cell pressure vessel modules in each island. After reacting in the fuel cells, the exhaust gas preheats the incoming anode gas, is compressed to the cathode operating pressure, and is passed through a catalytic combustor.

The fuel cells utilize $85 \%$ of the hydrogen and carbon monoxide in the incoming fuel. Conversion to alternating current in the power conditioning equipment results in 67.15 MW output (16.79 MW per island). The unburned fuel in the anode exhaust is combusted in the catalytic combustor with some of the fuel cell oxidant. The combustor exhaust is mixed with the remainder of the oxidant and the cathode recycle gas stream before being admitted to the fuel cell cathode at $10000 \mathrm{~F}$.

The cathode exhaust stream splits into two parts. The first recycles $44 \%$ of the exhaust mass flow in order to remove the waste heat generated in the carbonate fuel cells. Heat is removed in a steam superheater and a boiler before the gas is recirculated to the cathode inlet pressure. The remaining cathode exhaust flows to an exhaust gas expander. The gas then preheais incoming oxidant air in a flnned-plate heat exchanger and provides feedwater heating in an economizer before being discharged to the slack at $2500 \mathrm{~F}$.

Each exhaust gas expander drives an air compressor and a generator delivering $6.07 \mathrm{MW}$ per island (24.28 MW total). The oxidant is preheated by the exhaust gas before being introduced into the catalytic combustor and cathode.

A single non-reheat steam turbine having $10000 \mathrm{~F}, 1800$ psig steam conditions and producing $18.57 \mathrm{MW}$ of power utilizes waste heat from the power plant. Steam for injection into the anode gas is extracted at 105 psia and $6000 \mathrm{~F}$, while the remaining steam is condensed at a back pressure of $2.5^{\prime \prime} \mathrm{Hg}$. A conventional wet cooling tower and circulating water system provides cooling to the surface condenser. Approximately $22 \%$ of the feedwater is used to produce saturated steam at 1860 psig in the four cathode gas recycle boilers, while the other $78 \%$ produces $1860 \mathrm{psig}$ steam in the heat recovery steam generator downstream of the gasifler. The combined fluw of saturated steam is superheated to $10000 \mathrm{~F}$ at $1800 \mathrm{psig}$ in the four cathode gas recycle superheaters and directed to the steam turbine to complete the steam cycle. 
With the exception of the fuel cells (which are discussed in the next section) and the catalytic combustor, all other equipment in the steam and power generation section of the plant is either commercially available or represents no advancement of state-of-the-art technology.

Other than the fuel cells, the catalytic combustor is the only developmental component in this plant section. However, combustors have been developed for richer gas streams (low Btu gas catalytic combustion) and for leaner gas streams (automobile exhaust catalytic combustion).

\section{Fuel Cell Modules}

In the molten carbonate fuel cell, the electrolyte consists of a mixture of carbonate salts dispersed in a support matrix which, at the operating temperature of about $1200^{\circ} \mathrm{F}$, is in a molten state. In the reference plant design, the fuel cell operates at a pressure of 100 psia. This is not an optimized value, but represents a level at which both fuel cell and bottoming cycle performance is reasonably good. The nominal fuel cell temperature of $1200^{\circ} \mathrm{F}$ is also a tradeoff between less internal resistance losses at higher temperatures and less loss of electrolyte through vaporization and (and thus reduced $l i f e$ ) at lower temperatures. As out lined in the next section, the fuel consumed in the cell is actually hydrogen, although carbon monoxide is utilized via the water-gas shift reaction in forming more hydrogen. An important parameter is the amount of fuel utilized in the carbonate fuel cell. This is defined as the percentage of $\mathrm{H}_{2}$ consumed in the cell relative to the amount of $\mathrm{H}_{2}+\mathrm{CO}$ fed to it. For the reference design plant, a fuel utilization of $85 \%$ was assumed. similarly, an oxidant utilization can be defined for both the oxygen and carbon dioxide fed to the cathode.

For the present design, each carbonate fuel cell produces 0.77 volts (dc) at. a current density of $150 \mathrm{a} / \mathrm{ft}^{2}\left(160 \mathrm{ma} / \mathrm{cm}^{2}\right)$. Approximately 700 cells are assembled into a stack by compressing the cells between end pressure plates.: Four stacks are arranged in a pressure vessel module to provide cell operating pressure. The modules are internally insulated to permit vessel construction of carbon steel. Each stack produces $1.071 \mathrm{MW}(\mathrm{dc})$ and each module has a de output of $4.284 \mathrm{MW}$.

The fuel cell modules are assumed to have heat losses equal to two percent of the gross power output. In addition; the goal for fuel cell useful. life is 40,000 operating hours.

Molten carbonate cells have been demonstrated at the pilot scale, but electrolyte management materials problems and sulfur poisoning have proven to be more troublesome than were originally anticipated. As a result, commercialization has been delayed pending the completion of additional bench and pilot scale investigations.

\section{Fuel Electrode Processes}

The fuel cell is an unusual device in that it depends, for its successful operation, on reactions at a triple junction between gas, electrode and electrolyte. Most chemical and combustion processes take place in a large volume or at least on a large surface. Due to the importance of this triple 
junction, a discussion follows which will be useful in discussing the effect of fuel gas contaminants on fuel cell performance.

When a metal plate is immersed in an ionized solution, the plate becomes charged negatively, positive metal ions go into solution and they form a positive film around the plate. The same equilibrium situation is developed around a second plate made of a different material. Since a different equilibrium situation exists at each plate, electrons will flow in a conductor connected between the two plates and positive ions will flow in the opposite direction thru the ionized solution. As a result, one of the metal plates will be consumed.

In the case of a fuel cell, non-reactive electrodes are used to contain the reaction and to collect the electrons, and hydrogen atoms are consumed instead of metal atoms.

In the case of the molten carbonate fuel cell, the electrolyce consists of a molten mixture of carbonate salts. Hydrogen is consumed, although carbon monoxide is also utilized via the water gas shift reaction. Carbonate ions migrate to the anode reaction zone. The electrodes generally used have sintered porous structures of nickel or nickel containing alloys. Sulfur and other contaminants can cause loss of électrolytic activity and luys of structural integrity in the porous anode. These problems are discussed in Section 2.4 .2

The distribution of electrolyte in the anode pores is thought to be governed only by capillary attraction, and all pores larger than the equilibrium diameter are assumed to be empty except for a thin film of electrolytc on the pore walls. Prior to the electrochemical reaction, the hydrogen molecules are chemisorbed on the electrode surface. They then split and migrate into the reaction zone.

Particles entrained in the anode fuel gas can degrade the fuel cell performance by being deposiced on the anode flow channel surfaces or pore surfaces.

The primary overall cell reaction consists of the conversion of hydrogen to water. Carbon monoxide is also converted to carbon dioxide. This oxidation of the carbon monoxide (1) competes with the bulk gas water gas shift reaction (2). However, reaction (3) can also occur if the carbon monoxide concentration becomes too high.

$$
\begin{aligned}
& \mathrm{CO}+\mathrm{CO}_{3}^{2-} \rightarrow 2 \mathrm{CO}_{2}+2 \mathrm{e}^{-} \\
& \mathrm{CO}+\mathrm{H}_{2} \mathrm{O} \leftrightarrows \mathrm{CO}_{2}+\mathrm{H}_{2} \\
& 2 \mathrm{CO} \leftrightarrows \mathrm{CO}_{2}+\mathrm{C}(\mathrm{s})
\end{aligned}
$$

Equation 3 (the Boudard reaction) can lead to carbon deposition within the fuel passages. In order to minimize carbon formation, steam is added to the feed gas to the anode. This forces reaction (2) to the right and consequently reaction ( 3 ) to the left. 


\section{Power Conditioning}

The fuel cell modules produce dc power which is converted to ac in the power conditioning equipment. Each fuel cell module feeds into its own specific inverter through a DC breaker and a smoothing reactor. Conversion from dc to ac is accomplished at an efficiency of $98 \%$.

Each inverter uses a constant current control loop. In the control scheme, a current reference is compared with a current feedback signal obtained from the fuel cell power circuit by means of a dc current sensing device. The error signal passes to a regulator that adjusts the thyristor firing delay angle to the value necessary to provide the current requested.

A master control system determines the direct current that the inverter is to extract from the fuel cell module. This is obtained from fuel cell anode mass flow measurement at each module.

All of the equipment for the power conditioning system has been proven though many years of application in manufacturing and utility industries.

\section{Water System}

The plant makeup water system consists of the following subsystems:

- Water supply system

- Primary water treatment system

- Service water system

- Demineralized water system

- Chemical injection system

\section{- Waste disposal system}

Raw water is supplied by the well water supply system. The water is first clarified in the primary clarifier. The clarified water is then split into two streams, one fed by gravity to the cooling tower basin for makeup to the circulating water system, the other pumped to the primary pressure filters. The filtered water is supplied to the service water system, the gasification plant and the demineralized water system. Portions of the filtered water are further processed in the demineralized water system which consists of a two bed cation strong base anion primary demineralizer followed by a mixed bed secondary demineralizer.

Acid, caustic, polymer and lime feed required for the primary water treatment system and the demineralized water system is supplied by the chemical injection system.

All equipment in the water plant is commercially available. 
A waste disposal system is provided to collect, store and then transfer to the evaporation pond all the wastes, sludges and drains from the plant other than cooling tower blowdown gasifier effluent water. Cooling tower blowdown is discharged by gravity and gasifier effluent is treated and discharged separately to the evaporation pond. The evaporation pond size is approximately 40 acres. The disposal system consists of a retention basin, duplex retention basin sump pump and all the necessary underground piping and instrumentation. Waste discharges from the various components in the plant are routed to the retention basin. The accumulated mixture of sludge is drained and periodically transferred from the retention basin sump pump to the evaporation pond for final disposal.

The effluent water treatment system is sized to process $60 \mathrm{gpm}$ of blowdown water from the gasifier. Water from the gasification plant clarifier is first contacted with steam in the $\mathrm{H}_{2} \mathrm{~S}$ stripper to remove free residual acid gases and to heat the water for chemical treating. The water is chemically treated in two mixing vessels. Ferrous sulfate is added in the first and lime slurry is added in the second. The resulting reactions cause sulfides and cyanides to precipitate. The water then passes to a settling tank where the precipitates settle. The underflow containing the precipitates is filtered. The filter cake is a residue that can be dumped with the slag from the gasifier unit. The settling tank overflow and water from the filter combine and pass through sand filters. Sand filter effluent flows to a surge tank from which it is pumped to the ammonia stripper. Filter back wash is also pumped from the ammonia stripper feed surge tanks. The water is stripped in a trayed column to remove ammonia using live sceam.

Stripper offgas is essentially ammonia and hydrogen sulfide that is treated in the sulfur recovery unit. The stripped water is cooled and sent to a biological treating system for removal of formate compounds. The biotreater effluent discharges to the evaporation pond. Hater from the balanoe pond flows to the aeration basin where bacterial cultures thrive on formate compounds remaining in the water, effectively removing them or their effect. from the evaporation pond. Water from the aeration basin flows to a clarifier where bacteria are separated by gravity and pumped to the digester. Clarified water than flows to the evaporation pond.

Effluent water is treated to remove undesirable contaminants to the following levels:

$$
\begin{aligned}
& \text { Sulfides - Less than } 1 \text { PPM } \\
& \text { Ammonia - Less than } 25 \text { PPM } \\
& \text { Formates - Less than } 10 \text { PPM } \\
& \text { Cyanides - Less than } 3 \text { PPM }
\end{aligned}
$$

All equipment is commercially available. 


\section{Plant Performance}

The gross electric power output of the plant is $113.92 \mathrm{MW}$ and auxiliary power requirements total $15.38 \mathrm{MW}$. Thus, the net power output is $98.54 \mathrm{MW}$, which corresponds to a coal pile-to-busbar efficiency of $48.9 \%(6990 \mathrm{Btu} / \mathrm{kWh}$ heat rate).

The fuel cells produce the largest portion of the plant gross power output, which is desirable since they generate power at the highest efficiency of any plant machine. The steam cycle has a relatively modest output for two reasons. The most important reason is that $44 \%$ of the incoming steam to the turbine is extracted for fuel cell anode gas carbon formation control. If the steam injection requirements to the fuel cells could be relaxed or if a more economical source of lower quality steam could be used for this purpose, this high quality steam would produce more energy in the steam cycle. A reheat turbine, if available, would more efficiently utilize the high temperature heat available in the cathode gas recycle loop and would also increase the steam cycle output.

The single largest auxiliary load is that of the oxygen plant compressors, which are assumed to be driven by electric induction motors. This load could be reduced somewhat by coupling the oxygen plant air compressors directly to the cathode exhaust gas expansion turbines in the plant and thus eliminate generator and motor losses. However, this option has the major disadvantages of adding complexity to the system and resulting in a loss of plant arrangement versatility. Such an approach is inconsistent with the guidance provided by utility participants who have repeatedly expressed preference for simpler systems. Accordingly, the integration of the oxygen plant compressor and cathode exhaust expander was not considered.

Table C-2 summarizes the power plant stream conditions, and the cleanup system stream conditions at full operating capacity have been included in section 3 (Table 3.5). The purpose of these two tables is to provide stream condition information for possible use in specifying power plant instrumentation.

The largest single heat loss in the plant is the heat content of the stack gases. This amounts to approximately $22 \%$ of the higher heating value of the input coal. This high value is a result of the injection of steam into the anode fuel gas. The steam passes through the anode and cathode of the fuel cell. and carries significant latent heat out the exhaust stack. Reduced steam injection requirements or an alternative method for controlling carbon formation would reduce this heat loss considerably. The next largest heat losses are cooling requirements for the steam cycle, gas cleanup and oxygen plant, in that order.

\section{Emission Requirements}

The emission requirements 1 isted below are based on the Federal New Source Performance Standards (NSPS) for air. In the reference plant, these requirements are easily met since the fuel cells require the removal of sulfur and particulates to levels much less than those specified. Sulfur emissions, for example, will be approximately two orders of magnitude lower than the requirement of 51 pounds per hour. Essentially no $\mathrm{NO}_{x}$ is formed in 
the fuel cells since no combustion takes place to fix the nitrogen in $\mathrm{NO}_{\mathrm{x}}$. Combustion of the anode exhaust gas may result in some $\mathrm{NO}_{x}$ formation.

$\mathrm{SO}_{2}$

$12.9 \mathrm{lb} / \mathrm{hr}$

$\mathrm{NO}_{\mathbf{x}}$

$6.51 \mathrm{~b} / \mathrm{hr}$

Particulates

$0.3 \mathrm{lb} / \mathrm{hr}$ 
Table C-2 MCFC Power Plant Stream Conditions

\section{Stream Name}

1. Oxygen

2. Coal

3. Recycle Water

4. Makeup Water

5. Slag/Ash

6. Effluent Water

7. Gas Cooler Outlet

8. H.P. Steam

9. Boiler Feed Water

10. Gas Expander Inlet

11. Gas Preheater Inlet

12. Anode Exhaust.

13. Cathode Inlet

14. Cathode Exhaust $\begin{array}{ccc}\begin{array}{c}\text { Pressure } \\ \text { (psig) }\end{array} & \begin{array}{c}\text { Temperature } \\ \left({ }^{\circ} \mathrm{F}\right)\end{array} \quad \begin{array}{c}\text { Flow } \\ (1 \mathrm{~b} / \mathrm{hr})\end{array}\end{array}$

720

272

47,132

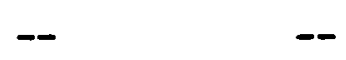

56,250

$-$

$-$

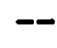

-

585

1875

585

500

88

84

86

84
$-$
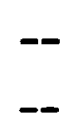

$=$

800

627

800

750

483

1,300

1,000

1,300
30,926

13,456

5,400

19,736

122,724

136,467

347,067

97,810

174,489

395,502

$1,600,704$

$1,379,691$ 


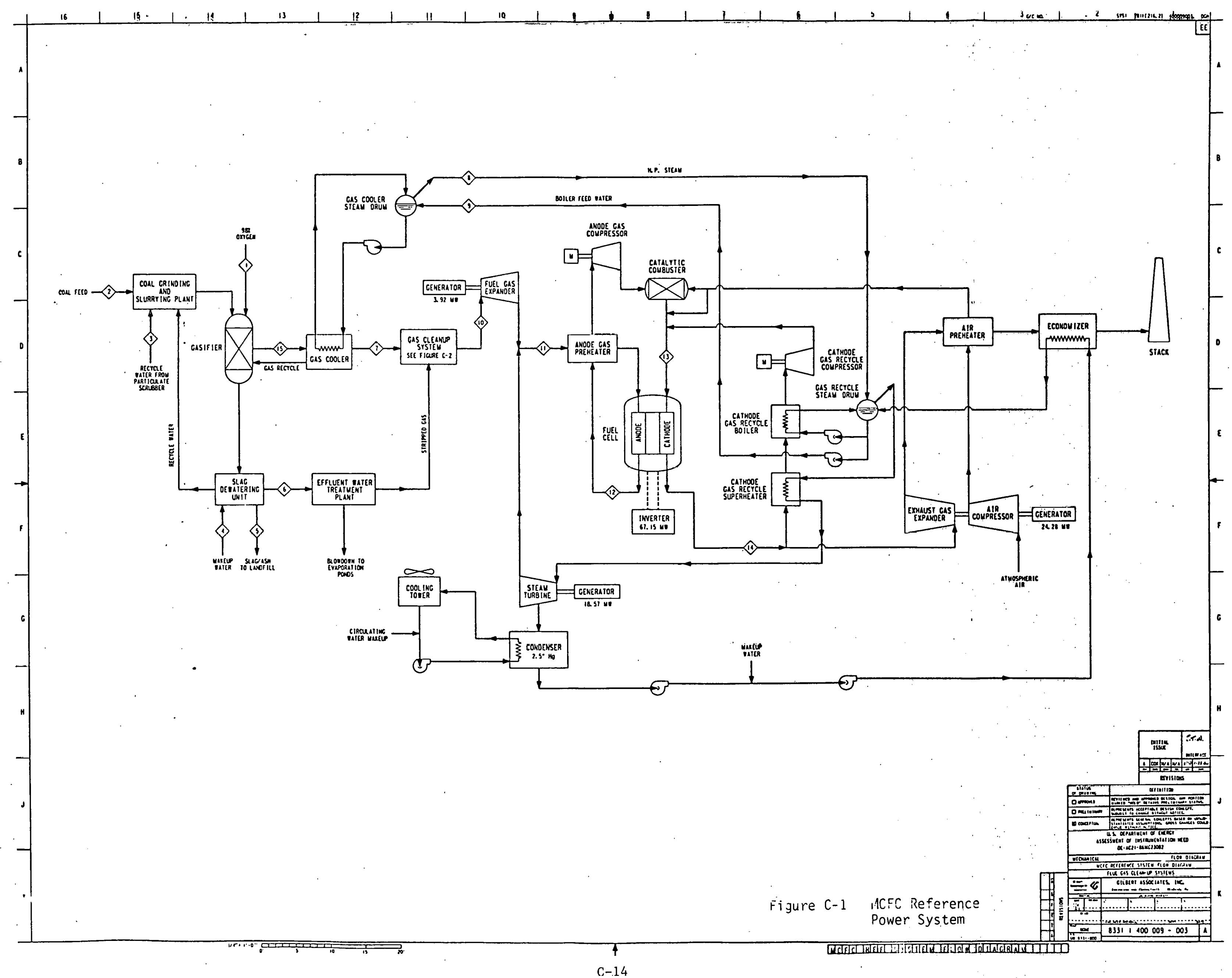




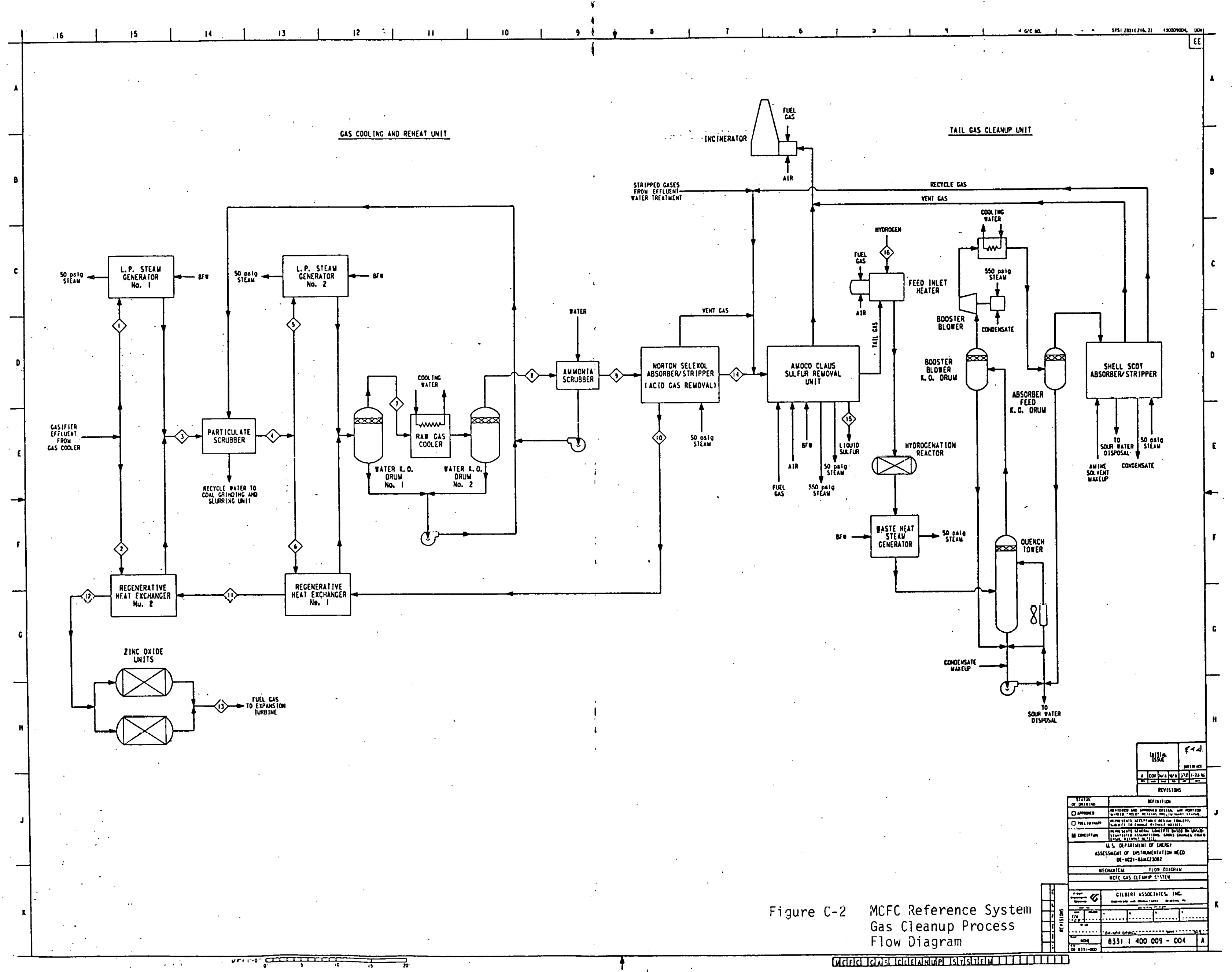


